\title{
A New Pattern Recognition Technique in Non Destructive Testing by the Use of Linear Discriminate Analysis
}

\author{
Saeedreza Ehteram \\ Department of Electrical Engineering \\ Iran University of Science \& Technology (IUST), Narmak, Tehran, Iran \\ Researcher of Young Researchers Club of Iran. \\ E-mail: sehteram@ee.iust.ac.ir \\ Alborz Rezazadeh Sereshkeh \\ Department of Electrical Engineering \\ Sharif University of Technology (SUT), Azadi St, Tehran, Iran \\ E-mail: rezazadeh@ee.sharif.edu \\ Seyed Z. Moussavi \\ Department of Electrical Engineering \\ Shahid Rajaee Teacher Training University (SRTTU), Lavizan, Tehran, Iran \\ E-mail: smoussavi@srttu.edu \\ Ali Sadr \\ Department of Electrical Engineering \\ Iran University of Science \& Technology (IUST), Narmak, Tehran, Iran \\ E-mail: Sadr@iust.ac.ir
}

\begin{abstract}
One of the most challenging scientific industrial courses in recent years is intelligent defect detection. Non Destructive Testing (NDT) techniques are the most useful methods due to their efficiency and low cost. Models were developed to determine surface-breaking defects along the applied field when using the magnetic flux leakage (MFL) non-destructive technique. The theoretical model fits the experimental MFL results from simulated defects. For MFL sensors, the normal magnetic leakage field is subsequently used for evaluation of defects. Permeability variations were neglected by employing a flux density close to sample saturation. Three different defect geometries were experimentally investigated and the validity of the analytical model was verified. Different Feature extractor functions are applied in this paper to yield fast decision and more accurate. Indeed more accuracy is because of decision on different features that yields by employing two kinds of feature extractors, PCA and DCT. By hiring a BELBIC (Brain Emotional Learning Based Intelligent Controller) controller on the extracted features, the results are more accurate in some cases. Linear Discriminate Analysis (LDA) is another helpful instrument that is employed precise decision. All feature extractions LDAs and Multilayer perceptron (MLP), are methods for identifying erosion defects are described and employed in this paper. Great accuracy rate in compare between results of related approaches suggests that this Method can be used as an algorithm of MFL data interpretation technique.
\end{abstract}

Keywords: Magnetic flux leakage, NDT, PCA, DCT, LDA, BELBIC, Multilayer Perceptron, Erosion defects 


\section{Introduction}

The pipeline transportation is one of the fundamental modes in petroleum and natural pipeline transportation. It is necessary for pipeline's security evaluation and maintenance to detect the pipeline regularly using pipeline detector and obtain the precise information of the defect (A. Bergamini, 2001)( A. Bergamini, 2002). Among various pipeline inspection technologies, MFL inspection is the most widespread and perfect one. Applying MFL inspection technology, the defect recognition is mainly completed by man at present. Indeed it needs long time for man to analyze a long pipeline data (M. Afzal and S. Upda, 2002). So finding the intellective technology to recognize pipeline defect quantitatively is urgent. This is not only a time consuming and tiring task; moreover, the result depends on human elements of uncertainty. So for this reason we applied a mathematical relation between the magnetic field applied on the surface and the defect properties. In this way an approach is to find many exactly samples from a defect which is sorted in the surface by its various radial and depth. In this paper, the pipeline MFL image is recognized in an artificial algorithm that is trained BP neural network (P. Ramuhalli, L. Udpa and S.S. Udpa, 2002). also In this work, an approach for the automatic detection of a defect is presented, where the NDE data are preprocessed using an analytical model of the magnetic flux and the extracted information is passed on to a panel of neural networks. Also this peper mentions employment of LDA in the application of defect detection.

\section{Database of defects from MFL testing}

The database of the experimental MFL signals that is employed in this project, is from Applied Magnetics group (AMG) in The department of physics from Queens in Canada. This database concludes signals of MFL that measured from Outside and Inside of a pipeline. Details of this database will lead to both un annealed and annealed data plots of increasing dent depths from $3 \mathrm{~mm}$ to $7 \mathrm{~mm}$, resulting in a total of 10 plots for each one. For an instance Figure 1 illustrates a measurement from an annealed and not annealed MFL measurement from inside and out side of a pipeline.

\section{Formulation of an analytical model from MFL defect measurements}

If a material is magnetized near saturation, the MFL field generated by a subsurface flaw can be described as follows:

$$
R_{y}(x, y)=\frac{2 x\left(y-2 H_{x} R^{2}\right)}{\left(x^{2}+y^{2} y^{2}\right.}
$$

Where $m$ is the dipole moment per unit length this is measured as follows

$$
h=1.05 \times 10^{-74} \quad n \pi=\frac{3}{2} h
$$

Where $h$ bar is the plank coefficient, $H a$ is the applied magnetic field that is 1 Tesla (C Mandache, B Shiari and L Clapham, 2005) and $a$ is the radius of the defect (D.E. Bray, 1997)(R. Christen, A. Bergamini and M. Motavalli, 2004). If the MFL on the surface of a sample is calculated, the variable $y$ is constant and is equal to the depth $h$ of the defect (see fig.2). So the magnitude of $h$ could specify the depth of defect. As mentioned above, it is not necessary to get physical information, like size or position of the defect. If the unknown system and material properties are defined in $p=2 h\left(m-2 H_{a} a^{2}\right)$ and $q=h^{2}$ parameters we obtain so the following simple fit function for the MFL on the surface of a sample could be illustrated as below:

$$
f^{\prime}(x)=\frac{m x}{\left(a+x^{2} y^{2}\right.}
$$

In the developed device the signal is measured by induction coils and for this reasons the measured signal is the derivative in $\mathrm{x}$ direction times the velocity of $\mathrm{f}(\mathrm{x})$ of measuring device. With regards to the previous equation, the MFL signal becomes as below. In this relation we try to calculate the rate of measured signal in time. So with acknowledge of velocity, that is rate of measuring device distance in time, and by timing this term to deviation of $f(x)$, we could reach to rate of delta $\mathrm{f}$ to delta $\mathrm{t}$ that is rate of depth in time.

$$
F(x)=v \cdot f^{5}(x)=v\left(\frac{p}{\left(q+x^{2}\right)^{2}}-\frac{4 x^{2}}{\left(q^{2}+x^{2}\right)^{2}}\right)
$$

On the assumption that the velocity is constant, a new parameter $P$ can be defined as:

$$
P=v \cdot p=2 h v\left(m-2 H_{a} a^{2}\right)
$$

\section{Feature extraction for recognition}

PCA is a well-known statistical technique for feature extraction. Each $\mathrm{M} \times \mathrm{N}$ MFL signal in the training set was row concatenated to form $\mathrm{MN} \times 1$ vector $x_{k}$. Given a set of training signals $\left\{\mathrm{x}_{\mathrm{k}}\right\}, \mathrm{k}=0,1, \ldots, \mathrm{N}_{\mathrm{T}}$ the mean vector of the training set was obtained as (M. Turk, A. Pentland, 1991). 


$$
\bar{x}=\frac{1}{x_{I}} \sum_{h=1}^{x_{2}} x_{R}
$$

A $\mathrm{N}_{\mathrm{T}} \times \mathrm{MN}$ training set matrix $\mathrm{X}=\left\{\mathrm{x}_{\mathrm{k}}-\bar{x}\right\}$ can now be built. The basis vectors are obtained by solving the Eigen value problem:

$$
\lambda=p^{2} \Sigma_{x} p
$$

Where $\Sigma_{X}=X X^{W}$ is the covariance matrix, $\mathrm{V}$ is the eigenvector matrix of $\Sigma_{X}$ and $\lambda$ is the corresponding diagonal matrix of Eigen values. As the PCA has the property of packing the greatest energy into the least number of principal components, eigenvectors corresponding to the $\mathrm{m}$ largest Eigen values in the PCA are selected to form a lower-dimensional subspace. It is proven that the residual reconstruction error generated by discarding the $\mathrm{N}_{\mathrm{r}}-\mathrm{m}$ components is low even for small m(Duda, R.O. and Hart, P.E., 1973).

As has been said, PCA computes the basis of a space which is represented by its training vectors. The basis vectors computed by PCA are in the direction of the largest variance of the training vectors. These basis vectors are computed by solution of an Eigen problem, and as such the basis vectors are eigenvectors. These eigenvectors are defined in the signal space. They can be viewed as signals and indeed look like its inherent shape. Hence they are usually referred to as Eigens.

A discrete cosine transform (DCT) is a Fourier-related transform similar to the discrete Fourier transform (DFT), but using only real numbers. DCTs are equivalent to DFTs of roughly twice the length, operating on real data with even symmetry (since the Fourier transform of a real and even function is real and even. The DCT, is often used in signal and signal processing, especially for lossy data compression, because it has a strong "energy compaction" property: most of the signal information tends to be concentrated in a few low-frequency components of the DCT (Ken cabeen, peter gent). This function is mathematically explained below:

$$
X_{n}=\sum x_{n}=1 x_{n} \cos \left[\frac{\pi}{N}\left(n+\frac{1}{2}\right) h\right]
$$

$k=0,1, \ldots, N-1$

For our reason this function is employed because if its strong behaviour on collecting the important information in low frequencies at the top left of the DCT matrix. The squared low dimensional matrixes could lead to best and rapid decisions in some cases this later could lead to the accuracy rate of $100 \%$ in some cases.

\subsection{Recognition of defects}

The recognition of pipeline corrosion defects in this paper includes preprocessing and classification analysis. The former can be accomplished by recognizing and classifying typical features of signals from magnetic flux signals in types of real signals or mathematical forms. An approach is to classifying and performs a true decision. For this reason, these are some different kinds of neural networks such as Multilayer Perceptron (MLP), Learning Vector Quantization (LVQ) (Martin Golz, David Sommer, 2006), Self Organized Machine (SOM) (Hiroshi Wakuya, Hiroyuki Harada, Katsunori Shida, 2007) and so on. In this work multilayer perceptrons are applied with BP structure.

\subsection{Classification for recognition}

According to construction of combiners, they are all made of learning process. Therefore to have different combiners different ways of training is essential. The process of learning is based on many ways such as: different ways to show inputs, samples for learning, training process, differ consulting technologies although in this task many theories are offered but each of them should due to some results:

1) The first requirement is that each expert has high level of performance and independently in deciding feature

2) Expert has an arithmetic mathematics table to refer this point as strong point of each expert.

Classifying is done by many ways such as: multilayer perceptron, (MLP), radial basis function (RBF), k-mean etc.

This paper presents MLP for classifying. MLP means multi layer perceptron. Classifying is done by neural networks such as MLP. Fundamental work of MLP is to changing weights between layers and each layer has (m) nodes. Number of input nodes is depended on dimension the database. Amount of nods located in hidden layer are subject to change by complicated rate of the expert. In this paper an approach is shown in follows that specifies the number of each layer this equations for this reason is earned exrimentally but the result of this employment is satisfied. In training situation the weights are subject to change until reaching the best weights.The number of training situations is determined by the number of epochs it is kept done until less mistakes appears in out put.

In this algorithm three Networks with the names of $+1 \quad 0 \quad-1$ are employed. All of these three experts are learned by a same set of database and the result of classification is achieved by voting the triple output. 


\subsection{Brain Emotional Learning Based Intelligent Controller (BELBIC)}

BELBIC is a computational model of learning system of human's brain. Amygdala and Orbitofrontal cortex play the most important roles in this learning method. The structure of BELBIC is shown in Fig. 3

In the Thalamus part of this model, some simple pre-processing on sensory input signals such as noise reduction on filtering can be done.

Sensory cortex's inputs are come from thalamus part. Sensory cortex should subdivide and discriminate the coarse input from thalamus.

The next step is Orbitofrontal cortex. This part's task is to inhibit inappropriate response from Amygdala based on the context given by the hippocampus. Amygdala is responsible for the emotional evaluation of stimuli.

BELBIC receives sensory input signals via thalamus. After preprocessing in sensory input, the input signal will be sent to Amygdala and sensory cortex. These parts compute their output based on emotional signal received from environment. Ultimate output is calculated by subtracting Amygdala's output from orbitofrontal cortex's output.

The Thalamic connection is calculated as the maximum overall Sensory Input $\mathrm{S}$ and becomes another input to Amygdala as described in Eq. (9). Unlike other inputs to Amygdala, the thalamic input is not projected into the orbitofrontal part and cannot be inhibited by itself

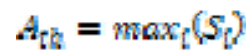

For each A node in Amygdala, there is a plastic connection weight $\mathrm{V}$. Any input is multiplied by this weight to provide the output of the node. The $\mathrm{O}$ nodes behave analogously, with a connection weight $\mathrm{W}$ applied to the input signal to create an output. The connection weights $V_{i}$ are adjusted proportionally to the difference between the emotional stress and activation of the A nodes. The $\alpha$ term is a constant that is used to adjust the learning speed. In order to modify the update rule the sensory signal value is multiplied inside max operator

$$
\Delta P_{l}=\alpha\left(\max \left(0, S_{l}\left(s t \text { tress }-\Sigma A_{l}\right)\right]\right)
$$

In formula (10) Amygdala learning rule is presented. This is an instance of a simple associative learning system. The real difference between this system and similar associative learning system is the fact that this weight-adjusting rule is monotonic, i.e., the weights $\mathrm{V}$ cannot decrease. At first glance, this may seem like a fairly substantial drawback; however, there are good reasons for this design choice. Once an emotional reaction has been learned, this should be permanent. The orbitofrontal part inhibits this reaction when it is inappropriate.

The reinforcement signal for the $\mathrm{O}$ nodes is calculated as the difference between the previous output $\mathrm{E}$ and the reinforcing signal stress. In other words, the $\mathrm{O}$ nodes compare the expected and received reinforcement signals; therefore, inhibiting the output of the model should be a mismatch. In (11), the learning rule in the orbitofrontal cortex is presented

$$
\left.\Delta W_{l}=\beta i S_{l} \Sigma^{\prime}\left(O_{j}-s t r a s\right)\right]
$$

The orbitofrontal learning rule is very similar to the Amygdala rule. The only difference is that the orbitofrontal connection weight can either increase or decrease as needed to track the required inhibition. Parameter $\mathrm{b}$ is another learning rate constant. The A nodes produce their outputs proportionally to their contribution in predicting the reward or stress signal stress, while the $\mathrm{O}$ nodes inhibit the output of $\mathrm{E}$ when necessary

$$
\begin{aligned}
& A_{l}=S_{l} F_{l} \\
& \partial_{l}=S_{l} W_{l}
\end{aligned}
$$

\section{$E=\Sigma A_{l}-\Sigma \rho_{\mathrm{L}}$}

Eq. (12) presents the model output expression (M.R. Jamali, A. Arami, M. Dehyadegari, C. Lucas, Z. Navabi, 2008).

\subsection{Linear Discriminate analysis (LDA)}

Linear discriminant analysis (LDA) is a popular holistic feature extraction technique for object recognition. LDA determines a set of projection vectors maximizing the between-class scatter matrix $S_{\mathrm{b}}$ and minimizing the within-class scatter matrix $S_{\mathrm{w}}$ in the projection feature space. A $2 \mathrm{D}$ object signal is viewed as a vector of $n$ dimension. The training set contains $M$ samples $\{X Y M$, belonging to $L$ individual classes

$\left\{x_{j}\right\}^{2}=1$

Unlike PCA that extracts features to best represent object signals, LDA aims to construct the subspace which best discriminates different object classes. Therefore, LDA is more suitable for the classification problem than PCA. 
A typical LDA implementation is carried out via scatter matrices analysis (Saeedreza Ehteram, Ali Sadr, 2007). We compute the within and between-class scatter matrices as follows

$$
\frac{1}{N} \Sigma Y_{1} \operatorname{Pr}\left(C_{0}\right) \Sigma i
$$

Here Sw is the Within-class Scatter Matrix showing the average scatter of the sample vectors $\mathrm{x}$ of different class Ci around their respective mean $\mathrm{M}$ :

$$
S_{b}=\frac{1}{M} \sum_{i} \operatorname{Pr}\left(C_{2}\right)\left(n_{1}-m_{2}\right)\left(m_{l}-m\right)^{T}
$$

Similarly $\mathrm{S}_{\mathrm{b}}$ is the Between-class Scatter Matrix, representing the scatter of the conditional mean vectors mi's around the overall mean vector $\mathrm{m}$

$$
\Sigma i=E\left[\left(X-m_{i}\right)\left(X-n_{i}\right)^{T}\right]
$$

The distance measure used in the matching could be a simple Euclidean, or a weighted Euclidean distance. It has been suggested that the weighted Euclidean distance will give better classification than the simple Euclidean distance (S. Chandrasekaran, B.S. Manjunath, Y.F. Wang, J. Winkeler, and H. Zhang, 1997), where the weights are the normalized versions of the eigenvalues. But it turns out that this weighted measure is sensitive to whether the corresponding persons have been seen during the training stage or not. To account for this, we devised a simple scheme to detect whether the person in the testing signal has been trained or not and then use either a weighted Euclidean distance or a simple Euclidean distance respectively.

\section{Employed algorithm}

We have applied similar algorithm to SSCE (Saeedreza Ehteram, Seyed Z. Moussavi, 2007) to database of MFL signals. In this map we apply preprocessing to the crude data this section is discussed and as a brief it contains extracting different kinds of defects from physical formulation and normalization then three classes perform a decision on the their inputs, the rate of each of which is composed by a voter to achieve a well decision. See fig. 4.

\section{Results and discussion}

Above a robust algorithm is defined, an important point of it is employing Linear discriminate analysis (LDA) in a same algorithm with a twin well-known statistical feature extraction functions. In order to investigate the statistical distribution of the error rate, three neural networks with the same structure and transfer functions (but with different number of neurons that are referred to initial state) were trained with the not same data set (Saeedreza Ehteram, Ali Sadr, Seyed zeinolabedin Mousavi, 2007)( R. Ebrahimpour, S. R. Ehteram, E. Kabir, 2005)( R. Ebrahimpour, Seyed Zeinolabedin Moussavi, and Saeedreza. Ehteram, 2006).In this approach each expert is trained to recognize o sort of defect so that each of which experts in final are tried to find three common sort of defects. Then the accuracy rate of each network is calculated. To calculate different numbers of input parameters were trained and compared to the network described in the above sections. The following experiential rule was used to define the structure of the network: $N_{\text {mput }}=2 \times P$

$N_{\text {Bididen }}=\operatorname{apprax}\left(N_{\text {m }}+N_{\text {owt }}\right)$

(16)

$N_{\text {Mut }}=2 \times P$

Where $N$ is the number of neurons in the corresponding layer and $P$ is the number of input parameters that could be even or odd. In this project first we try to test a simple network by different characteristics and then we design three experts. In some information about the set of trained networks is given by accuracy rate as well as the worst and the best network, respectively. Furthermore, maximum or minimum of the average of output of each network in ten times training is mentioned. Summary of the network performance for different input parameters is as follows: P1, p2, q1, q2, q3

As is demonstrated in the table below there is $\mathrm{q} 1, \mathrm{q} 2, \mathrm{q} 3, \mathrm{P} 1, \mathrm{P} 2$ parameters. These parameters are described as follows in (17):

$$
\begin{array}{ll}
P=v \cdot p=2 h v\left(n+2 h_{\alpha} a^{2}\right) & \\
q=h^{2} & \\
\mathrm{P} 1=\mathrm{P} \text { for } \mathrm{h}=0.002 \& \mathrm{a}=0.001 \quad[\mathrm{~m}] & \\
\mathrm{P} 2=\mathrm{P} \text { for } \mathrm{h}=0.003 \& \mathrm{a}=0.0015 \quad[\mathrm{~m}] & \\
\mathrm{q} 1=\mathrm{q} \text { for } \mathrm{h}=0.002 & {[\mathrm{~m}]} \\
\mathrm{q} 2=\mathrm{q} \text { for } \mathrm{h}=0.003 & {[\mathrm{~m}]} \\
\mathrm{q} 3=\mathrm{q} \text { for } \mathrm{h}=0.004 & {[\mathrm{~m}]}
\end{array}
$$


So by training classes with these triple clusters of data, class one could discriminate features of depth, better than radius and momentum.

\subsection{Historical discussion}

To date, all published research based on the analytical model of dipolar magnetic charge, (Dobmann G and H“oller P, 1980)( Shcherbinin V E and Pashagin A I, 1972)( F“orster F, 1986)( Edwards C and Palmer S B, 1986)( Mandal K and Atherton D L, 1998), this later is discussed before and defined as $m$ parameter. But for an exception, reference (Uetake I and Saito T, 1997) is presented. This reference is just discussed a single defect. , The often encountered practical situation of two adjacent defects is also discussed only by Uetake and Saito(Uetake I and Saito T, 1997), but their study is limited to slots with parallel walls, of a maximum of $4 \mathrm{~mm}$ in length. In this study we consider a multiple defect case. That is consist of triple recognition we claim that this algorithm could satisfy almost all of defects. With increase in computational capabilities, finite element analysis can now compete with analytical methods. Since the proceeding numerical modeling of MFL phenomena is exposed by Lord and co-workers (Hwang $\mathrm{J} H$ and Lord W, 1975)(LordWand Hwang J H, 1977)( Lord W, Bridges J M, Yen W and Palanisamy R, 1978), the finite element analysis of defect-induced magnetic signals has become increasingly popular. In oppose of the significant progress made in this area to include non-linear material properties (Atherton D L and Daly M G, 1987)( Patel U and Rodger D, 1995)( Altschuler E and Pignotti A, 1995), a quantitative relationship between magnetic leakage field and defect length has not been clearly specified. Furthermore, numerical modeling involves a direct MFL approach, since it includes predefined defect geometries and material characteristics. Calibration of the MFL signals in terms of defect depth has been studied both through finite element modeling (LordWand Hwang J H, 1977)( Lord W, Bridges J M, Yen W and Palanisamy R, 1978) (Atherton D L and Daly M G, 1987)( Altschuler E and Pignotti A, 1995)and through analytical methods based on dipolar magnetic charge (Lord W, Bridges J M, Yen W and Palanisamy R, 1978)( Philip J, Rao C B, Jayakumar T and Raj B, 2000). Two of the numerical analysis studies (LordWand Hwang J H, 1997)( Altschuler E and Pignotti A, 1995) correctly predicted that the amplitude of the normal MFL signal Component increases with defect depth, and that the separation between the extreme MFL values is directly proportional to the Defect length. In this paper, with regards to previous works, a new simple algorithm is applied that could exactly determine defects with various shapes. For problem of encountering different kinds of defects we initializes deferent defects with three classes which each of them tries to learn a defect with determined characteristics. These features are an estimate of three large groups of defects.

\section{Conclusion}

In this study, we have discussed intelligent defect recognition directly from MFL signals. An analytical model is employed to account defects in order to correlate the normal component MFL profile with the defect dimension along the Impregnating magnetic field. The efficiency of the model was confirmed through experimental results in MFL defect detection. A clear advantage of the method presented here is the low number of parameters that have to be considered. For a satisfactory estimation we classify all the defects in three groups with different shapes in this case all the defects ranged to depth of 2 till 4 millimeter and radius of 1 up to 1.5 millimeters. These later are subject to recognize. For this reason three expert systems were learned to recognize the request. Employing BELBIC controller helped us to calculate more accurate results. Also this algorithm is equipped with linear discriminate analysis (LDA) the result of all are shown and discussed well in table 1 . And at the end of our processing scheme voter starts to vote between the results of three experts. The accuracy rate of 100 percent shows the efficiency of the mentioned devised algorithm.

\section{References}

A. Bergamini, (2001). Nondestructive testing of stay cables, IABSE conference on cable-supported bridges, pp. 312-313.

A. Bergamini, (2002). Nondestructive testing of stay cables-field experience in South East Asia, Third World conference on structural control vol. 2 (2002), pp. 1057-1064.

Altschuler E and Pignotti A. (1995). NDT \& E Int. 28 pp.35-40.

Atherton D L and Daly M G. (1987). NDT Int. 20 pp.235-8.

C Mandache, B Shiari and L Clapham. (2005). "Defect separation considerations in magnetic flux leakage inspection" Insight Vol 47 No 5 May 2005 pp.271

D.E. Bray, (1997). Nondestructive evaluation (revised ed.), CRC Press, Boca Raton, FL (1997).

Dobmann G and H“oller P. (1980). Research Techniques in Nondestrucrive testing R. S. Sharp (New York: Academic) vol IV, pp.39-69.

Duda, R.O. and Hart, P.E., (1973). Pattern Classification and Scene Analysis, John Wiley \& Sons. 
Edwards C and Palmer S B. (1986). J. Phys. D: Appl. Phys. 196pp.57-73

Eval. 36 pp.46-54

F"orster F. (1986). NDT Int. 19 3-13

Hiroshi Wakuya, Hiroyuki Harada, Katsunori Shida. (2007). "An architecture of self-organizing map for temporal signal processing and its application to a Braille recognition task" Wiley Periodicals, Inc. Syst Comp Jpn, 38(3): 62- 71, 2007.

Hwang J H and Lord W. (1975). J. Testing Eval. 3 pp.21-5.

Ken cabeen, peter gent. "Image compression and the discrete cosine transform" math45 collage of Redwoods, pp1,2.

Lord W, Bridges J M, Yen W and Palanisamy R. (1978). Mater.

LordWand Hwang J H. (1977). Br. J. Non-dest. Testing 19 pp.14-18.

M. Afzal and S. Upda, (2002). Advanced signal processing of magnetic flux leakage data obtained from seamless steel pipeline, NDT\&E Int 35 (2002) (7), pp. 449-457. SummaryPlus | Full Text + Links | PDF (428 K) | View Record in Scopus $\mid$ Cited By in Scopus (15)

M. Turk, A. Pentland, (1991). "Eigenfaces for Recognition", Journal of Cognitive Neuroscience, vol. 3, pp. 71-86.

M.R. Jamali , A. Arami, M. Dehyadegari, C. Lucas, Z. Navabi, (2008). "Emotion on FPGA: Model driven approach" ESWA 3156 No. of Pages 10, Model 5G,20 October 2008.

Mandal K and Atherton D L. (1998). J. Phys. D: Appl. Phys. 31 pp.3211-17.

Martin Golz, David Sommer, (2006). "The Performance of LVQ Based Automatic Relevance Determination Applied to Spontaneous Biosignals, KES 2006, Bournemouth, UK, October 9-11, 2006. Proceedings, Part III, Lecture Notes in Computer Science, Springer Berlin / Heidelberg, 2006. pp. 1256-1263.

P. Ramuhalli, L. Udpa and S.S. Udpa, (2002). Electromagnetic NDE signal inversion by function-approximation neural networks, IEEE Trans Magnetics 38 (2002) (6), pp. 3633-3642. Full Text via CrossRef | View Record in Scopus | Cited By in Scopus (20).

Patel U and Rodger D. (1995). IEEE Trans. Magn. 31 pp.2170-3.

Philip J, Rao C B, Jayakumar T and Raj B. (2000). NDT \& E Int. 33 pp.289-95.

Qi Jiang, Qingmei Sui, Nan Lu, Paschalis Zachariades, Jihong Wang.” Detection and estimation of oil gas pipeline Corrosion defects "http://corporate.coventry.ac.uk/conten

R. Christen, A. Bergamini and M. Motavalli, (2004). Three-dimensional localization of defects in stay cables using magnetic flux leakage methods, J Non Destructive Eval 22 (2004) (3), pp. 93-101.

R. Ebrahimpour, S. R. Ehteram, E. Kabir, (2005). "Face Recognition by Multiple Classifiers, a Divide-and-Conquer Approach ", Lecture Note in Computer Science (LNCS), vol. 3686, pp. 225-232, September 2005.

R. Ebrahimpour, Seyed Zeinolabedin Moussavi, and Saeedreza. (2006). Ehteram (Iran)" Multiple Binary Classifier Fusion (MBCF) in Application of Satimage Database" IASTED from proceeding (522) Applied Simulation and Modeling 2006-Greece.

R.R. da Silva, S.D. Soares, L.P. Caloba, M.H.S. Siqueira and J.M.A. Rebello, (2006). Detection of the propagation of defects in ressurized pipes by means of the acoustic emission technique using artificial neural networks, Insight $\mathbf{4 8}$ (2006) (1), pp. 45-51. Full Text via CrossRef View Record in Scopus Cited By in Scopus (3).

S. Chandrasekaran, B.S. Manjunath, Y.F. Wang, J. Winkeler, and H. Zhang, (1997). An Eigensapce update algorithm for image analysis,", to appear in the journal Graphical Model and Image Processing, 1997.

Saeedreza Ehteram, Ali Sadr, Seyed zeinolabedin Mousavi (2007). "Rapid face recognition by regional feature extraction ", INISTA 2007 conference Istanbul Turkey20 - 23 June2007, pp. 262-269, 2007.

Saeedreza Ehteram, Seyed Z. Moussavi. (2007). "Semantic Supervised clustering to land Extraction on satimage database" journal of Global engineering, science and technology (GESTS), Seul korea March 2007, pp.117-125

Shcherbinin V E and Pashagin A I. (1972). Defektoskopyia pp.874-82.

Uetake I and Saito T. (1997). NDT \& E Int. 30 pp.371-7.

Y. Chung Bang, L. Jong Won, K. Jae Dong and M. Kyung Won, (2003). Damage estimation method using committee of neural networks, Proceedings of the SPIE — the international society for optical engineering vol. 5047 (2003), pp. 263-274. 
Table 1.Three Networks performance by different parameters

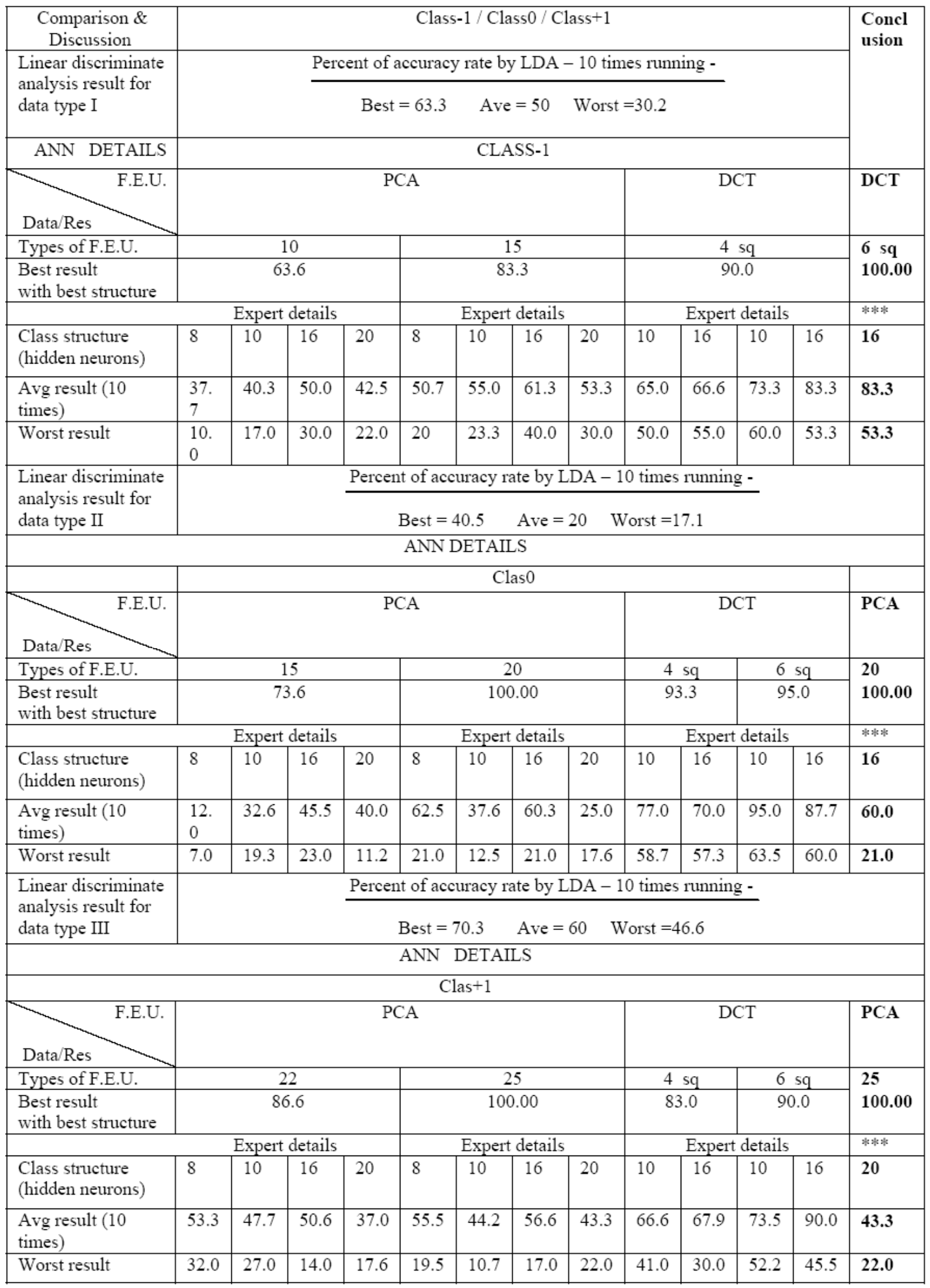



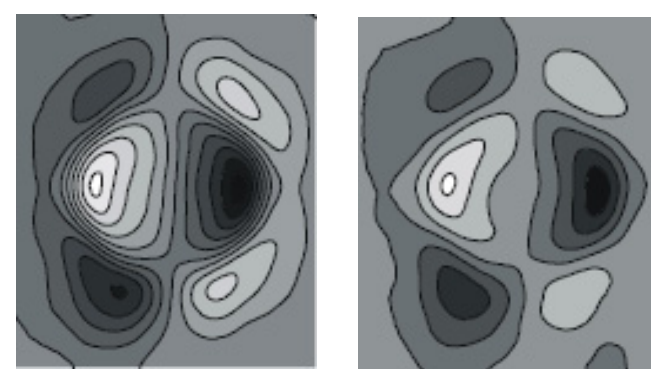

Figure 1. after anneal(left) and before anneal (right) from outside of a $3 \mathrm{~mm}$ pipeline

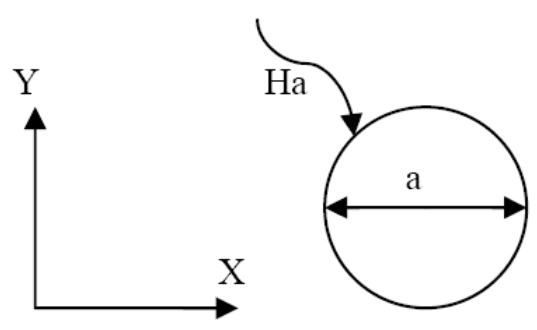

Figure 2. System of coordinates for the calculation of the magnetic flux leakage of a subsurface flaw

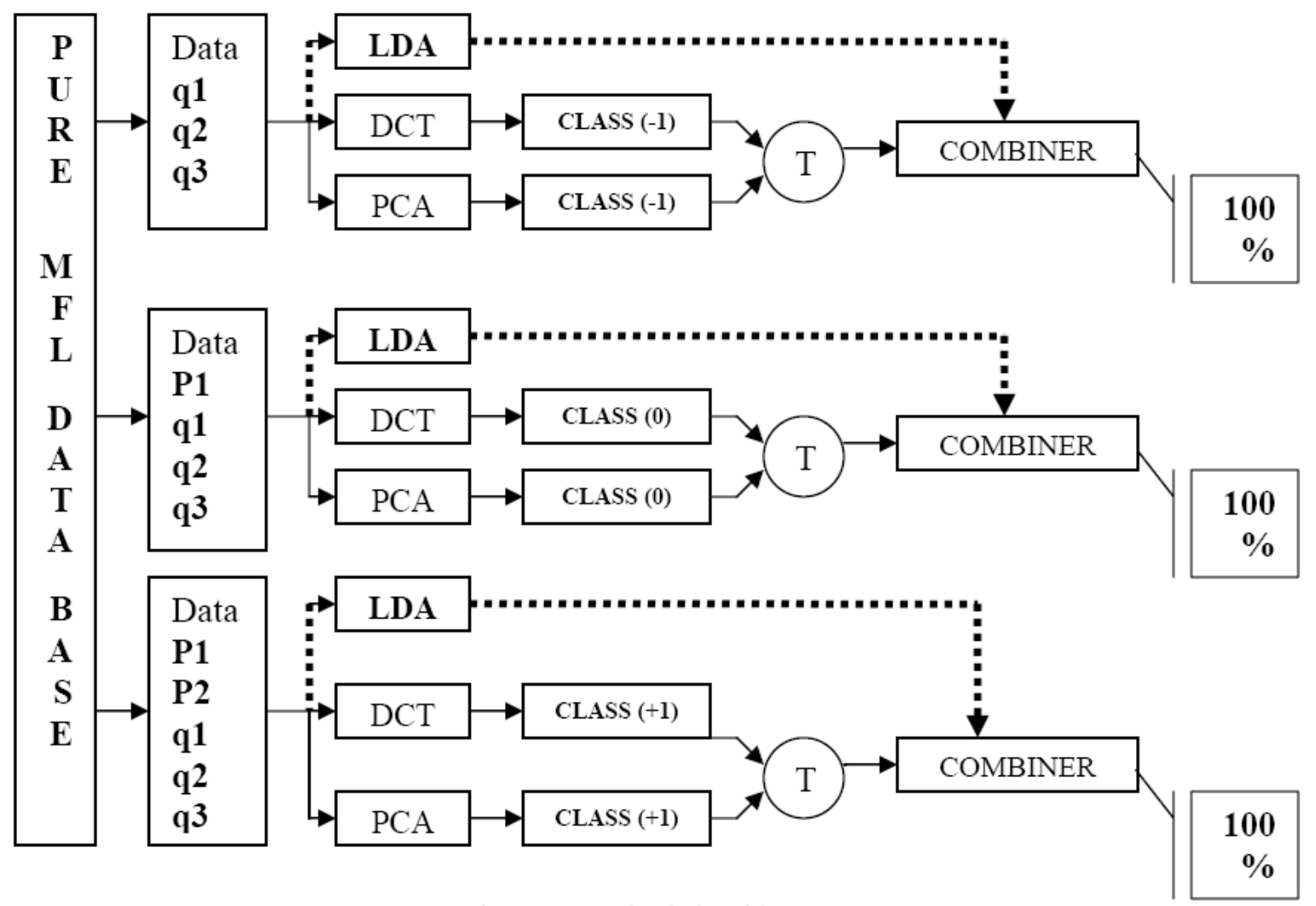

Figure 3. Devised algorithm 


\title{
The Network Identity Authentication System
}

\section{Based on Iris Feature Identification}

\author{
Hua Jiang \\ College of Computer Science, Liaocheng University, Shandong 252059, China \\ E-mail: jianghua@lcu.edu.cn \\ Shasha Zhang \\ College of Computer Science, Liaocheng University, Shandong 252059, China
}

\begin{abstract}
By researching the mothed of iris identification integrating the iris features with the secure network communication, this paper designs a new Iris-Based Network Authentification System. The system can complete access control in security. The system has many merits, such as finer security, high identification rate, and so on.

Keywords: Identity authentication, Iris feature, Nnetwork security

In computer network applications, especially in e-commerce applications, the computer's identity authentication method which can effectively prevent fake identity log in is very important technology. However, the biological features of humanity like appearance, fingerprint, iris, sound, gait, and signature, etc, because they have the characteristics of uniqueness, invariability and conveniency, ect, and they can be gathered on real-time once identity authentication will be carried on,thus the case of password being forgotten and ID being stolen totally eliminated. So the identity authentication based biological features is more securing. The iris has many unique features such as "can not transform, difficult to camouflages, non-offensive (or non-contact type)" (Daugman, 1998, p.33-39), etc, and the iris recognition technology is the highest precision of the biometric technology. (Tian,2005,p.230-232, 257). Therefore the iris recognition will become an important ways of identity recognition in the future.
\end{abstract}

\section{Iris Characteristic Recognition Technology}

Iris is the part which surround the pupils in the eyeball, above it covers extremely complex extremely complex zigzag network-like pattern and each person's iris pattern is different (shown in Figure 1.The iris recognition technology is to use computer to quantify and analysis data for the Iris feature, to confirm the real identity of the person. Iris identity recognition constitutes several parts (Daugman,2004, p. 21-30): iris acquisition, iris image's pretreatment (localization, normalizing), iris image feature's extraction, match and recognition. Among them, The acquisition of iris images is the first step of iris recognition, it can be acquired by corresponding apparatus.

\subsection{Iris localization and normalization}

The initial Iris image contains much invalid information, so it should be divided from the image at first, that's iris localization. The iris localization algorithm bases on the canny edge detection and the Hough transform algorithm, and it has good localization effect (shown in Figure 2). The annulu between 2 rings in figure 2 is the iris texture part.

In order to realize exactly match, we use the method of polar coordinates to normalize the located iris (Wang, 2002, p. 1-10)(as shown in Figure 3), it is to standardize the iris annulus to the unified template region to compensates variations caused by the pupil's zoom. Take the pupil center as the polar coordinate center, make a ray which can form angle $\theta$ with the horizontal line. The intersection point between the ray and iris inside and outside boundary respectively are $(\operatorname{xp}(\theta), y p(\theta)$ and $(\operatorname{xs}(\theta), y s(\theta)$. Formula $(1)$ can be used to map each point in iris image to the polar coordinate $(\mathrm{r}, \theta)$.

$$
\left\{\begin{array}{l}
x(r, \theta)=(1-r) x_{p}(\theta)+r x_{s}(\theta) \\
y(r, \theta)=(1-r) y_{p}(\theta)+r y_{s}(\theta)
\end{array} \mathrm{r} \in[0,1], \quad \theta \in[0,2 \pi]\right.
$$

In the polar coordinate(r, $\theta$ ), The normalized image can be unwrap into a rectangle in the size of $64 \times 1024$ (shown in Figure 3).For improving the effect of iris recognition and reducing the influence of nonuniform illumination, the iris image is transformed by hisotgram eaqualization(Huang,2002, p.404-409) (shown in Figure 4). 


\subsection{Iris feature extraction and recognition}

Iris feature can be extracted after localization and normalized. One of the effective strategies to extract texture information from the image is to convolute the image and the bandpass filter, the bandpass filter can be realized by choosing 2D Gabor filter, shown as formula(2), then transforms it to formula (3) of the polar coordinate, and coding the characteristic of the iris using complex 2D Gabor wavelet demodulation (process seen in reference 4).

$$
\begin{gathered}
G(x, y)=\exp \left\{-\pi\left[\left(x-x_{0}\right)^{2} a^{2}+\left(y-y_{0}\right)^{2} \beta^{2}\right]\right\} \times \exp \left\{-2 \pi j\left[u_{0}\left(x-x_{0}\right)+v_{0}\left(y-y_{0}\right)\right]\right\}(2) \\
G(r, \theta)=e^{-i w\left(\theta-\theta_{0}\right)} e^{-\left(r-r_{0}\right) / \alpha^{2}} e^{-\left(\theta-\theta_{0}\right) / \beta^{2}}
\end{gathered}
$$

$\alpha, \beta$ is the scale factor of the filter, and it is in reverse proportion with $\omega$, then a group of Self-Similar,multi-criterion wavelet whose frequency modulation direction along the direction of $\theta$ be created, and $\theta 0$ and $\mathrm{r} 0$.determinet its position. The texture image includes DC(Direct Current) component, in order to make the calculated iris code independent of the illumination intensity, bandpass filter should be used to remove the DC component, high frequency component and high frequency noise in the image. The filter imaginary part is a bandpass, therefore this filter can extract the texture reliably; and an iris characteristic only needs 256 bytes to express.

The iris characteristic recognition is realized by comparing Hamming distance (HD) (Daugman,2003,p.279-291) between two iris characteristic codes, the different iris codes are compared according to the bit XOR (shown as formula 4).

$$
H D=\frac{1}{3200} \sum_{j=1}^{3200} A_{j}(X O R) B_{j}
$$

A and B express different iris code, $\mathrm{j}$ expresses the bit of the iris code.In order to avoid the shifting of the 8 segments iris quantitative results for iris turning,so the two iris corresponding segment codes should be shifting comparied, each segment code's shifting number is 10 . From these shifting comparisons the smallestHD as this segment's Hamming distance. These 8 segments'HD average is the two iris's HD.Experiments show that the HD of the same iris's maximum value $<0.25[6]$, and the different iris's minimum value $>0.35$, so the separation point can be choosed from 0.25 to 0.35 . In order to reduce the error rate, we choose 0.27 as the separation point, if $\mathrm{HD}<0.27$, they are the same iris, or they are difference.

\section{Design and Analysis of Network Identity Authentication System on Iris Recognition}

\subsection{System Architecture}

In foundation of iris recognition, this article uses client/server pattern, designs a completely long-distance identity authentication system based on iris, its structure shown in Figure 5.The client side mainly completes the preparatory work of the iris recognition, including iris image gathering, image preprocessing, iris characteristic code's extraction,then transmits the 256 bit iris characteristic codes and user's other identity information to server to request authenticate. The server side has the database of iris characteristic and other identity information,mainly completes the iris characteristic's compariton,finds the corresponding iris from the characteristic base, then return the match result and the user information to the client side.

\subsection{Authentication Process}

The authentication process of this identity authentication system including two stages: registration stage and authentication stage. Considering the security, the iris characteristic code and other information should be encrypted during the communication process between client and server. This system uses the RSA encryption algorithm.

(1) Registration stage. If the user uses this system first time, then the first request to the server should be the identity registration.The server add user's iris characteristic and other information to the database to prepare for authentication.

1) User inputs ID,the system collects iris image,and extracts 256 bit iris characteristic codes after image preprocessing, and then add it and the user ID to the database.

2) The server produces server public key (KUs) and the private key (KRs) on real-time, and KRs is saved on the server.

(2) Authentication stage. Authentication process shown in figure 6.

Client: (1)Collects user's iris, inputs user's ID, obtains iris condition code Irfeature after analysis.(2)Produces user public key KUc and private key KRc on real-time using RSA encryption algorithm.(3) Encrypts user ID,KUC,Irfeature, time stamp and other information to $\mathrm{W}$ by server public key,and sends $\mathrm{W}$ to sever,W=EKU s[ID+KUC+Irfeature+T+others], $\mathrm{T}$ is time stamp, it is used for make identify the interaction uniquely.

2) Server:(1) After receiving $W$ at time stamp T', the server decrypts $W$ to $W 1$ using KRs, W1=DKRs[W] .(2)Takes out ID, Irfeature, $T, K U c$ in $W 1$, match the characteristic database and judge whether it is a valid user.(3) If ( $\left.T^{\prime}-T\right) \geq \Delta T$, the server refuses to request, the user registers, $\Delta \mathrm{t}$ is a expected value of transport delay(Zhou,2004,p.52 55).(4)If 
authenticates successfully, the server sends message $\mathrm{W}^{\prime}=\mathrm{EKUc}\left[\mathrm{T}, \mathrm{T}^{\prime}\right]$ to the user.Because only the server can decrypts $\mathrm{W}$, then obtains $\mathrm{T}, \mathrm{KUc}$, and $\mathrm{T}$ makes the user confirm $\mathrm{W}^{\prime}$ is send by the server, and the information has not been distorted.(5)The user returns a encrypted W' by KUs to make the server convinced that the other side is the user itself.

After this connection's end, the key Kuc and KRc are not saved to reduces the possibility of the keys being stolen and ensure the security of communication.

\subsection{Analysis of System Performance}

Compares with the traditional network identity authentication method, this system combines recognition technology based on the iris trick with the RSA encryption technology.This system not only has advantages such as the Strong Robustness, high flexible, high recognition rate, quickly recognition speed etc., but also has following characteristics:

(1)The user produces KUc and KRc in the client side on real-time. This can reduces the possibility that the key is stolen and assures the communication security.

(2) This system make use of iris's uniqueness and conveniences. The client collects iris on real-time every time when authenticates, so that the possibility of invader stealing the user's iris information from the client side greatly reduced.

(3) Iris feature which in database on server have been encrypted, so the invader unable to obtain the user's true iris information from the server.

(4) The server accepts the cryptographic KUc information which transmits from the client only when the user has been passed the iris authentication. Therefore user's public key KUc and private key KRc are unknowable in the entire process of communication.

(5) Database on server saves the user name, user ID, iris characteristic code, registration date,connection condition and so on. When the user registers, the user iris information can be retrieved by user ID directly.So the massively search is avoided, and the efficiency is greatly raised.

(6) There are 3 interactions between the server and the user during the entire process of communication, it guarantees that the information is not stolen or distorted at all.So the the degree of information security is strengthened.

To testify the feasibility and correctness of the proposed systems, 36 people's irises are collected under different time and conditions.Each person has 5 iris samples, they constitute a small database which is composed of 180 iris images, and each iris image is 8 bit gray images with $640 \times 480$ pixel.Then the person's identity be Recognized randomly, each person's identity can be distinguished successfully in 2 seconds. The ARR (accurate recognition rate) can reache above 99\%; the WER(word error rate) is 0 . But this system also has some insufficiencies simultaneously, for instance, the registration time is longer because the distance between eyes and collection can not control well. Because the system's recognition efficiency is decided by the scale of the characteristic base and the network complexity, the system need to be optimized and improved in the further.

\section{Conclusion}

This article utilzed the iris' characteristic of uniqueness, stability and convenience and RSA encryption systems, studied and designed a remot identity authentication system.. The practical test results shows that the identity authentication system combines recognition with encryption algorithm can achieve the goal of the remote login of identity authentication truly. Along with the reduction of the cost of iris' collection and further optimization of the match efficiency, network identity recognition technology based on iris will be promoted to more domains.

\section{References}

Daugman,J. (1998). Recognizing people by their iris pattern.Informa-tion.Security Technical Report, 3(1), 33-39.

Daugman,J. (2003). The importance of being random: Statistical principles of iris recognition. Pattern Recognition, 36(2), 279-291.

Daugman,J. (2004). How Iris Recognition Works. IEEE Trans. CSVT, 14(1), 21-30.

Huang Huifang \& Hu Guangshu. (2002). The iris recognition algorithm's research and realizes. The Infrared and Laser Engineering, 31(5), 404-409.

Tian Qichuan,Pan Quan \& Cheng Yongmei etc. (2005). Iris Encoding Algorithm Based on Local Edge Detection, Application Reasearch of Computers, 22(8), 230-232, 257.

Wang Yunhong, Zhu Yong \& Tan Tieniu. (2002). Identity authtication based on iris. Automation journal, 28(1), 1-10.

Zhou Gongye \& Liu Zhiqin. (2004). A long-distance status authentication plan based on fingerprint recognition. Computer project and science, 26(7), 52 55. 


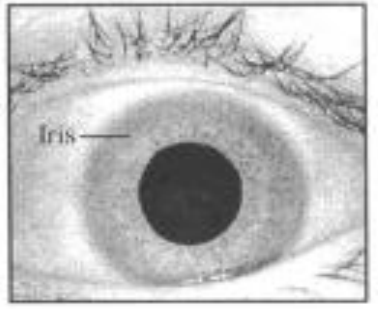

Figure 1. original image

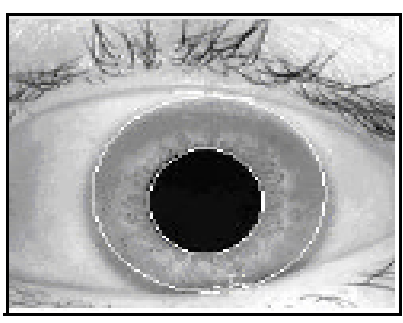

Figure 2. iris location

Figure 3. the normalized iris

Figure 4. the histogram equalization

Client

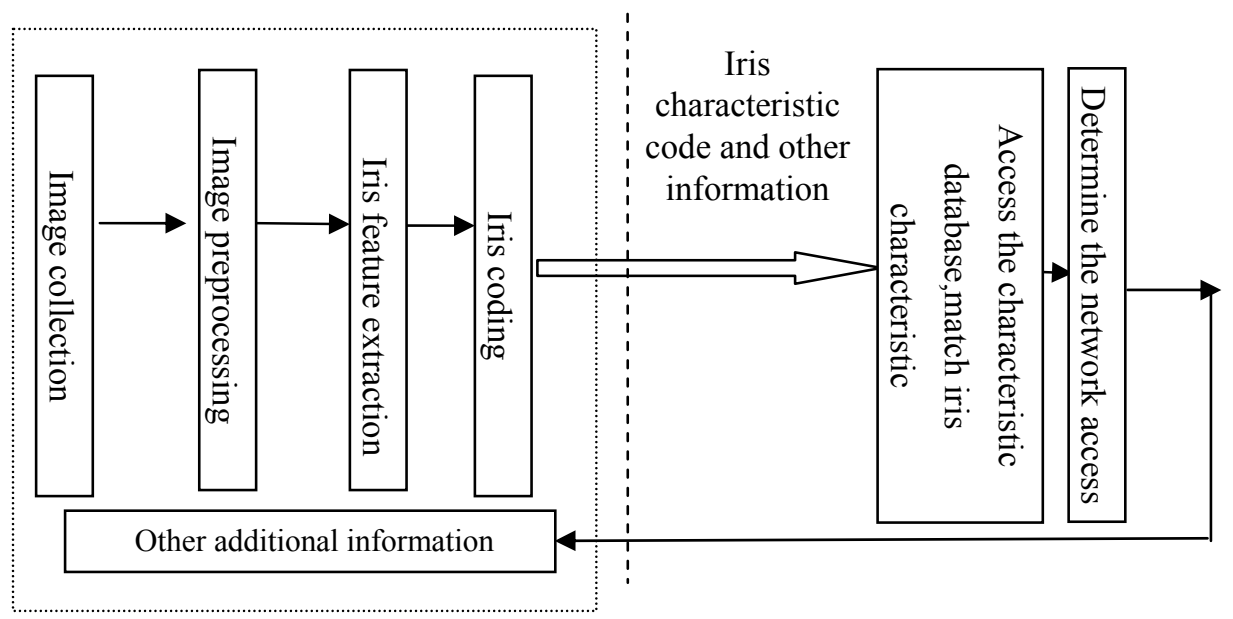

Figure 5. the remote authentication system based on iris characteristic

Client

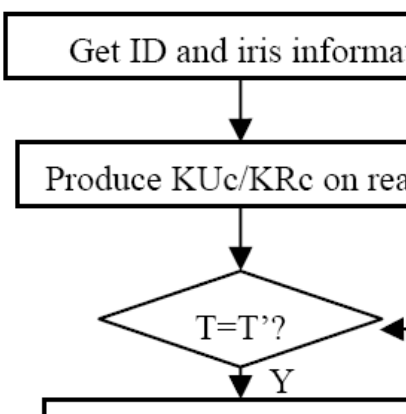

The information not be distorted
Server

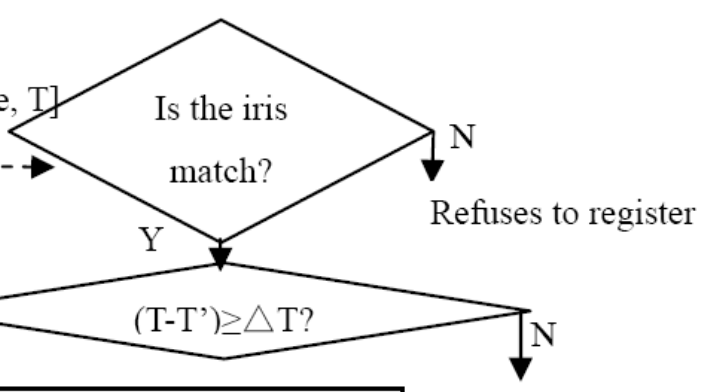

Authenticates successfully

Overtime, registers again

Figure 6. schematic drawing of status authentication process 


\title{
Modern Applied Science
}

\section{Biobleaching of Textile Dye Effluent Using Mixed}

\section{Culture through an Immobilized Packed Bed Bio Reactor (IPBBR)}

\author{
B.Manikandan (Corresponding Author) \\ School of Chemical Engineering, SRM University \\ Kattankulathur, Kancheepuram District \\ Tamil Nadu, India \\ Postal Code - 603203 \\ Tel: 91-94-4410-7040_E-mail: mani_dind@yahoo.com \\ V. Ramamurthi \\ Department of Chemical Engineering, A.C.Technology \\ Anna University, Chennai \\ Tamil Nadu, India \\ Postal Code -600025 \\ R. Karthikeyan \\ School of Chemical Engineering, SRM University \\ Kattankulathur, Kancheepuram District \\ Tamil Nadu, India \\ Postal Code - 603203 \\ T.R.Sundararaman \\ Department of Chemical Engineering, Adhiparasakthi Engineering College \\ Melmaruvathur, Tamil Nadu, India \\ Postal Code -603319
}

\begin{abstract}
A bacterial consortium was raised to treat the textile dying effluent. The mixed culture for biobleaching was isolated from the sludge and dye effluent contaminated soil from ETP houses. Among the several isolated representatives' genera, pseudomonas pudita and Bacillus subtillus were found to be the potential strains with synergetic mode of biobleaching. 80-90\% of decolorization along with 2-3 fold decrease in BOD and COD was observed using the bacterial consortium. This study exemplified the treatment feasibility of bacterial consortium over an immobilized packed bed as a biobleaching agent for treating textile dye effluents.
\end{abstract}

Keywords: Textile dye, Immobilization, Packed bed, BOD, COD, TDS, TSS

\section{Introduction}

Major pollutants in waste water from food processing, cosmetics, paper, dye manufacturing, Printing and Textile are color left by dyes (D.K.M. Markanday et al., 1999). Among these, textile industries consumes large volumes of water and chemicals for wet processing of Textiles (P.Nigam etal., 2001). The waste from the dying operations in the Textile industries may contain dyes of various intense colors, such as dyes having the functional groups of alkene, aromatic, C-N bond, S-O bond of red color. Some are made by inorganic molecules such as Al-O, Si-O, K-O, N=N bond which responsible for color development in the waste water (Balasubramanian et al.,1987). In this case, the Reactive B dye is considered for the treatment process. The discharge of dye bearing waste waters in to natural stream or on land has created significant concern as the dye impart toxicity and impedes light penetration and thus upsets the biological activity and also the ground water due to the soil leaching (Ray et al., 1986). Irrigation with raw dying factory effluent at different concentrations drastically reduced the germination, and vigor index of crops like Rice, cowpea and maize, 
and nitrogen fixation in green gram. But the diluted effluent improved the groundnut germination and increased the chlorophyll, carbohydrate and protein contents and the biologically treated effluent enhance the yield and quality of many cereals and pulses. This effluent when passed through by ash can be safely used for afforestation (Ramachandran., 1994). There are more than 100,000 commercially available dyes. With over $7 \times 10^{5}$ ton of dyes are produced annually (Meyar et al., 1981; Zollinger et al., 1987). The presence of very low concentrations of dyes in effluent highly visible and undesirable (Nigam et al., 2000). Intake of such determined water results in many physiological and pathological effects and the reports of the effect of congo red dye gave a decrease in erythrocyte counts and hemoglobin content in human (subramaniyan et al., 1999). Also dyes can cause for allergic dermatitis, Skin irritation, cancer and mutation (Namasivayam et al., 1996) and carcinogens and toxicity of azo dyes especially benzidine based dyes are well known because of their mutagenicity and carcinogenicity. Thus colors in the waste water have to be removed before it is discharged in to a water body or on land. Some conventional methods like coagulation and flocculation (Panswed \& wongoxaisuwam et al., 1986), reverse osmosis (Cohen, 1978), and activated carbon adsorption (venkat rao et al., 1987) and some nonconventional methods like Adsorption, Particularity with low cost materials such as industrial wastes (Ramakrishna etal., 1997), Clays (Jaung et al., 1997), Plant portions (Liversidge et al., 1997; Lebek etal., 1996) and polymeric gels (karzdog et al., 1997), wood charcoal (E.balssubramanian et al., 1999) and also biosorption by using low cost adsorption like Elchhonia root and shoot, Orange peel (C.Namasivayam et al., 1996), saw dust \& baggase (D.K.Markendey et al., 1999), wood (poots et al., 1978), Biogas waste slurry (Yamina et al., 1992a; 1992b), rice hulls (Nawer et al., 1989), banana pith (kanchana; 1992, 1993) and waste coir pith (Kathirvelu et al., 1994) are examined. These conventional and nonconventional effects do not show significant effectiveness or economic advantage and also taken long time and consumes more water. Azo dyes degradation occurred through an oxygen insensitive azoreductase which catalyzed the reductive cleavage of azo groups using $\mathrm{NAD}(\mathrm{P}) \mathrm{H}$ as an electron donor (Zimmerman et al., 1982). Various anaerobic bacteria have been reported (Meyer 1981) to degrade Azo dyes by reducing the Azo linkage and forming colourless and toxic aromatic amines. The bacterial decolorization is normally faster, but it may require a mixed bacterial community to degrade dyes completely (Haug et al., 1991). The decolorization effect is examined by using the bacterial consortium of pseudomonas pudita and Bacillus subtillus for biobleaching of textile dye effluent. The decolorization is done through an immobilized packing of bacterial consortium and hence the process is an eco friendly one.

\section{Material and methods}

\subsection{Raising the bacterial consortium}

The sludge and dye effluents contaminated soil were collected aseptically and stored under refrigerated condition. For raising bacterial consortium they were enriched with mineral salt medium. The enriched inoculum was checked for its decolorization ability on the dye effluent. Later they were used as inoculum for immobilization.

\subsection{Media formulation}

(Table 1)

\subsection{Immobilization}

Immobilization, the restriction of bacterial activity in confined space was prepared as a bed of column. The advantage is immobilized bed induces high retention time there by increases the efficiency of decolorization. The contaminant regulation i.e. escape of microorganisms in the downstream is reduced.

\subsection{The Experimental procedure}

A piece of "polyurethane foam" was cut and dropped in to the prepared mineral media. Then it was inoculated with bacterial consortium and kept for $24 \mathrm{hrs}$. After the period it was observed the bacterial growth on the layer of foam. The persistence of the bacteria was also satisfactory. Thus this polyurethane foam was put up as the packing material.

\section{Immobilized packed bed bio reactor (IPBBR)}

\subsection{Construction and operation}

The IPBB was incorporated with polyurethane foam packing mounted over a suitable support. The bioreactor is of aerobic, upward flow operation. Air was sterilized by passing through a laminar flow chamber.

\subsection{Reactor startup and Cell immobilization}

Initially the Bioreactor was autoclaved twice at $121^{\circ} \mathrm{c}$ for $15 \mathrm{~min}$ with an overnight interval. After autoclaving, the bacteria suspension was inoculated aseptically. The entire consortium were grown and attached to the surface of Polyurethane foam within 2 days. The growth medium in the bioreactor was replaced with processing medium, after the initial growth and immobilization phase.

\section{Results and discussion}

Both initial and final parameters of the effluent of before and after the experiments are tabulated in Tables 2 and 3. 


\subsection{Results}

This textile dye effluent after treated through this immobilized packed bed bio reactor has shown $80-90 \%$ decolorization and a considerable decrease in COD and BOD altogether.

\subsection{Discussion}

The degradation of aromatic substance can be achieved under different redox conditions. Under Nitrate reducing conditions, Nitrate is used as potential electron acceptor. It seems that toluene is the most easily degraded compound under this reducing environment. Microbial transformation of aromatic substance is mainly due to aerobic processes. Aerobic organisms alter the resonance energy by hydroxylating the benzene ring with the direct use of the molecular oxygen by mono or di oxygeneses and so, facilitate the subsequent ring cleavage by other di oxygeneses. Oxygen is required as terminal electron acceptor during microbial respirations and also for insertion into aromatic cycles.

\section{Oxygeneses}

These are the key enzymes in aerobic degradation of aromatic compounds. They may be classified into two groups. Mono oxygeneses introduce one atom of oxygen or molecular oxygen into substrate, whereas dioxygeneses introduce two oxygen atoms into one molecule of substrate. Reaction catalyzed by oxygeneses can be reported by

\subsection{Mono Oxygeneses}

$\mathrm{R}-\mathrm{H}+\mathrm{O}_{2}+\mathrm{NAD}(\mathrm{P}) \mathrm{H}+\mathrm{H}^{+}$

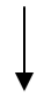

$\mathrm{R}-\mathrm{OH}+\mathrm{H}_{2} \mathrm{O}+\mathrm{NAD}(\mathrm{P})^{+}$

\subsection{Di Oxygeneses}

$$
\mathrm{R}+\mathrm{O}_{2}+\mathrm{NAD}(\mathrm{P}) \mathrm{H}+\mathrm{H}^{+}
$$

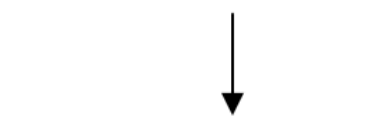

$$
\mathrm{R}(\mathrm{OH})_{2}+\mathrm{NAD}(\mathrm{P})^{+}
$$

Where, $\mathrm{R}$ and $\mathrm{R}-\mathrm{H}$ are the substrate and $\mathrm{NAD}(\mathrm{P}) \mathrm{H}$ is an external co factor, source of electrons.

Catabolism of aromatic substances generally involves multicomponent iron containing oxygeneses. These enzymatic system ensure three main reactions
- $\quad$ The oxidation of $\mathrm{NAD}(\mathrm{P}) \mathrm{H}$
- The transfer of electrons to molecular oxygen
- The terminal oxygenation of the substrate

Three different multicomponent oxygeneses are found in bacteria. Cytochrome $\mathrm{P}-450$ mono oxygeneses, methane oxygenases and related systems and multicomponent mono and di oxygeneses system, which contain non - iron sulphur cluster. These types of multicomponent oxygeneses differ mainly in the nature of iron containing group on the terminal oxygeneses component, which binds the molecular oxygen. It is either $\mathrm{Fe}$ in cytochrome $\mathrm{P}-450$ systems or a bi nuclear $(\mathrm{Fe}-\mathrm{O}-\mathrm{Fe})$. Iron center in methane mono oxygenase or simply $\mathrm{Fe}^{2+}$ in oxygeneses containing iron sulfur $(2 \mathrm{Fe}-2 \mathrm{~S})$ cluster.

\subsection{Formation of biofilm over inert materials}

In search of a good packing material for immobilization, various materials have been tried out. These includes raschig porcelain rings, nylon scrubber, glass beads, polyurethane foam etc. since immobilization requires an inert material along with a good area of contact, " polyurethane foam" is found to meet the requirements and hence taken up as packing material. Focus is mainly made on the design of a cost effective bio reactor. The required parameters have been met along with safety precautions and with high efficiency of the immobilized bed, the bio reactor was designed. The design was made keeping in mind the eco friendly disposal of textile dye effluents. 


\section{Conclusion}

The decolorization of the textile dye effluents was made easy with the help of immobilized packed bed bioreactor (IPBB).

Though the traditional methods are available, biobleaching was selected for two major reasons:

1) Cost effective process

2) Eco friendly process

The control of pollutants was achieved in a great fashion through immobilization. The highlight of the immobilized bed is its reuse. It was stable towards reuse and can be used for both batch and semi batch process.

\section{References}

Banat, I.M., Nigam,P.,D.and Marchant,R. (1996). Microbial decolorization of textile dye containing effluents : a review.Biores. Technol., 58, pp.217-227.

Cohen,H., (1978). The use of Ultrafiltration membrane treatment of textile dye house waste: $2^{\text {nd }}$ National conference of Complete Water Reuse, Chicago, American Inst. Chem.Engg. pp.992-995.

Haug, W., Schmidt, A., Nortemann, B., Hampel, D.C., Stoiz, A., Knackmuss, H.J. (1991). Mieralization of the sulfonated azo dye mordant yellow 3 by 6-aminonapthalene-2-sulfonate-degrading bacterial consprtium: Appl. Environ. Microbiology. 57. pp.3144-3149.

Meyer, U., (1981). Biodegradation of synthetic organic colorants. In: Leisinger, T., Cook, A.M., Hunter, R., Nuesch, J. (Eds.), FEMS Symposium 12, Academic Press, Londen, pp.371-385.

Namasivayam, C., Muniasamy,K., Gayathri,k., etal., (1996). Removal of Dyes from aqueous solutions by cellulosic waste orange peel: Bioresource Technology, 57, pp.37-43.

Nigam,P et al., (2000). Textile effluent decolorization and dye-adsorbed agricultural residue biodegradation: Bioresouece Technology, 77, 247-255.

Nigam,P., (2001). Color Removal from Textile waste water using bioculture in continuous mode: Bioresource Technology., 77, pp.247-255.

Pragya sharma., Amarjeet Kaur and D.K.Markanday. (1999). Biosorption of the dye by various low cost adsorbent - A lab scale investigation: International Journal of Environmental Protection., 19, pp.442-445.

Ramachandran, K. (1994). Studies on the effect of dyeing factory effluent oil soils and adjoining ground water. M.Sc (Ag.) thesis submitted to Tamilnadu agricultural University, Coimbatore. India.

Subramanian,E., Muthusamy,M and Palanivel Rajan,K. (1999). Adsorptive Removal behaviors of crosslinked Polyvinylpyrrolidone and wood charcoal with Direct Blue 2B, Textile Industry Dye Effluent: Indian Journal of Environmental Protection, 19, pp.446-450.

Zimmermann, T., Kulla, H.G., leisinger, T., (1982). Properties of purified orange II azoreductase, The enzyme initiating azo dye degradation by Psedomonas KF46: Eur..j.Biochem. 129. pp.197-203.

Zollinger, H. (1987). Color chemistry-Synthesis, Properties of Organic Dyes and pigments. VCH publishers, newyork, pp. 92-100.

Table 1. Mineral salt medium

\begin{tabular}{|l|l|}
\hline \multicolumn{1}{|c|}{ Material } & \multicolumn{1}{c|}{ Composition } \\
\hline (NH4)2SO4 & $1 \mathrm{~g} / \mathrm{L}$ \\
\hline $\mathrm{K} 2 \mathrm{HPO} 4$ & $2 \mathrm{~g} / \mathrm{L}$ \\
\hline $\mathrm{KH} 2 \mathrm{PO} 4$ & $1 \mathrm{~g} / \mathrm{L}$ \\
\hline $\mathrm{FeSO} 4.6 \mathrm{H} 2 \mathrm{O}$ & $0.001 \mathrm{~g} / \mathrm{L}$ \\
\hline $\mathrm{MgCl} 2.7 \mathrm{H} 2 \mathrm{O}$ & $0.3 \mathrm{~g} / \mathrm{L}$ \\
\hline
\end{tabular}


Table 2. Initial parameters of the effluent

\begin{tabular}{|l|l|}
\hline \multicolumn{1}{|c|}{ Parameters } & \multicolumn{1}{c|}{ Values } \\
\hline Total Solids & $9200 \mathrm{mg} / \mathrm{L}$ \\
\hline Total Dissolved Solids & $2800 \mathrm{mg} / \mathrm{L}$ \\
\hline Total Suspended Solids & $6200 \mathrm{mg} / \mathrm{L}$ \\
\hline COD & $3000 \mathrm{mg} / \mathrm{L}$ \\
\hline BOD & $2600 \mathrm{mg} / \mathrm{L}$ \\
\hline $\mathrm{pH}$ & 10.2 \\
\hline Color & Blue \\
\hline
\end{tabular}

Table 3. Final parameters of the effluent

\begin{tabular}{|l|l|}
\hline Parameters & \multicolumn{1}{|c|}{ Values } \\
\hline Total Solids & $5600 \mathrm{mg} / \mathrm{L}$ \\
\hline Total Dissolved Solids & $1200 \mathrm{mg} / \mathrm{L}$ \\
\hline Total Suspended Solids & $4400 \mathrm{mg} / \mathrm{L}$ \\
\hline COD & $700 \mathrm{mg} / \mathrm{L}$ \\
\hline BOD & $60 \mathrm{mg} / \mathrm{L}$ \\
\hline $\mathrm{pH}$ & 8.1 \\
\hline Color & Pale Yellow \\
\hline
\end{tabular}

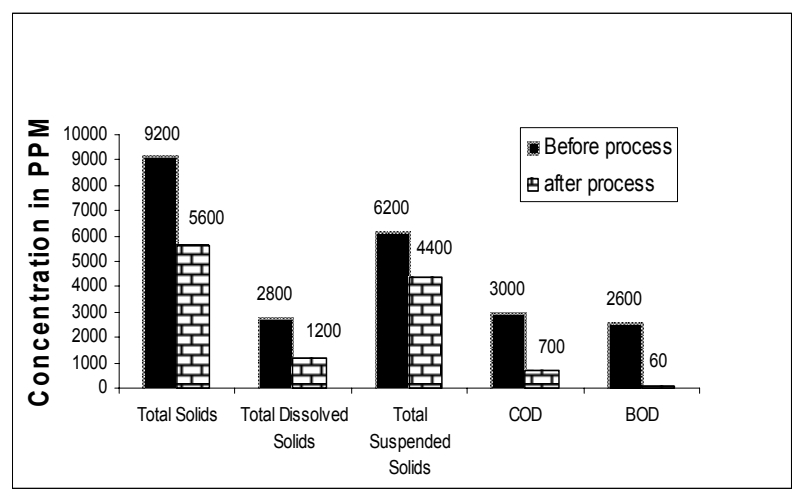

Figure 1. Bacterial Consortium effect of decolorization on Textile dye effluent 


\title{
A Study of an Evaluation Model on Manufacturing Execution System in Paper-making Enterprises
}

\author{
Zhihong Xu \\ Key Lab for Paper Science and Technology of Ministry of Education \\ Shandong Institute of Light Industry \\ Shandong 250353, China \\ E-mail:xzh1385@163.com \\ Feng Huang \\ The State Key Laboratory for Microbial Technology \\ Shandong University, Shandong 250100, China \\ Jiachuan Chen \& Guihua Yang \\ Key Lab for Paper Science and Technology of Ministry of Education \\ Shandong Institute of Light Industry \\ Shandong 250353, China
}

\begin{abstract}
Manufacturing execution system (MES) is a production management technology and real-time information system which lies between the enterprise upper layer (ERP) and the bottom layer (PLC/DCS) and faces to workshop layer. MES's concept, its functional model and its important status in the manufacture industry are introduced in this article. Based on the production practice in Kunshan Banknote Paper Mill, an evaluation model of EMS is set up. The model also has a certain reference value to the construction of management information system (MIS) for the relative industries.
\end{abstract}

Keywords: Pulp and paper industry, Manufacturing execution system, Furzzy evaluating method

\section{Introduction}

The construction of informationization has made considerable progress with years of development in domestic paper industry. Large and medium-sized paper-making enterprises has widely adopted Enterprise Resource Planning (ERP) for enterprise production planning management and Process Control System (PCS) for control of paper production process. However, it lacks effective unity and communication of model and information between the production planning management of upper layer and the process control of bottom layer, which cause unsuccessful performance of specific business functions in the control layer in time, bad visibility of production information such as supplies, equipment, product quality and order information etc, as well as difficulties of information communication. In response to this question, Manufacturing Execution System (MES) emerged.

MES is an information system in factory layer permanently between planning system of enterprise leadership and direct industrial control system of production process. It provides data and information of all the resources of the production process like personnel, equipment, materials, tools and customer requirements for operators and managers in a current perspective. And it focuses on improving the manufacturing process using information technology. On the one hand, MES eliminates the information divide between ERP and PCS, so that operators and managers can grasp the actual situation of production timely and accurately in the planning process, and be well guided to formulate practical plans in production process at the same time; on the other hand, operators and managers can track the status information of products in the production process in time using MES so as to control inventory effectively, while the consumer can know the implementation of order before delivery.

\section{Characteristics of paper making industry and the applications of MES}

As a part of process industry, the characteristics of pulp and paper industry are as follows: the flow of materiel and energy is running during the production process, and the producing technics and methods are complex, however, the 
process flow and the products are relatively stable; production can be more flexible in some measure via adjusting the technological parameter online; production process involves a variety of physical and chemical process, so it has complex mechanism and big quantity of data information, and is very difficult to deal with; it has a nice producing rhythmicity and requires better continuity and balance, as well as highly requirement in automatization of the production process control and device control; the management and decision-making of investment, update, rebuilding and servicing of the devices are quite intricate, at the same time, peculiar requirements of storage and contamination are needed(Liu, Tieming, Xong, Gang, Shen, Judong, et al, 2000)(Li, Minghui, Wang, Mengxiao, Hu, Nanjiang, 2006).

(1) characteristics and requirements of integrated management

Integrated management has functions of producing planning and attempering, which can coordinate every working procedure range from raw material, energy supply, manufacture to shipment, in order to expediting the circulation of raw material and finished product, and to increase the liquidity.

(2) characteristics and requirements of production control

Since the production of pulp and paper industry is continuous, emphasizing the integrity of production process becomes very important, which needs us to consider different devices and production processes as a whole. Terrible conditions involving high temperature, dampness, vibration, and serious erosion in pulp and paper production process can lead to serious equipment depreciation. Some of the key production equipments need regular inspection and maintenance, including preventive maintenance and on-line diagnoses. Variables of pulp and paper production process variables related strongly to each other as well as serious coupling, which put forward higher requirements of fault diagnosis technology.

(3) characteristics and design requirements of cleaner production

Paper industry is an important basic industry of the national economy providing social production and living of necessary various paper products. At the same time, it is concerned from all sides because of its substantial energy consumption, water consumption, as well as a direct impact on the environment. Paper-making enterprises should strengthen its information technology of information collection, treatment and decision-making functions in terms of saving energy, reducing pollution emissions and comprehensive utilization of resources.

\section{MES evaluation model}

\subsection{Evaluation model index system}

MES evaluation requires a variety of indicators(J. Sarkis and R.P. Sundarraj, 2005)( J.S.Dyer, 1999)(S.Schenkerman, 1999). The quality evaluation index setting is directly related to the quality or success of the MES performance evaluation. Choosing the correct and reasonable performance evaluation indicators can assist businesses and MES to optimize the allocation of resources, to improve system performance, to propose measures for improvement. Therefore, to determination the performance evaluation indicators should follow the following principles:

(1)Systematicness: It must reflect the comprehensive situation of the production process, and grasp the main factors affecting the system.

(2)Levels: A complex process at different levels is decomposed into multiple sub-processes, the evaluation indicators of which are different of the general, and the same level indicators should be given appropriate weight.

(3)Mensurability: The meaning of indicators is clear, and the data needed are facilitated to collect and analyse.

(4) A combination of qualitative and quantitative: The value of quantitative indicators can be calculated in accordance with the corresponding formula; while the quantifiable results of qualitative indicators are evaluated based on the evaluation criteria and the actual situation, as well as personal experience by the relevant staff, and qualitative indicators can make up for disadvantage that some indicators are currently unable to obtain accurate data.

(5) Relativity: Various indicators should reflect the system performance from different angles. Selection of different indicators like that to do evaluation can master the operation of the system much completely.

When designing index system, we drew on a number of other studies in this area. For example, we studied how to assess the core competitiveness of paper-making enterprises using AHP from Sun Chunlei(Sun, Chunlei, 2004), and evaluated the implementation capacity of information of manufacturing sector using fuzzy evaluation method and AHP from Qi Ershi, Li Gang and Song Chunhua(Qi, Ershi, Li, Gang, Song, Ninghua, 2006).

The emphases of our evaluation model are to investigate the capacity of improving performance of MES for paper production. And then we got the following model:

According to the actual situation of enterprises, we broke all the relevant factors down into several levels from top to bottom in accordance with the different properties, and set up a three-tier model structure.

Target layer: That is, production performance evaluation and analysis of paper-making enterprise MES. 
Criteria layer: Various influencing factors of the implementation of paper-making enterprise resource planning and production processes, which we summed up in five areas: integration factors; production factors; quality factor; resource utilization factors; cleaner production factors.

Indicator layer: every specific indicators element impacting the criteria layer.

The indicator system is shown in Figure 1.

The four indicators of cleaner production factors in this model are "lower pollution \& waste reduction", "waste utilization", "pollution control" and "energy consumption", and the data can be obtained in accordance with the evaluation system of Development and Reform Commission.

In all the indicators, integration factors and cleaner production factors are qualitative ones, and such indicators obtain data by investigation or expert scoring method; while the other three indicators are quantitative, and such indicators obtain data by current statistics report or equipment real-time production data.

\subsection{Fuzzy evaluation method}

We adopt a fuzzy evaluation method to calculate. Readers can access the relevant literature to know the algorithm ( $\mathrm{Li}$, Enke, Ma, Yuxiang, 2000)( Tao, Qing, Zheng, Wentang, 2002). Because of space limitations we only write its basic calculation steps without detailed introduction: (1) to set up performance evaluation index system;(2) hiring of experts to determine the weights of the performance indicators;(3) to determine the membership function $\mathrm{u}(\mathrm{x})$ of some performance indicators according to historical data and expertise;(4) to obtain the eigen value (actual value) of each factor using data collection or system simulation software;(5) to substitute Eigen values of each factors in the membership function $u(x)$, and to generate a degree of membership;(6) to obtain fuzzy evaluation value $B ;(7)$ to get the best integrated performance results and sort orders of each scheme.

\section{Examples}

\section{1 study}

(1)Kunshan Banknote Paper Mill has a history of producing anti-counterfeiting prper such as banknote more than 30 years, who owns 4 banknote paper producing line with international advanced level of the 1990's. Their products passed the IS09001, IS014001 and OHSAS 18001 International Certification, and they have used ERP systems successfully. We separately studied the production performance before and after the implementation of MES in the enterprise, which do a more favorable evaluation of the effect of MES.

(2)Shandong Huatai Paper Group is a large paper company in China, which applied the Enterprise Resource Planning (ERP) system early and achieved excellent effect. Huatai is one of a few paper-making enterprises whose construction of enterprise information is very prominent. They developed part of MES system in collaboration with Shandong University, Northwestern Polytechnical University and University of Petroleum (East China). The reason why we studied them is that it has a representation in the paper industry.

\subsection{Calculation}

\subsubsection{Hiring of experts and scoring each indicator}

We use AHP to calculate the weight vector set A of indicator layer. So:

$\mathrm{A}=\{0.061,0.045,0.095,0.104,0.14,0.093,0.117,0.073,0.078,0.039,0.024,0.017,0.031,0.029,0.054\}$

\subsubsection{Determine the evaluation set}

We determine the production performance evaluation level as verty good, good, mediocre and bad, which corresponds to level $1,2,3,4$ respectively.

In this evaluation system there are qualitative indicators and quantitative indicators.

Adopting expert scoring method to generate the degree of membership of qualitative indicators, the group of experts give scores to the performanc of each indication of evaluation object based on a ten-point system, then generate the degree of membership dividing the score by 10 .

We adopt membership functio of fuzzy math to generate the degree of membership of quantitative indicators. Then we take "program completion rate" of the indicators for example to calculate the degree of membership of quantitative indicators.

4.2.3 Determine the membership function

We make $4^{\text {th }}$ level membership function of 4 classes for each quantitative indicator with higher or lower semi-trapezoidal method. Taking "program completion rate" of the indicators for example, higher semi-trapezoidal method are suitable for "program completion rate" according to industry standards and previous production experience $4^{\text {th }}$ level membership function of 4 classes are as follows. 


$$
\begin{aligned}
& \mu_{1}(x)_{1}= \begin{cases}0 & x \leq 0.83 \\
(x-0.83) / 0.16 & 0.83<x<0.99 \\
1 & x \geq 0.99\end{cases} \\
& \mu_{1}(x)_{2}= \begin{cases}x-0.7 & 0.7<x<0.8 \\
(0.9-x) / 0.1 & 0.8<x<0.9 \\
0 & x \leq 0.7, x \geq 0.9\end{cases} \\
& \mu_{1}(x)_{3}= \begin{cases}x-0.5 & 0.5<x<0.68 \\
(x-0.68) / 0.13 & 0.68<x<0.81 \\
0 & x \leq 0.5, x \geq 0.81\end{cases} \\
& \mu_{1}(x)_{4}= \begin{cases}0 & x>0.6 \\
(0.6-x) / 0.3 & 0.3<x<0.6 \\
1 & x \leq 0.3\end{cases}
\end{aligned}
$$

4.2.4 Obtain the eigenvalues of various indicators(measured value)

According to statistics of production management of Kunshan Banknote Paper Mill and analysis of report forms of Shandong Huatai Paper Group combined with expert interviews, we obtained data sheet of three objects in the following tables(table 1).

4.2.5 Substitute the eigenvalues(measured value) in the membership function to generate the degree of membership

We substitute the Program completion rate(C5) of Kunshan Banknote Paper Mill which is 0.841 into membership function $\mu_{1}(x), \mu_{2}(x), \mu_{3}(x), \mu_{4}(x)$ respectively, then generate a degree of membership $r_{5 j}=\{0.538,0.462,0,0\}, j=1,2,3,4$.

In the same way, we can get the result of evaluating each indicator of three objects using membership degree, then obtain a $10 \times 4$ fuzzy evaluation matrix. After determining the degree of membership of all qualitative and quantitative indicators, we have to normalize the degree of membership. The evaluation results of Kunshan Banknote Paper Mill (after the application of MES) are in table 2. And we omit the fuzzy evaluation matrixs of the other 2 objects.

4.2.6 The table of obtain the best production performance evaluation(table 3)

\subsection{Conclusion}

(1)Based on the "maximum membership grade principle" in fuzzy comprehensive evaluation ${ }_{2}$ performance evaluation of three objects are in table 4. MES production performance of Huatai Group reached the "very good" level, which received the highest rating of the three objects. This showed that the application and design of MES system were indeed at the leading level. The effect of production performance of Kunshan Banknote Paper Mill after the application of MES was better than before. Therefore, the effect of production performance of Kunshan Banknote Paper Mill after the application of current MES is notable judging from the results of the evaluation. They certainly exist a gap with the advanced domestic enterprises.

(2) In order to assess the conclusions scientifically, accurately and in time, we should pay attention to the following points: to begin with, experts should be authoritative and representative, what's more, Implementation dynamic management should be implemented, that is the evaluation system need periodic assessment, indicator system and the weight should be adjusted timely as well.

\section{References}

J. Sarkis and R.P. Sundarraj. (2005). "Evaluation of Enterprise Information Technologies: A Decision Model for High-Level Consideration of Strategic and Operational Issues",J. IEEE Trans, on Systems, Man, and Cybernetics-Part C Vol., Issue 99, pp.1-14.

J.S.Dyer, (1999). "Remarks on the Analytic Hierarchy Process”, J. Manage. Sci. , vol.36, no.3, pp.249-268.

Li, Enke, Ma, Yuxiang. (2000). "Fuzzy and Analytic Hierarchy Process Models for Comprehensive Evaluation of Information Systems",J. Journal of The China Society for Scientific and Technical Information, Vol.19, No.2, April,pp 181-186. 
Li, Minghui, Wang, Mengxiao, Hu, Nanjiang. (2006). “Application of MES in Papermaking Industry”,J. Transactions of China Pulp and Paper, Vol.21,No.4,pp 94-96.

Liu, Tieming, Xong, Gang, Shen, Judong, et al. (2000). "Research on the Application of CIMS in a Modern Pulp\& Paper Industry",J. Industrial Instrumentation \& Automation, No.3,pp 3-6.

MES Software Evaluation / Selection, MESA international, White Paper No.4, 1996.

Qi, Ershi, Li, Gang, Song, Ninghua. (2006). "Evaluation Methods of MIE Implementation Ability Analysis and Application”, J. JOURNAL OF TIANJIN UNIVERSITY (SOCIALS CIENCES), Vol.8,No.2,Mar,pp 98-102.

S.Schenkerman, (1994). “Avoiding Rank Reversal in AHP Decision-support Models",J. Eur.J.Oper.Res., vol.74, pp.407-419.

Sun, Chunlei. (2004). "Evaluation Method of Core Competence of Pulp\&Paper Enterprise",J. China Pulp \& Paper,Vo1.23,No.1,pp 53-56.

Tao, Qing, Zheng, Wentang. (2002). "Mathematical Moder's Building for Valuation of Tenders of Project Items", $J$. Application of statistics and management, Vol.21, No.6,Dec,pp 37-41.

The Benefits of MES: A Report from the Field, MESA international, White Paper No.1,May, 1997.

Table 1. Data sheet of three study indicators

\begin{tabular}{|c|c|c|c|}
\hline indicator & $\begin{array}{l}\text { Huatai } \\
\text { Group }\end{array}$ & $\begin{array}{l}\text { Kunshan Banknote Paper Mill } \\
\text { (after the application of MES) }\end{array}$ & $\begin{array}{l}\text { Kunshan Banknote Paper Mill } \\
\text { (before the application of MES) }\end{array}$ \\
\hline rejection rate $(\mathrm{C} 3)$ & 0.012 & 0.018 & 0.024 \\
\hline $\begin{array}{l}\text { qualification rate of first } \\
\text { acceptance check }(\mathrm{C} 4)\end{array}$ & 0.982 & 0.985 & 0.920 \\
\hline program completion rate(C5) & 0.867 & 0.841 & 0.812 \\
\hline $\begin{array}{l}\text { the rate of balanced } \\
\text { production(C6) }\end{array}$ & 0.743 & 0.704 & 0.658 \\
\hline order fulfilment rate(C7) & 0.941 & 0.978 & 0.969 \\
\hline $\begin{array}{l}\text { average circulation time of } \\
\text { equipments (C9) }\end{array}$ & 0.769 & 0.742 & 0.631 \\
\hline resource utilization $\operatorname{rate}(\mathrm{C} 8)$ & 0.725 & 0.606 & 0.549 \\
\hline equipment failure rate(C10) & 0.264 & 0.372 & 0.367 \\
\hline $\begin{array}{l}\text { materials consumption } \\
\operatorname{rate}(\mathrm{C} 11)\end{array}$ & 0.146 & 0.179 & 0.233 \\
\hline
\end{tabular}


Table 2. Evaluation matrix of Kunshan Banknote Paper Mill (after the application of MES)

\begin{tabular}{lllll}
\hline \multirow{2}{*}{ Indicator } & rating scale & & & \\
\cline { 2 - 5 } C1 & verty good & good & 0 & bad \\
C2 & 0.7 & 0.3 & 0.1 & 0 \\
C3 & 0.7 & 0.2 & 0 & 0 \\
C4 & 0.634 & 0.366 & 0 & 0 \\
C5 & 0.475 & 0.525 & 0 & 0 \\
C6 & 0.538 & 0.462 & 0 & 0 \\
C7 & 0.725 & 0.275 & 0 & 0 \\
C8 & 0.593 & 0.407 & 0.247 & 0 \\
C9 & 0 & 0.753 & 0 & 0 \\
C10 & 0.409 & 0.569 & 0 \\
C11 & 0.591 & 0.431 & 0.372 & 0 \\
C12 & 0 & 0.628 & 0 & 0 \\
C13 & 0 & 0.4 & 0.4 & 0.1 \\
C14 & 0.6 & 0.3 & 0.2 & 0.1 \\
C15 & 0.2 & 0.2 & 0.2 & 0 \\
\hline
\end{tabular}

NOTE: evaluating C1,C2 and C12 adopting expert scoring method; evaluating C5 C11 adopting fuzzy evaluation method

Table 3. The able of Fuzzy Comprehensive Evaluation of MES production performance

\begin{tabular}{ll}
\hline object & Fuzzy Evaluation Value B \\
\hline $\begin{array}{l}\text { Huatai Group } \\
\text { Kunshan Banknote Paper Mill (after the application of }\end{array}$ & $(0.480,0.436,0.084,0)$ \\
MES) & \\
Kunshan Banknote Paper Mill (before the application of & $(0.230,0.248,0.346,0.176)$ \\
MES) & \\
\hline
\end{tabular}

Table 4. production system performance level

\begin{tabular}{ll}
\hline sort & object \\
\hline vry good & Huatai Group \\
good & Kunshan Banknote Paper Mill (after the application of MES) \\
mediocre & Kunshan Banknote Paper Mill (before the application of MES) \\
bad & $/$ \\
\hline
\end{tabular}


Target layer

Criteria layer

Indicator layer

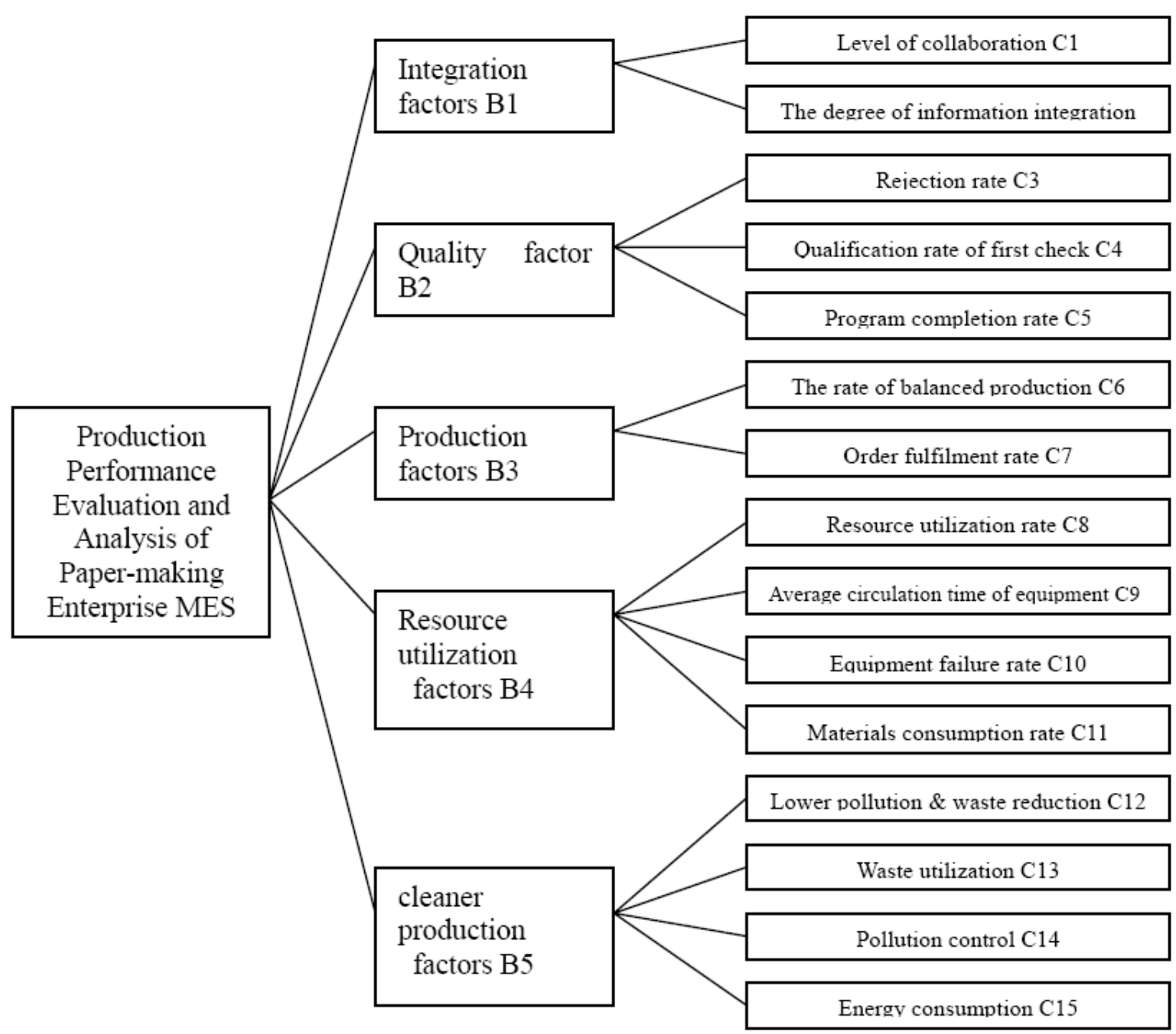

Figure 1. Evaluation model index system 
An Optimal Load Shedding Approach for Distribution Networks

\author{
with DGs Considering Capacity Deficiency
}

\title{
Modelling of Bulked Power Supply
}

\author{
Ahmad Reza Malekpour \\ Department of Electrical \& Electronic Eng. \\ School of Engineering, Shiraz University, Shiraz, I.R. of Iran \\ Tel: 98-711-230-3081 E-mail: malekpour_ahmad@yahoo.com \\ Ali Reza Seifi (Corresponding author) \\ Department of Electrical \& Electronic Eng. \\ School of Engineering, Shiraz University, Shiraz, I.R. of Iran \\ Tel: 98-711-230-3081Ｅ-mail: seifi@shirazu.ac.ir
}

\begin{abstract}
This paper discusses a genetic algorithm (GA) based optimal load shedding that can apply for electrical distribution networks with and without dispersed generators (DG). Also, the proposed method has the ability for considering constant and variable capacity deficiency caused by unscheduled outages in the bulked generation and transmission system of bulked power supply. The genetic algorithm (GA) is employed to search for the optimal load shedding strategy in distribution networks considering DGs in two cases of constant and variable modelling of bulked power supply of distribution networks. Electrical power distribution systems have a radial network and unidirectional power flows. With the advent of dispersed generations, the electrical distribution system has a locally looped network and bidirectional power flows. Therefore, installed DG in the electrical distribution systems can cause operational problems and impact on existing operational schemes. Introduction of DGs in electrical distribution systems has introduced many new issues in operational and planning level. Load shedding as one of operational issue has no exempt. The objective is to minimize the sum of curtailed load and also system losses within the frame-work of system operational and security constraints. The proposed method is tested on a radial distribution system with 33 load points for more practical applications.
\end{abstract}

Keywords: DG, Load shedding, Optimization, Capacity Deficiency Modelling

\section{INTRODUCTION}

The phenomenal growth in load demand both in developing and developed countries has emerged as a potential challenge to the power system planners and operators. Projections show that the growth in load demand is always going to be ahead of the growth in generation. Electric supply failures can have serious monetary impacts on the system customers. During an emergency situation, system operators are required to make load shedding decisions based on system security concerns, such as voltage, current, power and frequency constraints, to alleviate constraints and maintain system stability.

The distribution systems are the final link of the interconnection between power systems and the consumers. If there is the necessity to alleviate the load in order to guarantee the safety restrictions, usually the curtailment occurs in the distribution system. An important aspect in the operation of these systems is that the load curtailment originates from failures in the generation and transmission system. Distributed generation (DG) is normally defined as small generation units ( $<10$ MW) installed in distribution systems (Ackermann,T.; Andersson,G.; Soder, L. 2001). Distributed generation is expected to play an increasing role in emerging electric power systems. Studies have predicted that DG will be a significant percentage of all new generation going on line. It is predicted that they would have about $20 \%$ of new generations being installed (W. El-Khattam, M. M. A. Salama, 2004). They use different types of resources and technologies to serve energy to power systems. DG applications result in positive and negative side effects for both utility and customers (Daly, P.A.; Morrison, J)( Dugan, R.C.; McDermott, T. E.). Different techniques have been 
proposed to solve the load shedding problem in distribution network. Aoki et al (K. Aoki, N. Nara, M. Itoh and T. Satoh and H. Kuwabara, 1989)describes a load curtailment procedure as part of a service restoration algorithm considering a violation vector with current capacity and voltage drop violations as components. A quantity called effective length of remaining violations is defined in (K. Aoki, N. Nara, M. Itoh and T. Satoh and H. Kuwabara, 1989). Loads in the end sections of the violating feeders that have the smallest value of this quantity are curtailed. Sarma et al (N.D.R. Sarma, S. Ghosh, K.S. Prakasa Rao and M. Srinivas, 1994) consider load shedding in system with switch able capacitors and on-load tap changers. For voltage drop violations, if the load point with violation does not have a switch able capacitor, it will be shed. For current capacity violation at a component, a low priority load at a point beyond that component is shed. However, the steps to be taken when several current capacity and voltage drop violations are simultaneously present are not specified in this paper. Wang et al (P. Wang and R. Billinton, 2000) investigates the effect of load-shedding procedures on distribution system reliability cost indices. Customer concerns regarding interruption costs are incorporated in the load-shedding decision process when a bulk system deficiency occurs. Cost weight factors for different feeder types, based on capacity and cost match, are used to determine the load-shedding priority among feeders. In (Ding Xu and Adly Girgis, 2001), an optimal load shedding strategy for power system with multiple DGs is presented and in this paper discritization and mathematical programming has been introduced. In (W.P. Luan, M.R. Irving and J.S. Daniel, 2002), a genetic algorithm is employed to search for supply restoration and optimal load shedding in distribution networks. In (P.S. Nagendra Rao and K.S. Papa Rao, 2003) line ampacity violations and voltage drop violations at the load points are considering for load shedding in radial distribution systems. But, to our knowledge, hardly anything has been reported in the literature on the problem of online load shedding with the objective of minimizing system loss during generation deficiency conditions caused by unscheduled outages in generation and transmission system for maneuver applications in case of emergency for distribution system. In (A. R. Malekpour, A. R. Seifi, M. R. Hesamzadeh, 2006) authors applied a GA optimization method for load shedding in distribution networks considering DG units.

This paper presents a new approach for solving the steady state load-shedding problem in distribution network during generation deficiency conditions with DGs. The problem is formulated to minimize the sum of curtailed load and also system losses. The problem is subjected to equality and inequality constraints. The formulated optimization problem is solved using GAs technique (D.E. Goldberge, 1989). The method is tested on a radial distribution network with 33 load points. The effects of GAs parameters and operators are studied. Results are reported and discussed.

\section{Mathematical Model of The Problem}

Load shedding problem can be formulated as an optimization problem with the following objective function and constraints:

$$
\operatorname{Min}\left(\sum_{k=1}^{N b} R_{k} \times I_{k}^{2}\right)+W_{L} P_{L}
$$

Such that:

$$
\begin{aligned}
& P_{g i}-P_{d i}-V_{i} \sum_{j=1}^{N} V_{j} Y_{i j} \cos \left(\delta_{i}-\delta_{j}-\theta_{i j}\right)=0 \\
& Q_{g i}-Q_{d i}-V_{i} \sum_{j=1}^{N} V_{j} Y_{i j} \sin \left(\delta_{i}-\delta_{j}-\theta_{i j}\right)=0 \\
& V_{i}^{\min } \leq V_{i} \leq V_{i}^{\max } \\
& P_{i j}^{\min } \leq P_{i j} \leq P_{i j}^{\max } \\
& P_{g i}^{\min } \leq P_{g i} \leq P_{g i}^{\max } \\
& Q_{g i}=Q_{g} \quad \text { if } \quad Q_{g i}^{\min } \leq Q_{g i} \leq Q_{g i}^{\max } \\
& Q_{g i}=Q_{g i}^{\min } \text { if } Q_{g i} \leq Q_{g i}^{\min } \\
& Q_{g i}=Q_{g i}^{\max } \text { if } Q_{g i}^{\max } \leq Q_{g i}
\end{aligned}
$$

Where:

$\mathrm{N}_{\mathrm{b}}$ : Total number of branches

$\mathrm{R}_{\mathrm{k}}$ : Resistance of $\mathrm{k}^{\text {th }}$ branch

$\mathrm{I}_{\mathrm{k}}$ : Absolute value of current of the $\mathrm{k}^{\text {th }}$ branch

$\mathrm{W}_{\mathrm{L}}$ : Importance degree of customer $\mathrm{L}$

$\mathrm{P}_{\mathrm{L}}$ : Demand active power of customer $\mathrm{L}$ 
$P_{g i}$ : Generating active power at bus $\mathrm{i}$

$P_{g i}^{\min }:$ Minimum limit for generating active power at bus $\mathrm{i}$

$P_{g i}^{\max }$ : Maximum limit for generating active power at bus i

$P_{d i}$ : Demand active power at bus i

$V_{i}$ : Magnitude of voltage at bus $\mathrm{i}$

$Y_{i j}$ : Magnitude of $(\mathrm{i}, \mathrm{j})$ element of $\mathrm{Y}_{\mathrm{Bus}}$ admittance matrix

$\theta_{i j}:$ Angle of $(\mathrm{i}, \mathrm{j})$ element of $\mathrm{Y}_{\mathrm{Bus}}$ admittance matrix

$\delta_{i}$ : Angle of voltage at bus i

$Q_{g i}$ : Generating reactive power at bus i

$Q_{d i}:$ Demand reactive power at bus i

$V_{i}^{\min }:$ Minimum limit for magnitude of voltage at bus $\mathrm{i}$

$V_{i}^{\max } \quad$ : Maximum limit for magnitude of voltage at bus $\mathrm{i}$

$P_{i j}^{\min }:$ Minimum limit for active power of branch between buses $\mathrm{i}$ and $\mathrm{j}$

$P_{i j}^{\max }:$ Maximum limit for active power of branch between buses $\mathrm{i}$ and $\mathrm{j}$

In the set of equations (1) through (7), $R_{k} \times I_{k}{ }^{2}$ is the Ohmic loss of the kth branch while k refers to kth branch of the network. Equations (2) and (3) are well-known load flow equations. Security and operational constraints have been formulated as (4) and (5). Where, (4) refers to voltage limits and (5) point at thermal limit of distribution lines of the network. Equation set (7) refers to reactive limits of dispersed generators.

The steady state model of DG is used in this paper. This model is suitable for some kind of DGs such as gas turbine, combustion engines and hydro generation. DGs are modelled as constant power factor units. Considering this point, the bus connected to the DG can be modeled as PQ bus (Mardaneh M, Gharehpetian, G.B, 2004). The output and the ramp rate are two constraints for this kind of DG. It must be pointed out that minimum output of some generation is an important constraint because of the cogeneration. They must generate certain power to ensure the heat supply (Ding Xu and Adly Girgis, 2001). These constraints can be written as set of equations 7 with $N_{d g}$ as the number of installed DG in the system. Now the problem can be stated as minimization of the objective function (OBF) satisfying all system constraints stated above. A GA software package was written for simulation of load shedding in electrical distribution networks with and without DGs. This program initializes a random sample of individuals with different parameters to be optimized using the genetic algorithm approach. The population size of 100 is found to be appropriate for our problem. By tuning the GA parameters, the optimal performance was reached with one child per pair of parents. Chromosome length is of length number of buses plus one fitness bit.

\section{CASE STUDY}

A radial distribution network with 33 load points is used to simulate the load shedding problem with dispersed generation. The data of this test system is taken from (B.Venkatesh, R.Ranjan, 2003).

The system is a hypothetical $12.66 \mathrm{kV}$ system. When there is a disturbance in the network, the system operator may request the distribution utility or industrial customer to shed load to maintain the system integrity. Two cases are studied. Case 1 occurred when DGs can not compensate decrease in power flows to the network. (Decrease in power is more than total installed DGs). Case 2 occurred when DGs can compensate decrease in power flows to the network. (Decrease in power is not more than total installed DGs).

\subsection{Optimal load shedding considering constant capacity deficiency modelling of bulked power supply}

Suppose now that the power flows to the network decreases to 1.5 per unit (the power flows to the network without DG in normal case is 3.9128 per unit) and caused emergency case for loads. Using the proposed algorithm the resulting network topology is shown in Fig 1. The active and reactive load powers before and after load shedding can be compared in the network.

Table I shows the installation node and old and new operational power of DG's for the test system. DGs are installed in heavy loaded node. Suppose now that the power flows to the network decreases to $1.5 \mathrm{pu}$. Using the proposed algorithm in case 1 the resulting network topology is shown in Fig 2. 
Table II shows objective function, summation of loads, loss and profile index (PI) of case study with/without DG.

\subsection{Optimal load shedding considering variable capacity deficiency modeling of bulked power supply}

For the proposed system, using the proposed formulation, the total supplied load decreases to 3.045 per unit by 0.02 per unit decreasing step in case one and 2.985 to 1.505 per unit by 0.02 per unit decreasing step in case two.

For each case the result has been saved in a table and when the supplied power to the distribution system decreases in case of an emergency state, the optimum load shedding can be loaded from the table and applied to the system by system operator.

1) Load shedding is not necessary (case1)

Because the total maximum installed DGs is 0.793 per unit by decreasing the total supplied to 3.045 per unit by 0.02 per unit decreasing step load shedding is not needed and DGs can compensate the decreased power. Figure 3 shows the remained active load with and without DG in case one. Figure 4 and 5 shows the profile index (PI) and Percentage loss (the ratio of total loss to total generated power) of the system with and without DG in case one.

2) Load shedding is necessary (case2)

In this case because DGs are at maximum injection power by decreasing the total supplied load from 2.985 to 1.505 per unit by 0.02 per unit decreasing step load shedding is necessary and total decreased power can not be compensated by DGs. Figure 6, 7, and 8 shows the remained active load, profile index (PI) and Percentage loss of the system with and without DG considering variable capacity deficiency modeling of bulked power supply in case2.

\section{ANALYSIS OF THE RESULTS}

The proposed algorithm was successful in solving the optimization problem of optimal load shedding in distribution networks with and without installed DGs considering constant and variable capacity deficiency modeling of bulked power supply. When deficiency occurred the main objective would be maintaining much more load of the system. In case1 this objective is satisfied by DGs. Also the proposed algorithm can improve the percentage loss in comparison the cases without DG according to figures 3, 4, 5. But in contrast the voltage profile was worse than cases without DG. These results were also shown in case 2 and figures 6,7 , and 8 .

\section{Conclusion}

The energy deficit originated from failures in the generation and transmission systems promotes load curtailments in the distribution system. There are many policies or strategies that can be adopted to perform these load curtailments. This paper proposed a GA-based methodology for finding optimum load shedding strategy for distribution networks with and without installed DGs considering constant and variable capacity deficiency modeling of Bulked Power Supply points of distribution networks. The model is based on minimization of total curtailed load based on their assigned importance degree and system losses within the frame work of load shedding equality and inequality constraints. A test system was used in order to apply the methodology and the results were presented for the various load shedding alternatives.

\section{REFERENCES}

A. R. Malekpour, A. R. Seifi, M. R. Hesamzadeh, (2006). "Considering Dispersed Generation in Optimal Load Shedding for Distribution Networks", 14th Iranian Conference on Electrical Engineering, ICEE2006.

Ackermann,T.; Andersson,G.; Soder, L.; (2001). "Distributed Generation: A Definition", Electric Power Systems Research, Vol 57, 2001, pp 195-204.

B.Venkatesh, R.Ranjan, (2006). "Optimal radial distribution system reconfiguration using fuzzy adoption of evolutionary programming”, Electric Power System Research, 25 (2003) 775-780.

D.E. Goldberge, (1989). "Genetic Algorithms in Search, Optimization and Machine Learning”, Addison-Wesely, Reading, Ma.

Daly, P.A.; Morrison, J; "Understanding the Potential Benefits of Distributed Generation on Power Delivery Systems" IEEE Power Engineering Society Summer Meeting pp. A2-1/A2-13

Ding Xu and Adly Girgis. (2001). "Optimal Load Shedding Strategy in Power Systems with Distributed Generation", IEEE Winter meeting, Power Engineering Society, 2001, V01.2, pp.788-792.

Dugan, R.C.; McDermott, T. E.; "Operating Conflicts for Distributed Generation on Distribution Systems", IEEE Power Engineering Society Summer Meeting, ppA3-1/A3-6.

K. Aoki, N. Nara, M. Itoh and T. Satoh and H. Kuwabara, (1989). "A new algorithm for service restoration in distribution systems" IEEE PWRD, 4(3):1832-1839. 
Mardaneh M, Gharehpetian, G.B, (2004). "Siting and sizing of DG units using GA and OPF based technique", TENCON 2004. 2004 IEEE Region 10 Conference.

N.D.R. Sarma, S. Ghosh, K.S. Prakasa Rao and M. Srinivas, (1994). "Real time service restoration in distribution networks - a practical approach" IEEE PWRD, 9(4):2064-2070.

P. Wang and R. Billinton, (2000). "Optimum load-shedding technique to reduce the total customer interruption cost in a distribution system”, IEE Proc. - Gener. Transm.Distrib., Vol. 147, No. 1, pp. 51-56, Jan. 2000.

P.S. Nagendra Rao and K.S. Papa Rao, (2003). "An efficient load shedding algorithm for radial systems", TENCON 2003. IEEE Region

W. El-Khattam, M. M. A. Salama, (2004). "Distributed generation technologies, definitions and benefits", Electric Power Systems Research, Vol 71, 2004, pp 119-128.

W.P. Luan, M.R. Irving and J.S. Daniel (2002). "Genetic algorithm for supply restoration and optimal load shedding in power system distribution networks”, IEE Proc- Gener. Transm. Distrib, Vol 149, No. 2, March 2002.

TABle 1. Installed Node With Operating Point of DisPersed Generators

\begin{tabular}{cccc}
\hline \hline \multirow{2}{*}{ Node \# } & $\begin{array}{c}\text { Operating point of DG before } \\
\text { load shedding (kW/power factor) }\end{array}$ & $\begin{array}{c}\text { Operating point of DG after } \\
\text { load shedding (kW/power factor) }\end{array}$ & $\begin{array}{c}\text { Max active power } \\
(\mathrm{kW} / \text { power factor })\end{array}$ \\
\hline 4 & $50 / 0.8$ & $83.3 / 0.8$ & $193 / 0.8$ \\
7 & $100 / 0.9$ & $161.23 / 0.9$ & $175 / 0.9$ \\
25 & $200 / 0.9$ & $284.63 / 0.9$ & $300 / 0.9$ \\
30 & $100 / 1$ & $163.04 / 1$ & $175 / 1$ \\
\hline \hline
\end{tabular}

TABLE 2. OBJECTIVE FunCTION, TOTAL LOAD, LOSS, PI

\begin{tabular}{ccc}
\hline \hline Index & $\begin{array}{c}\text { Load } \\
\text { Shedding } \\
\text { without DG }\end{array}$ & $\begin{array}{c}\text { Load Shedding } \\
\text { with DG }\end{array}$ \\
\hline OBF & 6.189 & 4.12 \\
$\sum P_{\text {load }}$ & 1.464 & 2.211 \\
$\sum Q_{\text {load }}$ & 0.8162 & 1.1806 \\
Loss & 0.023 & 0.0225 \\
PI & 0.019435 & 0.017425 \\
\hline \hline
\end{tabular}




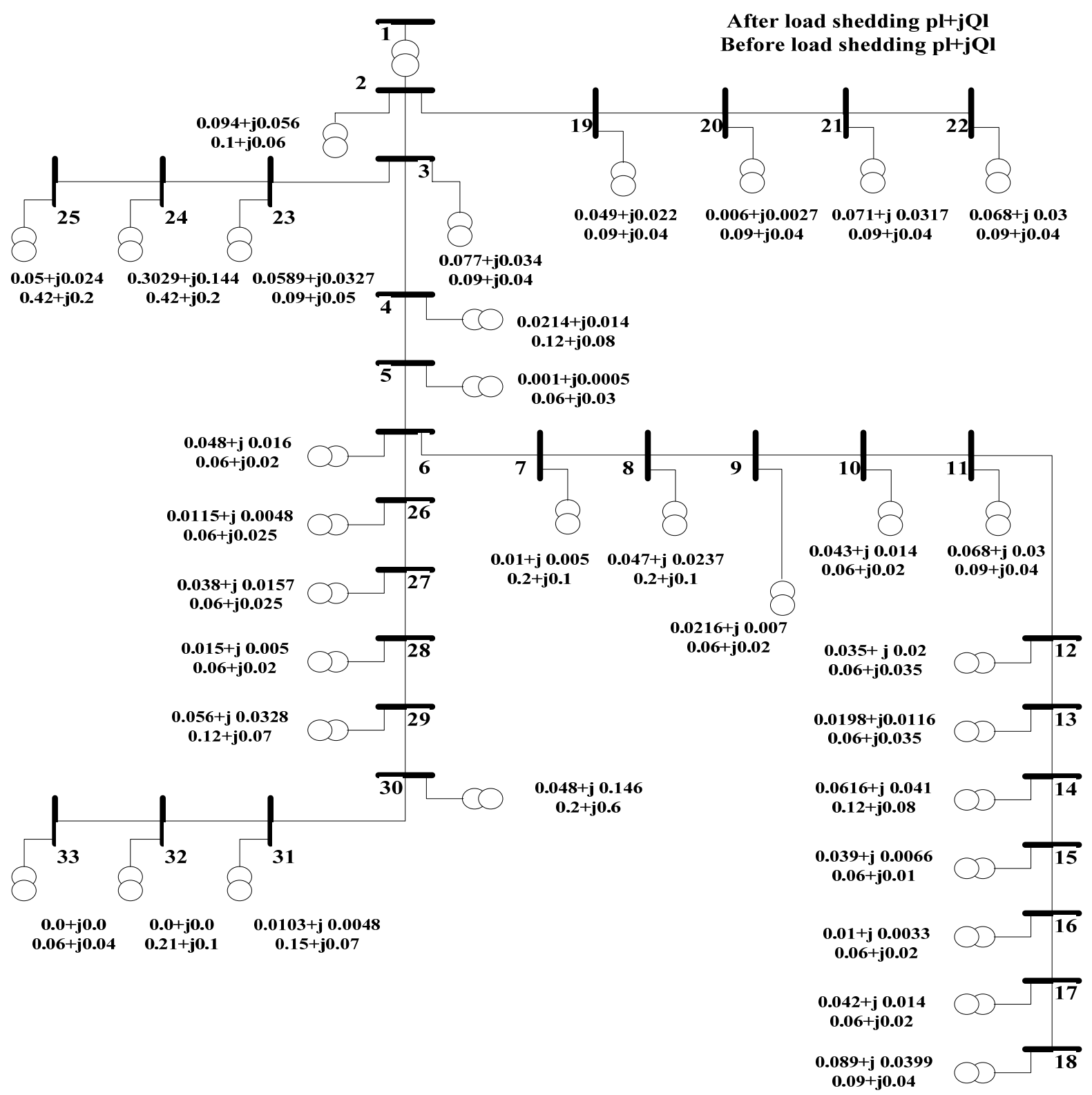

Figure 1. Optimal load shedding considering constant capacity deficiency modelling of bulked power supply with out installed dispersed generators 


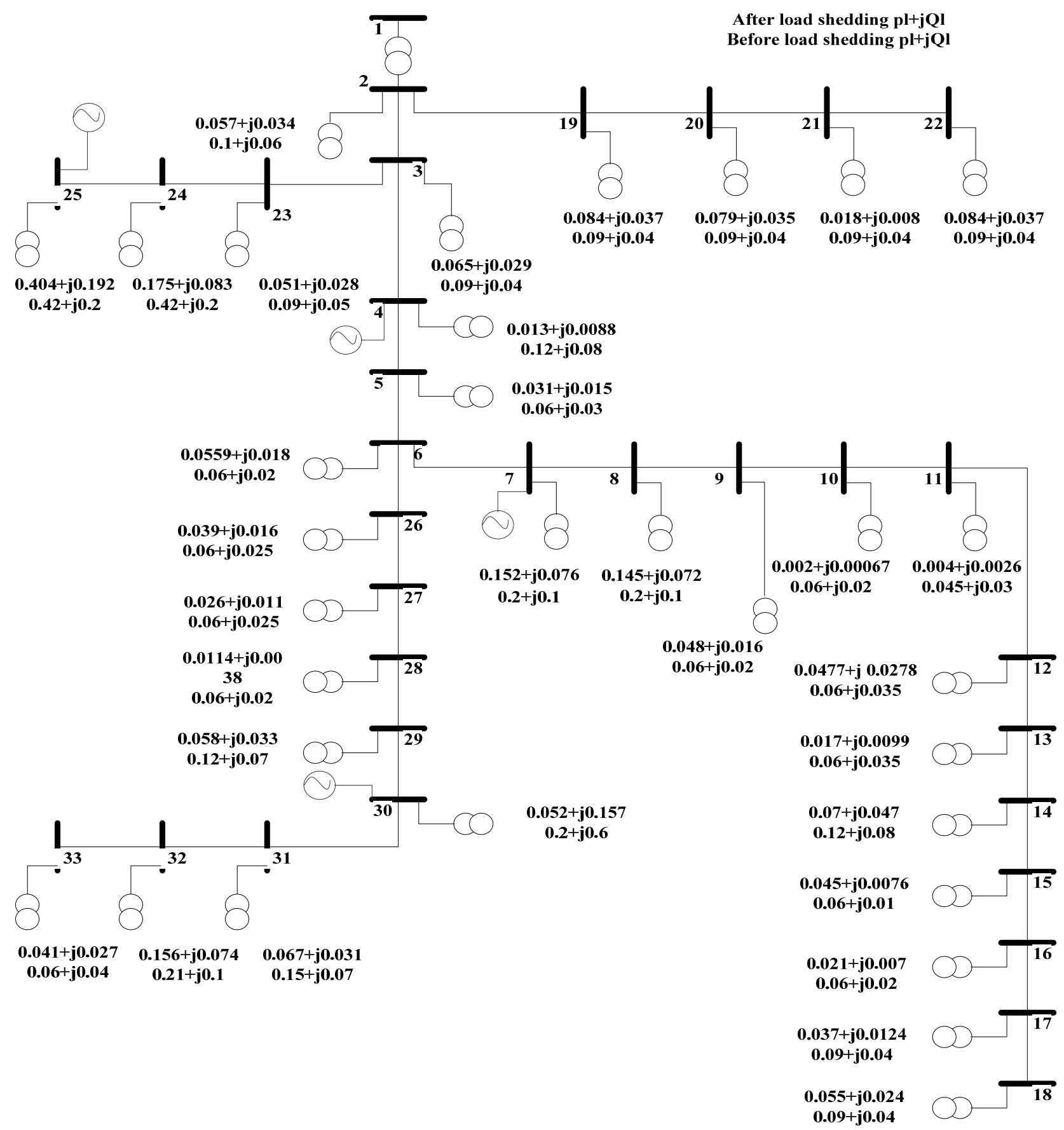

Figure 2. Optimal load shedding considering constant capacity deficiency modelling of bulked power supply with installed dispersed generators 


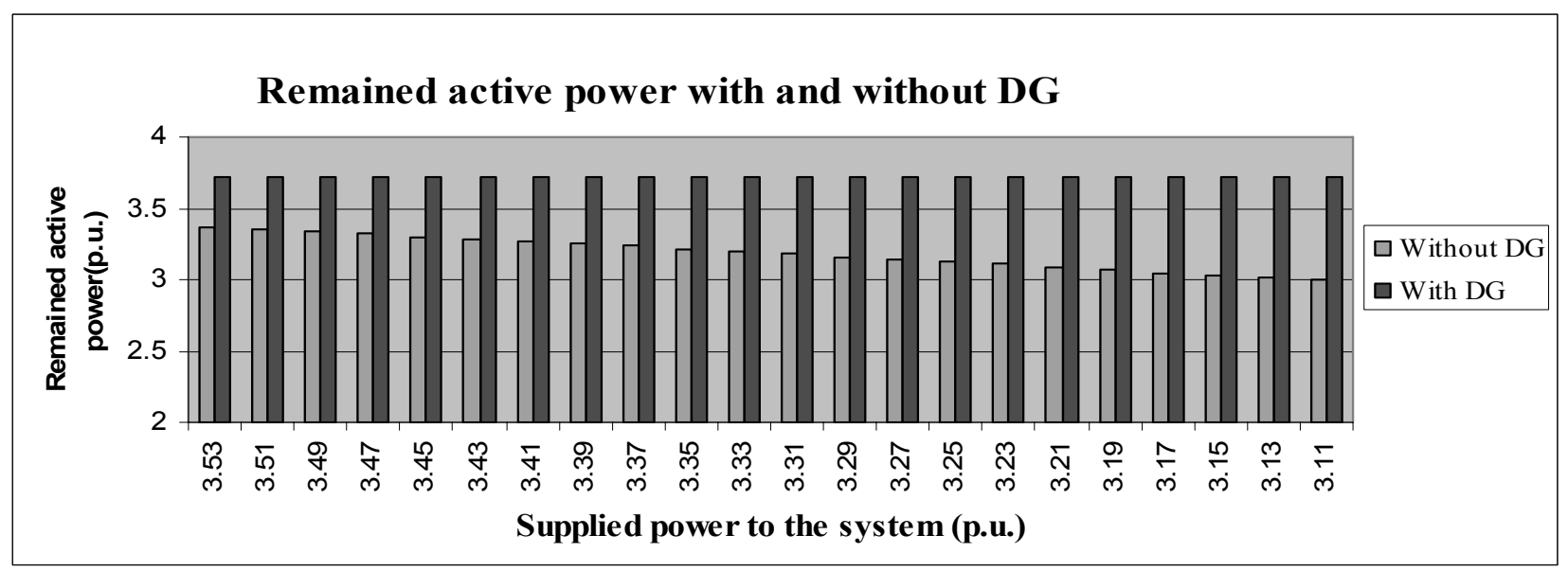

Figure 3. Remained active load of distribution network considering variable capacity deficiency modelling of bulked power supply with and without installed dispersed generators (case 1)

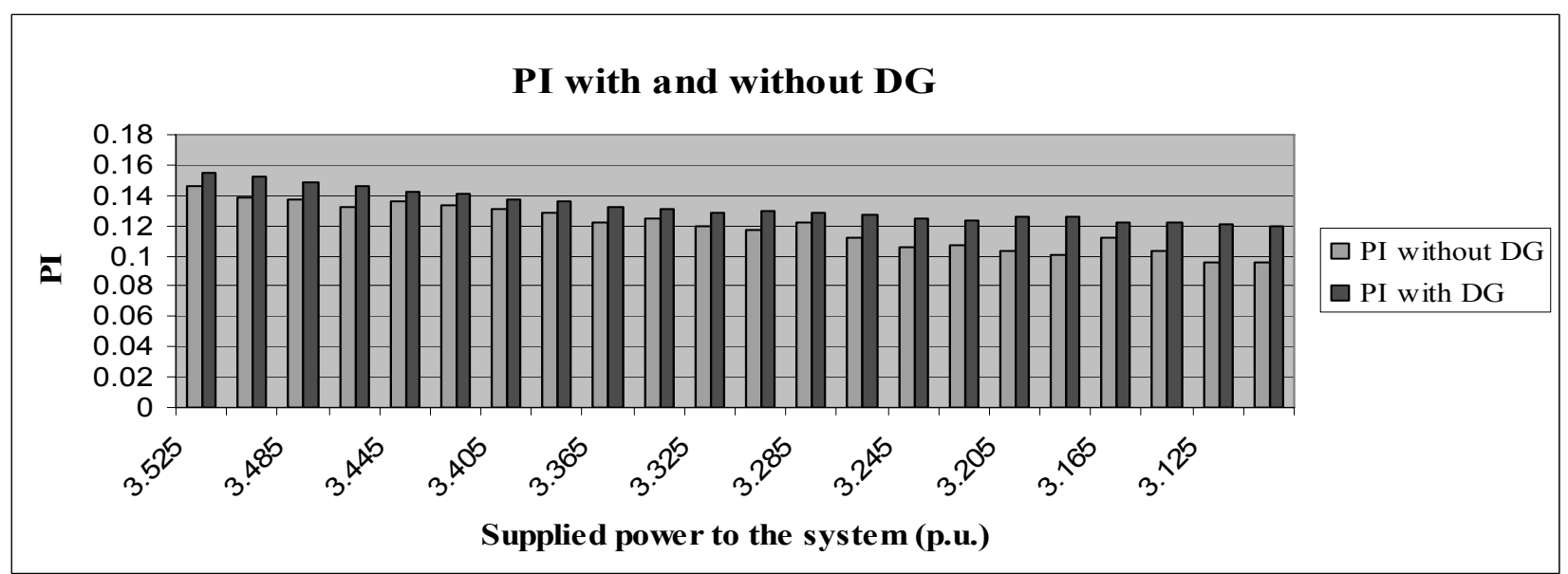

Figure 4. Profile index (PI) of distribution network considering variable capacity deficiency modeling of bulked power supply with and without installed dispersed generators (case 1)

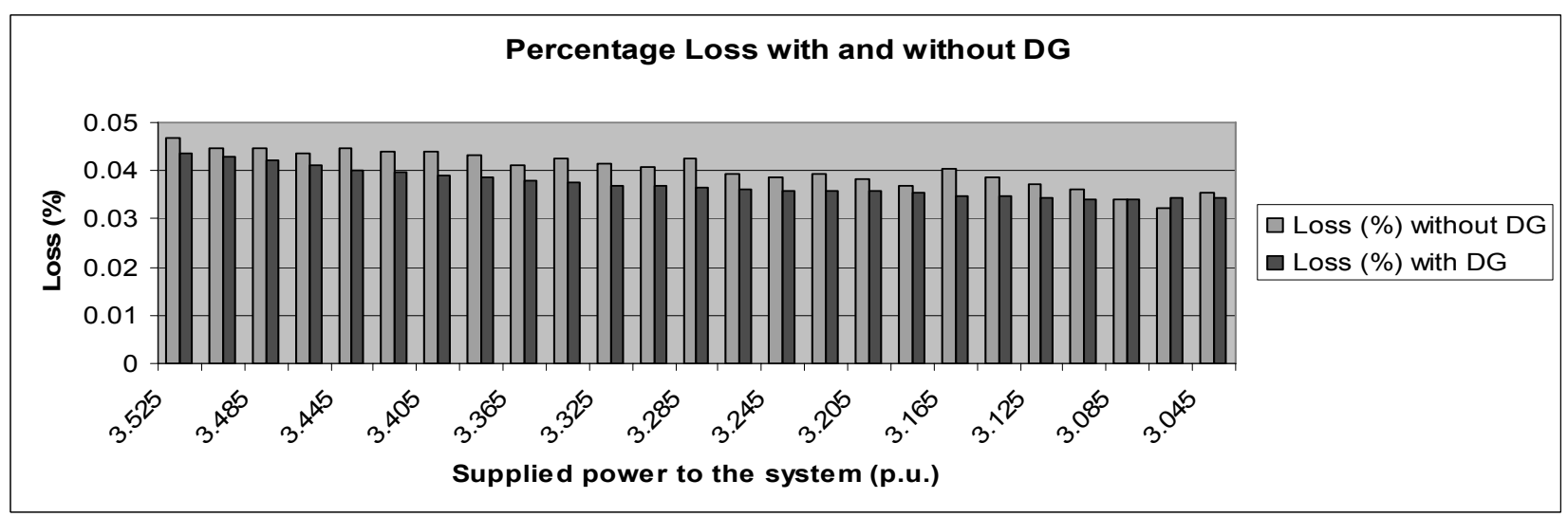

Figure 5. Percentage loss of distribution network considering variable capacity deficiency modeling of bulked power supply with and without installed dispersed generators (case 1) 


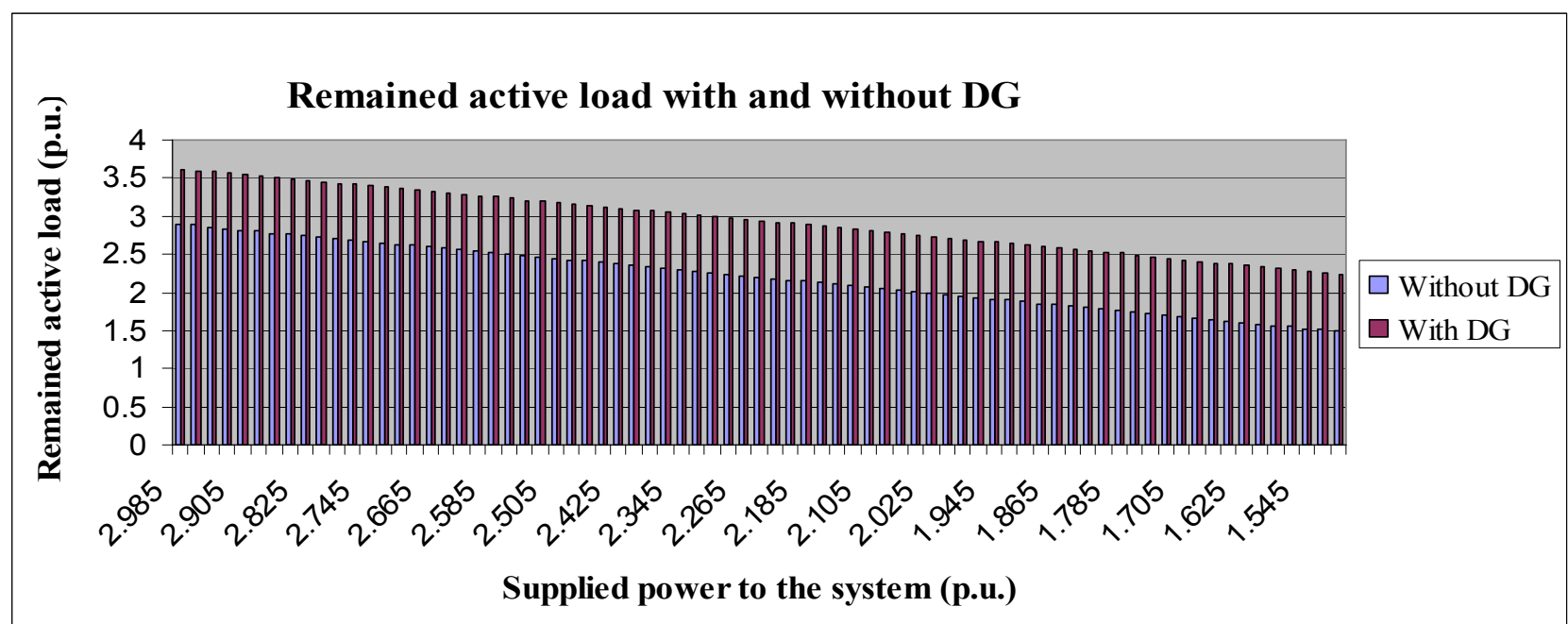

Figure 6. Remained active load of distribution network considering variable capacity deficiency modeling of bulked power supply with and without installed dispersed generators (case 2)

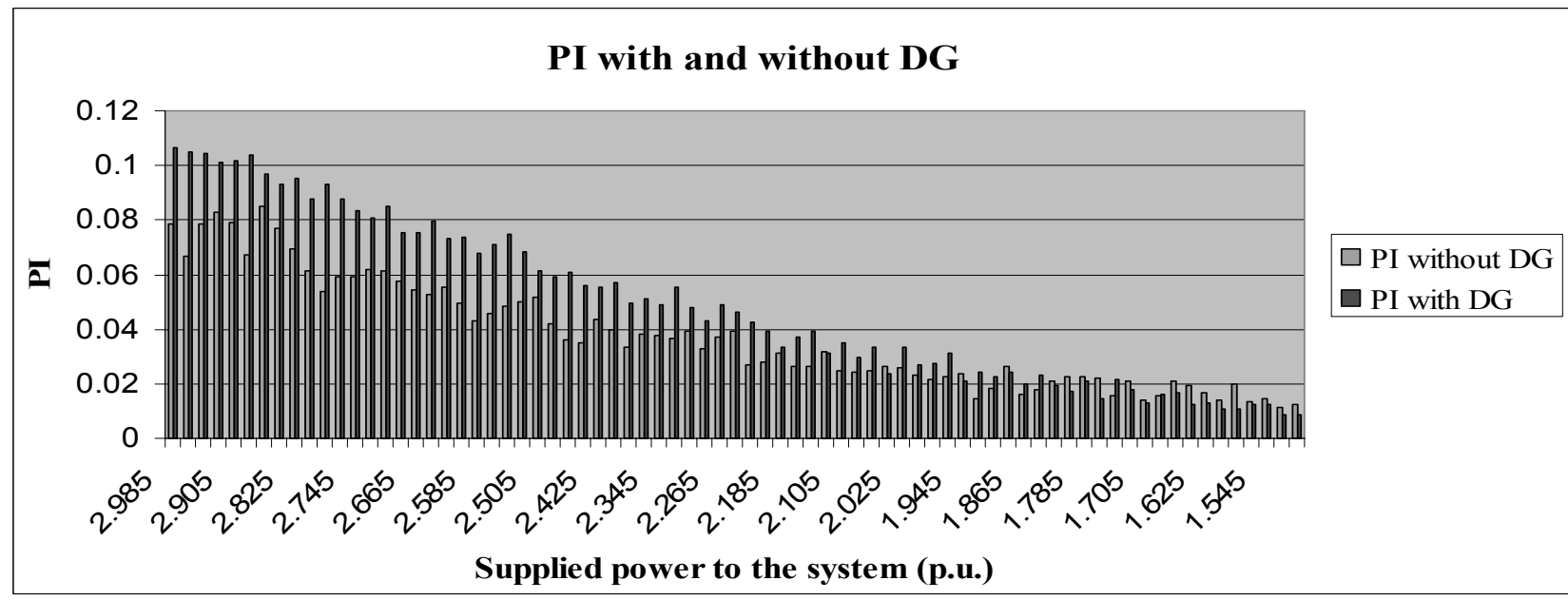

Figure 7. Profile index (PI) of distribution network considering variable capacity deficiency modeling of bulked power supply with and without installed dispersed generators (case 2)

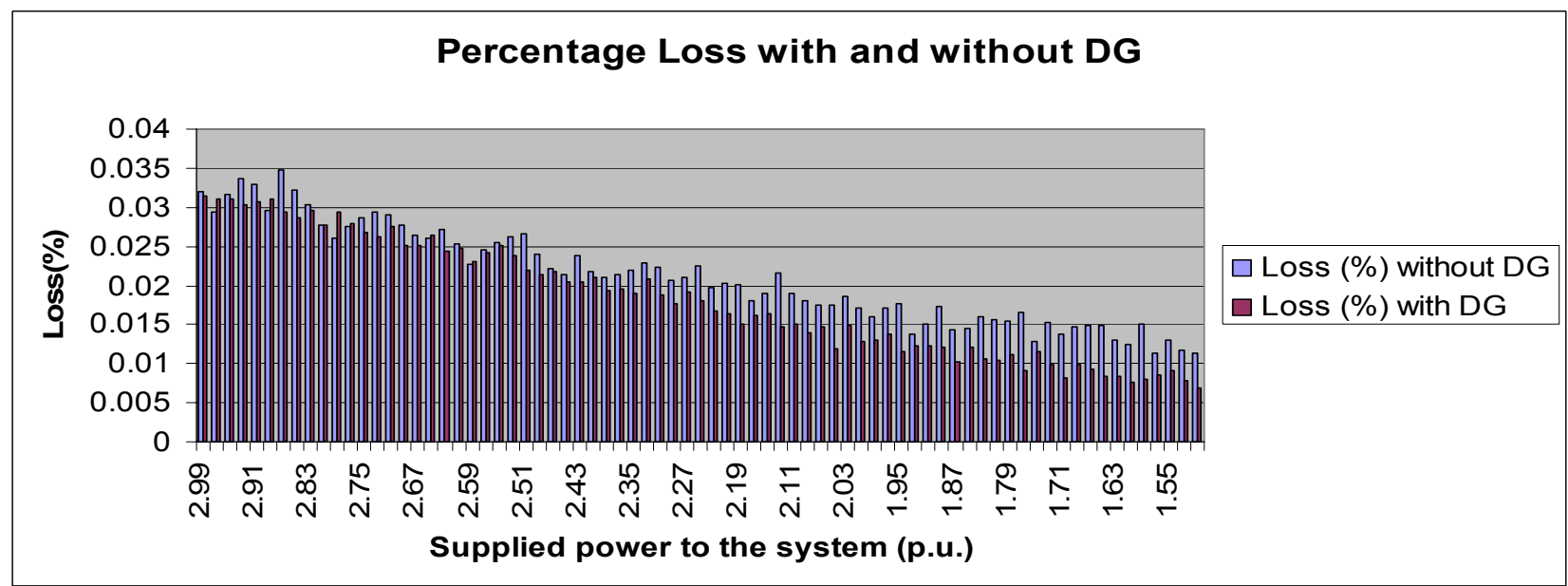

Figure 8. Percentage loss of distribution network considering variable capacity deficiency modeling of bulked power supply with and without installed dispersed generators (case 2) 


\title{
Applying Time Series Analysis Builds Stock Price Forecast Model
}

\author{
Jun Zhang (Corresponding author) \\ Department of Science, Yanshan University, Hebei 066004, China \\ Tel: 86-335-865-7691 E-mail:zhangjunmath@163.com \\ Rui Shan \&Wenfang Su \\ Department of Science, Yanshan University, Hebei 066004, China
}

\begin{abstract}
Time series analysis is a theory that used random process and mathematical statistics theory to analyze time .It is apply comprehensive to national economy macroeconomic adjustment and control, area complex development plan, enterprise operating management, market potential forecasting, weather hydrology prediction. It is an important means for estimation and forecast. The stock price has very deep effect to the economic benefits of the nation and the macro-economy policy. So people pay close attention to it. In this article, SSE composite index of one year is fitted two kinds of time series models, then forecast in short-time. Comparing the estimated valve with the true valve, the result is the relative error is small. So I think the model is suited to the data. At last, compare the two models.
\end{abstract}

Keywords: SSE composite index, Time series analysis, ARIMA model, ARCH model

In the production and scientific study, through carrying on observation and measurement to some group of or a variable, obtained a series of discrete digit in a series of times, the series is called time series. Put the series of discrete digitals form a series set. The series set is called time series. The time series analysis is a mathematical technique that through curve fitting and parameter estimation establish mathematical model with the system observation data and forecast the future trend. Stock price fluctuations has reflected the state economy change to a certain degree and affected the national macroeconomic policy. Therefore through economic indicator's change forecast stock price trend is the topic which throughout the people explore. Taken of time series analysis method not only is the cost low but also accuracy. But the stock price fluctuations is influenced by many kinds of the economic agent and the non-economic agent factors, for example the economic agent of market rate, fiscal levy, price level, domestic international political situation, war disaster, the non-economic agent factor of the investors mood and the transaction limits stipulation. This paper uses the time series analysis two kind of model fitting stock price trend.

\section{ARIMA model}

$\operatorname{ARIMA}(\mathrm{p}, \mathrm{d}, \mathrm{q})$ the model has the following structure:

$\left\{\begin{array}{l}\varphi(B) \nabla^{d} x_{t}=\theta(B) \varepsilon_{t} \\ E\left(\varepsilon_{t}\right)=0 \quad \operatorname{var}\left(\varepsilon_{t}\right)=\sigma_{\varepsilon}^{2} \quad E\left(\varepsilon_{t} \varepsilon_{s}\right)=0 \quad s \neq t \\ E\left(x_{s} \varepsilon_{t}\right)=0 \quad \forall s>t\end{array}\right.$

The abbreviated formula is $\nabla^{d} x_{t}=\frac{\theta(B)}{\varphi(B)} \varepsilon_{t},\left\{\varepsilon_{t}\right\}$ zero average value white noise series.

$\varphi(B)=1-\varphi_{1} B-\varphi_{2} B^{2}-\cdots-\varphi_{p} B^{p}$ is the autoregressive coefficient polynomial.

$\theta(B)=1-\theta_{1} B-\theta_{2} B^{2}-\cdots-\theta_{q} B^{q}$ is the moving average coefficient polynomial.

$\nabla^{d}=(1-B)^{d}, \quad \nabla$ is the difference operator, $\mathrm{d}$ is the difference order, $\mathrm{B}$ is backward shift operator $B x_{t}=x_{t-1}$.

\section{ARIMA model modeling step}

\subsection{Data processing}

First judge the series whether to be steady or not by observing the autocorrelation coefficient figure and the partial autocorrelation coefficient figure. Second if the series is not steady, carries on the series difference or the season 
difference for eliminating the tendency fluctuation and the season fluctuation. If the difference can not make the series to be steady, taking the logarithm to the series to eliminates the different variance, then make the series difference. Third the steady time series is carried on the white noise check to judge whether it to be related.

\section{Fix the step of the model}

First observe the autocorrelation coefficient figure and the partial autocorrelation coefficient figure of steady non-white noise series to fix model autoregressive step p and moving average step q. But the model is not necessarily only. Second selects the suitable estimation method to estimate the unknown parameter the value.

\subsection{Optimize model}

Carries on the residuals white noise check and the parameter significance check to the fitting model, selects superior model in the through the check models.

\subsection{Model prediction}

Using fitting model forecast the series short-term trend.

\section{ARCH model}

The ARCH model full title is auto regressive conditional different variance model.

Its complete structure is

$$
\left\{\begin{array}{l}
x_{t}=f\left(t, x_{t-1}, x_{t-2} \cdots\right)+\varepsilon_{t} \\
\varepsilon_{t}=\sqrt{h_{t}} e_{t} \\
h_{t}=\alpha_{0}+\sum_{j=1}^{q} \alpha_{i} \varepsilon_{t-j}^{2}
\end{array}\right.
$$

$f\left(t, x_{t-1}, x_{t-2} \cdots\right)+\varepsilon_{t}$ is the $\left\{x_{t}\right\}$ Auto-Regressive model; $e_{t} \sim$ i.i.d $\sim N(0,1)$. Series $\left\{\varepsilon_{t}\right\}$ is zero average value random residuals series and have different variance $\operatorname{var}\left(\varepsilon_{t}\right)=h_{t}$, different variance equal to average value of residual square series: $E\left(\varepsilon_{t}^{2}\right)=h_{t}$. Under normal distribution supposition $\varepsilon_{t} / \sqrt{h_{t}} \sim N(0,1)$, With residual square series autocorrelation coefficient inspects the different variance function the autocorrelation. If there is some autocorrelation coefficient is not zero, the residual square series autocorrelation coefficient is impermanent zero and different variance function exist autocorrelation. Then it is possible that through constructing residual square series autoregressive model to fit the different variance function $h_{t}=\alpha_{0}+\sum_{j=1}^{q} \alpha_{i} \varepsilon_{t-j}^{2}$.

\section{Example analyses}

The figure 1 shows the Shanghai Composite Index closing price data from January 18th, 2007 to January 13, 2008.

\subsection{Establish the ARIMA model}

The figure demonstrates that the series is not steady. The series has a certain trend, but does not have the season effect. Because of that reason carries the first order difference on this sequence. The following is autocorrelation and the partial autocorrelation coefficient chart and ADF Unit Root tests diagram. Because figure 2 and figure 3 shows autocorrelations and the partial autocorrelation coefficient of the series after first order difference are first order truncation, the first order difference sequence is steady. Figure 4 show all of the $\mathrm{P}$ value is smaller than 0.001.It is also explained that the sequence is steady. Both the two checks have confirmed the first order difference series is steady.

Figure 5 is the white noise check figure. It shows that under the level of $=0.05, \mathrm{P}$ value is all smaller than $\alpha$. The result indicated that first order difference series is non-white noise sequence. Because the first order difference sequence is steady non-white noise sequence, it is can be used to established the ARIMA model.

Because the autocorrelation and the partial autocorrelation coefficient of the difference series is first order truncation try to establish ARIMA $(1,1,0)$ model and ARIMA $(0,1,1)$ model. Make comparison the two models

Table 1 shows the AIC value and the SBC value and erroneous estimated value of the AR (1) model are smaller than those of MA (1) model. It can be determined that ARIMA $(1,1,0)$ model is better than ARIMA $(0,1,1)$ model. Therefore designate ARIMA $(1,1,0)$ model to fit the sequence. The chart 6 is the model parameter estimated value and the significance check and the residual white noise check result. Because the $\mathrm{P}$ value is bigger than 0.05 in the residual 
white noise check result, the residual is the white noise series.

The establishment model is $(1+0.29161 B)(1-B) x_{t}=11.08637 \varepsilon_{t}$.

Figure 7 shows fitting figure of $\operatorname{ARIMA}(1,1,0)$ model. The figure shows that the fitting figure and the original figure superpose basically. So we can decide the model build successfully.

The modeling goal is the forecast. Table 2 shows the model short-term predicted results. Comparing the predicted values with the true values, the relative errors are minor. Relative error's average value is 0.04072 .

\subsection{Establish the ARCH model}

Check the residual series which have rejected the tendency item to judge whether it to be the autocorrelation or the different variance. Figure 8 shows residual series DW check amount $\mathrm{P}$ value is smaller than 0.001 ; it explained that the residual series is the autocorrelation. And the PortmanteaQ statistics and Lagrange number multiplication LM check amount $\mathrm{P}$ value is smaller than 0.001 ; it explained that residual series is different variance

Set up the model after screening:

$x_{t}=2833+13.4309 t+u_{t}$

$u_{t}=0.8257 u_{t-1}+0.1262 u_{t-2}+\varepsilon_{t}$

$\varepsilon_{t}=\sqrt{h_{t}} e_{t}$

$h_{t}=14732+0.1966 \varepsilon_{t-1}^{2}$

After testing the parameters of the model are significant. The whole model's $R^{2}$ value is 0.9842 . It is to meet the requirements. Figure 9 shows ARCH model fitting figure. The red is the fitted curve, and the black is the original curve.

Table 3 is the short-term predicted of model results. Comparing the predicted values with the true values, the relative errors are minor. Relative error's average value is 0.01902 .

\section{Conclusion}

Comparing the two models, judging form the predicted outcome, the ARCH model relative error is smaller, so ARCH model fitting better than the ARIMA model. It is mainly because of the stock price change misalignment behavior; ARIMA model for time series prediction only considers the characteristics of the time series, without taking into account the stock price itself is affected by many unpredictable and complex factors; these factors can only indicated by the stochastic disturbing term in the ARIMA model that is actually unable to display in the forecast expectation value. In addition, ARIMA models generally assume that the model residuals are zero average value and same variance, but in fact stock index series of china often are different variance.

\section{References}

Brockwell P, J, \& Davis. R, A. (2001).Time series: theory and method . Springer Press.

GAO, H., X. (1998) .SAS system SAS/ETS the software user manual. China Statistics Press.

Hen, B., L. (2008).Stock price prediction model for the optimal selection, Statistics and Decision, (6), $135-137$.

KITAGAWA ,G,A (1981).nonstationary time series model and its fitting by recursive technique. J Time Ser Anal.2(2):103-116.

Wang, Y. (2005).Application time series analysis. People's University of China publishing house.

WONG, C, S. (2000) .On a mixture autoregressive model, J of the Royal Statistical Society (62) part1:95-115.

Table 1. model comparison form

\begin{tabular}{|c|c|c|c|}
\hline & AIC & SBC & Std Error \\
\hline ARIMA $(1,1,0)$ & 3014.754 & 3021.732 & 122.1921 \\
\hline ARIMA $(0,1,1)$ & 3026.719 & 3033.705 & 122.0717 \\
\hline
\end{tabular}


Table 2. ARIMA $(1,1,0)$ model predicted outcome

\begin{tabular}{|c|c|c|c|}
\hline Date & True values & Predicted values & Relative errors \\
\hline 20080114 & 5497.90 & 5490.87 & 0.0012 \\
\hline 20080115 & 5443.79 & 5503.47 & 0.0190 \\
\hline 20080116 & 5290.61 & 5514.19 & 0.0422 \\
\hline 20080117 & 5151.63 & 5525.47 & 0.0725 \\
\hline 20080118 & 5180.51 & 5525.47 & 0.0687 \\
\hline
\end{tabular}

Table 3. ARCH model predicted outcome

\begin{tabular}{|c|c|c|c|}
\hline Date & True values & Predicted values & Relative errors \\
\hline 20080114 & 5497.90 & 5518.28 & 0.0037 \\
\hline 20080115 & 5443.79 & 5531.48 & 0.0161 \\
\hline 20080116 & 5290.61 & 5480.21 & 0.0358 \\
\hline 20080117 & 5151.63 & 5334.09 & 0.0354 \\
\hline 20080118 & 5180.51 & 5201.56 & 0.0041 \\
\hline
\end{tabular}

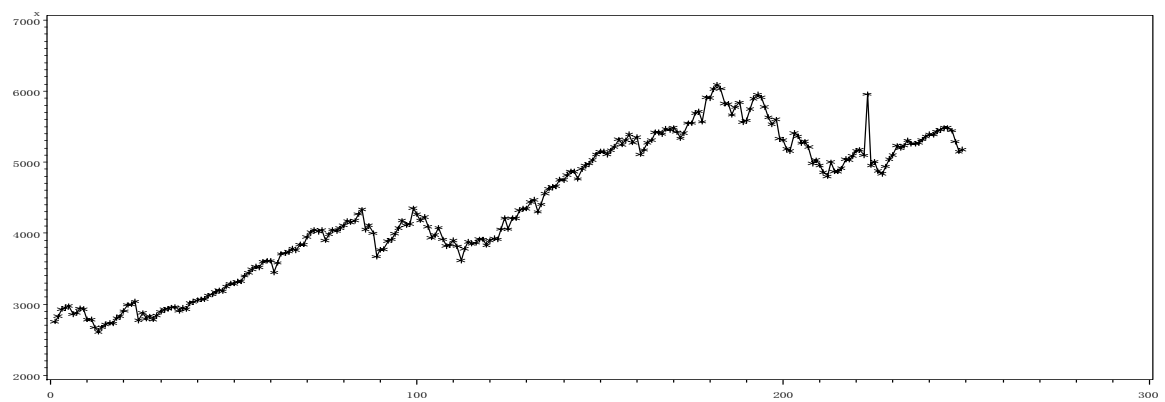

Figure 1. Shanghai Composite Index series figure

\begin{tabular}{clcl} 
Lag & Covariance & \multicolumn{2}{c}{ Correlation } \\
0 & 16003.489 & 1.00000 & $\mid$ \\
1 & -4474.896 & -.27962 & $\mid$ \\
2 & 660.600 & 0.04128 & $\mid$ \\
3 & 964.252 & 0.06025 & $\mid$ \\
4 & -717.344 & -.04482 & $\mid$ \\
5 & -917.712 & -.05734 & $\mid$ \\
6 & 719.487 & 0.04496 & $\mid$ \\
7 & -1074.005 & -.06711 & $\mid$ \\
8 & 184.910 & 0.01155 & $\mid$ \\
9 & -1411.894 & -.08822 & $\mid$ \\
10 & 542.795 & 0.03392 &
\end{tabular}

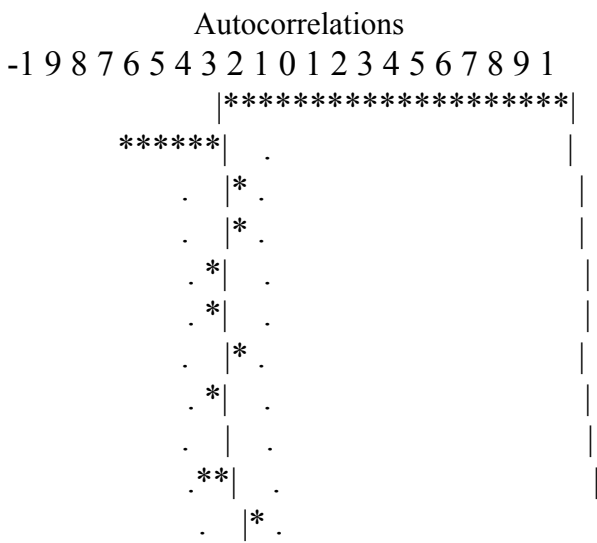

Figure 2. Autocorrelation coefficient figure
STD Error

$$
0
$$

0.063500

0.068285

0.068385

0.068599

0.068717

0.068910

0.069028

0.069290

0.069298

0.069750 


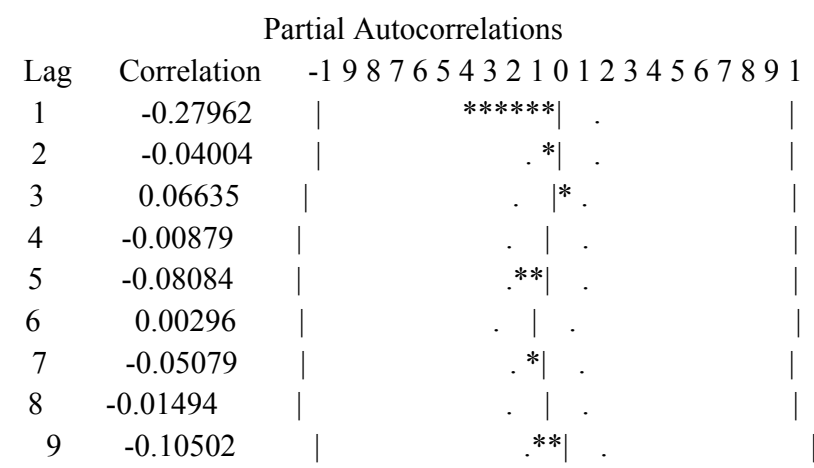

Figure 3. Partial autocorrelations coefficient figure

Augmented Dickey-Fuller Unit Root Tests

$$
\begin{array}{cccccccccc} 
& \multicolumn{1}{c}{\text { Type }} & \multicolumn{2}{c}{\text { Lags Rho }} & \text { Pr }<\text { Rho Tau } & \text { Pr }<\text { T au } & \text { F } & \text { Pr }>\text { F } \\
\text { Zero Mean } & 0 & -314.262 & 0.0001 & -20.75 & <.0001 & & & \\
1 & -332.927 & 0.0001 & -12.88 & <.0001 & & & \\
\text { Single Mean } & 0 & -316.073 & 0.0001 & -20.87 & <.0001 & 217.85 & 0.0010 \\
& 1 & -341.894 & 0.0001 & -13.01 & <.0001 & 84.62 & 0.0010 \\
\text { Trend } & 0 & -316.663 & 0.0001 & -20.88 & <.0001 & 217.99 & 0.0010 \\
& 1 & -344.224 & 0.0001 & -13.02 & <.0001 & 84.81 & 0.0010
\end{array}
$$

\begin{tabular}{|c|c|c|c|c|c|c|c|c|c|}
\hline Chi- & & $\operatorname{Pr}>$ & & & & & & & \\
\hline Square & DF & Chi Sq & & ----------- & -Autoco & lations-- & ----------- & & \\
\hline 6 & 22.84 & 6 & 0.0009 & -0.280 & 0.041 & 0.060 & -0.045 & -0.057 & 0.045 \\
\hline 12 & 28.59 & 12 & 0.0045 & -0.067 & 0.012 & -0.088 & 0.034 & 0.092 & 0.011 \\
\hline 18 & 30.11 & 18 & 0.0364 & -0.001 & 0.074 & 0.005 & 0.003 & 0.015 & -0.008 \\
\hline 24 & 35.26 & 24 & 0.0646 & 0.025 & -0.084 & -0.047 & 0.052 & 0.023 & -0.075 \\
\hline
\end{tabular}

\begin{tabular}{|c|c|c|c|c|c|c|c|c|c|c|}
\hline \multirow{3}{*}{$\begin{array}{l}\text { To } \\
\text { Lag }\end{array}$} & \multicolumn{10}{|c|}{ Autocorrelation Check of Residuals } \\
\hline & Chi- & & $\operatorname{Pr}>$ & & & & & & & \\
\hline & Square & DF & Chi Sc & $----\cdot$ & ------- & utocorrela & tions------. & ------- & & \\
\hline 6 & 3.28 & 5 & 0.6566 & -0.014 & -0.025 & 0.072 & -0.050 & -0.066 & 0.015 & \\
\hline & 12 & 11.09 & 11 & 0.4356 & -0.061 & -0.032 & -0.087 & 0.043 & 0.123 & 0.040 \\
\hline & 18 & 14.20 & 17 & 0.6532 & 0.026 & 0.093 & 0.033 & 0.017 & 0.030 & 0.016 \\
\hline 24 & 20.24 & 23 & 0.6276 & 0.011 & -0.106 & -0.087 & 0.023 & -0.020 & -0.053 & \\
\hline
\end{tabular}

Figure 4. ADF Unit Root Tests figure

Autocorrelation Check for White Noise

Figure 5. white noise inspection figures

\begin{tabular}{lccccr}
\multicolumn{5}{c}{ Unconditional Least Squares Estimation } \\
Parameter & Estimate & Standard & Approx & \\
MU & 11.08637 & 6.08708 & 1.82 & 0.0698 & 0 \\
AR1, 1 & -0.29161 & 0.06174 & -4.72 & $<.0001$ & 1
\end{tabular}

Figure 6. ARIMA $(1,1,0)$ model output result and residual check 


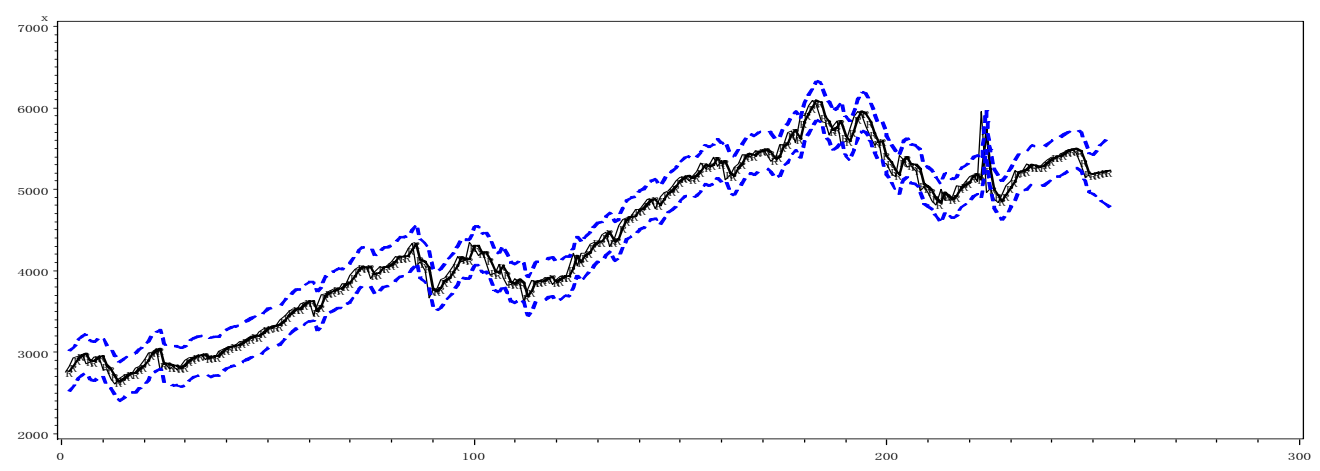

Figure 7. ARIMA $(1,1,0)$ model fitting figure

\begin{tabular}{ccccc}
\multicolumn{5}{c}{ Q and LM Tests for ARCH Disturbances } \\
Order & $\mathrm{Q}$ & $\operatorname{Pr}>\mathrm{Q}$ & $\mathrm{LM}$ & $\operatorname{Pr}>\mathrm{LM}$ \\
1 & 196.6829 & $<.0001$ & 198.7025 & $<.0001$ \\
2 & 351.0688 & $<.0001$ & 198.7249 & $<.0001$ \\
3 & 470.0340 & $<.0001$ & 198.9361 & $<.0001$ \\
4 & 560.3033 & $<.0001$ & 199.0966 & $<.0001$ \\
5 & 634.5792 & $<.0001$ & 199.6533 & $<.0001$ \\
6 & 697.4607 & $<.0001$ & 199.7831 & $<.0001$ \\
7 & 745.4301 & $<.0001$ & 200.5298 & $<.0001$ \\
8 & 788.5607 & $<.0001$ & 201.6425 & $<.0001$ \\
9 & 829.3971 & $<.0001$ & 202.1698 & $<.0001$ \\
10 & 871.2981 & $<.0001$ & 202.5459 & $<.0001$ \\
11 & 916.2612 & $<.0001$ & 202.6061 & $<.0001$ \\
12 & 957.3173 & $<.0001$ & 203.2968 & $<.0001$
\end{tabular}

Figure 8. Different variance check figure

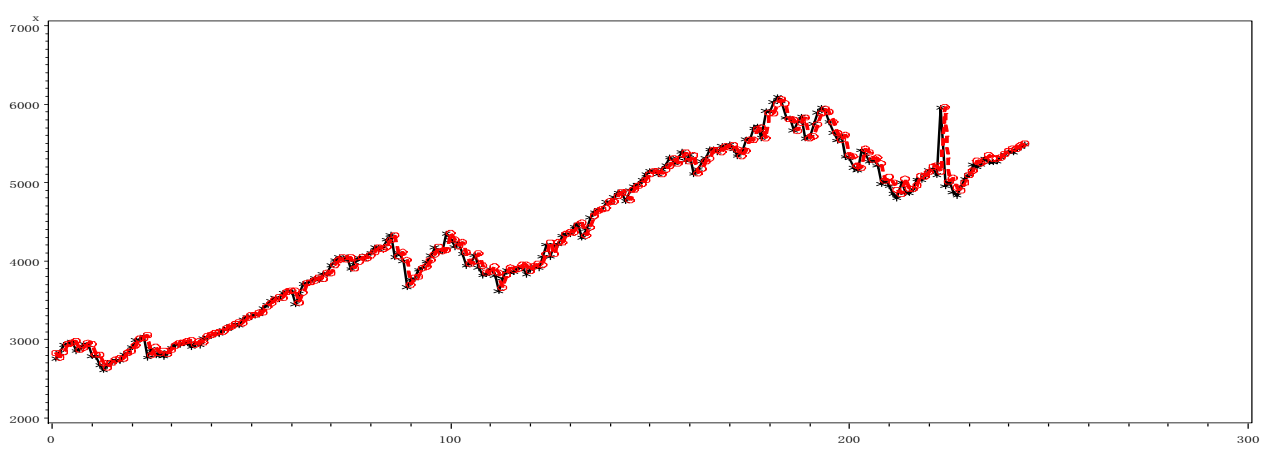

Figure 9. ARCH model rendering 


\title{
Prospective of Energy Efficiency Practice, Indicator and Power
}

\section{Supplies Efficiency}

\author{
Anwar Al-Mofleh \\ Department of Electrical and Electronic Engineering, University Science of Malaysia \\ Nibong Tebal, Penang, Malaysia \\ Soib Taib \\ Department of Electrical and Electronic Engineering, University Science of Malaysia \\ Nibong Tebal, Penang, Malaysia \\ E-mail: soibtaib@eng.usm.my \\ Wael Salah \& Mokhzaini Azizan \\ Department of Electrical and Electronic Engineering, University Science of Malaysia \\ Nibong Tebal, Penang, Malaysia
}

\begin{abstract}
Energy efficiency generates substantial financial savings while at the same time improving environmental, business, home, and transport benefit. The efficiency of energy use will lead to a reduction in national energy consumption, as well as by improving energy efficiency the cost of using energy can be kept low and not blown out of proportion. The concept of energy efficiency will be in the interest of both customers and manufacturers because of its financial advantages. Energy-efficiency standards and labels can be the most effective long-term energy-efficiency policy any government can implement. Improving energy efficiency of power supply is one of the most cost-effective and feasible option to meet the energy efficiency practices.
\end{abstract}

Keywords: Energy Efficiency, Indicators, Standard and label, Power supply

\section{Introduction}

Energy is necessary as resources of production and for its contribution to the quality of life. As a result, economic growth is strongly connected to energy consumption. As the development continues, the increasing demand for energy is followed by environmental problems and finally, the limits of energy resources. Energy efficiency is recognized as a key to soften the strained link between economic growth and the increase in energy consumption. Energy efficiency offers both financial and environmental benefits as well as benefits in energy security. Since the oil crises in the 1970's, a considerable increase in energy efficiency has been achieved in response to energy price increases and supply uncertainties, government policies, and independent technology improvements (IEA, 1997b). Saving energy brings benefits in term of technical and financial point of view and helps, indirectly, to combat climate change all around the world. It concerns all aspects of life and all application, and the building of an energy efficient system will help the change towards renewable energy supplies (Salmon 1996, Seabright 1996). Energy efficiency is a generic term which refers to using less energy to produce the same amount of services or useful output (Patterson, 1996). As mentioned by Bosseboeuf et al. (1997) two types of energy efficiency aspects are defined as; a) Economic energy efficiency means more production or better standard of living with the same or reduced amount of energy, and b) Techno-economic energy efficiency relates to a reduction in specific energy due to technical improvement, changes in behavior, better management, etc. Figure 1 shows the levels of energy with their respective sources as well as the involved energy transformation processes.

By definition, there is no one unequivocal quantitative measure of energy efficiency. The selected energy input and useful output vary according to the nature of the analysis to be undertaken, ranging from the monitoring of energy efficiency in individual processes through to policy analysis and evaluation and the appraisal of new technologies. In general, the energy efficiency indicators are of the form (Patterson, 1996):

$$
\frac{\text { Useful output of a process }}{\text { Energy input of a process }}
$$


Competitive markets have been promoted to open by many countries, thereby stimulating economic growth. They have reduced or removed subsidies on energy prices. And energy conservation programs have motivated the wider adoption of energy efficiency technologies (Seabright 1996). The inverse of energy efficiency is often referred as energy intensity. The useful output of the process can be an energy output, a physically defined output, or it could be enumerated in monetary units. The task of energy efficiency indicators is basically the evaluation of the results achieved, evaluation of targets, and evaluation of the relative situations among peer groups. The indicators help the evaluation of different energy policies, programs, and energy conservation investments, give information on the current situation is today compared to trends in the past and in the future, as well as promote the spread of more efficient technologies and operation procedures. By constructing energy efficiency indicators that compare similar energy consuming processes and eliminate external influences, comparative static analysis can also be applied to identify a relative improvement potential (APERC, 2000).

\section{Factors Affecting Energy Efficiency:}

There are three factors that will determine the amount of energy efficiency objects its life as shown in Figure2:

- $\quad$ Design construction:

Issues such as the layout of the building, it is insulation standards, the efficiency of its services plant and the extent of automatic controls.

$\bullet$ Operation and maintenance:

Issues such as structural repairs, replacement cycles for consumable component, boiler servicing and the regular calibration/ adjustment of control system.

- $\quad$ Occupant activity:

Issues such as how much equipment its installed and how it is used staff working practices can also influence the amount of energy used for lighting and other building services.

These factors will operate independently decisions taken at the design stage can also facilitate effective operation and maintenance and reduce the impact of occupant activity (Kilponen, 2003, Phylipsen, et.al, 1998).

\section{Energy-Efficiency Labels And Standards}

Before discussing the many aspects of energy efficiency labels and standards that follow, we define exactly what is meant by these two terms.

\section{Labels:}

Energy-efficiency labels are informative labels that are affixed to manufactured products and describe a product's energy performance (usually in the form of energy use, efficiency, or energy cost) to provide consumers with the data necessary for making informed purchases. The labels then are differentiate with three of its kind (Duffy, 1996, CLASP, 2002):

$$
\begin{aligned}
& \text { - } \quad \text { Endorsement labels, } \\
& \text { - } \quad \text { Information-only labels. }
\end{aligned}
$$

Endorsement labels are essentially "seals of approval" given according to products that meet specified criteria. Comparative labels allow consumers to compare performance among similar products using either discrete categories of performance or continuous scale. Information-only labels simply provide data on a product's performance. Energy labels can stand alone or complement energy standards. They provide information that allows consumers who care to select efficient models. Labels also provide a common energy-efficiency benchmark that makes it easier for utility companies and government energy-conservation agencies to offer consumers incentives to buy energy-efficient products. The effectiveness of energy labels is highly dependent on how they present information to the consumer. The format of the label, the level of market support, and the credibility of the labeling program sponsor are all key factors.

\section{Standards}

Energy-efficiency standards are procedures and regulations that prescribe the energy performance of manufactured products, sometimes prohibiting the sale of products that are less energy efficient than the minimum standard (Meyers, et, al. 2003). The term standards commonly encompass two possible meanings:

1) Well-defined protocols (or laboratory test procedures) by which to obtain a sufficiently accurate estimate of the energy performance of a product in the way it is typically used, or at least a relative ranking of its energy performance compared to other models. 
2) Target limits on energy performance (usually maximum energy use or minimum efficiency) based upon a specified test protocol. (McMahon and Turiel, 1997). The term norm is sometimes used instead of standard in Europe and Latin America to refer to the target limit. There are three types of energy-efficiency standards:

- $\quad$ Prescriptive standards - requiring that a particular feature or device be installed (e.g., insulation) or not installed (e.g., pilot lights) in all new products;

- $\quad$ Minimum energy-performance standards (MEPS) - prescribing minimum efficiencies (or maximum energy consumption - usually as a function of size or capacity) that manufacturers must achieve in each and every product, specifying the energy performance but not the technology or design details of the product;

- Class-average standards - specifying the average efficiency of a manufactured product, allowing each manufacturer to select the level of efficiency for each model so that the overall average is achieved.

\section{Power Supply And Energy Efficiency}

Power supplies are responsible for large energy consumption due to the large number of external power supplies in use and to the low efficiency of many power supply types present on the market at different loads including losses at no-load condition. European Commission commissioned a study to investigate a number of devices with no-load and standby losses. The Study on Miscellaneous Standby Power Consumption of Household Equipment indicated that power supplies contribute substantially to the electricity consumption of households in Europe. The study calculated an increase in electricity consumption of external power supplies no-load losses (Bertoldim 2004).

In most cases these power supplies are specified by the appliance manufacturer; production can be at the appliance manufacturer or at a dedicated manufacturer. Many of the external power supplies coming to the European market have a very low efficiency across the load curve. The study not only addresses the size of the power supplies consumption while in stand-by or no load, but also the necessary policies to reduce this consumption. It was clear that the final users have little information and choice in the selection of external power supplies, as these were supplied with the equipment (e.g. mobile telephone, portable audio equipment, portable power tools, etc.). Improving the efficiency with which energy is consumed by end-users is a central theme of energy policy within the European Community. Moreover there is a close link between the development of renewable energy sources and the efficiency use of energy and electricity to maximize the benefit of renewable energy sources (http://energyefficiency.jrc.cec.eu.int/).

\section{Conclusion}

Energy efficiency now is a central focus of many national energy policies and at the front of the debate on energy sustainability issues. The development of more disaggregated structural indicators is the key to obtaining a better understanding of the evaluation of energy services demand. Moreover better measurement of the impact of life-styles is necessary for cross-country comparisons. Many techniques have been developed to minimize the dynamic and static power consumed. To achieve further savings it is necessary to employ methods that do constrain functionality to Improving energy efficiency of end-use equipment is one of the most cost-effective and feasible option to meet the energy and environmental policy objectives.

\section{References}

APERC (2000). Energy efficiency indicators, a study of energy efficiency indicators for industry in APEC economies. Asia Pacific Energy Research Centre. Tokyo. ISBN 4-931482-05-8. 154 pp.

Bosseboeuf, D., Chateau, B., Lapillonne, B. (1997). Cross-country comparison on energy efficiency indicators: The on-going European effort towards common methodology. Energy Policy 7-9(25), 673-682.

IEA. (1997a). Indicators of energy use and efficiency. Understanding the link between energy and human activity. International Energy Agency. 330 pp. ISBN 92-64-14919-8.

IEA. (1997b) Energy efficiency initiative, Vol. 1, Energy policy analysis, International Energy Agency, 193 pp.

Patterson, M.G. (1996). What is energy efficiency? Concepts, indicators and Methodological issues. Energy Policy 5(24), 377-390.

Phylipsen, G., Blok, K., and Worrell, E. (1998). Handbook on International Comparisons of Energy Efficiency in the Manufacturing Industry. Department of Science, Technology and Society, Utrecht University.

Kilponen, L. (2003). Energy efficiency indicators in integrated pulp and paper mill research scheme. Helsinki University of Technology, Laboratory of Energy Economics and Power Plant Engineering.

Meyers, S., McMahon, J.E., McNeil, M., Liu, X. (2004). Realized and Prospective Impacts of U.S. Energy Efficiency Standards for Residential Appliances: Update, Lawrence Berkeley National Laboratory, Report No. LBNL-56417, 2005 (forthcoming). 
Meyers, S., McMahon, J.E., McNeil, M., Liu, X. (2003). Impacts of US Federal Energy Efficiency Standards For Residential Appliances, Energy, Volume 28, Issue 8, pp. 755-767.

S Taib et all: 'Promoting Energy Awareness and Efficiency: USM Strategy', The 8th Int Conference on Quality in Research (QIR) 2005 Proc., EEE1-003.

CLASP, (2002). Web site of the collaborative labeling and appliance standards program. ohttp://www.CLASPonline.org

Duffy, J., (1996). Energy Labeling, Standards and Building Codes: A Global Survey and Assessment for Developing Countries. International Institute for Energy Conservation. Washington, DC.

J. Seabright, S.G Smith, H.L.Vierbicher, Market conditions affecting energy efficiency investments, Energy Conversion Engineering Conference, 1996. IECEC 96. Proceedings of the 31st Intersociety,Volume 3, 11-16 Aug. 1996 Page(s): 1546 - 1551 vol.3

P.H Salmon-Cox, Energy efficiency initiatives in emerging markets and developing countries;Energy Conversion Engineering Conference, 1996. IECEC 96. Proceedings of the 31st Intersociety,Volume 3, 11-16 Aug. 1996 Page(s):1542 - 1545 vol.3.

P. Bertoldim European code of conduct to improve energy efficiency of power supply: the first policy action around the worldwide addressing external power supplies, Applied Power Electronics Conference and Exposition, 2004 . APEC '04. Nineteenth Annual IEEE, Volume 1, 2004 Page(s):329 - 331 Vol.1

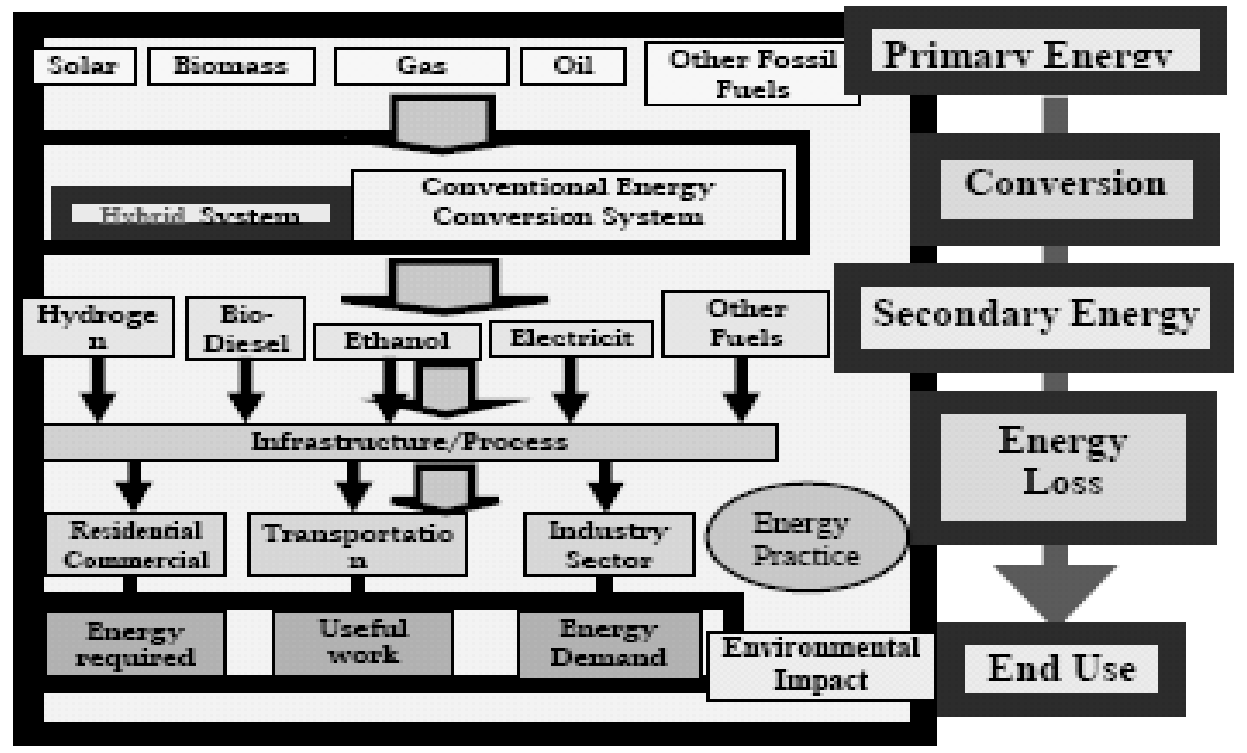

Figure 1. Energy Efficiency flow (Soib et, al .2005)

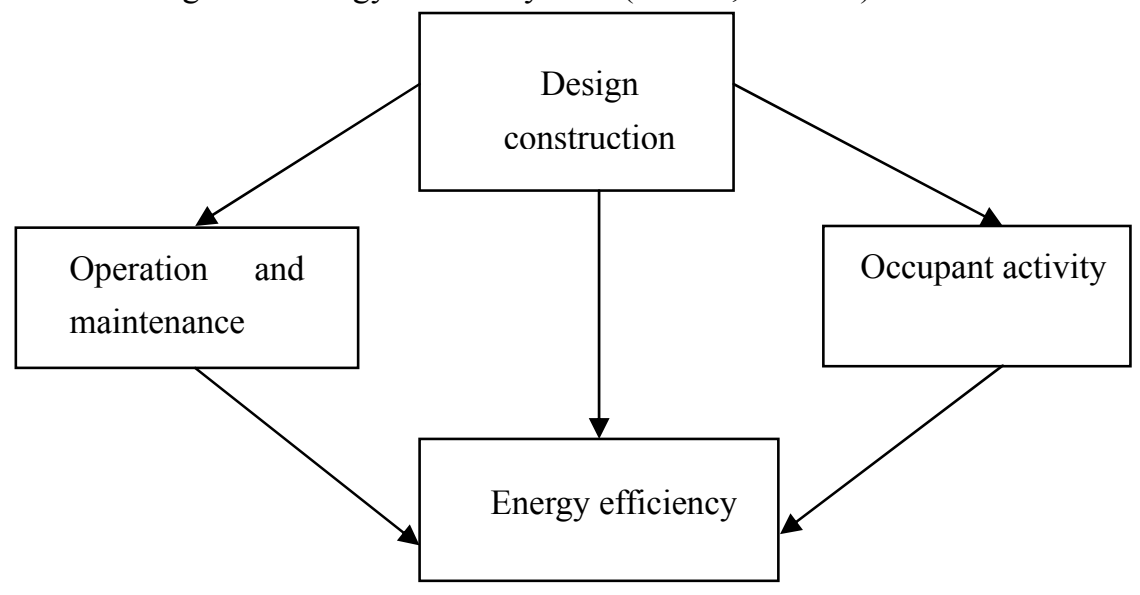

Figure 2. factors affecting energy efficiency 


\title{
Modern Applied Science
}

www.ccsenet.org/journal.html

\section{The Numerical Simulation and Control of Microstructure}

\section{in Heat-affected Zone in GMAW}

\author{
Tianqi Wang, Liangyu Li, Xiao Li \& Xu Yang \\ Tianjin Key Laboratory of Advanced Mechatronics Equipment Technology \\ Tianjin 300160, China \\ E-mail: wtq0622@163.com
}

\begin{abstract}
The grain size in heat affected zone (HAZ) of welding piece is an important element for evaluating the welding quality. The Monte Carlo (MC) technique, a stochastic simulation method, could be applied to simulate the microstructure in HAZ. A finite element model (FEM) was employed to simulate the GMAW temperature field and the data of the thermal cycle were used to combine with the MC numerically model to calculate the grain size in different welding heat input. Then mathematics model of the grain growth could be worked out by both the kinetic model and the MC model. The dynamic process was simulated by the result of the simulation. The experimental result was used to prove the validity of this method in simulating of microstructure.
\end{abstract}

Keywords: Finite element model, Monte Carlo model, Microstructure, Grain growth

\section{Introduction}

The grain size in HAZ is a very important characteristic for evaluating the properties of the welding piece. In welding process the heating and cooling of work piece are un-uniform and the welding parameters play an important role in the control of microstructure, so the research of grain growth during the different heat input are important.

Usually the study of microstructure is made through careful experiment, analysis and comparison. A lot of time and labor will be consumed. Wei et al. established a simulation of grain growth, used the 2-D MC model and the relationship between the MCS and the grain size in ferritic steel are obtained. Dai et al. proposed several improvements for MC simulation, in the program the shortcoming of primitive model could be overcome by these improvements. Shi et al. simulated the Austenite grain growth of the weld joints for the ultra fine grain reinforcement steel bar, in the simulation the heat pinning effect of temperature is considered. Wei et al. used three MC methods to simulate the grain growth in HAZ of stainless steel sus316.

In this study the FEM based on GMAW temperature field and the MC method of microstructure are combined. The two analytical solutions are used to study the relationship between different heat input and microstructure in HAZ. Many experiments are performed to evaluate the availability of the method.

\section{FEM model of welding temperature field and MC model of grain growth}

\subsection{Double-ellipsoidal heat source}

For the purpose to calculate the process of grain growth accurately, the thermal cycle obtained from the FEM model must be coincidence with the actual welding.

The double ellipsoidal heat source is chosen to use in the FEM analysis so that the distributive nature of the heat source provided by the electric arc is described more realistically. The heat flux equation is described respectively as:

The first semi-ellipsoidal equation which represents in front of the welding arc is:

$q_{f}=\frac{6 \sqrt{3} r_{f} Q}{a_{f} b c} \exp \left[-3\left(\frac{x-v t}{a_{f}}\right)^{2}-3\left(\frac{y}{b}\right)^{2}-3\left(\frac{z}{c}\right)^{2}\right]$

The second semi-ellipsoidal equation which describes the rear section of the arc is:

$q_{b}=\frac{6 \sqrt{3} r_{b} Q}{a_{b} b c} \exp \left[-3\left(\frac{x-v t}{a_{b}}\right)^{2}-3\left(\frac{y}{b}\right)^{2}-3\left(\frac{z}{c}\right)^{2}\right]$

where af,ab,b,c are shape parameters of double ellipsoidal heat source, $\mathrm{Q}$ refers to heat flux, $\mathrm{v}$ refers to weld speed, $\mathrm{t}$ 
refers to the time of welding process, $\mathrm{rf}$ and $\mathrm{rb}$ refer to proportion coefficient representing heat apportionment in front and back of the heat source respectively, where $\mathrm{rf}+\mathrm{rb}=2$.

In the process of GMAW, before the droplet dropped into the molten pool, the enthalpy of droplet could be described below:

$$
h_{d}=\int_{T o}^{T m} c_{p}(s) d T+\Delta h+\int_{T m}^{T d} c_{p}(l) d T
$$

The physical properties of Q235 steel are mentioned in the reference, and obtained by the interpolated calculation. In order to study the grain growth, the properties in some special temperature points are paid more attention. The metal property under $9000 \mathrm{C}$ is focused on because it is situation of the austenite grain growth. The solitary line temperature and liquid line temperature $(1492 / 15130 \mathrm{c})$ are considered to evaluate the shape and dimension of the weld pool in the simulation.

\subsection{The MC model and the improvement program}

Weld researchers have engaged the subject of controlling the microstructure in HAZ for a long time. The concept behind the Monte Carlo method in grain growth simulation is both simple and fascinating. There are no other experimental or theoretical inferences, nor mathematical approximations.

By developing a MC microstructure simulation program and adopting the new algorithm according to Dai's article, the efficiency of calculate analysis is improved. The relationship between the grain and the Monte Carlo step (MCS) in simulation could be obtained by regression analysis through many simulations. The equation derived from simulation as below, where the $\lambda$ is the constant of MC model.

$$
D=2.52 \lambda\left(\mathrm{t}_{\mathrm{mcs}}\right)^{0.34}
$$

\subsection{The mathematic model of austenite grain growth and experiment}

The chemical composition of Q235 is shown in table.1.The specimen is made by XQ-2 Metallographic Embed machine. Then it is fine polished, buffered and etched with a solution containing picric acid and surfactant. Specimen in the solution is heated until the solution gets boiled. In this method the austenite grain boundary has a priority shown under the microscope. The view field in the Olympus GX51 microscope is magnified 100 to 1000 times to observe the austenite grain, and the grain size is estimated.

According to the study of Sun Junsheng, the material parameters of Q235 are obtained. The material constant is $2.14 \times 1015 \mathrm{~mm} 4 / \mathrm{min}$, the activation energy is $54473 \mathrm{~J} / \mathrm{mol}$, the equation of Q235 is:

$$
D^{4}-D_{0}^{4}=2.7 \times 10^{15} \times 0.792 \sum_{t=90}^{t=900}\left[\exp \left(\frac{-63900 \times 0.852}{T(t)}\right)\right] \Delta t
$$

Where $\mathrm{D} 0=0.02 \mathrm{~mm}$, which is the initial size of grain. Substitute the equation 4 into equation 5 , and where $\lambda=5 \mu \mathrm{m}$, the equation of MSC is established below:

$$
t_{\text {mes }}=\left[\frac{\left(2.14 \times 10^{15} \sum_{t=900}^{t=900}\left[\exp \left(\frac{-54473}{T(t)}\right)\right] \Delta t+0.02^{4}\right)^{0.25}}{2.52 \times 0.005}\right]^{2.94}
$$

\section{Experiments and verification}

\subsection{The welding experiment}

The equipments used in experiment are Fanuc M100iB (a 6-DOF welding robot) and Lincoln Power Wave F355i (a welding control system). A software Wave Designer provided by Lincoln Electric is used to control the welding parameters in welding process, such as current, voltage, frequency, etc. The welding speed is set up by the teach pendant of the robot. The welding parameters are as shown as follow: the voltage of weld is $20 \mathrm{~V}$. The peak current is $200 \mathrm{~A}$ and the base current is $20 \mathrm{~A}$; the frequency of current is $50 \mathrm{HZ}$. The speed of welding is $4 \mathrm{~mm} / \mathrm{s}$. The wire feed speed is $47 \mathrm{~mm} / \mathrm{s}$. A shield gas is mixture of $5 \%$ co2 and $95 \%$ argon.

The work piece is made up of Q235 steel, whose volume is $100 \mathrm{~mm} \times 40 \mathrm{~mm} \times 3 \mathrm{~mm}$. After the welding completed the work piece is sectioned and polished. Then it will be etched with a solution which contains 97 percent ethanol and 3 percent nitric acid to reveal the weld pool shape. Finally XTL-3400 microscope is used to observe and get the picture of the work piece latitude section.

The latitude cross section derived from the simulation is chosen to compare with the experimental result. The 
comparison between calculated and measured is shown in table2.

The thermal cycle curves of different position from fusion line are obtained in the FEM software. A piecewise linear interpolation calculation is employed to calculate the data on the thermal cycle curves. And these data will be used to calculate the grain size.

The data of thermal cycle curve is substituted in the equation 5 . Then the grain size in different point will be calculated out. The relationship between temperature field and microstructure in HAZ is established.

The grain size in HAZ is estimated from specimen and grain size of experiment and calculation are compared. The result in fig. 3 shows that this method could predict the grain well.

A further operation is to display the simulation picture of microstructures in computer. In Fig.4 the distance from fusion line is 200 to $500 \mu \mathrm{m}$, and the view field amplified 200 times. The equation 5 is employed to calculate the MSC. And the data of MSC are used to simulate the microstructure. The result of simulation is obtained as Fig.5 shown.

\subsection{The relationship between grain size and heat input and grain size}

The grain size in the different heat input and different size of work piece could be obtained through the simulation of the FEM and MC method. Fig.6 (a) and (b) show the relationship of the grain size in different heat input. In the different welding power the process of grain growth is shown in fig. 6 (a). The more welding power would heat the work piece's temperature higher, and the cooling time would get longer. So that the grain size of corresponding points in the high welding power would larger than low one. As fig.6 (b) shown, the grain growth also could be affected by the different welding velocity. The heating time would be shortening by the quicker welding, and the growth of grain size could be smaller than slowly welding condition. As fig.6 (c) shown, in the same heat input, because the size of work piece is changed, the grain size would also different. In the condition that, following the thickness increased, the corresponding points in work piece would gain the less power, and the grain size would smaller than the points in the thin work piece.

\section{Conclusions}

(1) The kinetic model of grain growth of Q235 was obtained by the modification of the kinetic formula of low carbon steel.

(2) Based on the thermal cycle of FEM, the Q235 austenite grain growth in HAZ was simulated by MC method. The experiment is used to evaluate the validity of this method.

(3) The relationship between the grain size and the different heat input and different size of work piece was obtained.

\section{References}

Dai Changjian. (2005). The study of numerical analysis for the evolution of microstructure. Harbin: Harbin Institute of Technology (in Chinese).

Sun Junsheng, Wu Chuansong, Li Yajiang. (1999). Effect of welding heat input on microstructure and hardness in the HAZ of HQ130 steel. Shengyang: Acta Metallurgica Sinica, 1999, 35(9): 999 1004.

Wang Weibin, Shi Yaowu, Lei Yongping,et al. (2005). Numerical simulation on microstructure of dc flash butt welding for butt welding an $400 \mathrm{MPa}$ ultre0fine grain steel. Chinese Journal of Mechanical Engineering, 2005,41(1):77 81.

Wen Junqin, Liu Xinli, (2003). Mo Chunli. Application of computer simulation in welding microstructure. Electric Welding Machine, 2003, 33(1): 21 24.

Wu Chuansong. (1990). The numerical analysis in welding process. Harbin: Harbin Institute of Technology Press, 1990. (in Chinese)

Yanhong WEI, Yanli XU, Zhibo DONG and Jilin XIAO. (2007). Three dimensional Monte Carlo simulation of grain growth in HAZ of stainless steel SUS316. Key Engineering Materials, 2007, 353-358, 1923 1936.

Table 1. Chemical composition of weld material Q235 (\%)

\begin{tabular}{|c|c|c|c|c|c|c|}
\hline $\mathrm{C}$ & $\mathrm{Si}$ & $\mathrm{Mn}$ & $\mathrm{S}$ & $\mathrm{N}$ & $\mathrm{P}$ & $\mathrm{Al}$ \\
\hline \multicolumn{7}{|c|}{ 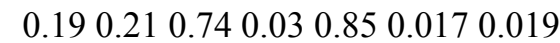 } \\
\hline
\end{tabular}


Table 2. Weld value's comparison between calculated and measured

\begin{tabular}{lcc}
\hline & width $\mathrm{W} / \mathrm{mm}$ & Penetration $\mathrm{h} / \mathrm{mm}$ \\
\hline calculation & 1.500 & 1.104 \\
experiment & 1.640 & 1.117 \\
\hline
\end{tabular}

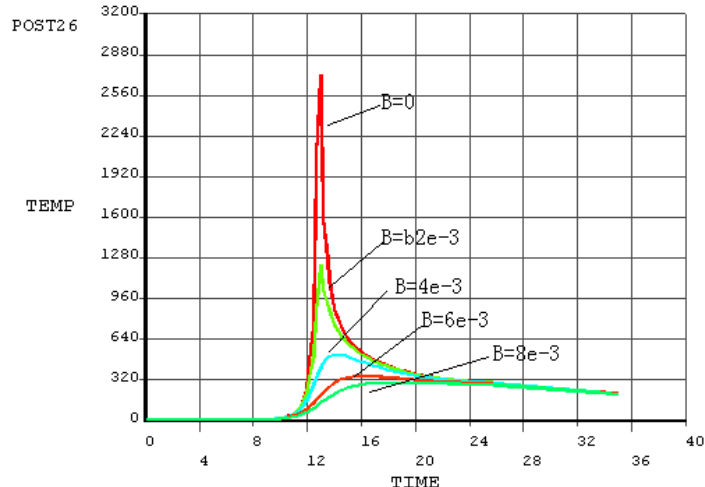

Figure 1. Thermal cycle curves of different position from center of heat source

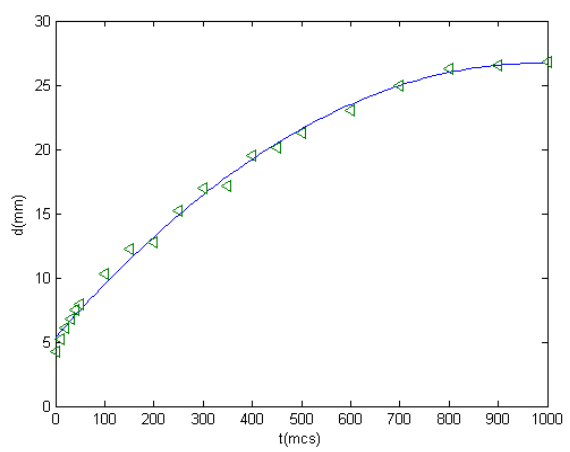

Figure 2. Relationship between MC step and the dimension of grain

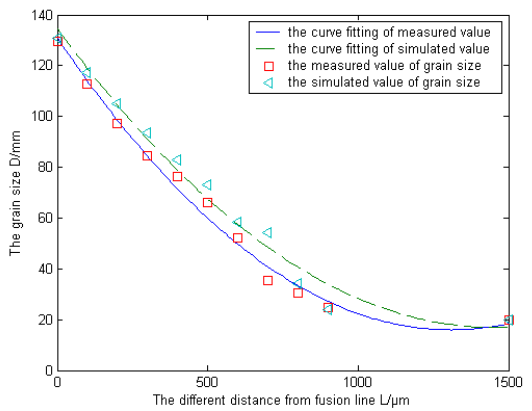

Figure 3. Grain size comparison of experiment and calculation

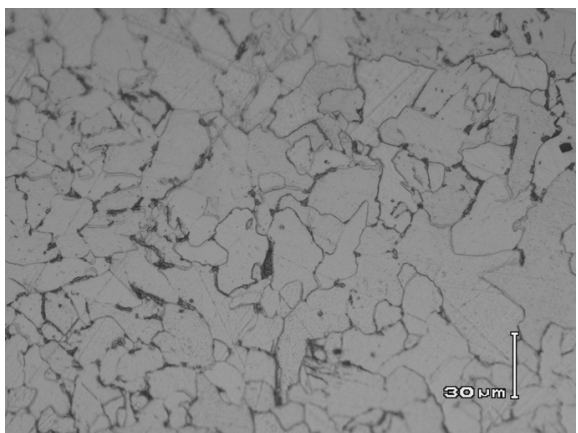

Figure 4. Microstructure of Austenite grains at positions in HAZ of Q235 


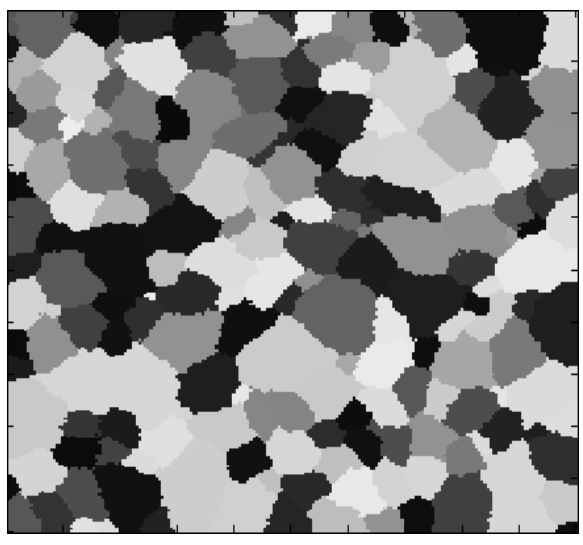

(a)

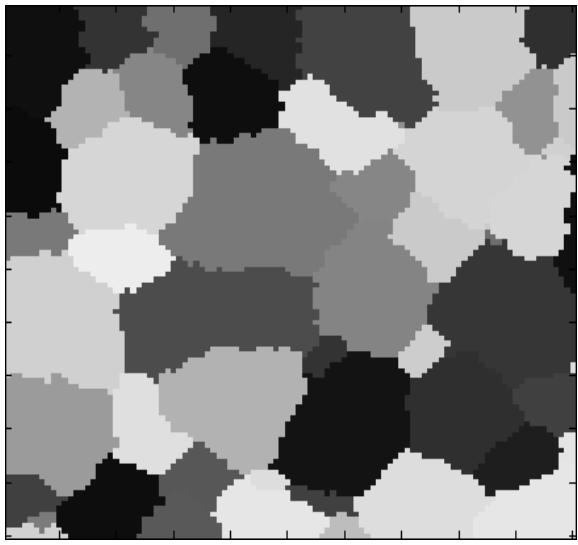

(b)

Figure 5. The simulation picture of Austenite in different position $(\mathrm{a}, \mathrm{b}$ indicate the $\mathrm{msc}=511 \mathrm{~d}=104.9 \mu \mathrm{m}$ and $\mathrm{msc}=175$ $\mathrm{d}=73.0 \mu \mathrm{m}$ respectively.)

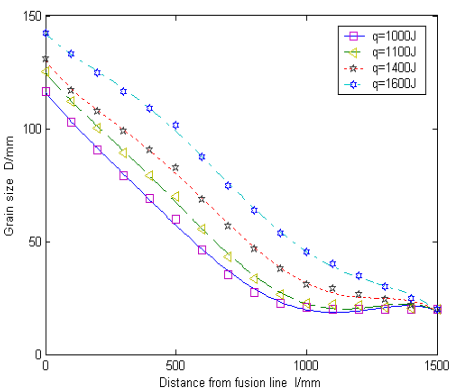

(a) Effect of different welding power

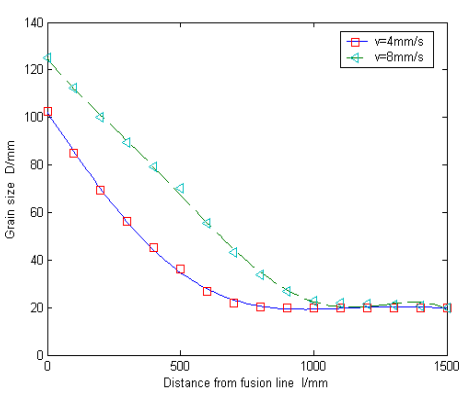

(b) Effect of different welding velocity

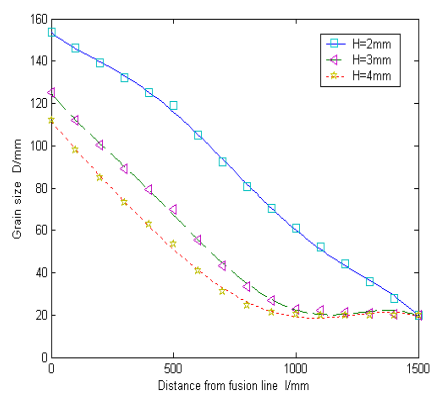

(c) Effect of different thickness

Figure 6. The compare of austenite size in different condition 


\title{
Modern Applied Science
}

Vol. 3, No. 5

www.ccsenet.org/journal.html

\section{The Management of Stakeholders' Needs and Expectations}

\section{in the Development of Construction Project}

\author{
in Malaysia \\ Roshana Takim (Corresponding author) \\ Graduate Centre Department, Faculty of Architecture, Planning \& Surveying \\ University Technology MARA (UiTM), Shah Alam, Malaysia \\ Tel: 60-3-5521-1567 E-mail: rtakim59@yahoo.co.uk
}

\begin{abstract}
This paper provides an analysis of the process used to identify project stakeholders, the factors used to manage their needs and expectations, and the implications of mismanaging their needs and expectations in the development of Malaysian construction projects. A survey was conducted among four construction stakeholders comprising: the Government, private clients, consultants and contractors. In total, 93 respondents completed the questionnaire. A list of 4 major processes and 22 possible critical factors for managing the stakeholders' needs and expectations are identified, in order for the respondents to determine their level of importance. The Kruskal-Wallis test of One-way ANOVA (Analysis of variance) is used to examine the significant difference in opinion between the four groups at the 5\% significance level.

The findings reveal that a formalised process is more effective in identifying project stakeholders. The priority criteria used to manage the stakeholders' needs and expectations differ between the private and public sectors. The government and consultants are confident that social and political matters are of the greatest importance, whereas the private sector puts a great deal of emphasis on forming project coalitions and lobby tactics mechanisms in managing the stakeholders' needs and expectations. It is expected that this study will provide some empirical insights into the process of stakeholder management in the development of construction projects in Malaysia.
\end{abstract}

Keywords: Malaysia, Questionnaire survey, Project performance, Project stakeholders

\section{Introduction}

Traditionally, the main participants in a construction project coalition are the client, the architect and the contractor. The interactions and interrelationships between these participants largely determine the overall performance of a construction project, and have the crucial responsibility for delivering a project to successful completion. However, looking upstream and downstream in the construction project life cycle, there are multiple attributes that contribute to the success of a project, and these are influenced by a variety of decisions made by various individuals, bodies and organisations (Love et al. 1998a). These internal and external participants are recognised as stakeholders who are actively involved in the project, or whose interests may be positively or negatively affected as a result of project execution (Jergeas et al. 2000).

Previous work by Turner (1999) and Moodley (1999) defined stakeholders as people or groups that have, or believe they have, legitimate claims against the substantive aspects of a project. These can include the team's families, people who buy the product or are affected by the end product and the local community at large. They recognise a link between project success and an ability to forge a fruitful alliance between those affected by the end product. Nevertheless, these groups also have a great deal of resources at their disposal to frustrate projects by action-group protest activity or other sophisticated means of action. Smith et al. (2001) contribute to the definition of stakeholders as representatives, direct and indirect, who may have an interest and can make a contribution to the proposed project. Winch (2002) provides a more comprehensive definition of stakeholders as those actors who will incur a direct benefit, or loss, as a result of the project. He reckons that two classifications of stakeholders exist in the construction industry, namely internal and external stakeholders. Internal stakeholders are people who have legal contact with the client and those clustered around the client on the demand side (employees, customers, end-users and financiers) and on the supply side (architect, engineers, contractors, trade contractors and material suppliers). The second classification is the external stakeholders who are comprised of private and public actors. The private actors are from the local residents, landowners, environmentalists, and archaeologists, whereas the public actors are from regulatory agencies, and local and national government. The internal stakeholders will largely be in support of the project and external stakeholders 
may be in favour, against, or indifferent. The above variation in definitions of stakeholders is quite significant. This degree of variation makes it difficult to ensure that all their needs and expectations are properly addressed and managed. Satisfying the needs of the client, users and others stakeholders is one of the criteria for project success, and failure to manage their needs and expectations may contribute to project failure (Turner 1999; Smith et al. 2001). Thus, an important aspect of project management is to obtain stakeholder buy-in and support for the project.

For the purpose of this research, stakeholders are defined "as being those who can influence the activities/final results of the project, whose lives or environment are positively or negatively affected by the project, and who receive direct and indirect benefit from it". They are limited to five groups namely: client, consultant, contractor, end-users and the community. This paper reports and comments on the following: (1) the process used to identify project stakeholders; (2) factors used to manage their needs and expectations; and (3) the implications for the mismanaging of their needs and expectations for Malaysian construction project development. It is part of a larger ongoing $\mathrm{PhD}$ research project into a framework for successful construction project performance from the client's perspective. This study utilises structured questionnaire research techniques, through the postal survey of four principal target groups (the Government, private client, consultants and contractors) in Malaysia. The different groups were targeted because they occupy different positions in the construction value chain and their perspectives would be valuable to this research.

\section{Models For Assessing And Managing Client And Stakeholders' Needs And Expectations In Construction Project Development}

Following an extensive literature search, two models are selected, namely: the strategic needs analysis (SNA) model (Smith et al,.2001) and the stakeholder management model (Jergeas et al. 2000). These models will form the basis of the following discussion.

The pre-design stage of construction projects is seen to be the focal point of construction project development. At this juncture, attention is given primarily to assessing the needs of the client, stakeholders and those of the design team. This is in line with the opinion of Love et al. (1998b), who stressed that decisions made during the formative and early design stages in the life of a project are seen as critical factors that must be taken into account if a project is to be delivered on time, to budget and to the desired quality. It is during these early stages that most of the critical decisions that affect the economy, efficiency, timing, functional content, appearance and the real value of the project are finalised and streamlined. Indeed, many researchers (Atkinson et al. 1997; Wateridge, 1998) have agreed that successful construction project performance is achieved when stakeholders meet their requirements, individually and collectively.

Previous literature suggests that in order to incorporate the needs of stakeholders into the formative stage of a project, it is necessary to allow the stakeholders to express their needs, views and expectations in an appropriate forum. In relation to this approach, Smith et al. (2001) in their studies proposed a model called Strategic Need Analysis (SNA) to assist clients, stakeholders and their design teams in determining their strategic needs for a given project. The SNA process is based on the involvement of as many significant stakeholders as is practically possible. The group includes: client; managers/executives, facility managers, project managers; employees; end-users, consultants and other design team members. The structure of the SNA process is based on the involvement of stakeholders at three levels, which consist of briefings, seminars and workshops. Level 1 is the briefing stage, where briefing is conducted in the form of seminars and workshops. At level 2, participants will be involved in developing alternative strategies for the achievement of corporate missions, whereas in level 3, participants will develop a detailed performance brief for the project implementation. The outcome of SNA is in developing a comprehensive performance brief to guide project team members to develop the project within adequate parameters.

Jergeas et al. (2000) in their studies, proposed a model of stakeholder management for construction projects. In their model, project stakeholders were initially defined and there followed an examination of the data collected during interviews with five project managers who work in three companies within the oil and gas industry. Ten major structured questions were asked and the expected answers were based on overall experiences. The ten questions are: processes used (formal/informal) to identify project stakeholders; effectiveness of the processes; methods employed to obtain stakeholder buy-in; typical stakeholders on a construction project; managing stakeholders throughout the project life cycle; maintaining the alignment of stakeholders during the project; obtaining feedback from stakeholders; communication interfaces with stakeholders in advance; improving stakeholder management; and, finally, problems encountered in the mismanagement of stakeholders. The results reveal that both formal and informal processes are used to identify project stakeholders and the processes are highly effective. Nevertheless, the formal process is more significant in order to obtain a stakeholders' buy-in. In summary, Jergeas et al. (2000) conclude that in order to improve stakeholders' management, communication, common goals, objectives and project priorities need to be systematically planned prior to embarking on to the project. Developing a more formalised process will avoid assumptions arising from the fact that the projects are very similar to one another. The limitation of this model is that the sample is too small and the results obtained might not be statistically valid. However, it does provide some guidelines for important elements in managing construction project stakeholders. 


\section{Research methodology}

\subsection{Data Collection Instrument}

The research on stakeholder management in construction project development adopted the ideas proposed by Smith et al. (2001) and Jergeas et al. (2000). The methodology adopted was based on a structured questionnaire-survey of four principal target groups within the Malaysian construction industry, focusing on the Klang Valley area. The data collection exercises were held in Malaysia over a period of three months ( $3^{\text {rd }}$ March to $25^{\text {th }}$ of April, 2003). Apart from the questionnaire survey, six case studies by means of in-depth interviews were also conducted within the stipulated time frame. However, the results of the case studies are still being processed and are not reported in this paper.

For the purpose of this article, results were merely based on the questionnaire survey. A questionnaire survey is one of the most cost effective ways to involve a large number of people in the process in order to achieve better results, as recommended by Andi and Minato, (2003). A fourteen-page structured questionnaire was distributed to the four targeted groups, representing a mixture of professionals, including those dealing with policy-formulation, design, construction, quantity surveying, and clients of construction projects. The four targeted populations were: government (public clients); private clients (developers); consultants (architects, quantity surveyors, civil \& structural engineers, mechanical \& electrical engineers) and contractors. However, for the project stakeholder section, a two-and-a half page questionnaire needed to be answered by those respondents. Respondents were required to rate each question on a five-point Likert scale that required a ranking (1-5), where one represented 'not important' and 5 represented 'extremely important', as the case might be.

Samples were randomly selected from the listing provided by their respective professional institutions. The target population for contractors was based on companies that are registered with the CIDB of Malaysia under the Class G7 (projects greater than Ringgit Malaysia 10 Million) categories and were identified from the CIDB directory. The states of Selangor and Kuala Lumpur were chosen because there were larger groups of professionals and Class G7 contractors registered in these regions, which brings the total percentage of the two states to around $61 \%$ (CIDB, 2003a).

\subsection{Response Rate}

As shown in Table 1, a total of 446 questionnaires were sent to the different target groups in Malaysian construction organisations. Ninety-three questionnaires were returned within two months of being sent out, making the total response rate 20.9 percent. All the questions were satisfactorily completed. The respondents had an average construction experience of approximately 16 years. The majority of them were in senior positions in their firms. Table 2 , however, shows the posts held by respondents. Twenty-one (29.5\%) respondents were from public clients, followed by $15(18.5 \%)$ from developers, 34 (17.8\%) from consultant organisations, and $23(22.3 \%)$ from contractor companies. The response rate of 20.9 percent is not uncommon and acceptable and is in line with the opinions of Akintoye (2000) and Dulami et al (2003). They reported that the norm response rate in the construction industry for postal questionnaire is around 20-30 percent. Ofori and Chan (2001) received a 26 percent response rate. Vidogah and Ndekugri (1998) received a 27 percent response rate and Shash (1993) a 28.3 percent rate. Notwithstanding this, the authors approached personal contacts in the construction industry and made follow-up calls. Several responses were received through this effort.

Respondents were required to tick as follows: Firstly, the types of processes used for identifying project stakeholders and how effective these processes are from a structured list of four items which ranged from an informal process; sign-off design Memorandum of Agreement (MOA) or design-basis memorandum (DBM); the preparation of a development plan (DP) and local advertisements and town hall meetings. Secondly, to tick relevant factors used by their company in managing the needs and expectations of project stakeholders, and to what extent can those factors be useful in project development and, thirdly, to state the possible implications of mismanaging the stakeholders' needs and expectations via a Likert scale. This technique is particularly helpful in examining the respondents' consideration of the degree of importance in identifying, managing and mismanaging the needs of construction project stakeholders in Malaysia. The results were analysed using the Statistical Package for the Social Sciences (SPSS).

\section{Data analysis and results}

The analyses primarily deal with the ranking of the variables, based on the mean values to determine their level of importance. It is then followed by comparing the mean values across the groups. The Kruskal-Wallis test One-Way ANOVA (Analysis of Variance) is used to examine the significant differences in the mean scores of the dependent variables, across the four groups (government, private client, consultant \& contractor). In addition, to see whether there is a statistically significant difference between the four groups, a one-to-one comparison is applied using the Mann-Whitney U test of two independent samples at the $5 \%$ significance level. The Wilcoxon Signed Rank Test is used to test the difference between the two sets of score. 
In addition, the objectives of the data analyses are to test two hypotheses: (1) the criteria used to identify project stakeholders would not vary according to the different types of project organisations and, (2) the criteria used to manage the needs and expectations of project stakeholders would not vary according to the different types of project organisations. The ANOVA provided an opportunity to clarify whether or not the opinions of the different project team members for managing project stakeholders in construction are the same or otherwise. The reliability of the 5-point Likert scale measurement is determined using Cronbach's alpha coefficient. This measures the internal consistency among the items on each factor and varies from 0 to 1 ; the higher the alpha, the greater the internal consistency reliability of the scale. According to Pallant (2001), the value for alpha should be greater than 0.7 for the scale to be reliable, whereas Nunnally (1978) suggests that the modest reliability scale is in the range of $0.50-0.60$. Hence, the results were in the range of 0.713-0.942 indicating that the data collected from the survey is interrelated and that scale was consistent with the sample.

\subsection{Identification of Project Stakeholders}

In the Malaysian construction industry, the available techniques for identifying project stakeholders are recognised to be as follows: signing-off formal agreements; signing of development plan \& documents; local advertising and community/town hall meetings; and through an informal process (those people who have direct/indirect effects on a project). With regard to the appointment of government projects, the Memorandum of Agreement (MOA) (BAM/JKR -Revised 1/83) constitutes the formal agreement between the government and respective consultants to provide the professional services for the work and in accordance with the Conditions of Engagement. This agreement is the Government's policy issued by the Ministry of Finance, Malaysia, and needs to be signed-off by the respective consultants and client and was applied to conventional projects. The distinctive numbers of stakeholders are limited to client, architects, engineers, quantity surveyors and planners. Apart from MOA, the signing-off development plan, pre-bid and contract documents are other ways of identifying project stakeholders. The informal process, however, deals with those people who have a direct/indirect effect on the development of the project and are recognised as end-users and surrounding communities. Table 3 shows the identification of project stakeholders in Malaysia

As expected, the study reveals that the main processes used to identify project stakeholders in Malaysia is the signing-off Memorandum of Agreement (MOA), followed by the preparation of the development plan, with overall mean scores of 3.99 and 3.79, respectively. The Kruskal Wallis One-Way ANOVA test for a k-independent sample indicated that there is no difference of opinion in the identification of project stakeholders by the groups (government, private client, consultant and contractor) at the 5\% significance level. Further observation showed that, the overall rating of 3.33 for the informal process is lower than 3.79 for the preparation of the development plan at the 0.05 level of significance $(p=0.002)$. Therefore, the two sets of scores are significantly different when the Wilcoxon Signed Rank Test of two related samples is applied. This suggests that the formal processes are the most significant for Malaysian construction organisations in identifying project stakeholders, compared to the informal techniques.

\subsection{Managing Stakeholders' Needs and Expectations}

Table 4 gives the overall mean scores and the priority ranking of the groups' perceptions of factors used to manage the project stakeholders' needs and expectations in the development of Malaysian construction projects.

For a descriptive analysis and for the sake of readability, the overall mean scores on the five most important factors were selected. Among these factors, keeping stakeholders satisfied showed the highest rank (ranked $1^{\text {st }}$ ) with the overall mean score of 3.78. This is followed by 'keeping stakeholders well-informed,' ranked $2^{\text {nd }}$ (overall mean $=3.58$ ), 'focussing on the definition of project mission', ranked $3^{\text {rd }}$ (overall mean $=3.54$ ), 'visual techniques', ranked $4^{\text {th }}$ (overall mean $=3.53$ ), and 'forming project coalitions', ranked $5^{\text {th }}$ (overall mean=3.53). When a comparison was made across the groups, the results indicated that those respondents from the Government and consultants agreed to place a higher priority (ranked $1^{\text {st }}$ ) on 'keeping stakeholders satisfied' than did private clients and contractors. In contrast, the private client ranked $1^{\text {st }}$ on 'forming project coalitions', while, contractors ranked $1^{\text {st }}$ on 'lobby tactics'

A possible explanation is that, the Government and their consultants are used to dealing with top management level, end-users and surrounding communities as their answerable stakeholders while implementing construction projects. Therefore, if satisfactions are not properly addressed, the top management will be dissatisfied, and fail to support, appreciate and value the project. Subsequently, the negative reactions from end-users might disrupt partially or fully the progress of the project as mentioned by Jergeas et al, (2000). On the other hand, forming project coalition is of interest to the private sector since a temporary coalition will assist them to shape the strategy of the project and minimise conflicts (Newcombe, 2003). The contractor, however, puts a great deal of emphasis on 'lobby tactics'. This is factual and it is not uncommon for contractors to use the lobby tactics mechanism to get the intended project from clients (private or public) as well as swift approval from the respective authorities. To a certain extent, a contractor will need to establish a good reputation by means of lobby tactics and it seems to be more pragmatic than ethical. On the whole, the overall mean scores for all the factors are higher than the mid-point score of 2.5, with the exception of 2 factors: mitigate/ change the project (mean value $=2.36$ ) and compensating stakeholders (mean value $=2.29$ ). Hence, 
it can be interpreted that the Malaysian construction professionals agreed that those factors are essential in managing stakeholders' needs and expectations in the development of project (Cheung and Yeung, 1998).

In addition, Table 4 shows the results of the Kruskal-Wallis test for a k-independent sample. The test indicated that 4 variables (1, 15, 12 and 2) exhibited a statistically significant difference at the $1 \%$ and $5 \%$ significance level, respectively. The remaining 18 variables indicated no statistically significant difference in opinion between the four groups at the $5 \%$ significance level. To see whether there is a statistically significant difference between the four groups, a one-to-one comparison was applied using the Mann-Whitney $\mathrm{U}$ test of two independent samples at the $5 \%$ significant level. The results are tabulated in Table 5.

The results in Table 5 show that a statistically significant difference in 'mapping stakeholders' interests' existed between the Government and the private client (probability value $=0.002$ ), between the Government and the consultant (probability value $=0.019$ ), and between the Government and the contractor (probability value $=0.002$ ). This indicates that it is the Government that contributed to the difference between the groups at the $5 \%$ significance level criteria. The second observation regards the 'consult and refine' approach variable. Once more it is the Government that contributed to the difference between the groups (government/consultant with a probability value $=0.002$ ) and (government/contractor with a probability value=0.005). Conversely, for 'lobby tactics', initial observations revealed that there is a big gap between the Government, the private client, the consultant and the contractor, with scores of 2.67 and 2.50 and 2.80, and 4.0, respectively. In this case, it is the contractor who contributed to the difference between the groups, based on the confirmation of the Mann-Whitney $U$ test of two independent samples. Thirdly, there is also, a statistically significant difference in 'articulating stakeholders' interests' existing between the Government and the private client (probability value $=0.003$ ) and between the Government and the contractor (probability value $=0.040$ ). The Mann-Whitney U test shows that it is the Government that contributed to the difference between the groups.

\subsection{Implications of Mismanaging Stakeholders' Needs and Expectations}

Further results from the questionnaire revealed that 'client and stakeholders will be dissatisfied with the project outcomes' if project stakeholders are not properly managed, with the overall mean scores of 4.00 and 3.88 , respectively, within the groups. These are the highest ranked out of 14 variables (client will be dissatisfied; stakeholders will be dissatisfied; project failure; affecting future relationships; stakeholders fail to support the project; conflicts; disrupted project progress; fail to determine definition of project success; not enough endorsement to start the project; meeting unintended goals; negative community reaction; stakeholder intervention; completed building will not be used; and strike).

Moreover, factors on contributing to project failure (overall mean=3.65); affecting future relationships (overall mean=3.59); failure to support the project (overall mean=3.53); and conflicts (overall mean=3.50) are among the most important critical factors that might occur in mismanaging the stakeholders' needs and expectations. The Kruskal Wallis One-Way ANOVA test for a k-independent sample indicated that there is no statistical difference of opinion on the overall implications of mismanaging the stakeholders' needs and expectations by the group at the 5\% significance level.

\section{Conclusions}

This paper examines the current views on identifying project stakeholders and managing their needs and expectations in construction project development in Malaysia. Based on the empirical research, a few findings have emerged as follows: Firstly, the four sectors in Malaysia (government, private client, consultant, and contractor) are in broad agreement that a systematic formal process is more effective and is employed for identifying project stakeholders. The formal processes are recognised as: 'Sign-off Memorandum of Agreement (MOA)' and the 'Preparation of Development Plan (PDP)'. The Kruskal-Wallis test confirmed that there is no discrepancy existing between the groups. Therefore, the first hypothesis could not be rejected.

Secondly, the findings indicated that priority criteria used to manage the stakeholders' needs and expectations differ between the public and private sectors in Malaysia, depending on their interests. The Government and the consultants put more emphasis on keeping their stakeholders' satisfied, well-informed, and educating them by means of providing forums, open communications interfaces and visual techniques (photomontage and project models). This reinforces the belief that any criteria possibly affecting a project in terms of social obligations and political interference are most likely to be of great importance to the Government and their consultants. The political decisions and top management's support of the project by providing the necessary money, man-power and other sufficient resources are needed for the successful implementation of the project (Manley, 1975).

In contrast, private clients ranked the factor 'forming a project coalition' as highly important, followed by 'focussing on the definition of project mission'. Contractor however, chose 'lobby tactics', followed by 'keeping stakeholders well-informed' and 'focussing on the definition of project mission' to be highly essential in managing their project stakeholders. The study conducted by Newcombe (2003) reveals that clients' attitudes towards the development of a 
project are unpredictable and may change as it progresses. Thus, by forming a project coalition or alliances with them it will assist and encourage them to maintain their level of predictability, interest and power to ensure the successful implementation of project strategies. Further, failure to focus on the definition of project mission may end up with the project meeting goals that were never intended by the potential stakeholders (Karlsen, 2002)

Moreover, in managing the stakeholders' needs and expectations, the results disclose that out of 22 variables, 4 (18\%) variables exhibited a statistically significant difference in opinion between the groups at the $5 \%$ significance level. The Government and contractors are seen to be the notable groups that showed the most inconsistency and uncertainty amongst the groups. This implies that the second hypothesis could not be totally rejected.

The research has also addressed some results that could be used to improve on the effects of mismanaging the stakeholders' needs and expectations. It is suggested that the involvement of project stakeholders is required throughout the project life cycle, particularly in the front-end project planning. Overall communications with various stakeholders are to be emphasised by the project client in order to achieve alignment and feedback between them. This is fundamental since the project client and end-users are significantly more important than other stakeholders and have the sole power in bringing any hidden agendas and project priorities to the forefront (Jergeas et al. 2000; Karlsen, 2002). The importance of interaction with the project's client and end-users throughout the duration of the project is paramount, since it is the project client who defines and finances the project, while it is the end-users who decide about the usefulness of the project results.

The results of this study offer an insight into stakeholder management in the development of Malaysian construction projects and will hopefully provide valuable guidelines, especially to client organisations (public or private), for managing their construction project stakeholders.

\section{References}

Akintoye, A. (2000). Analysis of factors influencing project cost estimating practice. Construction Management and Economics, 18: pp 77-89

Andi and Minato, T. (2003). Design document quality in the Japanese construction industry: factors influencing and impacts on construction process. International Journal of Project Management, 21:pp537-546.

Atkinson, A.A., Waterhouse, J.H., and Wells, R.B. (1997). A stakeholder approach to strategic performance measurement. Sloan Management Review; Cambridge, 38 (3), pp 25-37.

Cheung, S., and Yeung, Y. (1998). The effectiveness of the dispute resolution advisor system: a critical appraisal. International Journal of Project Management, 16(6), pp 367-374

CIDB (2003a) CIDB Contractors Registration Report, Construction Industry Development Board, Malaysia. Kuala Lumpur: CIDB Publications

Dulami, M.F., Ling, F.Y.Y., and Bajracharya, A. (2003). Organisational motivation and inter-organisational interaction in construction innovation in Singapore. Construction Management and Economics, 21: pp 307-318

Jergeas, G.F., Williamson, E., Skulmoski, G.J., and Thomas, J. L (2000). Stakeholder management on Construction Projects. AACE International Transaction, pp 12.1-12.5

Karlsen, J.T. (2002). Project stakeholder management. Engineering Management Journal, 14 (4), pp19-24

Love, P.E.D., Gunasekaran, A., and Li, H. (1998b). Concurrent engineering: a strategy for procuring construction projects. International Journal of Project Management, 16(2), pp 375-383

Love, P.E.D., Skitmore, R.M. and Earl, G. (1998a). Selecting a suitable procurement method for a building project. Construction Management and Economics, 16(2), pp 221-233

Moodley, K. (1999). Project Performance enhancement-improving relations with community stakeholders, in Ogunlana, S. (Ed), Profitable Partnering in Construction Procurement. London: E\&F Spon

Newcombe, R. (2003). From client to project stakeholders: a stakeholder mapping approach. Construction Management and Economics, 21: pp 841-848

Nunnally,I. (1978). Psychometric theory. New York: McGraw-Hill

Ofori, G., and Gu, G. (2001) ISO 9000 Certification of Singapore construction enterprises: its costs and benefits and its role in the development of the industry. Engineering, Construction and Architectural Management, 8(2), pp 145-157

Pallant, J. (2001). SPSS Survival Manual. A step by step guide to data analysis using SPSS for windows (Version 10-11). Buckingham: Open University Press.

Smith, J., Love, P.E.D., and Wyatt, R. (2001). To build or not to build? Assessing the strategic needs of construction industry clients and their stakeholders. Structural survey, 19(2), pp 121-132 
Turner, R. J. (1999). The Handbook of Project-Based Management (2 ${ }^{\text {nd }}$ Edition): Improving the processes for achieving strategic objectives. London: McGraw-Hill Companies

Vidogah,W. and Ndekugri, I (1998). Improving the management of claims on construction contracts: consultant's perspective, Construction Management and Economics, 16: pp 363-372

Wateridge, J. (1998). How can IS/IT projects be measured for success. International Journal of Project Management, 16 (1), pp 59-63

Winch, G.M. (2002). Managing Construction Projects: An Information Processing Approach. Oxford: Blackwell Science Ltd.

Table 1. Response data

\begin{tabular}{|l|lr|r|}
\hline Type of organisation & \multicolumn{2}{|l|}{ Number of questionnaires } & \multicolumn{1}{|c|}{ Percentage return } \\
\hline & Sent & Return & $(\%)$ \\
\hline Government & 71 & 21 & 29.5 \\
Developers & 81 & 15 & 18.5 \\
Consultants & 191 & 34 & 17.8 \\
Contractors & 103 & 23 & 22.3 \\
\hline Total & 446 & 93 & 20.9 \\
\hline
\end{tabular}

Table 2. Profile of respondents and their experiences

\begin{tabular}{|c|c|c|cc|}
\hline \multirow{2}{*}{$\begin{array}{c}\text { Sample } \\
\text { Type of }\end{array}$} & \multicolumn{2}{|c|}{ Designation } & Experience in the construction industry \\
(years)
\end{tabular}

Table 3. The mean score of ranking-identification of project stakeholders

\begin{tabular}{|c|l|c|c|c|c|c|c|c|}
\hline$V$ & Processes & $\begin{array}{l}\text { Overall } \\
\text { mean } \\
\text { score }\end{array}$ & Government & $\begin{array}{l}\text { Private } \\
\text { client }\end{array}$ & Consultants & Contractor & $\begin{array}{l}\text { Chi-sq } \\
\text { uare } \\
\text { value }\end{array}$ & $\begin{array}{l}\text { Kruskal- } \\
\text { Wallis } \\
\text { Sig } p\end{array}$ \\
\hline 2 & $\begin{array}{l}\text { Sign-off Memorandum o } \\
\text { Agreement (MOA) }\end{array}$ & 3.99 & 3.55 & 3.92 & 4.00 & 4.36 & 4.312 & 0.230 \\
\hline 3 & $\begin{array}{l}\text { The preparation of the } \\
\text { Development Plan (DP) }\end{array}$ & 3.79 & 3.33 & 3.67 & 4.00 & 3.86 & 3.182 & 0.364 \\
\hline 1 & Informal process & 3.33 & 3.05 & 3.43 & 3.33 & 3.56 & 3.087 & 0.378 \\
\hline 4 & $\begin{array}{l}\text { Local advertising and } \\
\text { town hall meetings }\end{array}$ & 3.13 & 2.75 & 3.11 & 3.00 & 3.75 & 4.434 & 0.218 \\
\hline
\end{tabular}


Table 4. The mean score of ranking-managing stakeholders' needs and expectations

\begin{tabular}{|c|c|c|c|c|c|c|c|c|}
\hline$V$ & Factors & $\begin{array}{l}\text { Overall } \\
\text { mean } \\
\text { score }\end{array}$ & Government & $\begin{array}{l}\text { Private } \\
\text { Client }\end{array}$ & Consultant & Contractor & $\begin{array}{l}\text { Chi- } \\
\text { square } \\
\text { value }\end{array}$ & $\begin{array}{l}\text { Kruskal } \\
\text { - Wallis } \\
\text { Sig } p\end{array}$ \\
\hline 11 & $\begin{array}{l}\text { Keep satisfied (complying } \\
\text { with stakeholders } \\
\text { requirements but subject to } \\
\text { constraints) }\end{array}$ & 3.78 & 3.63 & 3.83 & 3.90 & 3.75 & 1.174 & 0.759 \\
\hline 9 & $\begin{array}{l}\text { Keep stakeholders well } \\
\text { informed }\end{array}$ & 3.58 & 3.56 & 3.11 & 3.53 & 3.89 & 4.231 & 0.238 \\
\hline 5 & $\begin{array}{l}\text { Focussing on the definition of } \\
\text { project mission }\end{array}$ & 3.54 & 2.82 & 3.89 & 3.58 & 3.83 & 7.913 & $\begin{array}{l}0.048 \\
(0.05)\end{array}$ \\
\hline 17 & Visual techniques & 3.53 & 3.00 & 3.50 & 3.63 & 3.69 & 3.291 & 0.349 \\
\hline 16 & Forming project coalitions & 3.53 & 2.90 & 3.90 & 3.60 & 3.60 & 5.552 & 0.136 \\
\hline 13 & No bribe \& ignore strategies & 3.49 & 2.71 & 3.50 & 3.76 & 3.55 & 5.022 & 0.170 \\
\hline 4 & Educate stakeholders & 3.45 & 3.46 & 3.29 & 3.52 & 3.43 & 0.338 & 0.953 \\
\hline 1 & $\begin{array}{l}\text { Mapping stakeholders' } \\
\text { interests }\end{array}$ & 3.42 & 2.64 & 3.83 & 3.44 & 3.80 & 11.934 & $0.008 * *$ \\
\hline 6 & $\begin{array}{l}\text { Negotiating a compromise } \\
\text { between stakeholders }\end{array}$ & 3.37 & 3.00 & 3.57 & 3.18 & 3.80 & 6.981 & 0.072 \\
\hline 14 & $\begin{array}{l}\text { Forums and open } \\
\text { communication interfaces }\end{array}$ & 3.33 & 3.21 & 3.33 & 3.44 & 3.27 & 0.851 & 0.837 \\
\hline 8 & $\begin{array}{l}\text { Minimal effort (public } \\
\text { relation approach) }\end{array}$ & 3.29 & 2.90 & 3.63 & 3.07 & 3.78 & 5.364 & 0.147 \\
\hline 12 & Consult and refine approach & 3.28 & 2.64 & 3.20 & 3.50 & 3.60 & 11.195 & $0.011 *$ \\
\hline 19 & $\begin{array}{l}\text { Obtaining stakeholders' } \\
\text { feedback }\end{array}$ & 3.24 & 2.93 & 3.11 & 3.28 & 3.62 & 3.232 & 0.357 \\
\hline 22 & $\begin{array}{l}\text { Resolve differences between } \\
\text { or among stakeholders }\end{array}$ & 3.21 & 2.50 & 3.57 & 3.24 & 3.50 & 4.240 & 0.237 \\
\hline 18 & $\begin{array}{l}\text { Maintaining alignment } \\
\text { between stakeholders }\end{array}$ & 3.18 & 2.77 & 3.27 & 3.18 & 3.50 & 3.988 & 0.263 \\
\hline 10 & $\begin{array}{l}\text { Constantly selling and } \\
\text { reselling the project }\end{array}$ & 3.18 & 2.67 & 3.67 & 3.00 & 3.50 & 6.048 & 0.109 \\
\hline 15 & Lobby tactics & 3.15 & 2.67 & 2.50 & 2.80 & 4.00 & 11.880 & $0.008 * *$ \\
\hline 2 & $\begin{array}{l}\text { Articulating stakeholders' } \\
\text { interest }\end{array}$ & 3.15 & 2.50 & 3.88 & 3.08 & 3.33 & 9.266 & $0.026 *$ \\
\hline 7 & $\begin{array}{l}\text { Emphasis on social } \\
\text { responsibility }\end{array}$ & 3.06 & 3.00 & 3.00 & 2.75 & 3.58 & 4.824 & 0.185 \\
\hline 3 & $\begin{array}{l}\text { Changing of all opponents to } \\
\text { supporters }\end{array}$ & 2.90 & 2.50 & 2.67 & 3.00 & 3.25 & 1.273 & 0.736 \\
\hline 20 & Mitigate/change the project & 2.36 & 2.13 & 1.67 & 2.62 & 2.50 & 2.686 & 0.443 \\
\hline 21 & Compensate stakeholders & 2.29 & 2.11 & 1.50 & 2.60 & 2.60 & 3.841 & 0.279 \\
\hline
\end{tabular}

Reliability coefficient (Cronbach's alpha) $=0.9185$

*The mean difference is significant at the 0.05 level

$V=$ Variables

**The mean difference is significant at the 0.01level 
Table 5. Group differences test using Mann-Whitney U test of two independent samples

\begin{tabular}{|l|l|l|l|l|l|l|}
\hline Factors & $\begin{array}{l}\text { Government/ } \\
\text { private client }\end{array}$ & $\begin{array}{l}\text { Government/ } \\
\text { Consultant }\end{array}$ & $\begin{array}{l}\text { Government } \\
\text { Contractor }\end{array}$ & $\begin{array}{l}\text { Private } \\
\text { client/ } \\
\text { consultant }\end{array}$ & $\begin{array}{l}\text { Private } \\
\text { client/ } \\
\text { contractor }\end{array}$ & $\begin{array}{l}\text { Consultant/ } \\
\text { Contractor }\end{array}$ \\
\hline $\begin{array}{l}\text { Mapping stakeholders' } \\
\text { interests }\end{array}$ & $0.002^{*}$ & $0.019^{*}$ & $0.002^{*}$ & 0.460 & 0.896 & 0.506 \\
$\begin{array}{l}\text { Consult \& refine } \\
\text { approach }\end{array}$ & 0.170 & $0.002^{*}$ & $0.005^{*}$ & 0.493 & 0.422 & 0.728 \\
$\begin{array}{l}\text { Articulating } \\
\text { stakeholders } \\
\text { Interest }\end{array}$ & $\begin{array}{l}0.855 \\
0.003^{*}\end{array}$ & $\begin{array}{l}0.829 \\
0.118\end{array}$ & $\begin{array}{l}0.026^{*} \\
0.040^{*}\end{array}$ & $\begin{array}{l}0.452 \\
0.117\end{array}$ & $\begin{array}{l}0.006^{*} \\
0.197\end{array}$ \\
\hline
\end{tabular}

*The mean difference is significant at the 0.05 level 


\title{
Efficacy Trials of Crude Extraction from Artemisia Annul L. against Newcastle Disease Virus in Vivo in Xinjiang
}

\author{
Yali Liu \& Genqiang Yan (Corresponding author) \\ College of Animal Science \& Technology, Shihezi University, Shihezi 832003, China \\ E-mail:1yl125168@126.com \\ Guohui Chen \\ Animal Husbandry Department of Nankou Farm, Alar 843300, China \\ Jing Zhang \\ College of Food Science, Shihezi University, Shihezi 832003, China
}

\begin{abstract}
In the present paper, bioactive compounds were extracted using the water-boiling method and their effects on the inhibition of newcastle disease virus (NDV) were investigated through the cultivating of chicken embryos and trials of haem agglutination. Results showed that extracts of sweet wormwood (Artemisia annual L.) had no side effects, and along with the inoculation of both drug and NDV inhibited the proliferation of NDV in chicken embryos.
\end{abstract}

Keywords: Artemisia annul L., Chicken embryo, NDV, Inhibition

\section{Introduction}

ND is an important disease among poultry, which lead to immeasurable economic loss in breeding industry. As a result, lots of measures have been taken to prevent, control and eradicate ND. However, antibiotic and sulfonamides have no therapeutic effects on ND, and thus in order to investigate the effects of sweet wormwood on ND, inhibition trials of artificial infected ND by its extracts were observed in the present paper.

\section{Materials and methods}

\subsection{Materials}

\subsubsection{Chicken embryos for trial}

9 days old embryos were purchased from chicken embryo hatchery in Shihezi old street of Xinjiang.

\subsubsection{NDV field strains}

ND wild virus was provided by the lab of infectious disease infecting both domestic animals and human of Shihezi University. The HA titers of allantoic fluid in chicken embryo was $9 \log 2$, diluted into the concentration of $1 \times 10^{-1}$ by sterilized normal saline before application.

\subsubsection{Drugs}

Natural sweet wormwood was sampled in the suburb of Shihezi, flowers, leaves and fruits dried in the shade was cooked with water by the traditional decocting method, changed into slow fire after boiling, and replicated twice. Resultant extractions were filtered and then condensed into the solution of the concentration of $1 \mathrm{~g} / \mathrm{mL}$ by the evaporation method (Fu, 2005, P. 246).

\subsubsection{1\% Chicken red blood cells}

Blood was sampled from cocks, rinsed with normal saline for three times, and then diluted into $1 \%$.

\subsubsection{Apparatus}

Rotary evaporator(MCO-15AC, Japan); imported 96-well cell culture plates; oscillator (China); carbon dioxide incubator (China); super clean performance bench (SB-JS- , Shanghai medical treatment facility factory, Boxun Development Corporation); electric tachometer indicator thermostatic incubating oven(DPX-9272B-1, Shanghai Fuma experimental equipment Co. Ltd); Pulverizer; soxhlet extractor(China); casserole of decocting medicinal herbs; automatic autoclaving pot (SLP-32L, Japan); Low speed large capacity multi-tube centrifuge (LXJ-11B, Shenzhen, China ); electronic balance; oven. 


\subsection{Methods}

\subsection{1 $\mathrm{IC}_{50}$ Measurement}

Allantoic fluids were serially diluted into different concentrations, and then inoculated with chicken embryos. $\mathrm{IC}_{50}$ was obtained by the traditional methods. The concentration of inoculated allantoic fluid used for official test was diluted into $1: 500$.

\subsubsection{Acute toxicity test}

Original drug was doubling diluted with sterilized normal saline, and then both stock and dilution solutions were inoculated into five 9-days old chicken embryo allantoic fluids, each $0.2 \mathrm{ml}$, kept in the incubator for $72 \mathrm{~h} \mathrm{at} 37^{\circ} \mathrm{C}$. Survival condition was observed each day. The most high drug concentration was used as the initial concentration in official test when the whole chicken embryos were alive, normal saline used as control as well.

\subsubsection{Effects of sweet wormwood extracts on the proliferation of NDV}

According to the dilution concentration of allantoic fluid and drug concentration listed in Table 2, in group 120 chicken embryos were inoculated with drug solution $0.2 \mathrm{ml}$ and NDV dilution solutions $0.1 \mathrm{ml}$; in group 2 used as control, 20 chicken embryos were inoculated with normal saline $0.2 \mathrm{ml}$ and NDV dilution solutions $0.1 \mathrm{ml}$; in group 320 chicken embryos were inoculated neither NDV nor drug.

Aforementioned chicken embryos were incubated in $37^{\circ} \mathrm{C}$ thermostat, candling inspection each day for $2 \sim 3$ times, discarded the dead embryos in $24 \mathrm{~h}$, collected and freezed the dead ones after $24 \mathrm{~h}$, collected survival embryos in $96 \mathrm{~h}$ and allantoic fluid of dead embryos in 24 96h and stored at low temperature for further investigation, measured the hemagglutination titers respectively.

\section{Results and discussions}

\subsection{Drug toxicity trails}

Through three replicate trials, sweet wormwood with different concentration all had no obvious lethal effects on chicken embryos which was listed in Table 1 in detail. Therefore, the original concentration was used as initial concentration for official tests.

Prevention of NDV have been paid great attention all over the world, however, due to the continuous appearance of very virulent strains and variants and all kinds of vaccine failure factors, NDV are always easily epidemic. In the present paper, toxicity trails of sweet wormwood extracts was undertaken, and results showed that original extracts have on side effects on chicken embryos and could used as initial concentration.

\subsection{Effects of sweet wormwood extracts on the proliferation of NDV}

As seen from Table 3, in group 1 the dead and survival number of embryos were 2 and 1, respectively, which indicated that natural sweet wormwood could significantly inhibit the proliferation of NDV. It has been reported that other Chinese herbs could be used as agents against NDV but their effects were not ideal(Ben, 2007, PP. 33 34). In the present study, we proved that sweet wormwood could be used as an assistant curative against NDV.

\section{Conclusions}

ND is an infectious disease caused by NDV, due to the extensive application of vaccines, which was characterized in a chronic and sporadic manner. There are no efficacious therapeutics for NDV at present. There have been many successful experiences using Chinese herbs against NDV. In the present study, attempt was made to give theoretical basis for further curing NDV clinically. New bioactive compounds screened from plants have been an important way to obtain new drugs which attracted many researchers' attention(Tao, 1991, PP. 7 13). Effects of sweet wormwood on viruses have not been documented till present, less records of this plant used as drugs as well.

\section{References}

Ben, Q.Y., Fang, Z.W., \& Lin, C.L., et al. (2007). Reports of effects of Chinese herbs on the proliferation of NDV in chicken embryos. China poultry, 29(1):33 34.

Fu, M., Liu, S.G., \& Wu, X.J. (2005). Stuies on bacteriostastic comparison of Rubus tephrodes Hance and Xanthium sibiricum Patrin. Journal of China normal university (natural science), 39(2):246.

Tao, P.Z. (1991). Progress in studies of anti-virus drugs. Progress in pharmaceutical sciences, 9:7 13.

Xu, S.Y. (1994). Methodology of pharmacological experiments. Beijing: Human Sanitation Press. 
Table 1. Drug toxicity trails of extracts on chicken embryos

\begin{tabular}{|c|c|c|c|c|}
\hline \multirow{2}{*}{ Extractions concentration } & \multirow{3}{*}{ Inoculum size } & \multicolumn{3}{|c|}{ Survival condition } \\
\cline { 4 - 5 } & & $24 \mathrm{~h}$ & $48 \mathrm{~h}$ & $72 \mathrm{~h}$ \\
\hline \multirow{2}{*}{ Original concentration } & \multirow{3}{*}{$0.2 \mathrm{ml}$} & $* 5 / 5$ & $5 / 5$ & $5 / 5$ \\
\hline $1: 1$ & $5 / 5$ & $5 / 5$ & $5 / 5$ \\
\hline \multirow{2}{*}{$1: 2$} & $5 / 5$ & $5 / 5$ & $5 / 5$ \\
\hline & & $5 / 5$ & $5 / 5$ & $5 / 5$ \\
\hline
\end{tabular}

Note: *Denominator represented the inoculated number of embryos; numerator represented the number of survival embryos.

Table 2. Inhibition effects of sweet wormwood extracts

\begin{tabular}{|c|c|c|c|}
\hline Group & $\begin{array}{c}\text { Number of dead } \\
\text { embryos in } 24 \sim 72 \mathrm{~h}\end{array}$ & $\begin{array}{c}\text { Number of survival } \\
\text { embryos in } 72 \mathrm{~h}\end{array}$ & HA titers \\
\hline 1 & $4^{* *}$ & $15^{* *}$ & $0^{* *}$ \\
\hline 2 & 17 & 0 & $10 \log 2$ \\
\hline 3 & 0 & 19 & 0 \\
\hline
\end{tabular}

$* * \mathrm{p}<0.01$ 


\title{
Method for Analyzing Fish Assemblage Distribution with Application
}

\section{to Fishery Landings of Tropical Shallow Lake as Songkhla Lake, Thailand}

\author{
Sarawuth Chesoh \\ Pattani Inland Fisheries Research and Development Center \\ Department of Fisheries, Ministry of Agriculture and Co-operatives, Pattani, 94160, Thailand \\ Tel: 66-73-439-123 E-mail: chesoh.s@hotmail.com \\ Chamnein Choonpradub (Corresponding author) \\ Department of Mathematics and Computer Science, Faculty of Science and Technology \\ Prince of Songkla University, Pattani Campus, 94000, Thailand \\ Tel: 66-73-312-179 E-mail: cchamnei@bunga.pn.psu.ac.th
}

\begin{abstract}
Fish community structure can provide potentially powerful tools for assessing aquatic environmental health. Monthly catch weights in Songkhla Lake were recorded over the period January 2003 to December 2006 inclusive for each of 127 species: 72 were marine vertebrate; 22 freshwater vertebrate; 21 marine invertebrate; 10 diadromous, and 2 catadromous. Linear regression model base on the log-transformed catch weights classified species and months, using these factors as multiplicative determinants based on principal components were performed, enabling assessment of clustering of species. The model has four such components which correspond to predominant seasonal time series patterns, giving an r-squared value of $87.7 \%$. Purely seasonal patterns were identified for the first two components: estuarine and marine vertebrates showed considerable seasonal fluctuations but otherwise appeared to be steady over the four year period. Trends, mainly confined to the most recent year (2006) were identified for the third and fourth components: freshwater and estuarine fish had increasing catch weights, while the catch weights of marine invertebrates decreased. This model can provide practical lake information and reinforces that migratory fish species in tropical shallow lake need to be managed for sustaining their diversities.
\end{abstract}

Keywords: Catch pattern, Principal component regression, Fish clustering, Species diversity, Similarity index, Aquatic resource management

\section{Introduction}

A "shallow lake" is usually defined as a permanent standing body of water that is sufficiently shallow to allow light penetration to the bottom sediments adequate to potentially support photosynthesis of higher aquatic plants over the entire bottom (Wetzel, 2001). Fish assemblages are an important component of aquatic ecosystems of the lake basin and recognized as sensitive indicators of habitat disturbances, environmental deterioration, and overall ecosystem productivity (Gregory et al, 2009).

Songkhla Lake, the largest lagoonal water body of Thailand, covering 8,729 sq. km of the Lake Basin or 1,017 sq. km of main lake water body, is shallow (depth 1-2 $\mathrm{m}$ ) and located on the lower east coast of the peninsular opening to the Gulf of Thailand between latitudes of $7^{\circ} 10^{\prime}$ to $7^{\circ} 50^{\prime} \mathrm{N}$ and longitudes of $100^{\circ} 05^{\prime}$ to $100^{\circ} 40^{\prime} \mathrm{E}$ (Figure 1). The Basin spans about 150 kilometers from north to south and about 65 kilometers from east to west. In addition, it has a multifunctional ecosystem ranging from tropical rain forest in upstream watershed area to a complex regime of water quality: freshwater, brackish and saline water with tidal and sea water intrusion influences from the Gulf of Thailand, runoff in monsoon seasons via twelve major rivers and various streams, and general drainage (Ratanachai and Kanchanasuwan, 2005). Tropical shallow lakes have high biodiversity and are also threatened globally from anthropogenic pressures and looming global climate change (Cairns and Lackey, 1992; Gopal, 2005; Enric et al, 2007). Similarity, Songkhla Lake, the largest lagoonal water body of Thailand, is one example of a tropical shallow lake in Southeastern Asia where facing critical euthophication and loss of fish population (Chesoh et al, 2008; Chesoh and Lim, 2008).

Monitoring of fish communities is advocated as an alternative to water quality monitoring for assessing ecosystem integrity. Actually, some fish species are ubiquitous in all habitats, mostly are migratory species: anadromous, catadromous, amphidromous, and oceanodromous, and so have specific habitats in Songkhla Lake (Choonhapran, 1996). 
Several multivariate methods have been used to explain the assemblage structures and distribution patterns of fish including multivariate analysis of variance (Gauch, 1982; Jackson and Harvey, 1989; Ahmadi-Nedushan, et al, 2006).Unfortunately, ecological data are also some of the most complex, especially at large spatial and temporal scales concerning species composition and environmental factors, to analyze while the available resources often limit sample sizes. Statistically, principal components analysis (PCA) is an effective method of addressing the problems of large numbers of variables, multicollinearity and small sample sizes and PCA is also the approach most widely used to reduce the size of complex ecological data without losing information inherent in the data (Brazner and Beals, 1997, Vaughan and Ormerod, 2005, Chen el al, 2008). In this study, we attempt to analyze fish assemblage patterns across time and across species in catch weights of fishery landings from Songkhla Lake over a four years period. We applied an interesting principal components regression approach, a regression-based method for successfully dealing with multicollinearity and giving results in estimation and prediction better than ordinary least squares (Fekedulegn et al, 2002), and revealed different temporal patterns across species. A form of ordination of regression coefficients was used to break the fish species into each distinct category, again using interesting methodology that is not widely presented in this discipline.

The advantage of this study is that it provides a statistically valid model for measurement of ordering of species. It can then be used to provide essential information for ecosystem-based approaches to fisheries management in tropical shallow lakes as Songkhla Lake of Thailand.

\section{Materials and Methods}

\section{Study area and data source}

Songkhla Lake is shallow (depth 1-2 m) and located on the lower east coast of the peninsular opening to the Gulf of Thailand between latitudes of $7^{\circ} 10^{\prime}$ to $7^{\circ} 50^{\prime} \mathrm{N}$ and longitudes of $100^{\circ} 05^{\prime}$ to $100^{\circ} 40^{\prime} \mathrm{E}$ (Figure 1). The Basin spans about 150 kilometers from north to south and about 65 kilometers from east to west. The water regime is complex, with tidal and sea water intrusion influences from the Gulf of Thailand, runoff in monsoon seasons via twelve major rivers and various streams, and general drainage.

There are ten major fish catch landing sites around the entire Songkhla Lake (Figure 1): Khu Tao (KT), Kuan Nieng (KN), Pak Pa Yoon (PY), Jong Ke (JK), Lampam (LP), Thale Noi (TN), Ra Nod (RN), Ko Yai (KY), Khu Kud (KK) and Hua Khao Daeng (HD). These sites were selected for data collection from January 2003 to September 2005 by the National Institute of Coastal Aquaculture (NICA) of the Department of Fisheries of Thailand, and thereafter to December 2006 by the current authors. Data include daily records of species, weight of the catch; gear types used, and catch value. Fish samples were classified following scientific taxonomic systematics. In addition, six categories were defined in terms of biological and habitat characteristics: vertebrate or invertebrate, and freshwater, estuarine and marine habitat, following Choonhapran, 1996.

\section{[Figure 1 about here]}

\section{Statistical Analysis}

Various statistical methods are available for clustering aquatic and marine organisms according their patterns of variation in space and time (Hawkins et al, 2000; Joy and Death, 2000; Fre'dou et al, 2006). Clarke and Warwick (1994) have outlined many of these methods in detail. They include data transformation using square roots, fourth roots or logarithms to remove skewness, principal components analysis of covariance matrices, and ordination procedures based on Bray-Curtis similarity indexes giving multidimensional scaling (MDS) plots used to cluster taxa in space and time.

In this study, seasonal comparisons of fish abundance in terms of catch weight were transformed by taking natural logarithms to address statistical analysis requirements. Since the total catch weight $(w t)$ for a given species in a specific month can be zero, we used the transformation

$$
y=\ln (w t+1) .
$$

After preliminary analysis of average monthly catch weights and corresponding monetary values for each species over the four-year period, and changes in the annual total catch weights for each species from one year to the next, we then fitted a linear regression model to the log-transformed monthly catches. The model used is an extension of two-way analysis of variance (ANOVA) incorporating additional terms based on a PCA (Good, 1969; Theil, 1983; McNeil and Tukey, 1973; Booth et al, 2002). Briefly, PCA is a multivariate technique for examining the relationship between several quantitative variables. Fisheries data are commonly subject to atypical errors; especially the large number of variables measured, highly skewed and zero-inflated, resulting in outliers when modeling. A PCA can be used to reduce the size of a large set of the original variables with a few PCs without losing information inherent in the data (Cooley and Lohnes, 1971; Jackson and Chen, 2003; Chen et al, 2008).

The two-way ANOVA method is the simplest regression model that allows for differences between species $(s)$ and month $(t)$, and is expressed as the additive combination 


$$
y_{s t}=\mu_{s}+v_{t},
$$

This model has $S+T$ parameters, where $S$ and $T$ denote the numbers of fish species groups and observation months, respectively. It assumes that the distribution of a species group over the observation period is the same for all species groups, only differing in level through the parameter ${ }_{s}$. Similarly the model assumes that the temporal pattern ${ }_{t}$ is the same for all species groups.

PCA was performed on the correlation matrix from the complete set on 127 fish species and 48 months (2003 to 2006) of catch weights data record. Equation (2) can be generalized to overcome these limitations by defining predictor variables as principal components $\beta_{t}^{(k)}$ defined as the eigenvectors of the covariance matrix of the data, ordered by decreasing size of their corresponding eigenvalues (see, for example, Johnson and Wichern, 1998), namely,

$$
y_{s t}=\mu_{s}+\sum_{k=1}^{m} \alpha_{s}^{(k)} \beta_{t}^{(k)}
$$

In this formulation the data matrix has successive months as its $T$ column variables and species as its $S$ rows and we assume $S>T$. Each eigenvector is scaled to have sum of squares equal to 1 and each pair of eigenvectors has sum of products equal to 0 . The number of predictor variables selected for inclusion in the model will depend on biological considerations and the amount of total sample variance explained. The model (eqn 3 ) has taxa-specific parameters encapsulating the variation in catch weights between species, and $m$ sets of coefficients $\alpha_{s}^{(k)}, k=1,2, \ldots, m$, denoting the extent to which the taxa have each of the $m$ specific time-changing patterns. A detailed analysis of the goodness-of-fit that highlights individual anomalies involves graphing residuals against corresponding quantiles from the standardized normal distribution.

An advantage of this method over the more conventional approaches described by Clarke and Warwick (1997) is that it routinely provides standard errors for the taxa-specific parameters $\alpha_{s}^{(k)}, k=1,2, \ldots, m$, which in turn provide a valid statistical basis for pairwise comparisons of species based on chi-squared tests on Euclidean distances between their locations in the corresponding $m$-dimensional space (Anderson and Millar, 2004; Anderson, 2005; Legendre, 2005; Legendre et al, 2005).

We used the R statistical system (Venables and Smith, 2004) for statistical model fitting, assessing the goodness-of-fit, and plotting data, fitted models, parameters and confidence intervals.

\section{Results}

\section{General catch information}

During the 4 year study period from January 2003 to December 2006, the mean annual catch in Songkhla Lake was 2,499.9 tonnes (range 2,388.2 - 2,643.0). These fish were caught by three major types of fishing gear: set-bag net (64.7\% of catch weight), followed by traps $(21.8 \%)$ and gill nets $(13.5 \%)$. The most productive fishing ground was the Lower Lake and this accounted for $60 \%$ of the total annual catch, comprising the major groups of high economic importance among brackish and marine fish species. The second most productive fishing ground was the Middle Lake (22.8\%), dominated by brackish and euryhaline fish, and followed by the Upper Lake (17.2\%) where the most abundant fish in the catch were freshwater fish species. A total of 127 aquatic animal species belonging to 68 families were caught.

Figure 2 shows normal quantile plots of the 6,096 (48 months by 127 species) monthly catch weights, before and after taking the transformation (1). The distribution of the raw weights is highly skewed (skewness coefficient 18.6) with the bulk of the catch weights less than $10,000 \mathrm{~kg}$. There were only two monthly catches for any species exceeding 50,000 $\mathrm{kg}$, namely 158,230 kg for greasy back shrimp in March 2003 and 149,240 kg for short-nose pony fish in March 2006. Even when these two outliers are omitted the skewness is still high, though reduced to 5.7. In contrast, the transformed catch weights are well approximated by a normal distribution.

\section{[Figure 2 about here]}

Figure 3 shows scatter plots of the average catch weights per month for each of the 127 species over a four year period of the study (horizontal axis) and corresponding monetary values (vertical axis). The data are plotted linearly in the left panel and using log scales on each axis in the right panel. The alphabetic symbols denote species with noteworthy characteristics (see Table 1 for codes).

\section{[Figure 3 about here]}

The monetary values (in 1,000s of Baht per tonne) are computed simply by multiplying the average catch weights by the corresponding price per unit in weight. The four leading species (Broadhead anchovy, Sumatran silverside, Chacunda gizzard shad, and Black tiger shrimp) accounted for $21.4 \%$ of the total catch weight, contributing $6.35,5.32$, 5.28 and 4.46 percent, respectively. In monetary value, the four most valuable species (Black Tiger Shrimp, Chacunda gizzard shad, Sumatran silverside, and Greasy Grouper) accounted for $23.7 \%$ of the total value of the catch, 
contributing 10.67, 5.05, 4.24, and 3.70 percent, respectively. The fish with highest value (the Greasy Grouper; 250 baht per kilogram) made a relatively small contribution to the catch weight (1.95 tonnes per month). In contrast, the leading species (Broadhead anchovy; 30 baht per kilogram and used mainly for duck food) made a lesser value contribution.

Annual changes in catch weights from 2003-2004, 2004-2005 and 2005-06 for each species are shown in Figure 4. Most estuarine (green colour) and marine (magenta) invertebrates exhibited overall serious decline from $8.3 \%, 0.4 \%$ and $13.4 \%$, followed by freshwater fish (blue and one brown colour) from $9.2 \%, 23.9 \%$ and $1.4 \%$, respectively, while estuarine (red) and marine (grey) vertebrate exhibited quite steady change in study period from $16.7 \%, 3.1 \%$ and $15.4 \%$.

\section{[Figure 4 about here]}

\section{Temporal patterns of catch species diversity}

The catch weights of 127 fish species in 48-monthly collections from 2003 to 2006 were modeled using Equation (3).

The goodness of fit of the model shows that $m=4$ components fit the data reasonably well, with $\mathrm{r}^{2}$ equal to 0.877 , although the residuals plot indicates some departure from the statistical normality assumption. The $r^{2}$ value for the simple additive model based on Equation (2) was 0.722, whereas the values for model (3) were 0.776, 0.829 and 0.859 for $m=1,2$ and 3, respectively. Because the four components each have sum of squares equal to 1 , the standard errors for the $\alpha_{s}^{(k)}$ coefficients are all the same, having estimated value 0.489 . (Note that the . coefficients reflect the overall catch weights without regard to month-by-month changes, and thus depend largely on the biomass of the various species in the Lake.)

From the distribution of eigenvector plots of each of four components $\beta_{t}^{(k)}, k=1,2,3$ and 4 , all series display interpretable temporal patterns. The first component shows a similar seasonal pattern for the whole period, with a spike occurring in March of each year. As shown in Figure 5, this pattern is characterized by species like Russell's snapper (Lutjanus russellii) Red tilapia; alien hybrid fish (Oreochromis niloticus $\quad X \quad O$. Mossambicus), and Horse face roach (Acantopsis choirorhynchos), as shown in Figure 6.

\section{[Figure 5 about here]}

\section{[Figure 6 about here]}

The second component also shows a regular seasonal pattern with peaks occurring in February and declining to a minimum in December of each year after dipping in March. There is no species that solely exhibits this pattern, but it is clearly present in Spanish mackerel (Scomberomorus commerson), Dusky Jack (Caranx sexfasciatus) and Indo-pacific mackerel (Scomberomorus guttatus), as Figure 7 shows. However, these three species have maximum catch weights in March, indicating sufficient presence of the first component to offset the second component's March dip.

Figure 8 also shows three species that are characterized by third model component pattern: three-spot gourami (Trichogaster trichopterus), Croaking gourami (Trichopsis vittata), and Snakeskin gourami (Trichogaster pectoralis) with peaks occurring in November and declining to a minimum in March and April of each year.

Figure 9 shows three species that to some extent follow the pattern of the fourth component are characterized as species black tiger prawn (Penaeus monodon), black lancer catfish (Mystus cavasius), and shortnose ponyfish (Leiognathus brevirostris) with the slightly increasing trend to the recent year. In contrast to the regular seasonal cycles exhibited by the first two principal components, the third and fourth components are less regular and show an upward trend that rises more sharply in the most recent year of the study period.

\section{[Figure 7 about here]}

\section{[Figure 8 about here]}

\section{[Figure 9 about here]}

Figure 10 shows scatter plots of the component coefficients $\alpha_{s}^{(k)}, k=14$, with the first two components plotted against each other on the left and the third and fourth on the right. In each plot pairs of points are joined if the distance between them in their four-dimensional space is not statistically significant at the $5 \%$ level. These p-values are the probabilities that a chi-squared statistic with 4 degrees of freedom exceeds $D /\left(2^{2}{ }^{2}\right)$, where $D$ is the Euclidean distance between the two points and is the common standard error of the $\alpha_{s}^{(k)}$ coefficients $(0.489)$.

\section{[Figure 10 about here]}

Two distinct clusters are clearly separated. The smaller cluster contains all freshwater species of vertebrates (blue symbols) and the single freshwater invertebrate (the giant freshwater prawn, brown, labeled g), whereas the second group contains all marine vertebrates (grey) and invertebrates (green). The estuarine species, red for invertebrates and magenta for vertebrates, appear in both clusters. 
The graph also shows a small disconnected cluster of marine vertebrates labeled by the symbols $\mathrm{T}$ (Spanish mackerel), $\mathrm{U}$ (dusky Jack) and e (Indo-Pacific mackerel), and singleton disconnected species labeled by the symbols V (greasy back shrimp), N (black lancer catfish), X (sand goby), a (spotted green pufferfish), b (cuttlefish), c (largescale tonguesole), $\mathrm{d}$ (spotted codlet) and $\mathrm{f}$ (lined silver grunt). The other points labeled with lower-case letters from $\mathrm{g}$ to $\mathrm{z}$ comprise all the remaining invertebrates, identified individually in Table 1, and includes all species not connected to other species of the same type within the same cluster.

\section{[Table 1 about here]}

Note that 12 of the 18 marine invertebrates are located within the smaller of the two clusters together with all the freshwater fish and two of the four estuarine invertebrates, whereas the other six are located in the larger cluster of estuarine and marine vertebrates.

\section{Discussion}

Our statistical model involves four components and gave an r-squared value of $87.7 \%$, with the first four components, $67.3 \%$ of the total variance could be explained. Although the model based on equation (2) had the correlation matrix from a data set of 127 species and 48 months and equation (3) had $m$ equal 4 whereas $S$ equal 127 that given a large number of parameters. Jong and Kotz (1999) reported the results of merging the concepts of PCA and multivariate regression showing the equivalence of optimization criterion involved in each one of them and also presented the scale invariance property of PCA derived by regression approach. This property allows us to rescale PCA without changing their capabilities. As previous mentions, PCA is a well known technique the aim of which is to synthesize huge amounts of numerical data by means of a low number of unobserved variables, called components while as least-squares techniques, commonly known, are not robust in the sense that outlying measurements can arbitrarily skew the solution from the desired solution (Hampel et al, 1986; Jolliffe, 1986). PCA is also of interest because they describe the predominant temporal (seasonal and trend) patterns present in the data. Even where trends are relatively small compared to seasonal patterns, they can highlight features of practical importance that might reflect lack of sustainability the fish catch or environmental degradation in the Lake. Throughout the study, the model was effective in clearly separating four distinctive fish community clusters. The first two components show purely seasonal patterns; the first pattern shows a spike occurring in March and the second has a peak in February with a gradual decline to December followed by a sharper increase. The third and fourth patterns show less pronounced seasonal effects with a trend increasing in the most recent year (2006).

Freshwater fish, together with black tiger shrimp, giant freshwater prawn, white seabass and mullets showed increasing catch weights, while other Penaeid shrimp (greasy back shrimp, green tiger prawn and small white shrimp), Mantis shrimp, Hamilton's thryssa (Thryssa dussumieri), and Chacunda gizzard shad decreased. In fact, the overall fishing effort in the Lake was fairly stable in time because both fishing gear and number of fishermen did not change substantially (NICA, 2007). Therefore, the increasing trend of black tiger prawn, giant freshwater prawn, white seabass and freshwater catfish might be due to increased seeding, stock enhancement and fishery rehabilitation projects by governmental agencies (NICA, 2007). However, increasing catch quantities may signal over-fishing and sizable quantities of by-catch fish caught unintentionally. Catch weights of large tooth flounder (Pseudorhombus arsius), bigeyed sand goby (Gnatholepis alliurus), short-nosed pony fish (Leiognathus brevirostris), naked-head glassy perchlet (Ambassis gymnocephalus) and starry triggerfish (Abalistes stellaris) increased whereas most estuarine and marine invertebrates and some high value freshwater fish had overall declines.

Plots of regression coefficients of principal components show two distinct clusters clearly separated between freshwater and saltwater fish. Some estuarine species (invertebrate and vertebrate) appear in both clusters because diadromous and euryhaline fish can adapt to a wide range of salinities and migrate between fresh and salt water (McDowall, 1995; Musick et al, 2001; Welcomme et al. 2006). For example, different life stages of Penaeid shrimp have distinct salinity preferences despite being marine invertebrate (Dall et al, 1990). Wirth et al (2004) reported that Penaeid shrimp can be raised in low salinity $(1.56 \mathrm{ppt})$ geothermal water at inland sites without adverse effect on growth and survival. Furthermore, these estuarine and marine invertebrate are usually found in shallow, semi-enclosed estuarine bays in the southern Gulf of Thailand (Hajisamae et al, 2006), and generally spawn and spend much of their adult life in saltwater or offshore, but enter the Lake seasonally (Yanez-Arancibia et al, 1994; Hajisamae et al, 2003; Khongchai et al, 2003).

The croaking gourami (Trichopsis vittata) is very sensitive to salinity change from freshwater (Liengpornpan et al, 2004), and appears at the bottom left of Figure 7 (labeled Z) within a sub-cluster of marine fish. The high salinity offshore marine vertebrates such as Spanish mackerel (Scomberomorus commerson), Dusky Jack (Caranx sexfasciatus), and Indopacific mackerel (Scomberomorus guttatus) are found from the edge of the continental shelf to shallow coastal waters (Froese and Pauly, 2004), and appear at the top right of Figure 7 (labeled T, U and e, respectively). The spotted green pufferfish (a), spotted codlet (d), lined silver grunt (f), Greasy back shrimp (V) and Sand goby (X) appear as singletons disconnected to other major marine vertebrates, and have a less regular catches with substantial seasonal variation in monthly catch weights. 
The salinity in various locations in the Lake also depends on the season, dropping substantially during the heavy monsoon that usually occurs from October to December (Chesoh and Lim, 2008). These seasonal patterns affect fish distribution and food web structure from different habitats (Winemiller and Jepsen, 1998; Thompson and Townsend, 1999; Gibson et al, 2000), and encourage major events in the life cycle of each species that take advantage of increased productivity. Alien fish species, namely Mozambique tilapia, hybrid red tilapia and African walking catfish, are increasingly found in the Lake and might destroy native species or alter the gene pool (Balon and Bruton, 1986; Salonen and Mutenia, 2007).

This study reflects the broad band of fish assemblage distribution according to distance from the Lake's junction with the Gulf of Thailand from saline to brackish water to freshwater, with some species confined to specific salinity bands, some euryhaline marine invertebrate species preferring to feed in low salinity biotopes, and others dwelling everywhere. Generally, the lake fishing is based on trapping the fish on their passage from their feeding ground to spawning and nursery grounds (Katselis et al, 2003). This seasonal pattern reinforces that these migratory fish species in tropical shallow lake need to be managed for sustaining their diversities.

Various manuals commonly used multivariate analysis package in ecology, in summarizing the methods that are currently used for analyzing fish community data. However, these methods are most commonly used for abundance as measured using counts of fish, presence or absences, or semi-quantitative measures, rather than monthly catch weights. Our model presents a valid statistical basis for pairwise comparisons of species using chi-squared tests on Euclidean distances in the ordination space, regression coefficients was used to break the fish species into distinct categories. However, the study does not take account of environmental factors and types of fishing gear used. Generally, multivariate regression models are performed by applying criterion of minimizing residual sum of square without employing the concepts of eigenvectors and eigenvalues. PCR purpose is not to obtain the best of the linear transformation matrix but rather to solve the problems of multicollinearity among predictor variables (Jong and Kotz, 1999). Therefore, application of linear regression approach to principal component analysis in fishery data will be widespread and increasing. We confirm that the robust techniques like those proposed will prove useful as linear models are used to represent more realistic data sets.

\section{Acknowledgements}

We would like to express our sincere gratitude to Prof. Don McNeil, Apiradee Lim, and Phattrawan Tongkumchum for their invaluable assistance, encouragement and helpful guidance. We also thank the Songkhla Provincial Fisheries Office, the Phattalung Provincial Fisheries Office and the National Institute of Coastal Aquaculture (NICA), Department of Fisheries, Thailand, for allowing us to use their data.

\section{References}

Anderson, M. J. \& Millar, R. B. (2004). Spatial variation and effects of habitat on temperate reef fish assemblages in northeastern New Zealand. Journal of Experimental Marine Biology and Ecology, 305, 191-221.

Anderson, M. J. (2005). Distance-Based Tests for Homogeneity of Multivariate Dispersions. Biometrics, 62, 245-253.

Balon, E. K. \& Bruton, M. N. (1986). Introduction of alien species of why scientific advice is not heeded. Environmental Biology of Fishes, 16, 225-230.

Booth, H., Maindonard, J. \& Smith, L. (2002). Applying Lee-Carter under conditions of variable mortality decline. Population Studies, 56, 352-336.

Brazner, J. C. \& Beals, E.W. (1997). Patterns in fish assemblages from coastal wetland and beach habitats in Green Bay, Lake Michigan: a multivariate analysis of biotic and abiotic forcing factors. Canadian Journal of Fisheries and Aquatic Sciences, 54, 1743-1759.

Cairns, M. A. \& Lackey, R. T. (1992). Biodiversity and management of natural resources: the issues. Fisheries, 17, 6-10.

Chen, Y., Chen, X. \& Xu, L. (2008). Developing a size indicator for fish populations. Scientia Marina, 72, 221-229.

Chesoh, S. \& Lim, A. (2008). Forecasting fish catches in the Songkhla Lake basin. ScienceAsia, 34, 335-340.

Chesoh, S., Lim, A. \& Tongkumchum, P. (2008). Model predicting Chlorophyll-a concentration as an index of potential occurrence of eutrophication in Songkhla Lake, Thailand. In: Sengupta, M. \& Dalwani, R. (Eds), pp 834-839. In Taal 2007: The 12th World Lake Conference, 28 October - 2 November 2007, Jaipur, India.

Choonhapran, A. (1996). Study on Fisheries Resources and Population Changes in Songkhla Lake: Case study on 3 Fishing Gears. Technical paper 18/1996, National Institute of Coastal Aquaculture (NICA), Songkhla, Thailand, pp $1-32$.

Clarke, K. R. \& Warwick, R. M. (1994). Change in Marine Communities: An Approach to Statistical Analysis and Interpretation. Plymouth: PRIMERE Ltd, pp 1-144. 
Cooley, W. W. \& Lohnes, P. R. (1971). Multivariate Data Analysis. New York: John Wiley \& Sons.

Dall, W., Hill, B. J., Rothlisberg, P. C. \& Staples, D. J. (1990). Biology of the Penaeidae. In: Blaxter JHS, Southward AJ (Eds), Advances in Marine Biology, vol 27. London, UK: Academic Press, pp 1-489.

Enric, S., Knowlton, N. (Lead Authors) \& Duffy, J. D. (Topic Editor). (2007). "Global marine biodiversity trends" In: encyclopedia of Earth. Eds. Cutler J. Cleveland (Washington, DC: Environmental Information Coalition, National Council for Science and the Environment). Available: http://www.eoearth.org/article/Global_marine_biodiversity_trends (March 6, 2008)

Frédou, T., Ferreira, B. P. \& Letourneur, Y. (2006). A univariate and multivariate study of reef fisheries off Northeastern Brazil. Journal of Marine Science, 63, 883-896.

Fekedulegn, B. D., Colbert, J. J., Hicks, R.. R. Jr. \& Schuckers, M. E. (2002). Coping with multicollinearity: an example on application of principal components regression in dendroecology. [Online] Available: http://www.fs.fed.us/ne (February 13, 2009)

Froese, R. \& Pauly, D. (eds). (2004). FishBase. World Wide Web electronic publication version (10/2004). [Online] Available: http://www.fishbase.org (January 23, 2008)

Gauch, H. G., Jr. 1982. Multivariate Analysis in Community Structure. Cambridge University Press, Cambridge.

Gibson, G. R., Bowman, M.L., Gerritsen, J. \& Snyder, B. D. (2000). Estuarine and Coastal Marine Waters: Bioassessment and Biocriteria Technical Guidance. EPA 822-B-00-024. Office of Water, Washington, DC: US Environmental Protection Agency.

Good, I. J. (1969). Some Applications of the Singular decomposition of a matrix. Technometrics, 11, 823-831.

Gopal, B. (2005). Does inland aquatic biodiversity have a future in Asian developing countries?. Hydrobiologia, 542, $69-75$.

Gregory, S., Wildman, R., Ashkenas, L., Wildman, K. \& Haggerty, P. (2009). Fish Assemblages. [Online] Available : http://www.fsl.orst.edu/pnwerc/wrb/Atlas_web_compressed/4.Biotic_Systems/4d.fish_assmbl_web.pdf (February 13, 2009)

Hajisamae, S., Choua, L. M. \& Ibrahimb, S. (2003). Feeding habits and trophic organization of the fish community in shallow waters of an impacted tropical habitat. Estuarine, Coastal and Shelf Science, 58, 89-98.

Hajisamae, S., Yeesin, P. \& Chaimongkol, S. (2006). Habitat utilization by fishes in a shallow, semi-enclosed estuarine bay in southern Gulf of Thailand. Estuarine, Coastal and Shelf Science, 68, 647-655.

Hampel, F., Ronchetti, E., Rousseeuw, P. \& Stahel, W. (1986). Robust Statistics: The Approach Based on Influence Functions. New York: John Wiley \& Sons.

Hawkins, C. P., Norris, R. H., Hogue, J. N. \& Feminella, J. W. (2000). Development and evaluation of predictive models for measuring the biological integrity of streams. Ecological Applications, 10, 1456-1477.

Hynes, H. B. N. (1970). The Ecology of Running Waters. Liverpool, Great Britain: Liverpool University Press, pp $1-555$.

ILEC. (2005). Managing Lakes and their Basins for Sustainable Use: A Report for Lake Basin Managers and Stakeholders. Kusatsu, Japan: International Lake Environment Committee Foundation, pp 1-146.

Jackson, D. A. \& Chen, Y. (2003). Robust principal component analysis of ecological data. Environmetrics, 14, 1-11.

Jackson, D.A. \& Harvey, H. H. (1989). Biogeographic associations in fish assemblages: local versus regional processes. Ecology, 70, 1472-1484.

Johnson, R.A. \& Wichern, D.W. (1998). Applied multivariate statistical analysis. (4th ed.). New Jersey: Prentice Hall, pp 1-816.

Jolliffe, I. T. (1986). Principal Component Analysis. New York: Springer-Verlag.

Jong, J. \& Kotz, S. (1999). On a Relation between Principal Components and Regression Analysis. The American Statistician, 53, 349-351.

Joy, M. K. \& Death, R. G. (2000). Development and application of a predictive model of riverine fish community assemblages in the Taranaki region of the North Island, New Zealand. New Zealand Journal of Marine Freshwater Research, 34, 241-252.

Katselis, G., Koutsikopoulos, C., Dimitriou, E. \& Rogdakis, Y. (2003). Spatial patterns and temporal trends in the fishery landings of the Messolonghi-Etoliko lagoon system (western Greek coast). Scientia Marina, 67, 501-511. 
Khongchai, N., Vibunpant, S., Eiamsa-ard, M. \& Supongpan, M. (2003). Preliminary analysis of demersal fish assemblages in coastal waters of the Gulf of Thailand, In Silvestre G, Garces L, Stobutzki I, Ahmed M, Valmonte-Santos RA, Luna C, Lachica-Alino L, Munro P, et al (eds) Assessment, Management and Future Directions for Coastal Fisheries in Asian Countries. Worldfish Center Conference Proceedings 67, pp 249-262.

Legendre, P. (2005). Species associations: the Kendall coefficient of concordance revisited. Journal of Agricultural, Biological, and Environmental Statistics, 10, 226-245.

Legendre, P., Borcard, D. \& Peres-neto, P. (2005). Analyzing beta diversity: partitioning the spatial. Ecological Monographs, 75, 435-450.

Liengpornpan, S., Jaroensutasinee, M. \& Jaroensutasinee, K. (2004). Habitat Characteristics of Croaking Gouramis (Trichopsis Vittata). Organizing Committee of 30th Congress on Science and Technology of Thailand. [Online] Available: http://www.scisoc.or.th/stt/30/sec_b/paper/stt30_B0040.pdf (May 10, 2008).

McDowall, R. M. (1995). Seasonal pulses in migrations of New Zealand diadromous fish and the potential impacts of river mouth closure. New Zealand Journal of Marine and Freshwater Research, 29, 517-526.

McNeil, D. R. \& Tukey, T. W. (1973). Higher-order diagnosis of two-way tables, illustrated on two sets of demographic empirical distributions. Biometrics, 31, 487-510.

Musick, J. A., Harbin, M. M., Berkeley, S.A., Burgess, G. H., Eklund, A. M., Findley, L., Gilmore, R. G., Golden, J. T., et al. (2001). Marine, Estuarine, and Diadromous Fish Stocks at Risk of Extinction in North America (Exclusive of Pacific Salmonids). Fisheries, 25, 6-30.

Ahmadi-Nedushan, B., St-Hilaire, A., Bérubé, M., Robichaud, E., Thiémonge, N. \& Bobée, B. (2006). A review of statistical methods for the evaluation of aquatic habitat suitability for instream flow assessment. River Research and Applications, 22, 503-523.

National Institute of Coastal Aquaculture (NICA). (2007). Annual Report 2006. National Institute of Coastal Aquaculture. Department of Fisheries, Ministry of Agriculture and Co-operatives, Thailand. pp 1-102.

Ratanachai, C. \& Kanchanasuwan, W. (2005). Master Plan for Songkhla Lake Basin Management, Executive Summary (Team leader). Final report, Prince of Songkla University, Songkhla, Thailand, pp 1-59.

Salonen, E. \& Mutenia, A. (2007). Alien fish species in northernmost Finland. Helsinki. Finfish Game and Fisheries Research Institute, pp 1-16.

Theil, H. (1983). Linear Algebra and Matrix Methods in Econometrics. North-Holland Publishing Company, pp 1-64.

Thompson, R. M. \& Townsend, C. R. (1999). The effect of seasonal variation on the community structure and food-web attributes of two streams: implication for food-web science. OIKOS, 87, 75-88.

Venables, W. N. \& Smith, D. M. The R Development Core Team. (2004). An Introduction to R: Notes on R: A Programming Environment for Data Analysis and Graphics Version 2.6.2 (2008-2-08). [Online] Available: http://cran.r-project.org/doc/manuals/R-intro.pdf. (March 3, 2008)

Vaughan, I. P. \& Ormerod, S. J. (2005). Increasing the value of principal components analysis for simplifying ecological data: a case study with rivers and river birds. Journal of Applied Ecology, 42: 487-497.

Welcomme, R. L., Winemillerb, K. O. \& Cowx, I. G. (2006). Fish environmental guilds as a tool for assessment of ecological condition of rivers. River Research and Applications, 22, 377-396.

Wetzel, R.G. (2001). Limnology. Lake and River Ecosystems. (3rd ed.). San Diego: Academic Press.

Winemiller, K. O. \& Jepsen, D. B. (1998). Effects of seasonality and fish movement on tropical river food webs. Journal of Fish Biology, 53, 267-296.

Wirth, F. F., Dugger, D. M. \& Creswell, L. (2004). Commercial Scale Penaeid Shrimp Demonstration in Inland Freshwater Systems. Final Project Report for Cost Reimbursable Contract 007199 between FL DACS, Division of Aquaculture and University of Florida, IFAS. [Online] Available: http://Floridaaquaculture.com/publications/Penaeid\%20Shrimp\%20Report.pdf (February 25, 2008)

Yanez-Arancibia, A., Dominguez, A. L. L. \& Pauly, D. (1994). Coastal Lagoons as Fish Habitats, In Kjerjve B (ed) Coastal lagoon Processes. Amsterdam: Elservier Science Publishers, pp 363-376. 
Table 1. Species disconnected from a single cluster

\begin{tabular}{|c|c|c|c|c|}
\hline Label & Scientific name & Common name & family & Category \\
\hline $\mathrm{A}$ & Penaeus monodon & Black tiger shrimp & Penaeidae & Marine invertebrate \\
\hline $\mathrm{B}$ & Anodontostoma chacunda & Chacunda gizzard shad & Clupeidae & Marine vertebrate \\
\hline $\mathrm{C}$ & Hypoatherina valenciennei & Sumatran silverside & Atherinidae & Marine vertebrate \\
\hline $\mathrm{D}$ & Epinephelus coioides & Greasy grouper & Serranidae & Marine vertebrate \\
\hline E & Stolephorus $s p$ & Broadhead anchovy & Engraulidae & Estuarine vertebrate \\
\hline $\mathrm{F}$ & Trichogaster pectoralis & Snakeskin gourami & Osphronemidae & Freshwater vertebrate \\
\hline G & Portunus pelagicus & Blue swimming crab & Potunidae & Marine invertebrate \\
\hline $\mathrm{H}$ & Cyclocheilichthys apogon & Beardless barb & Cyprinidae & Freshwater vertebrate \\
\hline I & Eleutheronema tetradactylum & Fourfinger threadfin & Polynemidae & Marine vertebrate \\
\hline $\mathrm{J}$ & Puntius partipentazona & Sumatran tiger barb & Cyprinidae & Freshwater vertebrate \\
\hline $\mathrm{K}$ & Escualosa thoracata & Thai anchovy & Clupeidae & Estuarine invertebrate \\
\hline $\mathrm{L}$ & Johnius dussumieri & Sin croaker & Sciaenidae & Marine vertebrate \\
\hline M & Abalistes stellaris & Starry triggerfish & Balistidae & Marine vertebrate \\
\hline $\mathrm{N}$ & Mystus cavasius & Black lancer catfish & Bagridae & Freshwater vertebrate \\
\hline $\mathrm{O}$ & Lactarius lactarius & False trevelly & Lactariidae & Marine vertebrate \\
\hline $\mathrm{P}$ & Pseudorhombus arsius & Large tooth flounder & Paralichthyidae & Marine vertebrate \\
\hline Q & Lutjanus russellii & Russell's snapper & Lutjanidae & Marine vertebrate \\
\hline $\mathrm{R}$ & $\begin{array}{l}\text { Oreochromis niloticus } X \\
\text { O. Mossambicus }\end{array}$ & Red tilapia (hybrid tilapia) & Cichlidae & Marine vertebrate \\
\hline $\mathrm{S}$ & Acantopsis choirorhynchos & Horse face roach & Cobitidae & marine vertebrate \\
\hline $\mathrm{T}$ & Scomberomorus commerson & Spanish mackerel & Scombridae & Marine vertebrate \\
\hline $\mathrm{U}$ & Caranx sexfasciatus & Dusky Jack & Carangidae & Marine vertebrate \\
\hline $\mathrm{V}$ & Metapenaeus ensis & Greasy back shrimp & Penaeidae & Estuarine invertebrate \\
\hline W & Parapenaeopsis hardwickii & Spear shrimp & Penaeidae & Marine invertebrate \\
\hline $\mathrm{X}$ & Glossogobius aureus & Sand goby, Golden goby & Gobiidae & Estuarine vertebrate \\
\hline $\mathrm{Y}$ & Oreochromis mossambicus & Mozambique tilapia & Cichlidae & Marine vertebrate \\
\hline Z & Trichopsis vittata & Croaking gourami & Osphronemidae & Freshwater vertebrate \\
\hline a & Tetraodon nigroviridis & Spotted green pufferfish & Tetraodontidae & Marine vertebrate \\
\hline $\mathrm{b}$ & Sepioteuthis lessoniana & Cuttlefish & Loliginidae & Marine invertebrate \\
\hline $\mathrm{c}$ & Aseraggodes dubius & Largescale tonguesole & Soleidae & Marine vertebrate \\
\hline $\mathrm{d}$ & Bregmaceros mcclellandi & Spotted codlet & Bregmacerotidae & Marine vertebrate \\
\hline e & Scomberomorus guttatus & Indo-pacific mackerel & Scombridae & Marine vertebrate \\
\hline $\mathrm{f}$ & Pomadasys kaakan & Lined silver grunt & Haemulidae & Marine vertebrate \\
\hline g & Macrobrachium rosenbergii & Giant freshwater prawn & Palaemonidae & Freshwater invertebrate \\
\hline $\mathrm{h}$ & Macrobrachium equidens & Dwarf prawn & Palaemonidae & Estuarine invertebrate \\
\hline $\mathrm{i}$ & Metapenaeus ensis & Bird shrimp & Penaeidae & Estuarine invertebrate \\
\hline $\mathrm{j}$ & Acetes $s p$ & Acetes & Sergestidae & Estuarine invertebrate \\
\hline $\mathrm{k}$ & Cloridopsis dubia & Mantis shrimp & Squillidae & Marine invertebrate \\
\hline 1 & Penaeus merguiensis & Banana prawn & Penaeidae & Marine invertebrate \\
\hline $\mathrm{m}$ & Penaeus semisulcatus & Green tiger prawn & Penaeidae & Marine invertebrate \\
\hline $\mathrm{n}$ & Metapenaeus lysianassa & Small white shrimp & Penaeidae & Marine invertebrate \\
\hline $\mathrm{o}$ & Parapocryptes serperaster & Pink borrowing goby & Gobiidae & Marine vertebrate \\
\hline $\mathrm{p}$ & Triacanthus biaculeatus & Short-nosed tripodfish & Triacanthidae & Marine vertebrate \\
\hline $\mathrm{q}$ & Oxyurichthys microlepis & Smallscaled goby & Gobiidae & Estuarine vertebrate \\
\hline $\mathrm{r}$ & Terapon jarbua & Thornfish & Terapontidae & Marine vertebrate \\
\hline $\mathrm{s}$ & Trichiurus lepturus & Largehead hairtail & Trichiuridae & Marine vertebrate \\
\hline $\mathrm{t}$ & Uroteuthis duvauceli & Indian squid & Loliginidae & Marine invertebrate \\
\hline $\mathrm{u}$ & Metapenaeopsis stridulans & Fiddler shrimp & Penaeidae & Marine invertebrate \\
\hline $\mathrm{v}$ & Metapenaeus brevicornis & Yellow shrimp & Penaeidae & Marine invertebrate \\
\hline $\mathrm{w}$ & Octopus dollfusi & Dollfus' Octopus & Octopodidae & Marine invertebrate \\
\hline $\mathrm{x}$ & Leiognathus brevirostris & Short-nosed ponyfish & Leiognathidae & Estuarine vertebrate \\
\hline
\end{tabular}




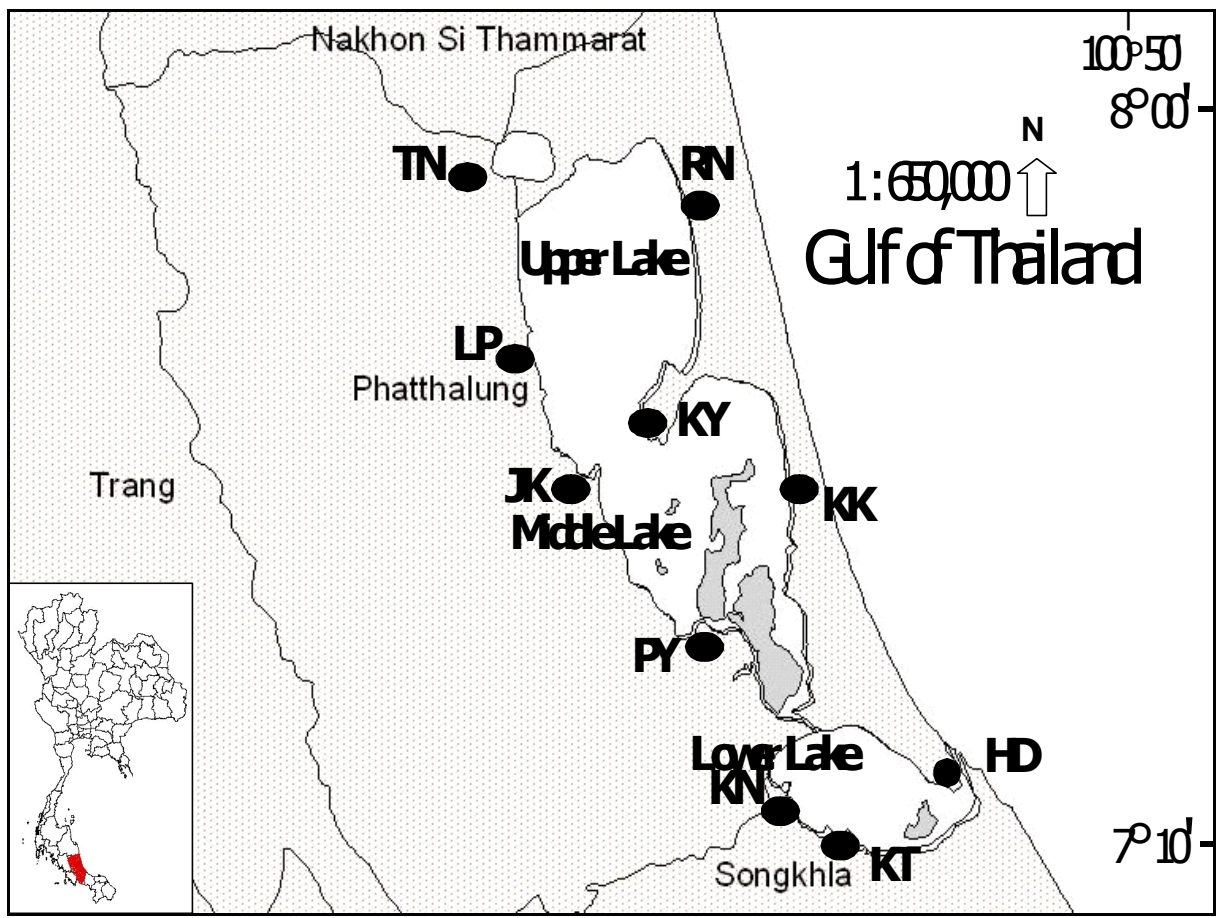

Figure 1. Map of Songkhla Lake and ten fish catch landing sites for data collection
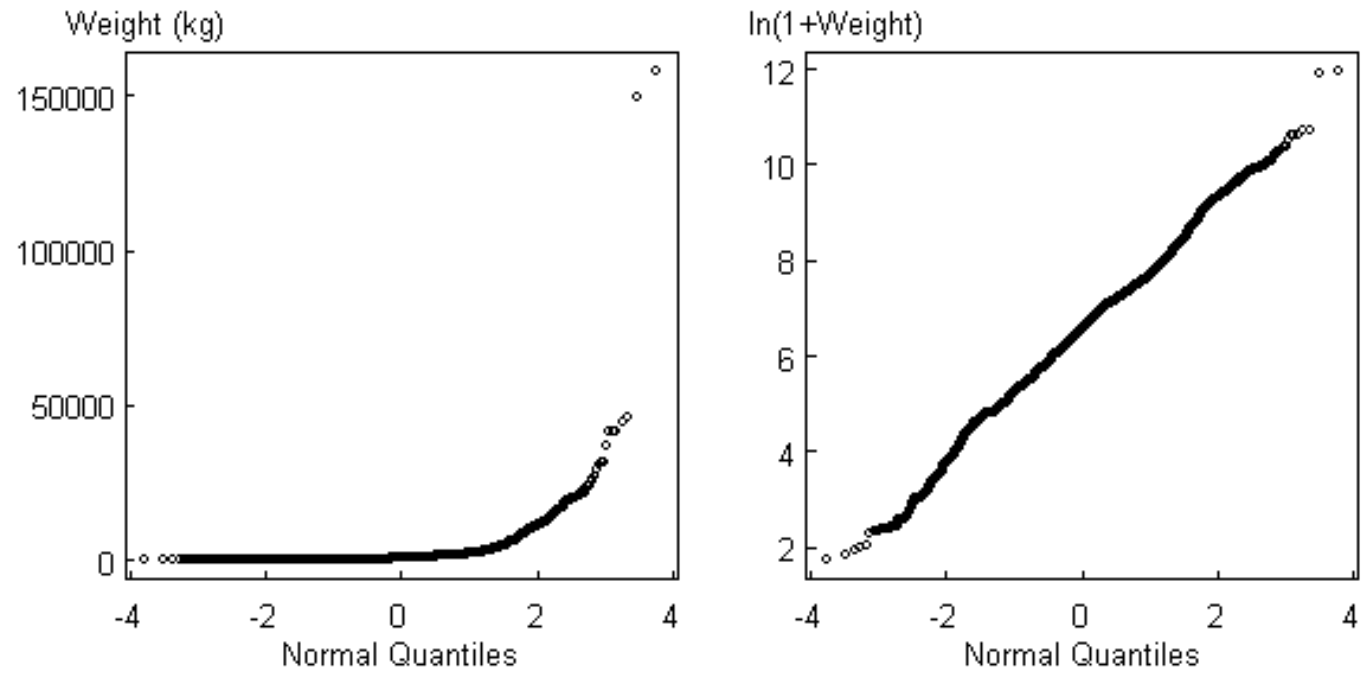

Figure 2. Distributions of monthly catch weights before and after data transformation 

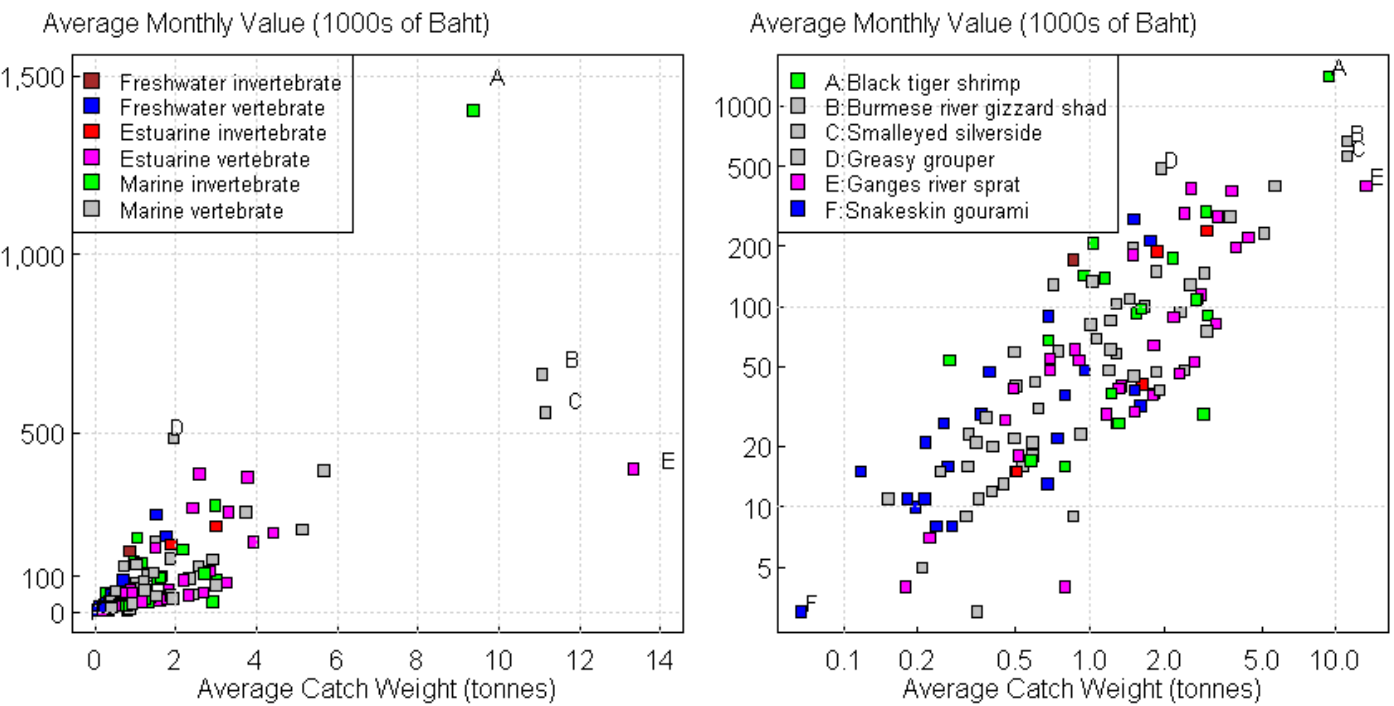

Figure 3. Scatter plots of average monthly catch weights and monetary value for each species
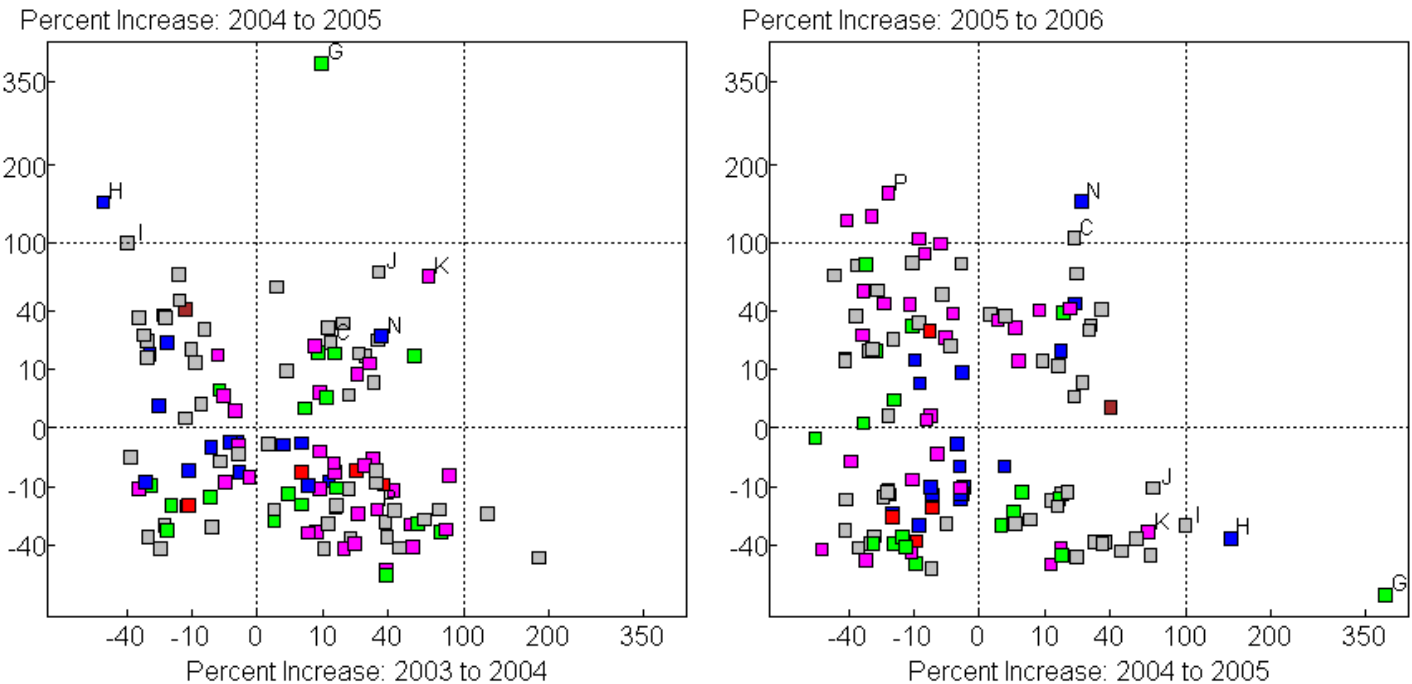

Figure 4. Annual catch weight changes for each species from 2003-2004, 2004-2005 and 2005-06 


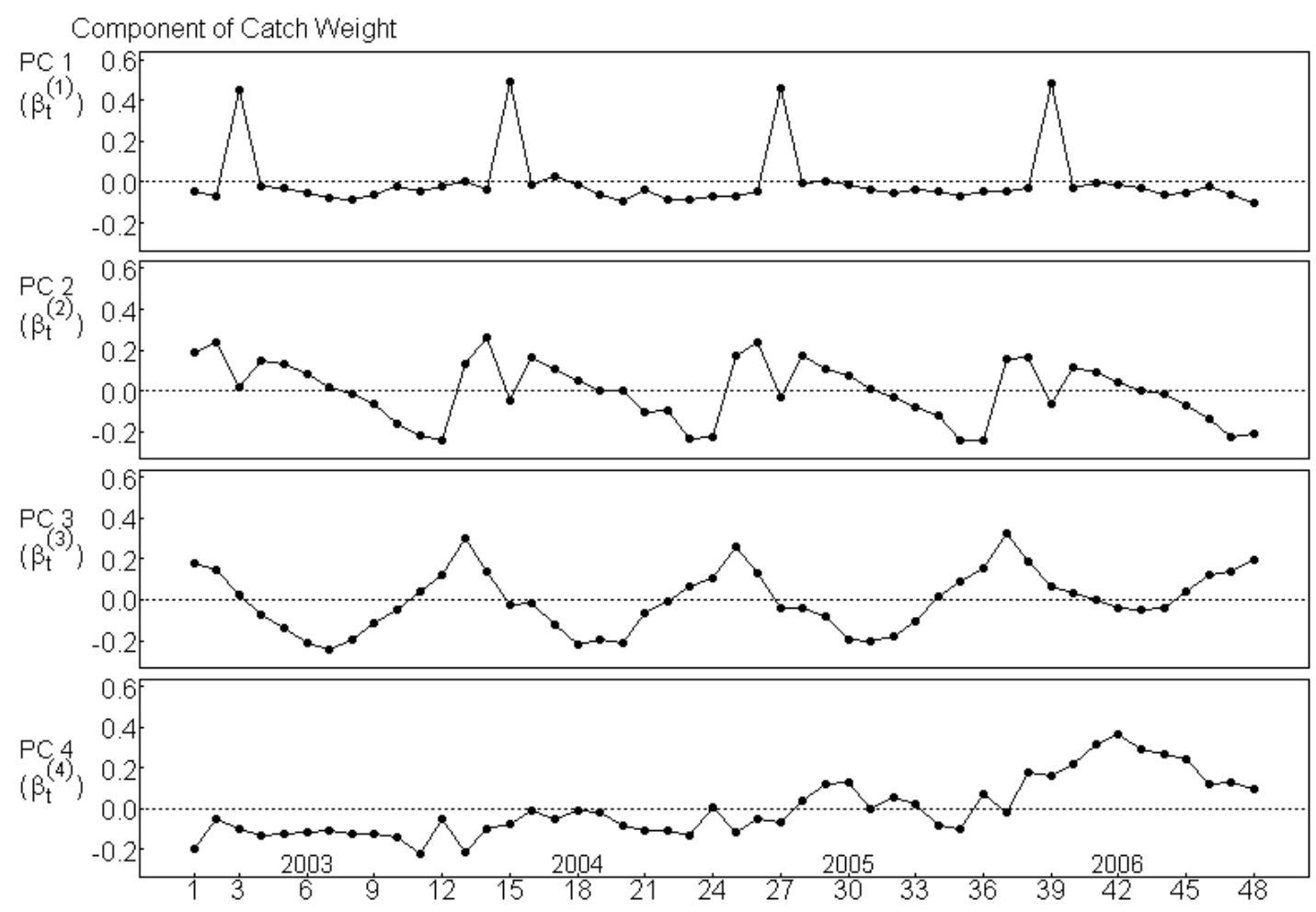

Figure 5. Plot of first four principal components of catch weights

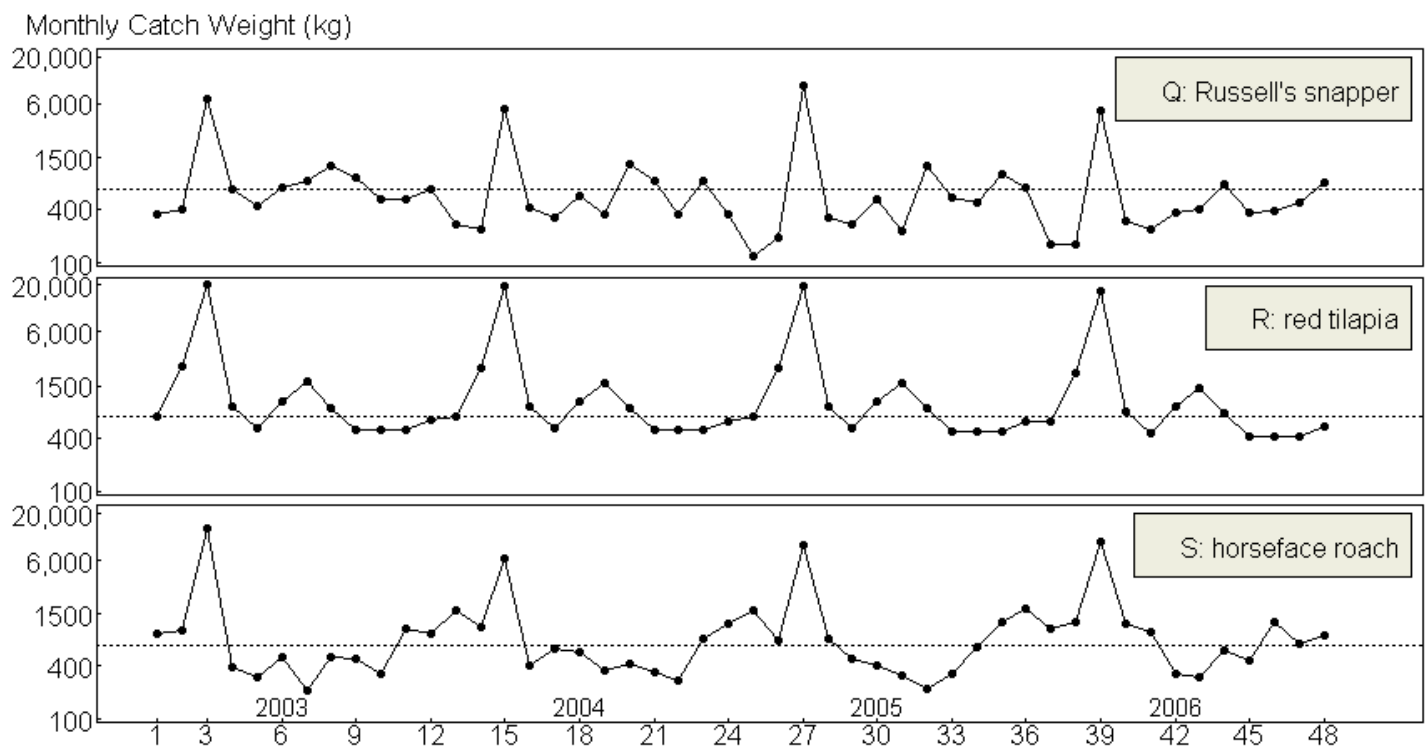

Figure 6. Monthly catch weights of species characterized by first model component 
Monthly Catch Weight $(\mathrm{kg})$

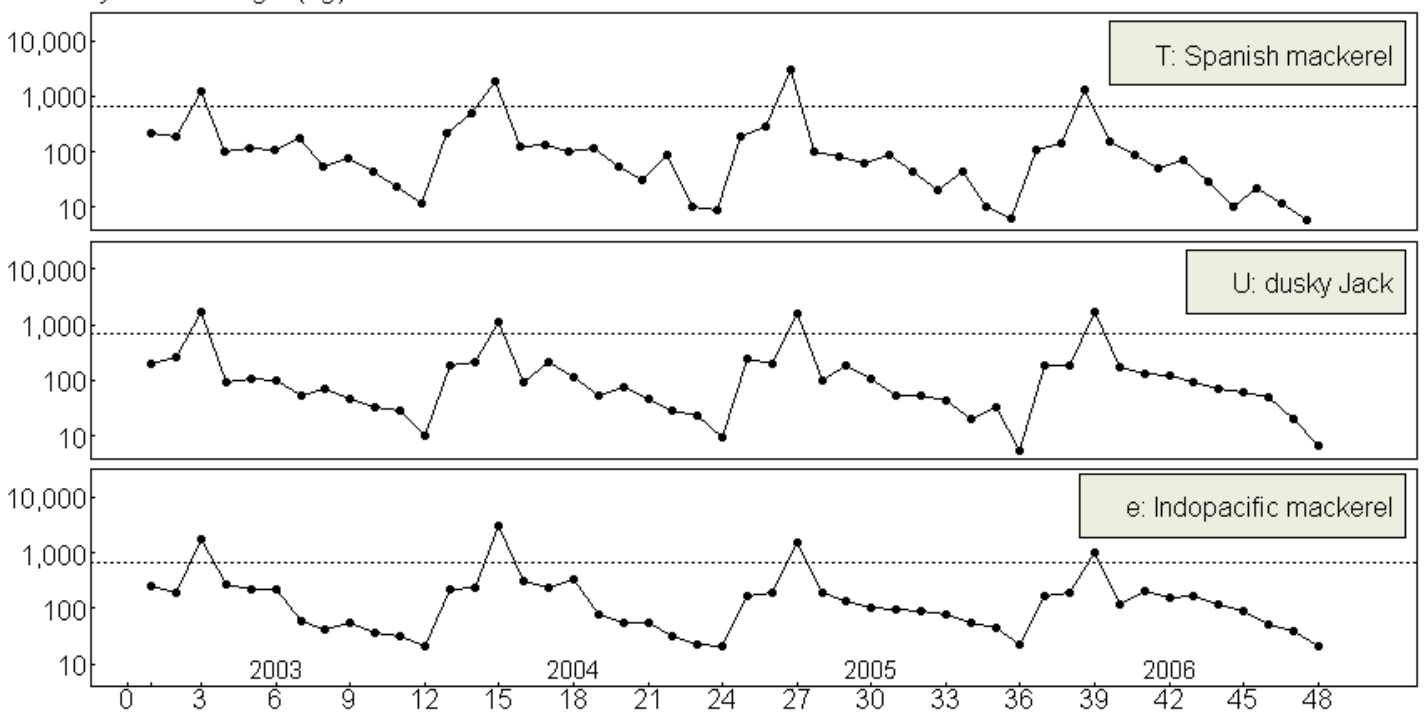

Figure 7. Monthly catch weights of species containing second model component

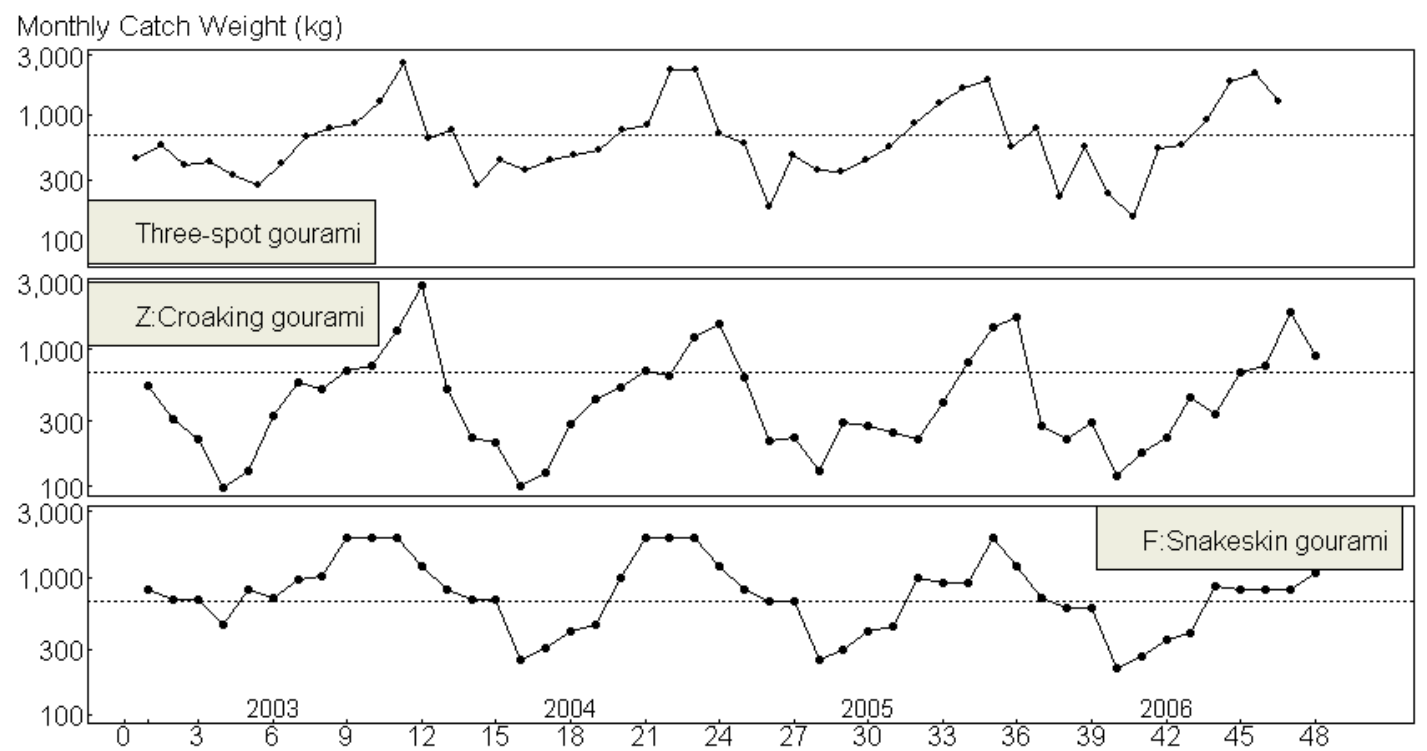

Figure 8. Monthly catch weights of species containing third model component 
Monthly Catch Weight $(\mathrm{kg})$

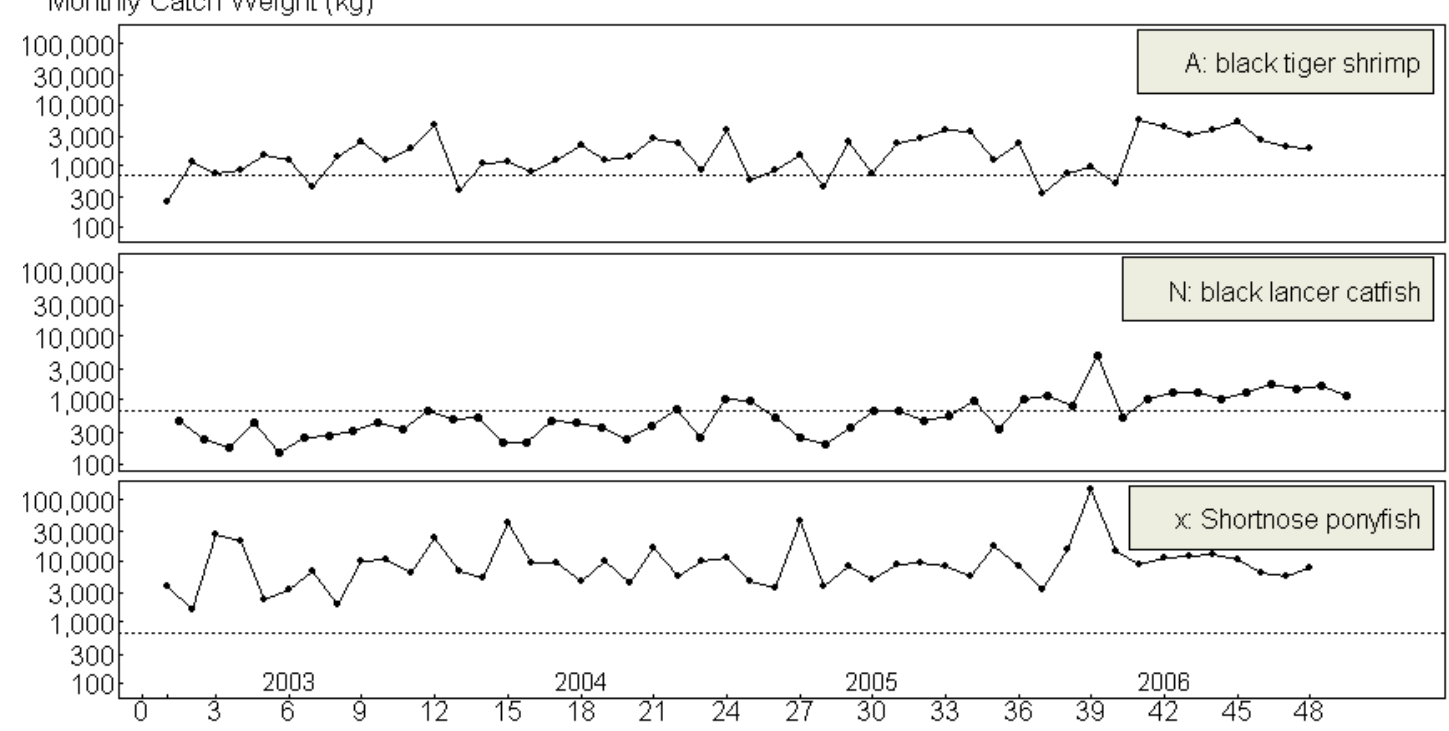

Figure 9. Monthly catch weights of species containing forth model component

Coefficient of Component 2

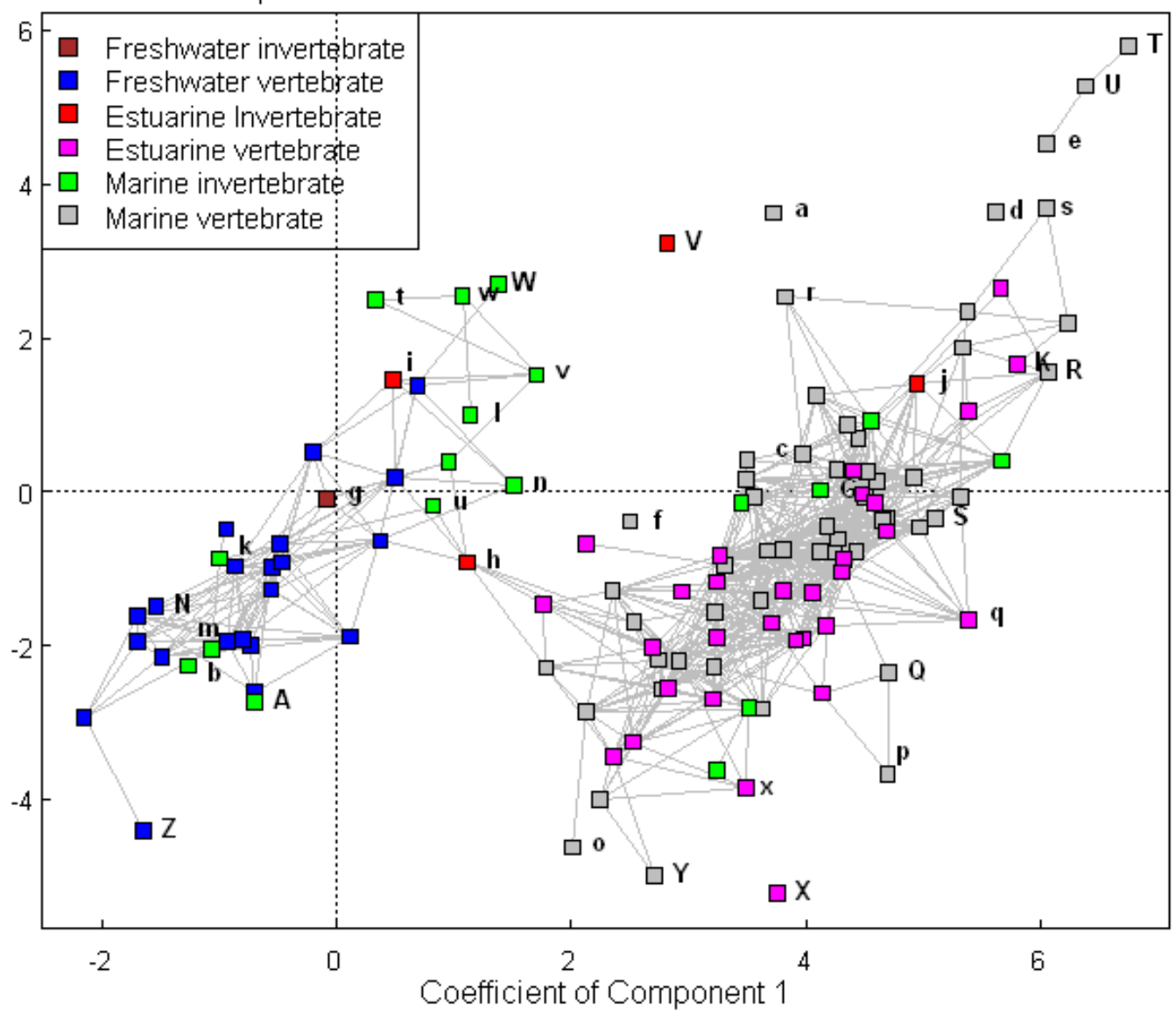

Figure 10. Scatter plots of regression coefficients of principal components 


\title{
Optimization of the Technology of Wire Drawing
}

\section{Based on Finite Element Modeling}

\author{
Gui'e Xu \\ School of Architecture Engineering \\ Nantong University \\ Jiangsu, China \\ Tel: 86-513-8501-2655 E-mial: xuge@ntu.edu.cn \\ Feng Fang \\ College of Material Science and Engineering \\ Southeast University \\ Jiangsu, China \\ Zhaoxia Li \\ College of Civil Engineering \\ Southeast University \\ Nanjing, Jiangsu, China
}

\begin{abstract}
The initiation and propagation rule of central flaw during wire drawing was modeled with the finite element method and theory of fracture mechanics. It is shown that: J-integral value increased with the increasing of the angle of drawing die, the friction coefficient between drawing die and wire and the initial dimension of the flaw. When friction coefficient equaled 0.1, J-integral value round the crack tip with the same flaw decreased with the decreasing of the angle of the die. J-integral value changed slightly and tended to be a constant value when the angle reached to $8^{\circ}$. The calculated results were then applied to improve the optimization of the technology for wire drawing.
\end{abstract}

Keywords: Drawing, Steel wire, Central flaw, Critical size, J-integral value

Wire drawing, an important means of cold forming process of forming, has received a wide range of applications in the production. Wire drawing process is very complex material deformation process, has many impact factors. Not only has material organizational changes (including the organization of deformation, the formation of micro-texture, etc.), also includes the process of drawing rod temperature, surface condition changes. Their drawing process, the deformation of the wire in the drawing process is mainly affected by four factors, die angle of the mold, the friction coefficient between materials and the mold, area shrinkage rate and hardening coefficient (Avitzur. B, 1968)(Z. Zimerman, and B. Avitzur, 1970)(Yu Wanhua, Huan Guanchang, Yuan Kang, 1994)(J. Luksza, J. Majta, M. Burdek, et al. 1998)( R. K. Chin, P.S. Steif, 1995). Configuration of these factors is reasonable or not drawing a direct impact on the quality of the process. Unreasonable configuration parameters are usually makes the formation of the core wire break or even crack in wire drawing process. High rate of broken wires in drawing has been an issue of great concern in the production.

A lot of study has been done about the deformation of materials in wire drawing process. Zimerman and Avitzur (Avitzur. B, 1968)(Z. Zimerman, and B. Avitzur, 1970) studied the effect of strain hardening on central bursting defects in drawing and extrusion. YU Wan-hua etc. (Yu Wanhua, Huan Guanchang, Yuan Kang, 1994) calculated the security zone map in which the core cracks are prevented. Luksza (J. Luksza, J. Majta, M. Burdek, et al. 1998), Chin (R. K. Chin, P.S. Steif, 1995), Ko (Ko. Dae-Cheol, Kim.Byung-Min, 2000), Komori (Kazutake. Komori, 2003) also took some numerical simulation analysis on the material deformation state in drawing process. These numerical simulation analyses may be effective, but the complexity of calculating was burdensome, and does not take into account the materials deformation state after crack initiation. In recent years, based on the finite element method of calculation software was perfect, powerful and fast, people could use it to optimize production or production process. In this paper, crack initiation stage was neglected; influence of existent cracks to the deformation in wire drawing was focused on. It 
has a study of the evolution of crack in the deformation region and explores the impact of parameters in wire drawing on the evolution of the department of core crack in the process, such as the friction coefficient, mold angle, etc. Assuming the pass rate of contraction, hardening coefficient unchanged.

\section{Analysis model of wire drawing process with a central flaw}

Consecutive 8-time drawing is widely used for wire drawing process today. This paper takes a production line of 8 molds as the research object, in which a steel rod with an initial diameter of $13 \mathrm{~mm}$ is drawn to a final diameter of $5.3 \mathrm{~mm}$. Material work hardening is occurred after each drawing, so the plastic of the material are reduced. With the increase of drawing time, the impact of residual strain to the rod is more serious, resulting in a more vulnerable expansion of crack in the final 1 or 2 pass, and even broken. So the study to this article dominates the deformation and crack evolution of the rod in the final pass. In order to simulate the possible internal defects may formed before the rod began its eighth drawing, firstly, defects in product are observed on the draw bench of a production line.

\subsection{Observation of Internal Defects in Drawing Wire}

Checking the results of samples coming from the production line may observe a certain proportion of the drawing fracture which named Nib-shaped fracture, the morphology of which shown as Figure 1 (a), which account for a certain number of broken wires rate. The shape of the fracture looks like a sharpened nib as observing from the drawing fracture sample photos. Such a fracture is formed from the expansion of the instability of a central defect by metallographic study, see Figure 1 (b). In this longitudinal profile of material containing inner cracks a sharpen-nib crack has formed. If this crack continues to expand, the fracture morphology ultimately will be as shown as Figure 1 (a).

The formation and expansion of central cracks is complex. On the one hand, the material deformation of the outer layer is not consistent with that of the inner layer, with a smallest deformation in the core. On the other hand, the material itself contains central defects. Combination of those two factors results in a materials failure launch easily from the central defects, firstly, that is, the formation and propagation of the crack even fracture. Ignore the complexity of defects, the simplest calculation model of the process of drawing is based on the assumption rod containing a disc-shaped initial central defect. And ignore the impact of the entrance and sizing of the mold, only take the role of cone deformation into account.

\subsection{Mechanical Properties of Drawing Wire}

Mechanical performance parameters of the drawing wire used in the simulated calculation are measured by standard experiment (Wang Zhutang, Guan Yandong, Xiao Jingrong, et al, 1989). According to the measured results, the material's true stress - strain curve is measured by extrapolation. Fracture toughness $\mathrm{J}_{\mathrm{IC}}$ (J-integral value) is measured by single-sample method with standard specimens. Take conditional yield strength $\sigma_{0.2}$ in unidirectional tensile test stress - strain curve as initial yield strength. Other yield strength is obtained by the extrapolation of stress - strain curve. Drawing forces are calculated with approximate formula (Wang Zhutang, Guan Yandong, Xiao Jingrong, et al, 1989) as following:

$$
\sigma_{r} \approx \sigma_{s}\left[(1+\mu \operatorname{ctg} \alpha) \ln \frac{A_{1}}{A_{2}}+\frac{4 \alpha}{3 \sqrt{3}}\right]
$$

The change of corresponding material parameters, such as the material's yield strength after drawing, and the technical parameters (all-pass response, drawing force, mold length) are the light of the actual value of production. Other material parameters determined by experiment, in that, elastic modulus $E=210 \mathrm{GPa}$, Poisson's ratio $v=0.25$.

\subsection{Analysis Models of Drawing Wire}

In the simulation of the eighth drawing pass, the residual strain generates before is negligible. Due to the symmetry, the problem can be simplified by setting up finite element model with axial symmetry unit, and assuming the defect is located at the center of the rod. Take that a simulation can only take a limited length and that the state of deformation should be as far as possible near the actual line both into account, the rod aspect ratio check (axial length / radius length) $\geq 5$, the ratio of rod length to initial crack size (axial length / $2 \mathrm{a}$ ) $\geq 10$ are used in the simulations. The finite element model of drawing wire set up with commercial software ANSYS and meshing near the crack tip are shown in Figure 2.

\section{Simulation of the Forming Process of a Fracture}

\subsection{Analysis on the formation of a Nib-shaped fracture}

Drawing from the aforementioned shortcomings within the sampling test results of the production line, we can see that in the observed fractures certain amounts of fracture are nib-shaped. The formation of Nib-shaped fracture is originated in the core defects in material. Stress concentration is occurred in the drawing stress state, and with an orientation obtuse with the drawing direction. When the defect size is bigger than critical size, the crack will expand gradually along the direction of the largest stress concentration, until a chevron crack forms. When the crack growth to a certain 
size it expands unstably and rapidly until the fracture formed, with the formation of a smaller shear lip in the final expansion stage. Fracture is nib-like: that is, the source region of crack, the symmetrical expansion zone of crack and the shear lip zone. Its formation process diagram is shown in Figure 3.

\subsection{Simulation to the formation of a Nib-shaped fracture}

Assuming no defects exist in the rod. A model is set up to simulate the wire drawing process of a Defect-free rod. The simulation showed that in the central location of the export of the Wire Drawing Die there achieves a smaller compressive stress and a larger axial tensile stress. These two stress combine to effect, resulting in a maximum stress in the export position. As the actual material is always uneven, and therefore, material in the center of the rod is more likely produce micro-cracks in wire drawing. In order to explore the mechanical causes of the formation of Nib-shaped fracture, based on this stress field further analysis and simulation is made to study internal stress distribution and stress concentration in crack tip with a central defect. In the first pull-out, the rod has not been strain-hardening and has good internal mobility. As the first pull-out is also the starting point of the internal non-uniform strain of the rod, the deformation in this drawing has been the best point of observing the trend of further deformation in material. So we observe the deformation trends of drawing wire in its first pull-out processes, while the study on internal stress distribution and stress concentration in crack tip after cracks is exist is based on the finial pass.

By the method described in 1.3 finite element models are set up to simulate drawing wire in Road 8(see Fig.2) and are used to study the stress concentration state around crack tip. Finite element analysis results shown in Figure 4 and 5 are stress distribution around crack tip when central defect is passing the mold-outer, when the rod bear a large deformation and stress concentration around crack tip has been serious. In the deformation zone of the mold, compression stress is mainly in radial and tensile stress is mainly in axial. While the crack growth mainly caused by the role of the tensile stress, there only shows axial stress distribution cloud, see figure 4. Figure 4 (a) is the axial stress distribution cloud, Figure 4 (b) is axial stress concentration around the crack tip. As shown in Figure 4(a) stress in axial is mainly tensile when the rod passing the die, with a larger stress near the crack and gradually decreased stress away. There is a clear stress concentration around the crack tip, and slightly away from the crack tip, stress concentration orientation has an obtuse angle to the drawing direction, as shown in Figure 4(b). According to this phenomenon, the process of crack growth can be described as, firstly the defect has a slight expansion with the vertical drawing direction, and then turns into a obtuse angle with the drawing direction. The calculation results are coincided with the actual observed experimental results (Fang. Feng, 2003).

\subsection{The Impact Factors of Nib-shaped Fracture}

Research on Nib-shaped fracture can help to determine the main reasons for the occurrence of broken wires in wire drawing, and from the location of material defects the defects in the original materials and the causes why they occur may be inferred, contributing to the improvement of rod production process and enhance their quality, and optimize the drawing process parameters.

There are many factors impact the morphology of Nib-like fracture, including the material performance parameters, the size of die angle in drawing, lubricant condition, the drawing rate, cooling conditions, where the research is focused on the impact of drawing angle of the die and lubrication to the morphology of nib-like fracture. Changing die angle in wire drawing, other parameters are unchanged. The results show that, with the wire drawing die angle increases, the oblique angle of nib-shaped fracture also become larger, that is, the nib become more slender. Change the friction coefficient between the drawing with the die, from $\mu=0.1$ to $\mu=0.3$, other parameters unchanged. The results showed that with increasing friction coefficient, the oblique angle of nib-shaped fracture is also smaller, i.e. shorter nib.

\section{The Critical Size of Central Defects}

For further quantification of the impact of process parameters to the crack tip stress field, such as die angle, friction coefficient, J-integral around crack tip are calculated with the simulation results of the ANSYS finite element models, which are based on the drawing road 8 .

\subsection{Relationship between J-integral and the die angle}

Change the die angle with other process parameters unchanged, the J-integral values for two crack sizes $(2 \mathrm{a}=20 \mu \mathrm{m}$ and $50 \mu \mathrm{m})$ are obtained, here with. The relationship curves between J-integral value and the die angle are shown as Figure 6 (a), in which the dotted line charts for the experimentally measured values JIC of the material. From the figure, we can see that changes of J-integral with the die angle-size for different crack size are basically the same. J-integral value also increases along with the increase in crack size. For the same size of the crack, J-integral value decreases as the die angle decreases until it get to a boundary, when J-integral value changes slightly and tends to a certain value, here about $8^{\circ}$.

From the above analysis we can see that smaller die-angle in wire drawing reduces the tendency of crack propagation. It is unsuitable for very small angle dies used in actual production process, as the need to consider the design and 
manufacture of molds, energy consumption in the process of drawing, productivity and other factors. Other settings unchanged, trades-off between the finished product quality and efficient pull-out, a die angle that both ensure a high area compression ratio and also greatly reduce the of crack propagation can be obtained, that is the best pulling angle. For the production of wire drawing, as the friction coefficient $\mu$ is about 0.1 , the best pulling angle is about $8^{\circ}$. With this die angle, the permitted defects within materials can have a relatively larger value, that is, brings a lower rate of broken wires in wire drawing.

\subsection{Relationship between J-integral and crack size}

Change the crack size with other process parameters unchanged, the J-integral values by the condition of the friction coefficient $(\mu)$ of 0.1 and 0.3 are obtained, here die angle $2 \alpha=8^{\circ}$. The relationship curves of J-integral values to micro-crack size are shown as Figure 6(b), in that the dotted line charts for the JIC value of the material. It can be seen from Figure 6(b) that J-integral value increases with the increase in crack size, and under the same initial defects $\mathrm{J}$-integral value is slightly larger with a larger coefficient of friction. The critical defect size is between $30 \mu \mathrm{m}$ and $40 \mu \mathrm{m}$ from the map also under the two cases of friction coefficient. The friction coefficient of actual process is of approximately 0.1 and observed critical crack size under this case is about $30 \mu \mathrm{m}$. This shows that simulation results are close to the actual situation.

\subsection{Relationship between J-integral and friction coefficient}

Now we take the case of die angle $2 \alpha=8^{\circ}$, and other process parameters unchanged, only with changing friction coefficient. The J-integral values are obtained for two different defect sizes $(20 \mu \mathrm{m}$ and $50 \mu \mathrm{m})$. The relationship curves of J-integral value to friction coefficient are shown as Figure 6(c). From the figure we can see that J-integral value increases with the increasing of friction coefficient. The greater the friction coefficient, the greater the J-integral value for the same initial defects. This is because the friction coefficient decreases causes a reducing friction, shear stress also decreases. As a result, the extent of stress concentration around crack tip decreased, corresponding J-integral value is also reduced.

\section{Optimization analysis on the drawing process Based on the simulation results}

Based on the above simulation and analysis results, for the pull-out production process with high carbon wire, we can draw the following advice:

For the same size of the crack, J-integral value decreases as the die angle decreases, until the later reach some certain boundary J-integral value changes in smaller, the certain value of die angle here is about $8^{\circ}$. Analysis showed that smaller die angle in wire drawing reduces the tendency of crack propagation. However, in order to ensure higher productivity, die angle also should not be too small. With improved friction performance friction coefficient $\mu$ in actual production is usually about 0.1 , the best pulling angle is $8^{\circ}$ or so for this case of friction coefficient. With this die angle, the permitted defects within materials can have a relatively larger value, that is, brings a lower rate of broken wires in wire drawing.

With the increase in friction coefficient, J-integral value increases; the greater the friction coefficient, the greater the J-integral value for the same initial defects. Thus, improving lubrication conditions of the drawing process means larger critical crack size in materials, in other words, brings a lower rate of broken wires in wire drawing.

With the best framework of process parameters, certain size of central initial defects in rod is permitted that will not expand in drawing, namely, the critical crack size. The critical size of central defects identified in this study is of $30-40 \mu \mathrm{m}$.

It is of great significance for the effectiveness of the production if we can carry out nondestructive testing in the rod to control the rod's quality before the drawing, by ensuring the quality of finished products at the same time saving materials.

\section{Concluding Remarks}

In this study, we benefit with the use of large-scale commercial software ANSYS and fracture mechanics theory for simulation of evolution law of defects in metal wire drawing process, as well as the impact of control parameters in the drawing process on the evolution of defects. Study on stress and strain field distribution in deformation zone with defect-free rod gives a verification of the formation mechanism of core chevron crack. As a result of rod material containing defects or drawing effects of several times before, the probability of crack expansion in the final two or one drawing has been great in multi-pass drawing, four factors have impact on the crack evolution; we use the finite element software to calculate the impact of friction coefficient and die angle on the evolution of cracks, then rational configuration is taken to adjust these factors for the purpose of reducing broken wires rate in its pull-out. It is concluded that the friction coefficient is 0.1 and the best pull-out angle is of approximately $8^{\circ}$ and the rate of broken wires can be reduced by improving the lubrication conditions in wire drawing; While the diameter of the disc-shaped surface crack in the central of the rod is no more than $30-40 \mu \mathrm{m}$, the wire break will not happen. 


\section{References}

Avitzur. B. (1968). Analysis of central bursting defects in extrusion and wire drawing. Transactions of the ASME Journal of Engineering for Industry. 1968, 90 (1): 79-91.

Fang. Feng. (2003). The performance and microstructure of $1860 \mathrm{Mpa}$ PC strand produced by little billet continuous casting hot continuous rolling. In: Department of Material Science and Engineering of Southeast University, NanJing, 2003.

J. Luksza, J. Majta, M. Burdek, et al. (1998). Modeling and measurements of mechanical behavior in multi-pass drawing process. Journal of Material Processing Technology, 1998, (80-81): 398-405.

Kazutake. Komori. (2003). Effect of ductile fracture criteria on chevron crack formation and evolution in drawing. International Journal of Mechanical Sciences. 2003(45): 141-160.

Ko. Dae-Cheol, Kim.Byung-Min. (2000). The prediction of central burst defects in extrusion and wire drawing. Journal of Material Processing Technology. 2000, (102): 19-24.

R. K. Chin, P.S. Steif. (1995). Computational study of strain inhomogeneity in wire drawing. Int. J Mach Tools Manufact. 1995, 35(8): 1087-1098.

Wang Zhutang, Guan Yandong, Xiao Jingrong, et al. (1989). Theorems of plastic metal forming. BeiJing: public of mechanical industry. 1989: 165-167.

Yu Wanhua, Huan Guanchang, Yuan Kang. (1994). Criterion for central bursting in wire during drawing. Journal of University of Science and Technology BeiJing, 1994, 10(2): 162-165.

Z. Zimerman, and B. Avitzur. (1970). Analysis of the effect of strain hardening on central bursting defects in drawing and extrusion. Transactions of the ASME Journal of Engineering for Industry. 1970(2): 135-145.

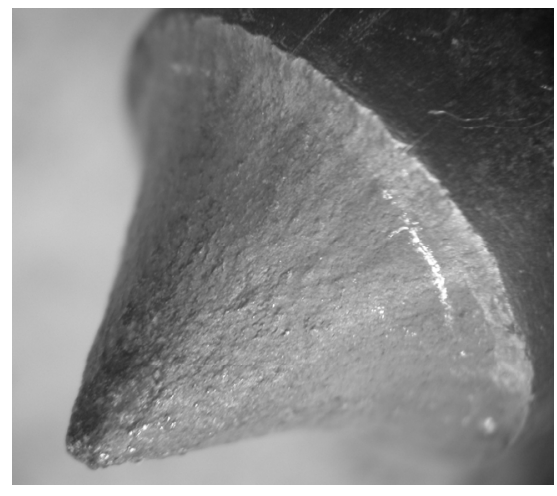

(a) Fracture surface

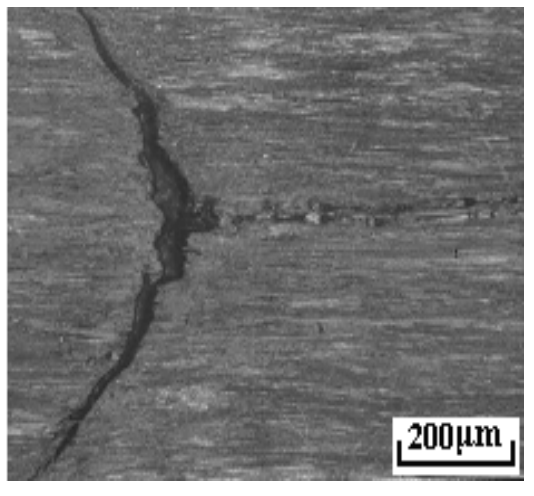

(b) vertical profile

Figure 1. Morphology of drawing fracture

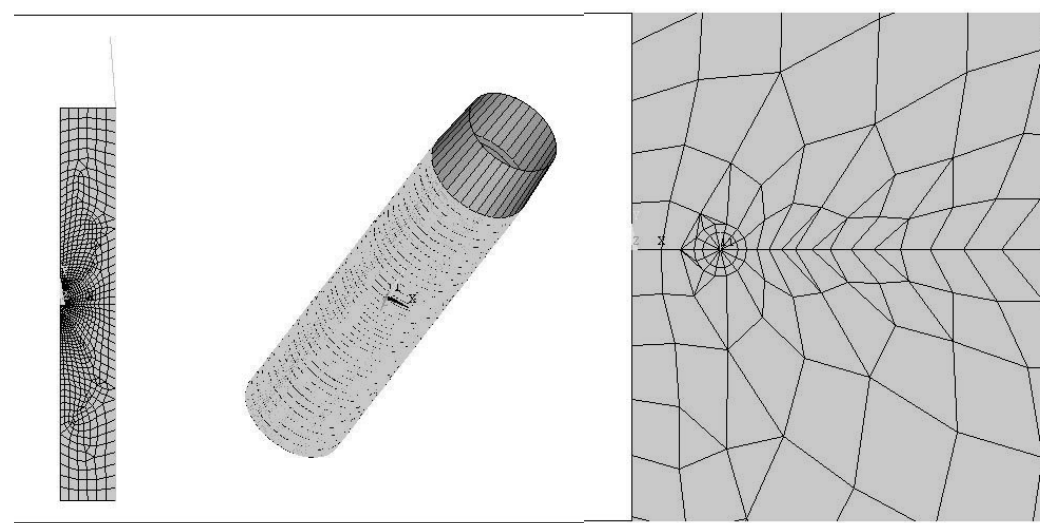

(a) Axial symmetry plane model (b) Axial symmetry model of the entire expansion $\quad$ (c) mesh near crack tip zone

Figure 2. Finite element model of drawing wire 


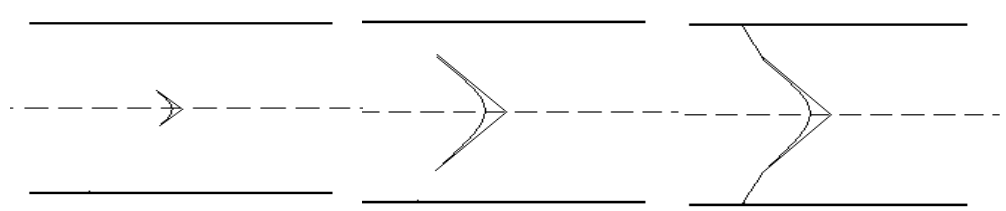

(a) Crack source; (b) expansion period; (c) period of fracture

Figure 3. Sketch man of nibbled pencil fracture formed
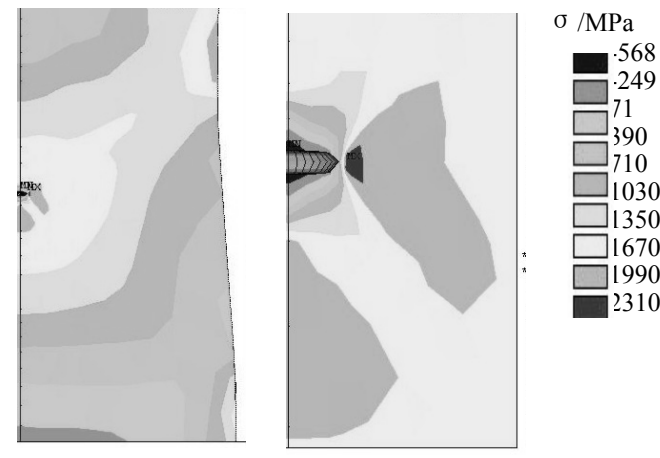

(a) Axial stress (b) stress concentration around crack tip

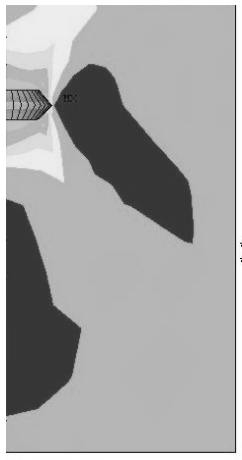

(a) $2 \alpha=30^{\circ}$

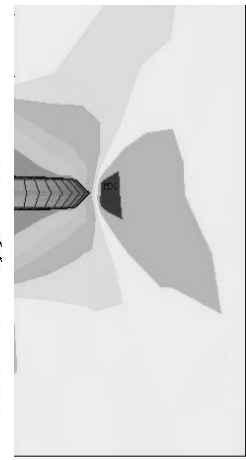

(b) $\mu$ $\sigma / \mathrm{MPa}$

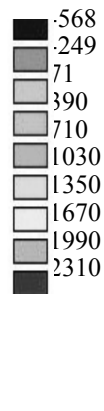

Figure 4. Nephogram of stress distributing in drawing mold (axial stress)

Figure 5. stress concentration
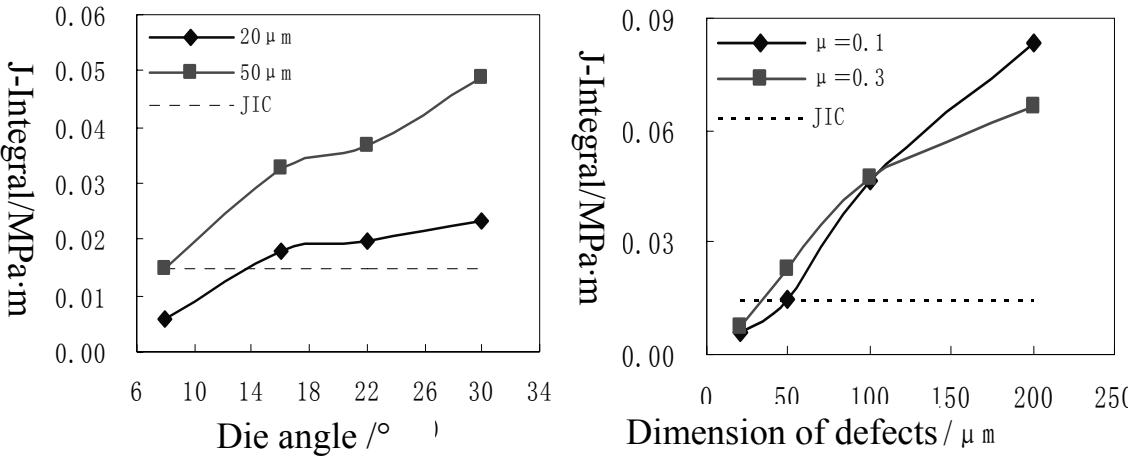

Dimension of defects / $\mu \mathrm{m}$

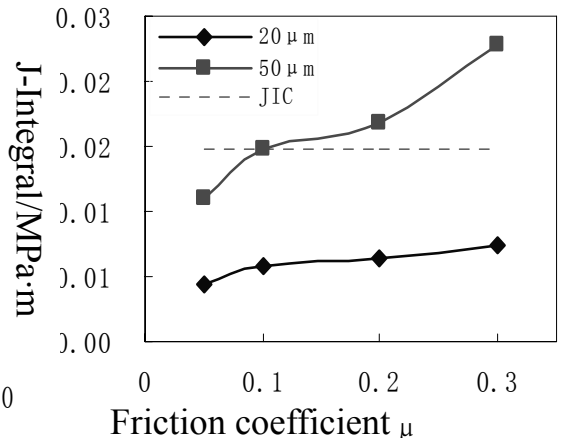

Friction coefficient $\mu$

(a) J-Integral versus apex angle

(b) J-Integral versus the dimension of defects (c) J-Integral versus friction coefficient

Figure 6. the relationship between J-integral and the die angle, crack size and friction coefficient 


\title{
Modern Applied Science
}

www.ccsenet.org/journal.html

\author{
Analysis of Mixed Soil Model Characteristics \\ ABDOULLAH NAMDAR \& G. S. GOPALAKRISHNA \\ DOS in Geology, Manasa Gangotr \\ Mysore University, Mysore, INDIA, 570006 \\ Tel: 91-98-8006-9130 E-mail: ab_namdar@yahoo.com
}

\begin{abstract}
Improvement of any site could be possible, if soil characteristics of site were clearly identified. 15 soil mixture models were developed. The angle of friction $(\Phi)$ and cohesive $(C)$ of mixed soil under the direct shear test at different level of moistures have been studied and corresponding bearing capacity were calculated. The angle of friction and cohesive of the mixed soil have positive correlation with the bearing capacity. The results also revealed that the mixed soils, which composed of good binding particles exhibited relatively high angle of friction, cohesive, shear strength and low degree of compressibility and settlement in the soil foundation.
\end{abstract}

Keywords: Soil Mixing, Angle of friction, Cohesive, Bearing Capacity, Terzaghi Method

\section{Introduction}

The bearing capacity is an important characteristic of the soil, which determines the safety of the structure built on it. Severe damage can be observed in the built structures during seismic force acting up on subsoil due to weak soil bearing capacity. The better method to reduce magnitude of damage caused to the structure due to weak bearing capacity of soil is excavating and replacement of some part or the whole of the soil foundation. There are other alternative methods through which the bearing capacity of the soil could be enhanced are geo-grid, Geo-textile, dewatering, compaction and micro pile methods.

The soil bearing capacity could be determined by analytical methods, plate bearing test, penetration test, model test, prototype tests and laboratory test (Venkataramaiah; 1993 and Murthy; 2002). There is also report on the improvement of ultimate bearing capacity by the soil confinement using a non-dimensional factor called the bearing capacity ratio (BCR). It has been observed that such confinement resists the lateral displacement of soil underneath the footing leads to a significant decrease in the vertical settlement and hence improving the ultimate bearing capacity (Vinod Kumar et al; 2007). Analysis of the condition of complete bearing capacity failure, usually termed general shear failure, can be made by assuming that the soil behaves like an ideally plastic material. The concept was first developed by Prandtl, and later extended by Terzaghi, Meyerhof and others (PUNMIA; 1988). There are also reports on determination of bearing capacity of soils by combining elasto-plastic finite element analysis with random field theory (Gordon \& Griffiths; 2000). Here the authors made an attempt to investigate the bearing capacity of mixed soil types. The mixed soils were consisted of soils, sand and gravels representing around Mysore.

\section{Methodologies and Experiment}

Here the experiments have been performed to determine the bearing capacity of soils with spatially random shear strength. The main objective of the investigation was to determine the extent to which spatial variability in soil properties affects the distribution of the computed bearing capacity and find out the best and economical soil mixer which could be a trustable soil foundation for any type of structures. The authors were carried out laboratory tests to calculation of bearing capacity for the mixed soils. The soil samples, sand and gravels were dried at $110^{\circ} \mathrm{C}$ for 24 hours to dehydrate. In the present experiments, 15 different mixed soil types consisting of soils-sand-gravels were prepared (table1). The density of the each models under different moisture conditions $(0 \%, 3 \%, 6 \%)$ were measured (fig. 1$)$. The direct shear test experiments for all the types were carried out (At different moisture content at the Geo-technical Engineering Laboratory, S. J. College of Engineering in Mysore) and cohesive of mixed soil (C), angle of fraction ( $\Phi)$ were measured. The results were illustrated in table 2 . Using $C, \Phi$ and density values and adopting Terzaghi's method, the bearing capacity for all mixed soil types were calculated, assuming $1.5 \mathrm{~m}$ depth and $2.5 \mathrm{~m}^{*} 2.5 \mathrm{~m}$ widths for square footing (figure 3).

Formulas used for calculation bearing capacity are as follows (PUNMIA; 1988): $\mathrm{q}_{\mathrm{f}}=1.3 \mathrm{C} \mathrm{N}_{\mathrm{c}}+\gamma \mathrm{DN}_{\mathrm{q}}+0.4 \gamma \mathrm{BN}_{\gamma}$. Also $\mathrm{N}_{\mathrm{q}}, \mathrm{N}_{\mathrm{c}}$ and $\mathrm{N}_{\gamma}$ are the general bearing capacity factors and depending upon Depth of footing, Shape of footing and angle of friction. 


\section{Results and Discussion}

In the present investigations, the experiments were conducted for finding the best and economical mixed soil type, which could be a trustable soil foundation for any type of structures. The maximum and minimum densities were exhibited in mixed soil types 3 and 2 respectively. The figure 1 has indicated negative correlation in general among density and moisture content (up to 6\%) under ambient conditions. The similar relationships could be observer between moisture and angle of friction ( $\Phi$ ) (fig 2 ) and also between moisture and soil bearing capacity (fig 3 ). As the moisture content increases, the soil become saturated and resulted decrease in internal friction among soil particles. There is a direct relationship between angle of friction and bearing capacity. At the $0 \%$ moisture the maximum and minimum bearing capacity could be observe in models $5,8\left(483835 \mathrm{Kg} / \mathrm{m}^{2}, 96781 \mathrm{Kg} / \mathrm{m}^{2}\right)$ respectively (table 2). High bearing capacity could be attributed since the type 5 of only red soil, gravels and sand representing in different sizes and shapes, which, drastically reduced voids percentage and increased friction between grains of the mixtures. This condition prevailed up to $3 \%$ of moisture and further increased of moisture content, lead to the saturation point of the mixture with moisture, which drastically reduced the bearing capacity of the model. Where as in type 8 consists of red and dark brown soils, where friction reduced due to morphology characteristics. This more prominent in model consist of only red soil at higher percent of moisture. The remaining soil mixture exhibited relatively lower bearing capacity but linearity with moisture content. The nature of mixed soil type and its morphology are the main factors controlling the bearing capacity. In a model with good binding of particles which lead to withstanding compressive well with high level of angel of friction, cohesive and eventually appeared good enough shear strength. Binding of particles is depending on shapes and sizes of them. The angular and differential sizes have more binding. Good binding of particles could reduce settlement and compressibility of soil.

The interaction between the coarse and fine-grained matrices affects the overall mechanical behavior of the mixture of the soils (Cabalar; 2008). The existing unusual soil volume change behavior like settlement under effective stress decrease during wetting and massive settlement near saturation, another odd behavior was encountered during laboratory inundation tests at different net stress (Md. Noor; et al 2008). Adding some granular soils to pure plastic clay will increase the stiffness of the clay material and decrease the differential behavior of any earth structure (Husseini; 2002). The results clearly revealed the soil mixture consisting of red soil, sand and gravels has exhibited high degree of bearing capacity and mechanical strength.

\section{Conclusion}

Soil Mixing is a technique, which could improve the physical characteristics of soil. The moistured soil mixtures have exhibited negative correlation with density, angle of friction and almost positive correlation with cohesive of soil mixtures. The angle of friction of soil mixtures has positive correlation with the bearing capacity. The soil mixture consists of red soil, sand and gravels is a better ground for the basement of structures under dry and low moisture conditions. The nature of mixed soil and its morphology are also the main factors determine the bearing capacity. A model with good binding of particles increased, angle of friction, cohesive and shear strength and also decreased compressibility and settlement of soil foundation.

\section{Acknowledgements}

The authors would like to express thanks to the technical staff of Department of Civil Engineering, SJCE, Mysore for providing laboratory facilities and express appreciate to Professor Syed Shakeeb Ur Rahman for his timely guidance.

\section{References}

Çabalar Ali Firat (2008), Effect of Fines Content on the Behavior of Mixed Samples of Sand, Electronic Journal of Geotechnical Engineering. 13, Bund. D.

Gordon A. Fenton \& Griffiths D. V (2000). Bearing Capacity of Spatially Random Soils, 8ASCE Specialty Conference on Probabilistic Mechanics and Structural Reliability, ASCE

Husseini Mir M. et al. (2002), Performance of Mixed-Clay as Core Material of Earth Dams, 7, Bundle A.

Md. Noor M.J et al (2008). Effective Stress and Complex Soil Settlement Behavior, Electronic Journal of Geotechnical Engineering, 13, Bund. H.

Murthy. V.S (2002). Geotechnical Engineering, (Eds), Published by CRC Press.

PUNMIA. B. C. (1988). Soil Mechanics and Foundations, Madras.

Venkatramaiah.C. (1993). Geotechnical engineering, (Eds), New Delhi: John Wiley Eastern.

Vinod Kumar Singh et al (2007). Effect of Soil Confinement on Ultimate Bearing Capacity of Square Footing Under Eccentric Inclined Load, Electronic Journal of Geotechnical Engineering, 12, Bund. E. 
Table 1. Mixed Soil models

\begin{tabular}{|c|c|c|c|c|c|c|c|c|c|}
\hline $\begin{array}{l}\text { S1. } \\
\text { No }\end{array}$ & $\begin{array}{l}\mathrm{RD} \\
(\%)\end{array}$ & $\begin{array}{c}S \\
(\%)\end{array}$ & $\begin{array}{l}\text { GL } \\
4.75 \\
\mathrm{~mm} \\
(\%)\end{array}$ & $\begin{array}{c}\text { GL } \\
2 \\
\mathrm{~mm} \\
(\%)\end{array}$ & $\begin{array}{l}\text { B S } \\
(\%)\end{array}$ & $\begin{array}{l}\text { GS } \\
(\%)\end{array}$ & $\begin{array}{c}\text { DBS } \\
\text { Soil } \\
(\%)\end{array}$ & $\begin{array}{l}\text { YS } \\
(\%)\end{array}$ & $\begin{array}{c}\text { LBS } \\
(\%)\end{array}$ \\
\hline 1 & 100 & 0 & 0 & 0 & 0 & 0 & 0 & 0 & 0 \\
\hline 2 & 55 & 45 & 0 & 0 & 0 & 0 & 0 & 0 & 0 \\
\hline 3 & 55 & 0 & 45 & 0 & 0 & 0 & 0 & 0 & 0 \\
\hline 4 & 55 & 0 & 0 & 45 & 0 & 0 & 0 & 0 & 0 \\
\hline 5 & 55 & 15 & 15 & 15 & 0 & 0 & 0 & 0 & 0 \\
\hline 6 & 55 & 0 & 0 & 0 & 45 & 0 & 0 & 0 & 0 \\
\hline 7 & 55 & 0 & 0 & 0 & 0 & 45 & 0 & 0 & 0 \\
\hline 8 & 55 & 0 & 0 & 0 & 0 & 0 & 45 & 0 & 0 \\
\hline 9 & 55 & 0 & 0 & 0 & 0 & 0 & 0 & 45 & 0 \\
\hline 10 & 90 & 0 & 0 & 0 & 2 & 2 & 2 & 2 & 2 \\
\hline 11 & 80 & 0 & 0 & 0 & 4 & 4 & 4 & 4 & 4 \\
\hline 12 & 70 & 0 & 0 & 0 & 6 & 6 & 6 & 6 & 6 \\
\hline 13 & 60 & 0 & 0 & 0 & 8 & 8 & 8 & 8 & 8 \\
\hline 14 & 50 & 0 & 0 & 0 & 10 & 10 & 10 & 10 & 10 \\
\hline 15 & 55 & 0 & 0 & 0 & 0 & 0 & 0 & 0 & 45 \\
\hline
\end{tabular}

Red Soil=RD, Sand= S, Gravel= GL, Black Soil= BS, Green Soil=GS, Dark Brown Soil= DBS, Yellow Soil=YS, Light Brown Soil=LBS

Table 2. Experiments Results

\begin{tabular}{|c|c|c|c|c|c|c|c|c|c|c|c|}
\hline $\mathrm{MN}$ & $\begin{array}{c}\text { Moisture } \\
(\%)\end{array}$ & $\begin{array}{c}\gamma \\
\mathrm{Kg} / \mathrm{m}^{3}\end{array}$ & $\begin{array}{c}\Phi \\
{\left[{ }^{\circ}\right]}\end{array}$ & $\begin{array}{c}\mathrm{C} \\
\mathrm{Kg} / \mathrm{m}^{2}\end{array}$ & $\begin{array}{c}\mathrm{B} \cdot \mathrm{C} \\
\mathrm{Kg} / \mathrm{m}^{2}\end{array}$ & $\mathrm{MN}$ & $\begin{array}{c}\text { Moisture } \\
(\%)\end{array}$ & $\begin{array}{c}\gamma \\
\mathrm{Kg} / \mathrm{m}^{3}\end{array}$ & $\begin{array}{c}\Phi \\
{\left[{ }^{\circ}\right]}\end{array}$ & $\begin{array}{c}\mathrm{C} \\
\mathrm{Kg} / \mathrm{m}^{2}\end{array}$ & $\begin{array}{c}\mathrm{B} . \mathrm{C} \\
\mathrm{Kg} / \mathrm{m}^{2}\end{array}$ \\
\hline 1 & 0 & 1203.9 & 38 & 0 & 210935 & 2 & 0 & 1278.3 & 35 & 0.1 & 133590 \\
\hline & 3 & 1105 & 30 & 0.02 & 59063 & & 3 & 1172.3 & 35 & 0 & 122505 \\
\hline & 6 & 1074.4 & 25 & 0.06 & 30891 & & 6 & 1018.3 & 31 & 0 & 63669 \\
\hline 3 & 0 & 1420 & 36.5 & 0.14 & 198607 & 4 & 0 & 1295.6 & 42 & 0 & 461739 \\
\hline & 3 & 1357.8 & 36 & 0.1 & 173902 & & 3 & 1246.7 & 38 & 0.06 & 218478 \\
\hline & 6 & 1246.7 & 31 & 0.2 & 77960 & & 6 & 1203.9 & 37 & 0 & 182559 \\
\hline 5 & 0 & 1357.6 & 42 & 0 & 483835 & 6 & 0 & 1172.3 & 37 & 0.12 & 177779 \\
\hline & 3 & 1345.6 & 39.5 & 0.1 & 283348 & & 3 & 1202.3 & 36 & 0.04 & 154059 \\
\hline & 6 & 1048.9 & 34 & 0 & 94138.8 & & 6 & 1048.9 & 33 & 0 & 84620 \\
\hline 7 & 0 & 1234.5 & 36 & 0 & 158102 & 8 & 0 & 1351.7 & 32 & 0 & 96781 \\
\hline & 3 & 1111.1 & 34 & 0 & 99721.2 & & 3 & 1202.9 & 32 & 0 & 86127 \\
\hline & 6 & 1080.5 & 33 & 0 & 87169.3 & & 6 & 1111.1 & 29 & 0 & 53899 \\
\hline 9 & 0 & 1160 & 35 & 0 & 121220 & 10 & 0 & 1048.9 & 37 & 0.04 & 159059 \\
\hline & 3 & 1246.7 & 32 & 0 & 89263.7 & & 3 & 1160 & 31 & 0.1 & 72534 \\
\hline & 6 & 1111.1 & 31 & 0.04 & 69473.7 & & 6 & 1111.1 & 29 & 0 & 53899 \\
\hline 11 & 0 & 1111.1 & 36 & 0 & 142299 & 12 & 0 & 1258.9 & 33 & 0 & 101562 \\
\hline & 3 & 1129.5 & 34 & 0 & 101373 & & 3 & 1258.9 & 32 & 0 & 90137 \\
\hline & 6 & 1172.3 & 31 & 0.05 & 73300.7 & & 6 & 1185.5 & 28.5 & 0 & 54580 \\
\hline 13 & 0 & 1172.3 & 35 & 0 & 122505 & 14 & 0 & 1296.6 & 36 & 0 & 166056 \\
\hline & 3 & 1372.2 & 33 & 0.06 & 107076 & & 3 & 1296.6 & 34 & 0 & 116370 \\
\hline & 6 & 1234.5 & 27.5 & 0.06 & 50740.4 & & 6 & 1129.5 & 32.5 & 0.04 & 85999 \\
\hline 15 & 0 & 1141.7 & 37 & 0 & 173127 & & & & & & \\
\hline & 3 & 1160 & 36 & 0 & 148561 & & & & & & \\
\hline & 6 & 1111.1 & 34 & 0 & 99721.2 & & & & & & \\
\hline
\end{tabular}

$\mathrm{MN}=$ Model No, $\mathrm{D}=$ Degree, $\mathrm{W}=$ Width, $\mathrm{S} . \mathrm{B} . \mathrm{C}=$ Bearing capacity, $\mathrm{OMC}=$ Optimum Moisture Content and $\mathrm{L}=$ Length 


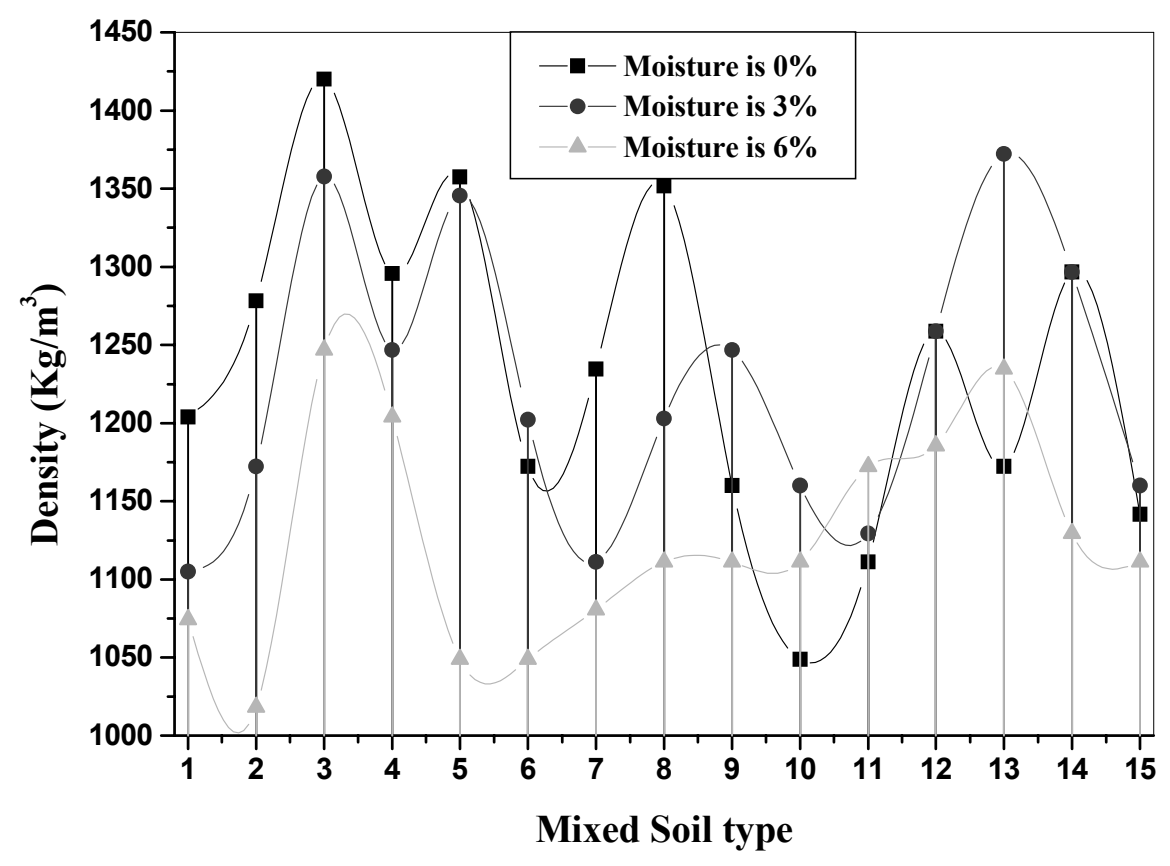

Fig . 1 . Mixed Soil type vs Density $\left(\mathrm{Kg} / \mathrm{m}^{3}\right)$

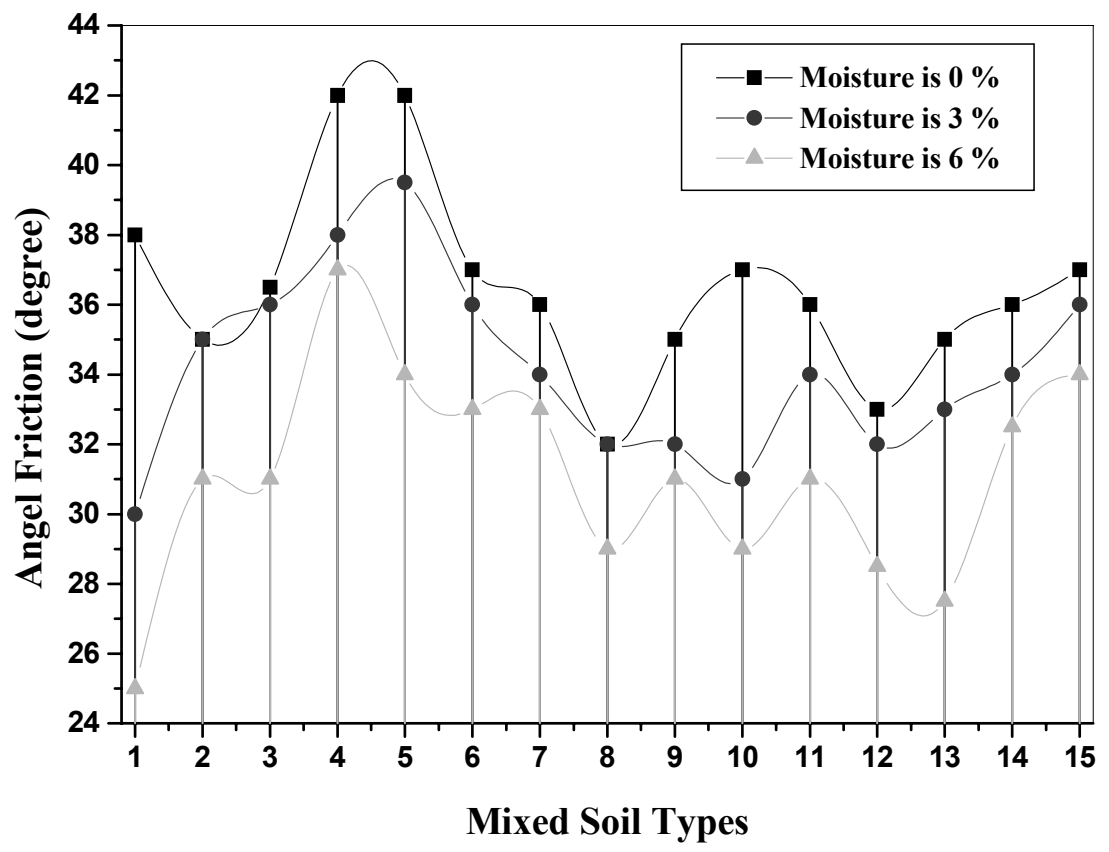

Fig . 2 . Mixed Soil Type vs Angel of Friction 


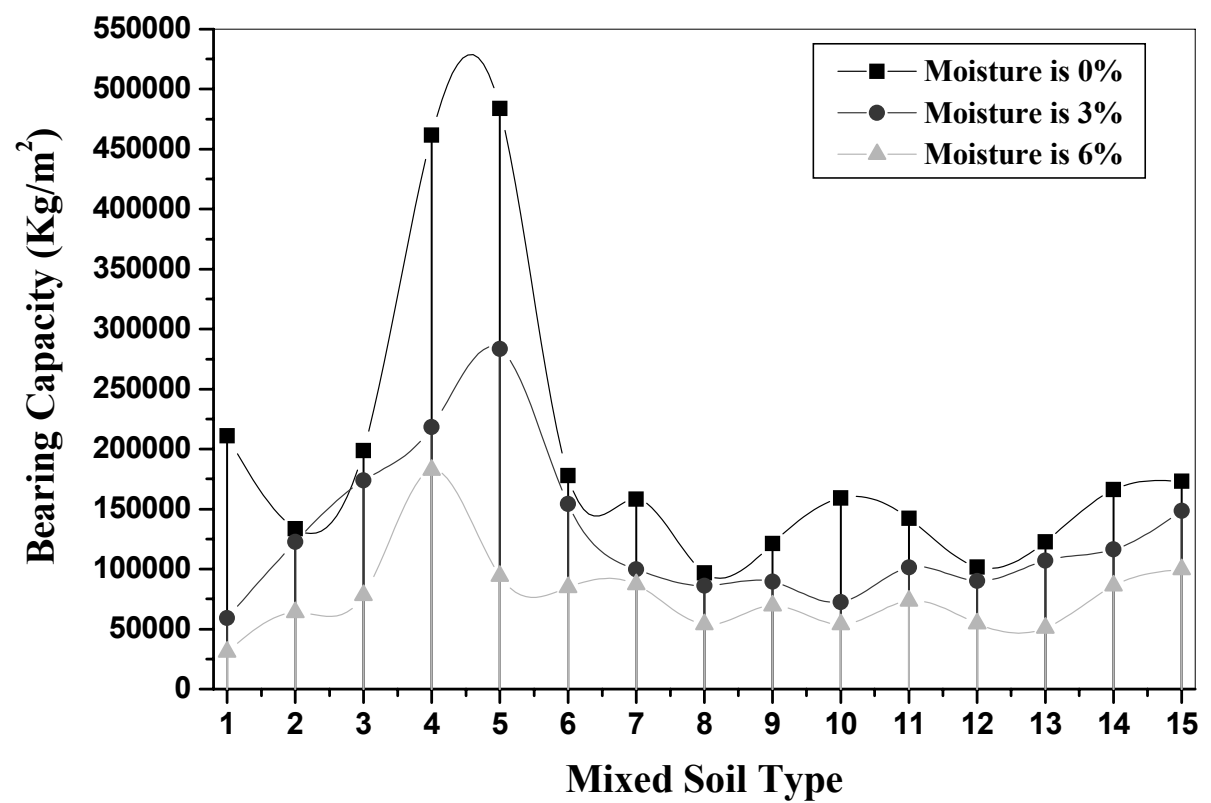

Fig . 3 . Mixed Soil Type vs Bearing Capacity $\left(\mathrm{Kg} / \mathrm{m}^{2}\right)$ 


\title{
One New Method on ARMA Model Parameters Estimation
}

\author{
Xiaoqin Cao (Corresponding author) \\ Department of Science, Yanshan University \\ Qin Huangdao 066004, China \\ E-mail:fanjing850328@163.com \\ Rui Shan \\ Department of Science, Yanshan University \\ Qin Huangdao 066004, China \\ E-mail: srlhy@hotmail.com \\ Jing Fan \& Peiliang Li \\ Department of Science, Yanshan University \\ Qin Huangdao 066004, China
}

\begin{abstract}
The estimation of ARMA model parameters really belongs to the least-square problem,in ARMA model because the residual are calculated by given time series, the time series and parameter are nonlinear.However it is difficult to calculate the derivative of objective function.This paper substitutes derivative with difference,then calculate the first derivative and the second derivative of objective function.Finally we prove that, under suitable hypotheses, the proposed algorithm converges globally.
\end{abstract}

Keywords: ARMA(n,m), Trust-region, BFGS

\section{Introduction}

For nonlinear least-squares problem,we minimize $\varepsilon_{t}$ in the sense of the sum of squares. We can take full advantage of their special structure to design a more effective method.For example,Gauss-Newton method,damping Gauss-Newton method \& LM method and so on. However Gauss-Newton method just use the information of the first derivative $\left(V_{k}\right)$ of the function to get the approximation of the Hesse matrix,however neglect the nonlinear items of the $\nabla^{2} S(\beta)$, therefore the performance and convergence of the Gauss-Newton method will certainly be affected.because of these problems,we present a new method.

In ARMA model,consider $\varepsilon_{t-1} \quad \varepsilon_{t-2} \quad \varepsilon_{t-m} \ldots$ are calculated by $x_{t-1} x_{t-2} \ldots$, therefore $X_{t}$ and $\beta$ are nonlinear.However when we only know the form of ARMA model,we are unable to directly express $\varepsilon_{t-1} \quad \varepsilon_{t-2} \ldots \varepsilon_{t-m}$ with $x_{t-1} \quad x_{t-2} \quad \ldots$ Therefore we substitute derivative with difference, and then calculate the approximation of the gradient and the Hesse matrixof the objective function.

Trust region methods are a class of optimization methods to guarantee the overall convergence of technologies.Although the trust region method can be traced back to Levenberg(1944),Marquardt(1963),Goldfeld,Quandt \& Trotter(1966), the modern trust region method is raised by Powell (1970).He clearly posed the trust region subproblem and the convergence theorem. These measures show the trust region has the greater advantages than the linear search method. We make a small improvement of the traditional trust region method,consider the non-linear degree of the nonlinear least-squares problem,and correct the Hesse matrix of the objective function from two respects to make the algorithm has a better nature.

\section{The basic theory}

\subsection{Objective function}

For $\operatorname{ARMA}(\mathrm{n}, \mathrm{m})$ model

$$
x_{t}=\varphi_{1} x_{t-1}+\varphi_{2} x_{t-2}+\ldots+\varphi_{n} x_{t-n}-\theta_{1} \varepsilon_{t-1}-\theta_{2} \varepsilon_{t-2}-\ldots-\theta_{m} \varepsilon_{t-m}+\varepsilon_{t}
$$

Substitute (1) with the form of the matrix 


$$
x_{t}=f\left(X_{t}, \beta\right)+\varepsilon_{t}
$$

Where

$$
\begin{aligned}
& X_{t}=\left[\begin{array}{llllllll}
x_{t-1} & x_{t-2} & \cdots & x_{t-n} & \varepsilon_{t-1} & \varepsilon_{t-2} & \cdots & \varepsilon_{t-m}
\end{array}\right]^{T}
\end{aligned}
$$

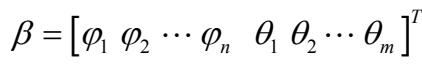

$$
\begin{aligned}
& f\left(X_{t}, \beta\right)=X_{t}^{T} \beta
\end{aligned}
$$

The so-called parameters estimation is to select the appropriate model parameters $\beta$, so that the residual sum of squares of the model is minimal

$$
\left.B(\beta)=\nabla^{2} S(\beta)=V(\beta)^{T} V(\beta)+\sum_{t=n+1}^{N} \varepsilon_{i}(\beta) \nabla^{2} \varepsilon_{i}(\beta) \sum_{t}\left[X_{t}, \beta\right)\right]^{2}
$$

For ARMA(n,m) model,because $f\left(X_{t}, \beta\right)$ is nonlinear function, this problem is called non-linear least-squares problem,we can adopt a variety of iterative methods of optimization theory to calculate it,finally obtain model parameters $\beta$ which make the objective function $S(\beta)$ minimal.

\subsection{Determination of initial value}

At the iterative calculations of nonlinear least-squares, we should give the initial value of iterative calculation.

2.2.1 Determination of parameters initial value $\beta^{0}$

The selection of the parameters initial value $\beta^{0}$ is extremely important,which relates to the convergence speed of iterative calculation, this paper uses the long autoregression model of $\operatorname{AR}_{\left(n_{0}\right)}$.

The transfer function of the equivalent system described by $\operatorname{AR}\left(n_{0}\right)$ model is

$$
\frac{1}{\varphi_{n_{0}}^{0}(B)}=\frac{1}{1-\sum_{i=1}^{n_{0}} I_{i} B^{i}}
$$

Where, $I_{i}$ is inverse function, $I_{i}$ equal $\mathrm{AR}$ model parameters $\varphi_{i}^{0}$

$$
I_{0}=-1, I_{j}= \begin{cases}\varphi_{j}^{0} & (1 \leq j \leq k) ; \\ 0 & (j>k) .\end{cases}
$$

the transfer function of the equivalent system described by ARMA $(n, m)$ model is

$$
\frac{\theta_{n}^{0}(B)}{\varphi_{m}^{0}(B)}=\frac{1-\sum_{j=1}^{n} \theta_{j}^{0} B^{j}}{1-\sum_{i=1}^{m} \varphi_{i}^{0} B^{i}}
$$

Because of the transfer function described in the system are equivalent,(4) and (5) should be equal,namely

$$
\begin{aligned}
& \left(1-I_{1} B-I_{2} B^{2}-\cdots-I_{n_{0}} B^{n_{0}}\right)\left(1-\theta_{1}^{0} B-\theta_{2}^{0} B^{2}-\cdots-\theta_{m}^{0} B^{m}\right)= \\
& 1-\varphi_{1}^{0} B-\varphi_{2}^{0} B^{2}-\cdots-\varphi_{n}^{0} B^{n}
\end{aligned}
$$

Compare the same power coefficient of B on both sides of (6), we have

$$
\left\{\begin{array}{l}
\varphi_{1}^{0}=\theta_{1}^{0}+I_{1} ; \\
\varphi_{2}^{0}=\theta_{2}^{0}-\theta_{1}^{0} I_{1}+I_{2} ; \\
\varphi_{3}^{0}=\theta_{3}^{0}-\theta_{2}^{0} I_{1}-\theta_{1}^{0} I_{2}+I_{3} ; \\
\quad \vdots \\
\varphi_{n}^{0}=-\theta_{m}^{0} I_{n-m}-\cdots-\theta_{2}^{0} I_{n-2}-\theta_{1}^{0} I_{n-1}+I_{n} ; \\
0=-\theta_{m}^{0} I_{k-m}-\cdots-\theta_{2}^{0} I_{k-2}-\theta_{1}^{0} I_{k-1}+I_{k} ; \quad(k>n)
\end{array}\right.
$$

For the first $\mathrm{n}$ equations of the formula,when $\theta_{j}^{0}$ is known,this is the linear equations about $\varphi_{i}^{0}, \varphi_{i}^{0}$ can be easily 
solved

$$
\left[\begin{array}{c}
\varphi_{1}^{0} \\
\varphi_{2}^{0} \\
\varphi_{3}^{0} \\
\vdots \\
\varphi_{n}^{0}
\end{array}\right]=\left[\begin{array}{c}
\theta_{1}^{0} \\
\theta_{2}^{0} \\
\theta_{3}^{0} \\
\vdots \\
\theta_{n}^{0}
\end{array}\right]+\left[\begin{array}{ccccc}
1 & 0 & 0 & \cdots & 0 \\
-\theta_{1}^{0} & 1 & 0 & \cdots & 0 \\
-\theta_{2}^{0} & -\theta_{1}^{0} & 1 & \cdots & 0 \\
\vdots & \vdots & \vdots & \vdots & \vdots \\
-\theta_{n-1}^{0} & -\theta_{n-2}^{0} & -\theta_{n-3}^{0} & \cdots & 1
\end{array}\right]\left[\begin{array}{c}
I_{1} \\
I_{2} \\
I_{3} \\
\vdots \\
I_{n}
\end{array}\right]
$$

When $j>m$, we set $\theta_{j}^{0}=0$.For the last formula in (7),we separately set $k=n+1, n+2, \cdots, n+m$, and $n+m=p$,written by matrix form

$$
\left[\begin{array}{c}
I_{n+1} \\
I_{n+2} \\
\vdots \\
I_{n+m}
\end{array}\right]=\left[\begin{array}{ccccc}
I_{n} & I_{n-1} & I_{n-2} & \cdots & I_{n+1-m} \\
I_{n+1} & I_{n} & I_{n-1} & \cdots & I_{n+2-m} \\
\vdots & \vdots & \vdots & \vdots & \vdots \\
I_{n+m-1} & I_{n+m-2} & I_{n+m-3} & \cdots & I_{n}
\end{array}\right]\left[\begin{array}{c}
\theta_{1}^{0} \\
\theta_{2}^{0} \\
\vdots \\
\theta_{m}^{0}
\end{array}\right]
$$

this is the linear equations about $\theta_{j}^{0}, \theta_{j}^{0}$ can be easily solved.Therefore,we first solve (9) to obtain $\theta_{j}^{0}$, then solve ( 8 ) to obtain $\varphi_{i}^{0}$, this is the calculation principle of long autoregression model.

2.2.2 Determination of residuals initial value $\varepsilon_{t}$

Residual value can be determined by the follow formula

$$
\left\{\begin{array}{c}
\varepsilon_{1}=x_{1} \\
\varepsilon_{2}=x_{2}-\varphi_{1} x_{1}+\theta_{1} \varepsilon_{1} \\
\varepsilon_{3}=x_{3}-\varphi_{1} x_{2}-\varphi_{2} x_{1}+\theta_{1} \varepsilon_{2}+\theta_{2} \varepsilon_{1} \\
\quad \vdots \\
\varepsilon_{n}=x_{n}-\varphi_{1} x_{n-1}-\cdots-\varphi_{n-1} x_{1}+ \\
\quad \theta_{1} \varepsilon_{n-1}+\cdots+\theta_{m} \varepsilon_{n-m}
\end{array}\right.
$$

2.3 The calculation of the gradient $g(\beta)$ and Hesse matrix $B(\beta)$ of the $S(\beta)$

We conduct Taylor expansion for $x_{t}$ in ARMA model at $\boldsymbol{\beta}^{0}$

$$
\begin{aligned}
& x_{t}=f\left(X_{t}, \boldsymbol{\beta}^{0}\right)+\left.\left(\beta_{1}-\beta_{1}^{0}\right) \frac{\partial f\left(X_{t}, \boldsymbol{\beta}\right)}{\partial \beta_{1}}\right|_{\boldsymbol{\beta}=\boldsymbol{\beta}^{0}}+\left(\beta_{2}-\beta_{2}^{0}\right) \frac{\partial f\left(X_{t}, \boldsymbol{\beta}\right)}{\partial \beta_{2}}+\cdots+ \\
& \left.\left(\beta_{p}-\beta_{p}^{0}\right) \frac{\partial f\left(X_{t}, \boldsymbol{\beta}\right)}{\partial \beta_{p}}\right|_{\boldsymbol{\beta}=\boldsymbol{\beta}^{0}}+o\left(\left(\beta_{1}-\beta_{1}^{0}\right)^{2}+\left(\beta_{2}-\beta_{2}^{0}\right)^{2}+\cdots+\left(\beta_{p}-\beta_{p}^{0}\right)^{2}\right)
\end{aligned}
$$

2.3.1 The calculation of the vector $\varepsilon_{t}^{k}$

$$
\varepsilon_{t}^{0}=x_{t}-\sum_{i=1}^{n} \varphi_{i}^{0} x_{t-i}+\sum_{j=1}^{m} \theta_{j}^{0} \varepsilon_{t-j}^{0} \quad(\mathrm{t}=\mathrm{n}+1, \mathrm{n}+2, \cdots \mathrm{N})
$$

Where,the initial value of the residual $\varepsilon_{1}^{0}, \varepsilon_{2}^{0}, \cdots \varepsilon_{n-1}^{0}, \varepsilon_{n}^{0}$ are calculated by (10), vector $\varepsilon_{0}=\left[\varepsilon_{n+1}^{0} \varepsilon_{n+2}^{0} \cdots \varepsilon_{N}^{0}\right]^{T}$. Therefore $\varepsilon_{k}=\left[\begin{array}{cccc}\varepsilon_{n+1}^{k} & \varepsilon_{n+2}^{k} \cdots \varepsilon_{N}^{k}\end{array}\right]^{T}$.

2.3.2 The calculation of the vector $V_{k}$

$$
V_{i t}^{k}=-\left.\frac{\partial \varepsilon_{t}}{\partial \beta_{i}}\right|_{\beta=\beta_{k}} \approx-\frac{\varepsilon_{t}\left(\beta^{k}+\Delta_{i}\right)-\varepsilon_{t}\left(\beta^{k}\right)}{\Delta}
$$

Where, $\Delta_{i}$ is $\mathrm{p}=\mathrm{n}+\mathrm{m}$ vector $\Delta_{i}=[0 \cdots 0 \Delta 0 \cdots 0]^{T}$, combining (12) with (14), we have 


$$
V_{i t}^{k}= \begin{cases}x_{t-i} & (1 \leq i \leq n) \\ -\varepsilon_{t-j}^{k} & (n+1 \leq i \leq n+m=p, j=i-n)\end{cases}
$$

We let $t=n+1, n+2, \cdots, N ; i=1,2 \cdots p=n+m$,

$$
V^{k}=\left[\begin{array}{cccccccc}
x_{n} & x_{n-1} & \cdots & x_{1} & -\varepsilon_{n}^{k} & -\varepsilon_{n-1}^{k} & \cdots & -\varepsilon_{n-m+1}^{k} \\
x_{n+1} & x_{n} & \cdots & x_{2} & -\varepsilon_{n+1}^{k} & -\varepsilon_{n}^{k} & \cdots & -\varepsilon_{n-m+2}^{k} \\
\vdots & \vdots & \vdots & \vdots & \vdots & \vdots & \vdots & \vdots \\
x_{N-1} & x_{N-2} & \cdots & x_{N-n}-\varepsilon_{N-1}^{k} & -\varepsilon_{N-2}^{k} & \cdots & -\varepsilon_{N-m}^{k}
\end{array}\right]
$$

Because $\varepsilon_{t-1} \quad \varepsilon_{t-2} \ldots \varepsilon_{t-m}$ in $x_{t}$ are unknown, which are calculated by $x_{t-1} \quad x_{t-2} \quad \ldots$,however we are unable to show $\varepsilon_{t-1} \quad \varepsilon_{t-2} \ldots \varepsilon_{t-m}$, then the gradient $g(\beta)$ and Hesse matrix $B(\beta)$ are unable to be calculated.We substitute derivative with difference to calculate the gradient $g(\beta)$ and Hesse matrix $B(\beta)$ of $S(\beta)$.

$$
\begin{aligned}
& g(\beta)=\nabla S(\beta)=V(\beta)^{T} \varepsilon(\beta) \\
& B(\beta)=\nabla^{2} S(\beta)=V(\beta)^{T} V(\beta)+\sum_{t=n+1}^{N} \varepsilon_{i}(\beta) \nabla^{2} \varepsilon_{i}(\beta)
\end{aligned}
$$

If the non-linear degree of the this problem is relatively high,we approximate Hesse matrix by BFGS formula;If the non-linear degree of the this problem is relatively low,we approximate Hesse matrix by first derivative.

\subsection{Trust region method}

Trust region method is iterative method,at each iteration,we solve trust region subproblem

$\left\{\begin{array}{l}\min q^{k}(d)=S\left(\boldsymbol{\beta}^{k}\right)+\left(g^{k}\right)^{T} d+\frac{1}{2} d^{T} B^{k} d \\ \text { s.t. }\|d\| \leq \Delta_{k}\end{array}\right.$

Where $g(\beta)=\nabla S(\beta)$ or its approximation, $\Delta_{k}$ is trust region radius.

At this iterative point $\boldsymbol{\beta}^{k}$, we solve the trust region subproblem to obtain the trial step $d_{k}$, we consider the actual reduction given by

$\Delta S_{k}=S_{k}-S_{k+1}$

and the predictable reduction will be given by

$\Delta S_{k}^{\text {pred }}=S_{k}-q^{k}\left(d_{k}\right)$

Define their ratio

$r^{k}=\frac{\Delta S_{k}}{\Delta S_{k}^{\text {pred }}}$

Trust region method adjust the radius of trust region by the information of their ratio .

\section{Algorithm}

Step 1 given time series $\left\{x_{t}\right\}(\mathrm{t}=1,2, \cdots \mathrm{N})$, model order $\mathrm{n}, \mathrm{m}$ and the initial value of the model parameters $\boldsymbol{\beta}^{0}=\left[\varphi_{1}^{0}, \cdots, \varphi_{n}^{0}, \theta_{1}^{0}, \cdots, \theta_{m}^{0}\right]^{T}$.

Step 2 calculate $\left\{\varepsilon_{t}^{k}\right\}(\mathrm{t}=\mathrm{n}+1, \mathrm{n}+2, \cdots \quad \mathrm{N})$,form vector $\varepsilon^{k}$,calculatev $V^{k}$ by (16). Then calculat $S^{k}=S\left(\boldsymbol{\beta}^{k}\right)=\left(\varepsilon^{k}\right)^{T} \varepsilon^{k}, g^{k}=\left(V^{k}\right)^{T} \varepsilon^{k}$ and $B^{k}=\left(V^{k}\right)^{T} V^{k}$.set $k=0, \Delta_{0}=\left\|g_{0}\right\|, 0<c_{1}<c_{2}<1$.

Step 3 solve the subproblem (18) and obtain $d_{k}$

Step 4 Set $\boldsymbol{\beta}^{k+1}=\boldsymbol{\beta}^{k}+d^{k}$, calculate $S\left(\boldsymbol{\beta}^{k+1}\right)$

if $S\left(\boldsymbol{\beta}^{k+1}\right)>S\left(\boldsymbol{\beta}^{k}\right)$ set $\Delta_{k+1}=\frac{\Delta_{k}}{2}$, go to step 3; 
else if $S\left(\boldsymbol{\beta}^{k+1}\right) \geq S\left(\boldsymbol{\beta}^{k}\right)+\rho\left(g^{k}\right)^{T}\left(\boldsymbol{\beta}^{k+1}-\boldsymbol{\beta}^{k}\right)$,

set $\Delta_{k+1}=-\Delta_{k} \frac{\left(g^{k}\right)^{T} d^{k}}{2\left(S^{k+1}-S^{k}-\left(g^{k}\right)^{T} d\right)}$, go to step 3;

else go to step 5 .

Step 5 if $S^{k+1}-S^{k} \leq \varepsilon \max \left(1, S^{k}\right)$,stop;else go to step 6 .

Step 6 calculate $V^{k+1}$ by (16)

Step 7 update trust region radius

$$
\Delta_{k+1}=\left\{\begin{array}{l}
2 \Delta_{k}, r_{k} \geq c_{2} \\
\frac{\Delta_{k}}{4}, r_{k} \leq c_{1} \\
\Delta_{k}, c_{1} \leq r_{k} \leq c_{2}
\end{array}\right.
$$

Step8 update $B^{k}$,set $\mathrm{k}=\mathrm{k}+1$, go to step 3 .

$$
B^{k+1}=\left\{\begin{array}{l}
B_{k}+\frac{y^{k}\left(y^{k}\right)^{T}}{\left(d^{k}\right)^{T} y^{k}}-\frac{\boldsymbol{B}^{k} d^{k}\left(d^{k}\right)^{T} \boldsymbol{B}^{k}}{d^{k} \boldsymbol{B}^{k} d^{k}}, \frac{S_{k}-S_{k+1}}{S_{k}}<\rho_{1}, \rho_{1} \in(0,1) \\
\left(V^{k+1}\right)^{T} V^{k+1}, \text { otherwise }
\end{array}\right.
$$

\section{The analysis of the convergence property}

Assumptions:

1) The level set $L(\beta)=\left\{\beta \mid S(\beta) \leq S\left(\beta_{0}\right)\right\}$ is bounded.

2) Hesse approximation matrix $B_{k}$ is uniformly bounded according to norm, namely $\left\|B_{k}\right\| \leq M, M$ is a positive constant.

3) The function $S$ is second continuously differentiable and has the lower bound at level set.

Lemma 1 if $d_{k}$ is the solution of (18), then it satisfies

$$
\begin{gathered}
\left(g_{k}\right)^{T} d_{k} \leq-\frac{1}{2}\left\|g_{k}\right\| \min \left\{\Delta_{k}, \frac{\left\|g_{k}\right\|}{\left\|B_{k}\right\|}\right\} \\
\left(g_{k}\right)^{T} d_{k}+\frac{1}{2} d_{k}^{T} B_{k} d_{k} \leq-\frac{1}{2}\left\|g_{k}\right\| \min \left\{\Delta_{k}, \frac{\left\|g_{k}\right\|}{\left\|B_{k}\right\|}\right\}
\end{gathered}
$$

Lemma 2 Assume $\left\{\beta_{k}\right\}$ are iterative sequence generated by the algorithm, then $S\left(\beta_{k}\right)$ is monotonous and non-increasing.

Proof:assume $\alpha_{k}=\frac{p}{2 L\left\|d_{k}\right\|^{2}},(L \geq 1)$,

where $p=\left\|g_{k}\right\| \min \left\{\Delta_{k}, \frac{\left\|g_{k}\right\|}{\left\|B_{k}\right\|}\right\}, \beta_{k+1}=\beta_{k}+\alpha_{k} d_{k}$

By the mean value theorem, there exists

$$
S\left(\beta_{k+1}\right)-S\left(\beta_{k}\right)=\bar{g}^{T}\left(\beta_{k+1}-\beta_{k}\right)
$$

Where $\bar{g}=g(\bar{x}), \bar{x} \in\left[x_{k+1}, x_{k}\right]$, by Lipschitz conditions, we have $\left\|x-x_{k}\right\| \leq \alpha_{k} d_{k}$ and

$$
\begin{aligned}
\bar{g}^{T}\left(\beta_{k+1}-\beta_{k}\right)= & \bar{g}_{k}^{T}\left(\beta_{k+1}-\beta_{k}\right)+\left(\bar{g}-g_{k}\right)^{T}\left(\beta_{k+1}-\beta_{k}\right) \\
& \leq \alpha_{k} g_{k}{ }^{T} d_{k}+\alpha_{k} L\left(\beta_{k+1}-\beta_{k}\right)^{T} d_{k} \\
& =\alpha_{k} g_{k}{ }^{T} d_{k}+\alpha_{k}^{2} L\left\|d_{k}\right\|^{2}
\end{aligned}
$$




$$
=\alpha_{k} g_{k}^{T} d_{k}+\alpha_{k} \frac{p}{2\left\|d_{k}\right\|^{2}}\left\|d_{k}\right\|^{2}
$$

By lemma 1,we have $\left(g_{k}\right)^{T} d_{k} \leq-\frac{p}{2}$, so $\bar{g}^{T}\left(\beta_{k+1}-\beta_{k}\right) \leq \alpha_{k}\left(-\frac{p}{2}+\frac{p}{2}\right)=0$

Therefore, $S\left(\beta_{k}\right)$ is monotonous and non-increasing.

Next we analyze the global convergence of this algorithm.

Theorem 1 If the assumptions hold,then the sequence generated by the algorithm satisfies $\liminf _{k \rightarrow \infty}\left\|g_{k}\right\|=0$.

Proof:Assume the conclusion does not hold,that is to say here exists $\varepsilon>0$, for all $k$, we have $\left\|g_{k}\right\| \geq \varepsilon$ and $-q^{k}\left(d^{k}\right) \geq \frac{1}{2}\left\|g_{k}\right\| \min \left\{\Delta_{k}, \frac{\left\|g_{k}\right\|}{\left\|B_{k}\right\|}\right\}$,

Because $\Delta_{k}$ has lower bound which is recorded as $\Delta \eta$ and $\left\|B_{k}\right\| \leq M$, we have

$$
-q^{k}\left(d^{k}\right) \geq \frac{1}{2} \varepsilon \min \left\{\Delta \eta, \frac{\varepsilon}{M}\right\}
$$

This show $-q^{k}\left(d^{k}\right)$ has lower bound,which is contradictory with $\lim _{k \rightarrow \infty}-q^{k}\left(d^{k}\right)=0$

This proposition is proved.

\section{References}

Y Dai. (2003). Convergence properties of the BFGS a lgorithm. Journal on Optimization, 2003, (13): 693 -701.

Yang,, Shuzi \& Wu, Ya. (2007). The engineering applications in time series analysis. Huazhong University of Science and Technology Publishing House.

Yuan, Gonglin \& Wei, Zengxin. (2004). One new BFGS trust region algorithm.Guangxi Science. 2004, $11,195 \sim 196$.

Zhang, Changhai, Fan, Ying, \& Zhang, Lianbing. (1993). An amendment to the trust region method and its convergence. Heilongjiang Science and Technology Press, 1993, 64 65.

Zhang, Jianahong \& Deng,Naiyang. (1999). A new quasi-Newton equation and related methods for unconstrained optimrzation. 1999,102(3); 147 187. 


\title{
Quantification of Sakuranetin in Paddy Leaves and Stem
}

\section{after Elicitation with Abiotic Elicitors (UV, $\mathrm{AgNO}_{3}, \mathrm{CuSO}_{4}$ )}

\author{
Mok Sam Lum (Corresponding author) \\ School of Sustainable Agriculture, Universiti Malaysia Sabah \\ Locked Bag 2073, 88999 Kota Kinabalu, Sabah, Malaysia \\ Tel: 60-88-320-000Ｅ-mail: 1mmoksam@ums.edu.my \\ Ratnavell Muniandy \\ School of Science and Technology, Universiti Malaysia Sabah \\ Locked Bag 2073, 88999 Kota Kinabalu, Sabah, Malaysia
}

\begin{abstract}
Phytoalexins are substances produced in appreciable amounts in plants only after stimulation of various biotic or abiotic agents. Sakuranetin was extracted from paddy leaves and stem after elicitated by silver nitrate, cuprum (II) sulfate and UV irradiation. Thin layer chromatography (TLC) was conducted to detect the presence of sakuranetin at $\mathrm{R}_{\mathrm{f}} 0.09$ under $365 \mathrm{~nm}$ UV light. Extracted sakuranetin was subjected to spectrophotometry at $337 \mathrm{~nm}$. The concentration of sakuranetin present in the sample was calculated. Elicitation by silver nitrate significantly accumulated the highest amount of sakuranetin in leaves of paddy followed by UV radiation and cuprum sulfate. However, elicitation by UV radiation and silver nitrate in paddy stems produced significantly highest amount of sakuranetin. Comparing of sakuranetin amount recovered from leaves and stem, the leaves appeared to be significantly accumulated higher amount of sakuranetin than that recovered from stem.
\end{abstract}

Keywords: Sakuranetin, Phytoalexins, Abiotic elicitors

\section{Introduction}

Plants also defense themselves through production of secondary metabolites like phytoalexins. Phytoalexin is toxic antimicrobial substances produced in appreciable amounts in plants only after stimulation by various types of pytopathogenic microorganisms or by chemical or mechanical injury (Agrios, 2004). Phytoalexins are produced by healthy cells adjacent to localized damaged and necrotic cells in response to material diffusing from the damaged cells. Resistance occurs when one or more phytoalexins reach a concentration sufficient to restrict pathogen development (Lo et al., 1996).

Phytoalexins like momilactones A and B (Cartwright et al., 1981), oryzalexins A-F, oryzalexin S, phytocassanes A-D (Dillon et al., 1997) and sakuranetin (Kodama et al., 1992) can be found in diseases-infected paddy plants. Sakuranetin can be induced under a variety of biotic and abiotic stress stimuli. Sakuranetin showed the highest antifungal activity among the rice phytoalexins and the content of sakuranetin in blast infected rice leaves is much higher than that of other rice phytoalexins (Kodama et al., 1992).

\section{Materials and Methods}

\subsection{Plant material and growth conditions}

The seeds of rice (Jaya variety) were germinated on cotton soaked in water in a small basin under laboratory temperature $\left(25^{\circ} \mathrm{C}\right)$ for six to ten days. The seedlings were then planted in sterilized organic soil. Basins without holes used to create flooded environment for optimum growing condition for paddy. Seedlings were grown under sun light (Dillon et al., 1997).

\subsection{Elicitation of sakuranetin using abiotic elicitors}

\subsubsection{Silver Nitrate $\left(\mathrm{AgNO}_{3}\right)$ Elicitation}

Fresh leaves and stems of 50 eight weeks aged paddy plants were sprayed with $1 \%$ of $\mathrm{AgNO}_{3}$ with a few drops of Tween 20. The plants were left for 3.5 days for phytoalexin accumulation. 


\subsubsection{Cuprum (II) sulfate $\left(\mathrm{CuSO}_{4}\right)$ elicitation}

Fresh leaves and stems of 50 eight weeks aged paddy plants were sprayed with $5 \%$ of $\mathrm{CuSO}_{4}$ with a few drops of Tween 20. The plants were left for 3.5 days for phytoalexin accumulation.

\subsubsection{UV irradiation of Sakuranetin}

About $15 \mathrm{~g}$ of fresh leaves and stems of eight weeks aged paddy plants were cut and floated with adaxial side upper-most in tap water with a drop of Tween 20 in a clear plastic sandwich box. The box was then irradiated with UV light for $20 \mathrm{~min}$. After irradiation, the box was sealed with cling film and incubated at $26^{\circ} \mathrm{C}$ under a 12 hours dark and 12 hours light regime, starting with a dark period of at least eight hours for 3.5 days (Dillon et al., 1997).

\subsection{Extraction of sakuranetin from rice leaves and stems}

Fifteen-gram of each leaves and stem were cut into small pieces $(1-2 \mathrm{~cm})$. Leaf and stem pieces were soaked into 100 $\mathrm{ml}$ of $70 \%$ aqueous Methanol (at boiling point) in a conical flask and boiled for $10 \mathrm{~min}$ on a hot water bath. After cooling, the flasks were left at room temperature for 24 hours in the dark. The extracts were then filtered through a Whatman No.1 filter paper and washed with $100 \mathrm{ml}$ of $70 \%$ aqueous methanol. The extracts were concentrated in vacuo at $40^{\circ} \mathrm{C}$. The concentrated leaf and stem extracts were re-extracted three times with $2 \mathrm{ml}$ of diethyl ether. The combined ether fractions were evaporated to dryness on a rotary evaporator (Dillon et al., 1997).

\subsection{Detection of sakuranetin by using thin layer chromatography}

Fifteen-milliliter of ethanol was added to the leaf and stem extracts. The extracts were spotted on thin layer chromatography (TLC) plate (Merck kiesel $60 \quad \mathrm{~F}_{254}$ ). The plates were developed in chromatography tanks pre-equilibrated with chloroform:ethanol $(97: 3 \mathrm{v} / \mathrm{v})$ as developing solvent. Sakuranetin was detected at $R_{\mathrm{f}} 0.09$ as a green fluorescence under ultraviolet light $(365 \mathrm{~nm})$. Green fluorescence zone was marked under ultraviolet and scraped off into centrifuge tubes and eluted with chloroform:ethanol, 90:10 v/v. After filtering, the elute was concentrated to dryness (Atkinson \& Blakeman, 1982).

\subsection{Quantification of sakuranetin by spectrophotometry}

The recovered sakuranetin was subjected to spectrophotometry with a maximum absorbance at $337 \mathrm{~nm}$ (Dillon et al., 1997). Using absorbtivity coefficient concentration of sakuranetin, the quantity of sakuranetin in sample was determined by Beer-Lambert Law.

\section{Results}

\subsection{Elicitation of sakuranetin}

After two days of elicitation with silver nitrate, cuprum sulfate and UV radiation, the leaves and stem of paddy started to show necrosis (Figure 1, Figure 2, Figure 3 and Figure4), whereas control leaves remained green for this period. These showed that a hypersensitive reaction had taken place.

\subsection{Detection of sakuranetin by Thin Layer Chromatography (TLC)}

All the extracts were developed in TLC plates to detect the presence of sakuranetin zone. Sakuranetin clearly can be seen under UV light at $365 \mathrm{~nm}$ with green fluorescence colour at $\mathrm{R}_{\mathrm{f}}$ value 0.09 as in Figure 6 (Atkinson and Blakemen, 1982). Trace amount of Sakuranetin was also detected at $R_{f} 0.09$ in the control although the leaves and stems were not subjected to any chemical treatments (Figure 5).

\subsection{Quantification of recovered sakuranetin}

Sakuranetin recovered from TLC was subjected to spectrophotometry at $337 \mathrm{~nm}$ for quantification. Graph from spectrophotometry for sakuranetin is shows maximum absorbance is $337 \mathrm{~nm}$. Figure 7 illustrates the amount of sakuranetin accumulated in paddy leaves and stems after elicitation by UV radiation, silver nitrate and cuprum sulfate. Elicitation by silver nitrate significantly accumulated the highest amount of sakuranetin in leaves of paddy followed by elicitation by UV radiation and cuprum sulfate. However, elicitation by UV radiation and silver nitrate in paddy stems produced significantly highest amount of sakuranetin. Comparing sakuranetin amount recovered from both leaves and stem, leaves appeared to be significantly higher than that recovered from stem.

\section{Discussion}

Leaves and stem of paddy plants which already elicited by abiotic factors showed necrosis. High amount of sakuranetin can be extracted at the location from leaves that showed necrosis (Figure 1 \& Figure 2). Previous study on Ribes nigrum leaves indicated sakuranetin was largely associated with the adaxial surface but low level of sakuranetin were found in abaxial surface extracts (Atkinson \& Blakeman, 1982). They suggested that difference in structure of glands in both adaxial and abaxial sides might be the reasons for their different chemical contents. In addition, Dillon et al. (1997) suggested that adaxial surface of paddy leaves should receive UV irradiation in the methods. Tween 20 was used when silver nitrate and $\mathrm{CuSO}_{4}$ were sprayed so that adhesion of the droplet on waxy leaves surface will give positive result. 
Dark brown and chlorosis patches were observed on the leaves of elicited plant. Based on the observation, the dark brown patches were actually changed by the stained of abiotic agents and developed more rapidly than chlorosis. Chlorosis appears in later stages of elicitation due to structural change in the cell itself. Damage in cell such as swollen and disruption of chloroplast caused this yellowish lesion. Destruction of chloroplast decreased the photosynthesis rates and finally plants will die (Miyake et al., 2006). Elicitation of $\mathrm{AgNO}_{3}$ also caused desiccation on protoplasm. Removal of water lead to the decreasing of protoplast volume that may itself have serious structural and metabolic consequences such as disruption in stem and leaves thus caused the plant wilted. Less dark brown lesion and chlorosis was observed in stem (Figure $3 \&$ Figure 4 ) than leaves. It is because the surface of stem is covered by thick lignin compared to leaf that helps them to prevent from absorption of silver nitrate into the cell.

Elicitation by $\mathrm{AgNO}_{3}$ significantly accumulated the highest amount of sakuranetin in paddy leaves followed by elicitation by $\mathrm{CuSO}_{4}$ and $\mathrm{UV}$ irradiation. However, elicitation by UV irradiation and $\mathrm{AgNO}_{3}$ in paddy stems produced significantly highest amount of sakuranetin. Leaves appeared to be significantly accumulated higher sakuranetin amount compare to stems (Figure 7).

The quantity of sakuranetin produced in stem part after $\mathrm{AgNO}_{3}$ elicitation and UV irradiation was not significantly different (Figure 7). Thus, is probably due to the hard surface of the stem. The spraying might not be a suitable method for the $\mathrm{AgNO}_{3}$ and $\mathrm{CuSO}_{4}$ to be fully taken up into the stem. Thus, sakuranetin accumulation in the stem after elicited with abiotic agents was lower than in leaves.

There is no any research has been carried out before on paddy stem for sakuranetin accumulation. In this study, compared to leaves, stem accumulated lower amount of sakuranetin using all the three types of elicitation methods. According to Dillon et al. (1997), production of sakuranetin in paddy plant is a localized reaction. Compare to leaves, stem hardly produce lesions after elicitation. Therefore, fewer sakuranetin accumulated in stems.

Trace amount of sakuranetin was also detected at $R_{\mathrm{f}} 0.09$ in the control, although the leaves were not subjected to any chemical treatments (Figure 5). The mean value of the sakuranetin produced in paddy leaves and stems were 0.11 $\mu \mathrm{gml}^{-1}$ and $0.09 \mu \mathrm{gml}^{-1}$ respectively. However, the paddy leaves and stem elicited by $\mathrm{AgNO}_{3}, \mathrm{UV}$ and $\mathrm{CuSO}_{4}$ were accumulated higher amount of sakuranetin compared to control plates. It is known that biosynthesis of phytoalexins can be triggered by biotic and abiotic agents. Abiotic elicitors include chemicals, such as mercury salts and copper, physical agents such as injury, partial freezing and thawing, and UV radiation (Ebel, 1986; Soylu et al., 2002). Thus, slightly production of sakuranetin in control might be due to the non biological stress, such as the rapid temperature changed outside our Lab.

Production of sakuranetin after elicitation by chemical elicitors like silver nitrate is higher compared to the non-chemical abiotic elicitors. The production of sakuranetin using chemical abiotic elicitors might not only caused by stress factor. Higher accumulation of sakuranetin may also due to either the release of plant's constitutive elicitors or the increased activities of the enzymes (Darvill \& Albersheim, 1984) that could be intermediate in the elicitation of phytoalexin. Increase in the activities of enzymes have always been a reason for the production of phytoalexins and many researches had been done to investigate the degree of enzymes activities in conjunction with the phytoalexin synthesized (Hardviger \& Schwochau, 1971; Loschke et al., 1983). This may also be applicable for sakuranetin as well.

\section{Conclusion}

Different amounts of sakuranentin were recovered from the extraction of elicited paddy leaves and stems. In this research, leaves produced higher amount of sakuranetin compared to stems. Comparison in the effectiveness of abiotic elicitors that have been used in this research, $\mathrm{AgNO}_{3}$ is the best abiotic elicitors. $\mathrm{AgNO}_{3}$ elicitation produced higher amount of sakuranetin followed by UV-irradiation and $\mathrm{CuSO}_{4}$.

\section{Acknowledgments}

The authors are grateful to the Universiti Malaysia Sabah, Malaysia for the facilities provided to complete this project.

\section{References}

Agrios, G. N. (2004). Plant Pathology. (5 ${ }^{\text {th }}$ ed.). New York: Elsevier Academic Press, pp. 627-633.

Atkinson, P., \& Blakeman, J. P. (1982). Seasonal occurrence of an antimicrobial flavanone, sakuranetin, associated with glands of leaves of Ribes nigrum. The New Phytologist, 92, 63-74.

Cartwright, D. W., Langcake, P., Pryce, R. J., Leworthy, D. P., \& Ride, J. P. (1981). Isolation and characterization of two phytoalexins from rice as momilactones A and B. Phytochemistry, 20, 535-537.

Darvill, A. G., \& Albersheim, P. (1984). Phytoalexins and their elicitors. Annual Review of Plant Physiology, 35, 243-275.

Dillon, V. M., Overton, J., Grayer, R. J., \& Harbone, J. B. (1997). Differences in phytoalexin response among rice cultivars of different resistance to blast. Phytochemistry, 44 (4), 559-603. 
Ebel, J. (1986). Phytoalexin synthesis: The biochemical analysis of the induction process. Annual Review of Phytopathology, 24, 235-264.

Hadwiger, L. A., \& Schwochau, M. E. (1971). Ultraviolet light-induced formation of pisatin \& phenylamine ammonia lyase. Plant Physiology, 47, 588-590.

Kodama, O., Miyakawa, J., Akatsuka, T., \& Kiyosawa, S. (1992). Sakuranetin, a flavonone phytoalexin from UV-irradiated rice leaves. Phytochemistry, 31 (11), 3807-3809.

Lo, S. C., Weiergang, I., Bonham, C., Hipskind, J., Wood, K., \& Nicholson, R. L. (1996). Phytoalexin accumulation in sorghum: Identification of a methyl ether of luteolinidin. Physiological and Molecular Plant Pathology, 49, $21-31$.

Loschke, D. C., Hadwiger, L. A., \& Wagoner, W. (1983). Comparison of mRNA population coding for phenylalanine ammonia lyse and other peptides from from pea tissue treated with biotic and abiotic phytoalexin inducers. Physiological Plant Pathology, 23, 163-173.

Miyake, H., Mitsuya, S., \& Md. Shahidur, R. (2006). Ultrastructural effects of salinity stress in higher plants. In: Ashwani, A.K. \& Takabe, T. (ed), Abiotic stress tolerance in plants. Springer, Netherlands, pp. 215-226.

Soylu, S., Bennett, M. H., \& Mansfields, J. W. (2002). Induction of phyotoalexin accumulationin broad bean (Vicia faba L.) cotyledons following treatments with biotic and abiotic elicitors. Turkish Journal of Agriculture and Forestry, $26,343-348$.

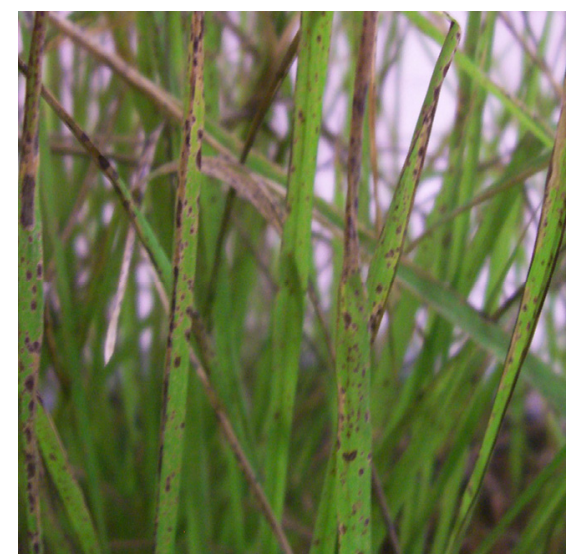

Figure 1. Necrotic phases in paddy leaves after elicitation by $\mathrm{AgNO}_{3}$

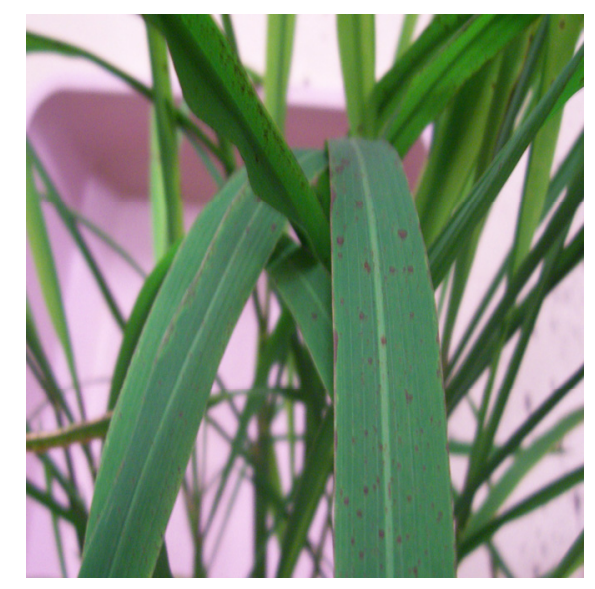

Figure 2. Necrotic phases in paddy leaves after elicitation by $\mathrm{CuSO}_{4}$ 


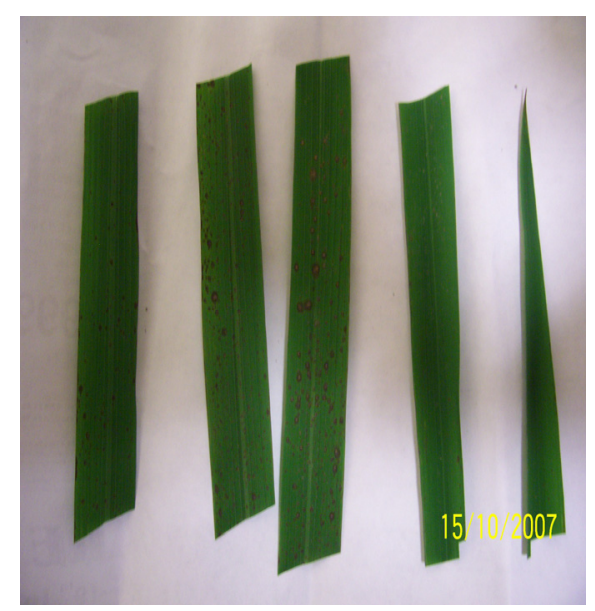

Figure 3. Necrotic phases in paddy leaves after elicitation by UV irradiation

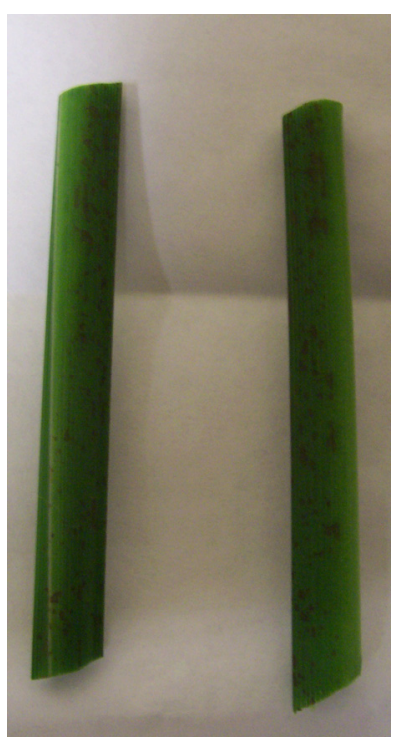

4(a)

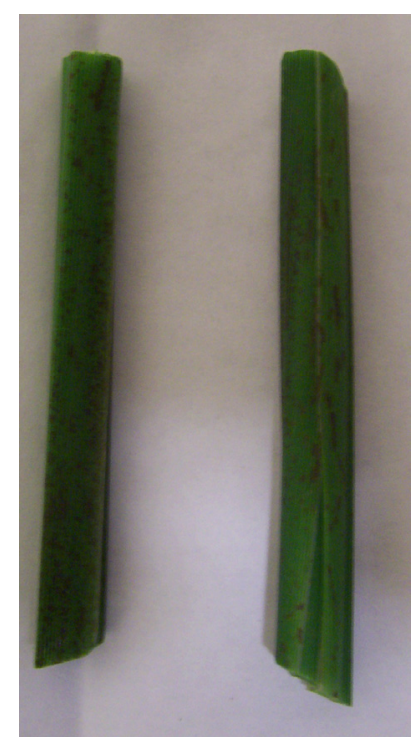

4(b)

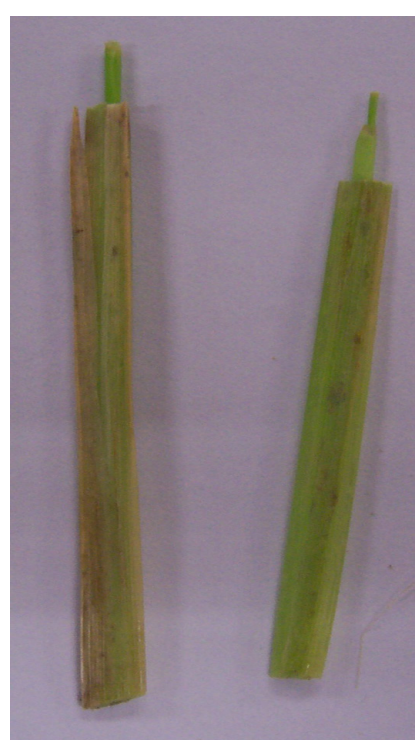

$4(\mathrm{c})$

Figure 4. Necrotic phases in paddy stem after elicitation by (a) $\mathrm{CuSO}_{4}$, (b) $\mathrm{AgNO}_{3}$ (c) UV irradiation

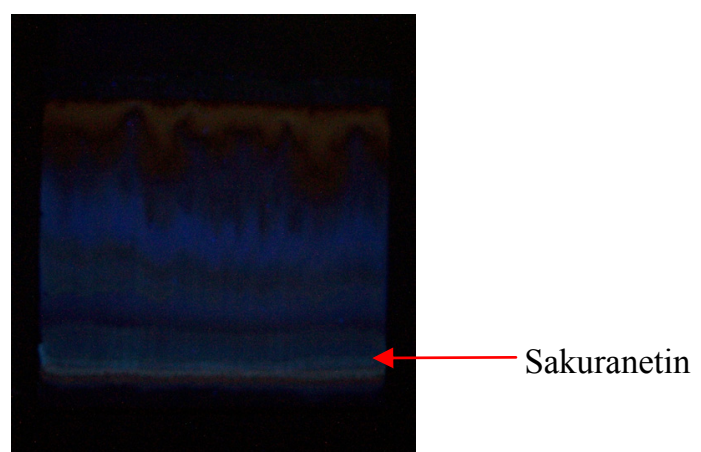

Figure 5. The presence of a trace amount of sakuranetin at $\mathrm{R}_{\mathrm{f}}$ value 0.09 in control TLC plate for leaves under $365 \mathrm{~nm}$ UV light 


\section{Elicitation}

(a) $\mathrm{AgNO}_{3}$

(b) $\mathrm{CuSO}_{4}$

(c) UV irradiation
TLC Plates

Leaves

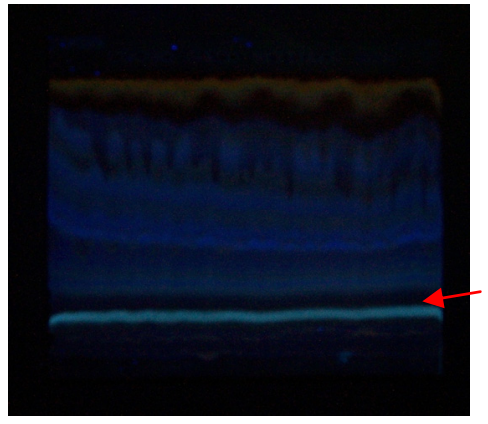

Sakuraneti
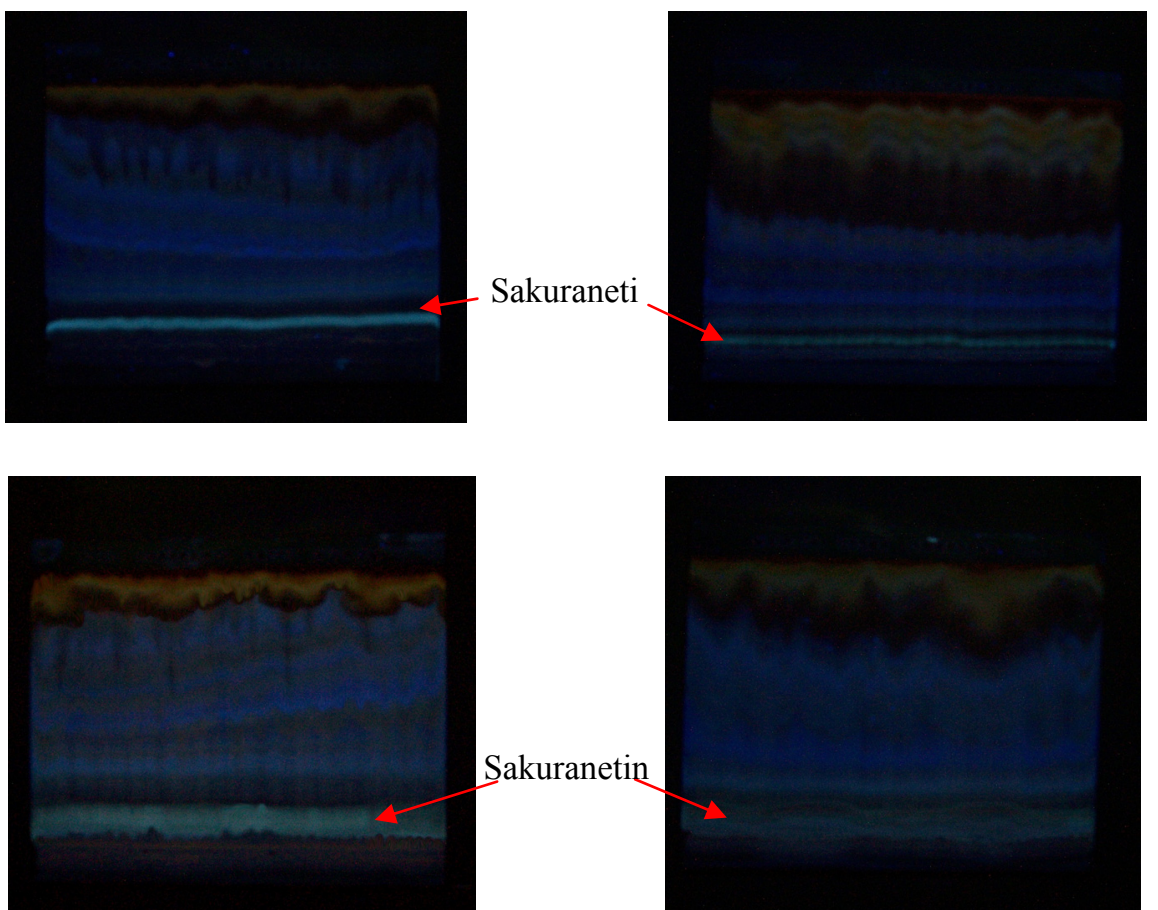

Sakuranetin
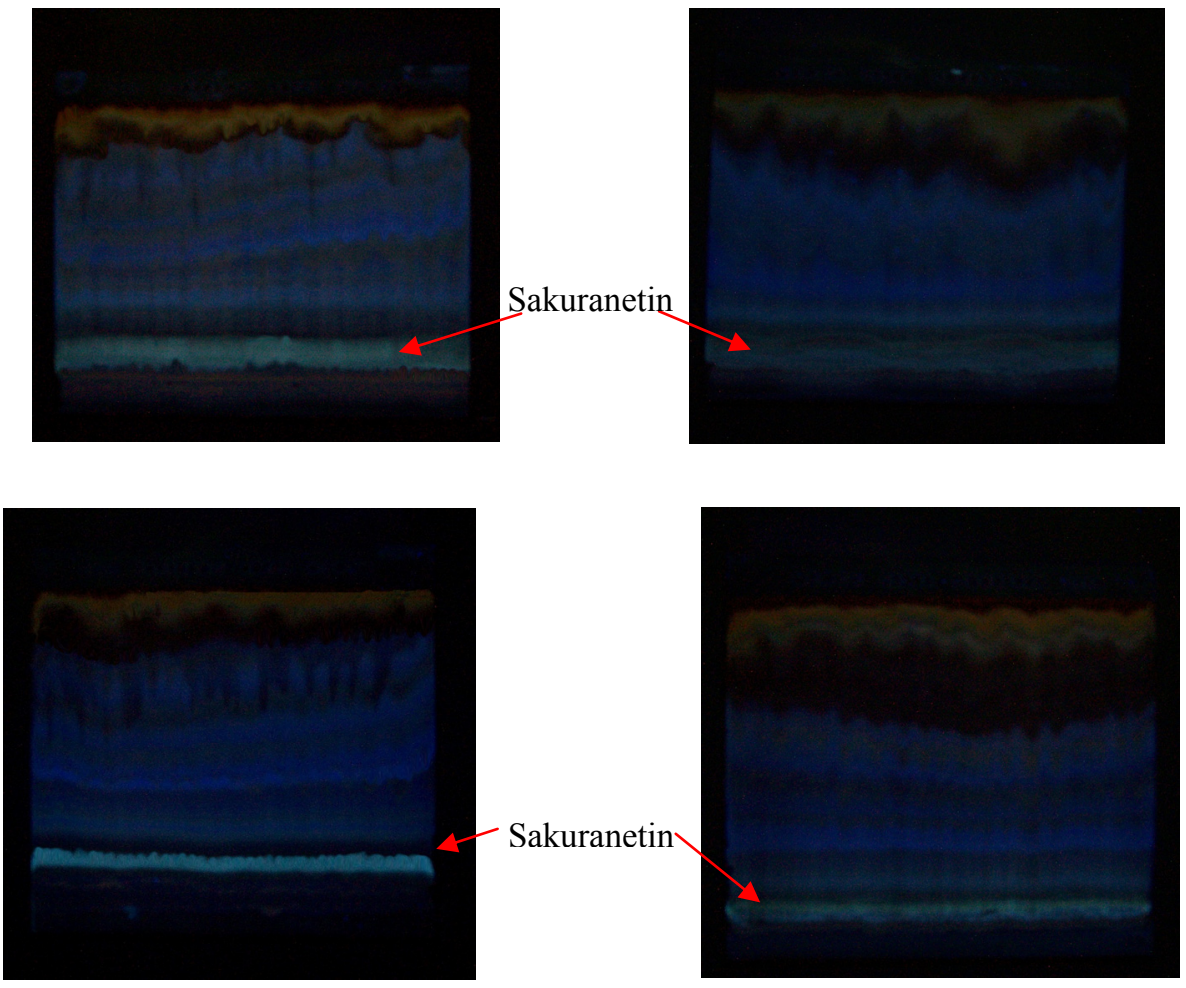

Figure 6. The presence of Sakuranetin at $\mathrm{R}_{\mathrm{f}}$ value 0.09 in TLC plate under $365 \mathrm{~nm}$ UV light for leaves and stem subjected to $\mathrm{AgNO}_{3}$ elicitation, $\mathrm{CuSO}_{4}$ elicitation, and $\mathrm{UV}$ irradiation 


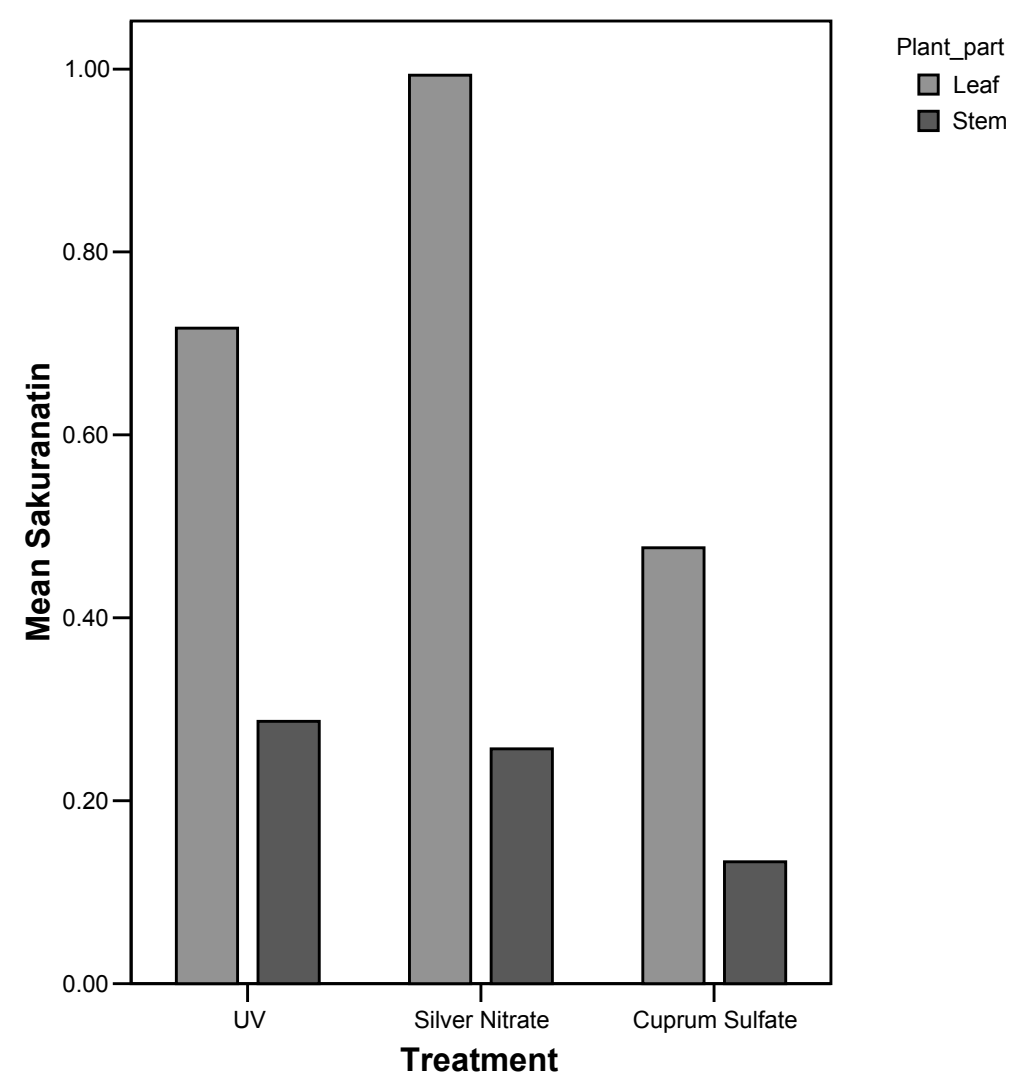

Figure 7. Sakuranetin recovered in paddy leaves and stem after elicitation by UV irradiation, silver nitrate and cuprum sulfate in bar chart 


\title{
VC++ Programming Implementation of Profile Processing
}

\author{
for BMP Image File Extraction
}

\author{
Zheng Dong, Liangyu Li \& Junfeng Li \\ College of Information and Communication Engineering \\ Tianjin Polytechnic University, Tianjin 300160, China \\ E-mail: dongzheng829@163.com
}

\begin{abstract}
To analyze the image shape, it is necessary to express the profile character of image by special method under certain situation, and the aim of image profile extraction is to obtain the exterior profile character of image. Taking the BMP image file as the example, in this article, we used $\mathrm{VC}++$ to implement the read, image strengthening, threshold division and profile extraction of 256bits color graph, and obtained the bitmap file which could fulfill the image analysis finally.
\end{abstract}

Keywords: BMP image file, $\mathrm{VC}++$, Profile Extraction

The image profile extraction is an important image processing technology, and it is the key approach to better implement image analysis and the based to fully grasp image information.

The profile of the image is one important character of the image. The so-called profile means the set of the pixel points which pixel values change obvious surrounding the image, and it is the basic character depending by image analysis.

\section{BMP image file}

BMP (Bit Map Picture) format is a sort of standard format to exchange image and image data in Windows. The data of BMP image include bit map file header, bit map information header, palette and image data.

In the BMP image file, the bit map file header is the structure which length is fixed to be 14 bytes and the bit map information header is also the structure which length is fixed to be 40 bytes. The palette exists only for those bit map files which need palette. The true color palette doesn't need palette, and the bit map information header directly follows image data. The image data is the actual image data. For the bit maps which use palette, the image data are the index values of the image pixel color in the palette, and for the true color image, the image data are actual $R$ value, $G$ value and $B$ value.

\section{Image processing process}

\subsection{Image read}

The image read is the first approach for the image processing, and in this approach, the height and width of the image should be read, and whether the image needs to be printed should be judged and the memory space should be distributed for reading image data.

The bit file is stored according to rows, and it is scanned from left to right and from the top down, and recorded the pixel value of every pixel point in turn. Supposed that one image has $m$ rows and $n$ lines, the storage sequence of BMP file is to scan the information in the m-1 row from the 0 'th list to the $\mathrm{n}-1$ list, and scan the information in the m-2 row until the 0 'th row is scanned completely.

\subsection{Image smoothing}

Image smoothing is a sort of applied digital image processing technology, and its main aim is to reduce the noise of the image. The neighborhood average generally can be used to reduce the noise in the space filed. And in the frequency field, because the noise spectrum always exists in the high frequency band, so we can adopt various low pass filters to eliminate the noise.

In the experiment, we adopt the idea of smoothing template to eliminate the noise, and it mainly eliminates certain noise in the image through the average operation of one points with several neighboring points, and whether the template we select, we treat the present pixel and neighboring pixel points equally without discrimination and implement average processing uniformly, so we can effectively eliminate the noise in the image, and the main advantages of the method include simple algorithm and quick computation speed, and its disadvantage is that it will induce certain blurs in the 
image.

We can adopt different templates to eliminate different noises, and the smoothing effect is related with the diameter of the neighborhood (the size of the template). The diameter is larger, the blur degree of the image is higher, or vice versa.

The usual templates include $\frac{1}{9}\left[\begin{array}{lll}1 & 1 & 1 \\ 1 & 1 & 1 \\ 1 & 1 & 1\end{array}\right], \frac{1}{16}\left[\begin{array}{lll}1 & 2 & 1 \\ 2 & 4 & 2 \\ 1 & 2 & 1\end{array}\right]$ and $\frac{1}{25}\left[\begin{array}{lllll}1 & 1 & 1 & 1 & 1 \\ 1 & 1 & 1 & 1 & 1 \\ 1 & 1 & 1 & 1 & 1 \\ 1 & 1 & 1 & 1 & 1 \\ 1 & 1 & 1 & 1 & 1\end{array}\right]$.

The mathematical meaning of the neighborhood averaging can be denoted by the following formula.

$g(x, y)=\frac{1}{M} \sum_{(i, j) \in s} f(i, j)$

Where, $x, y=0,1 \ldots N-1, S$ is the set of the neighborhood taking $(x, y)$ as the center, and $M$ is the integer in $S$.

In the experiment, we utilize the $\mathrm{VC}++$ to compile the code to implement the image smoothing processing, and the result which applies the average template $\frac{1}{9}\left[\begin{array}{lll}1 & 1 & 1 \\ 1 & 1 & 1 \\ 1 & 1 & 1\end{array}\right]$ to deal with the image is seen in Figure 2.

\subsection{Binary processing and threshold division}

The usual threshold processing is the binary processing of the image, which selects one threshold and converts the image into the binary image for image division, margin follow and other pre-processing.

$g(x, y)=\left\{\begin{array}{c}0 f(x, y)<T \\ 255 f(x, y) \geq T\end{array}\right.$

The function of the threshold processing is to appoint a threshold by the user, and if the grey value of certain pixel in the image is less than the value, so set up the grey value of this pixel as 0 (black), or else set up the grey value of this pixel as 255 (white).

In the threshold process of the image, it is very important to select the threshold, and the processing results will be different because of different thresholds. If the threshold is too big, the surplus part in the image will be extracted, and if the threshold is too small, some concerned things will be lost.

Based on above reasons, the method to select the threshold in the experiment is the method of the self-adaptive threshold selection.

The self-adaptive threshold selection is that each pixel confirms a neighborhood window surrounding itself, and then we compute the maximum and minimum of the pixels in the window, and take the average of the computation results as the threshold of the image. As seen in Figure 3, the selected window includes 8 neighborhoods, and in practice, we can also select bigger window, but if the window is bigger, we will need deal with more data and more time.

In the Figure 3, suppose $\mathrm{C}$ is the present pixel, $\mathrm{P}$ are the 8 neighborhood pixels surrounding $\mathrm{C}$, and suppose maxVaule denotes the maximum value in the 8 neighborhood pixels, and minValue denotes the minimum value in the 8 neighborhood pixels, so its threshold is

$\mathrm{T}=\frac{\text { maxValue }+ \text { minValue }}{2}$

The processing result by adopting the confirming method of self-adaptive threshold is seen in Figure 4.

\subsection{Image profile extraction}

The aim of profile extraction is to obtain the exterior profile character of the image and prepare for the shape analysis of the image.

The algorithm of binary image profile extraction is to empty all interior points. If one point in the original image is black and its 8 neighboring points all are black, it indicates this point is the interior point, and it should be deleted (set up its white pixel values is 255). Implement this operation to all pixel points in the image to complete the extraction of image profile.

The profile extraction result of the image in the experiment is seen in Figure 5. 


\section{Analysis of experiment results}

In the experiment, we comprehensively utilize the BMP image file read, image smoothing, image binary processing and threshold division, and image profile extraction to basically complete the pre-processing of image.

From the example, we can see that the noise can be effectively eliminated after the image is smoothed. The profile extraction can offer conveniences for the analysis or identification of image shape.

\section{References}

Liu, Shuang. (2005). Study of Image Threshold Methods' Selection and Algorithms Implementing for Image Segmentation. Computer Technology and Application. No.21(2). P.73-75.

Qiu, Shikeji. (2006). Representative Algorithm and Implementation of Visual C++ Digital Image Processing. Beijing: People's Posting Press. P.370-418.

YanF X, Zhang H \& Kube C R. (2005). A multistage adaptive thresholding method. Pattern Recognition Letters. No.26. P.1183-1191.

Zhang, Junli \& Liu, Shuzhi. (2005). Practice and Enhancement of Visual C++: Image Processing and Engineering Application. Beijing: China Railway Publishing House. P.115-198.

Zhou, Changfa. (2004). Mastery of Visual C++ Image Processing Programming. Beijing: Electronics Industry Press. P.230-299.

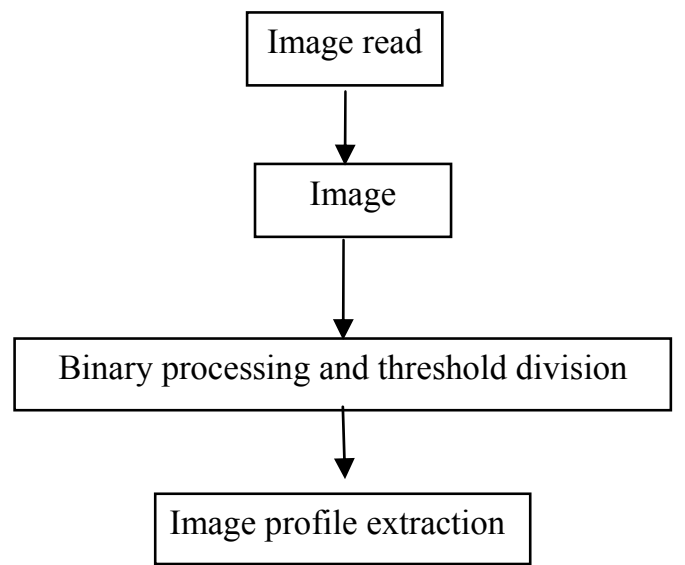

Figure 1. Approaches of Image Profile Extraction

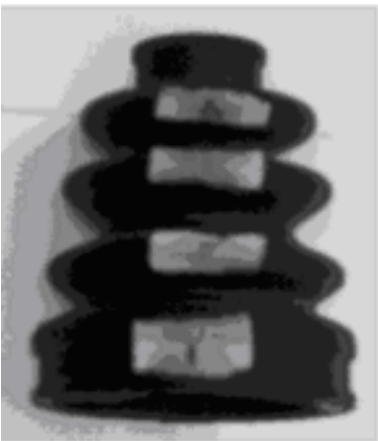

Figure 2. Image after Average Template Processing

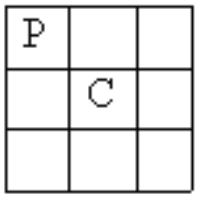

Figure 3. Confirming Method of Self-adaptive Threshold 


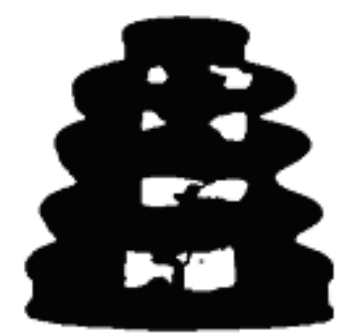

Figure 4. Image after Self-adaptive Threshold Processing

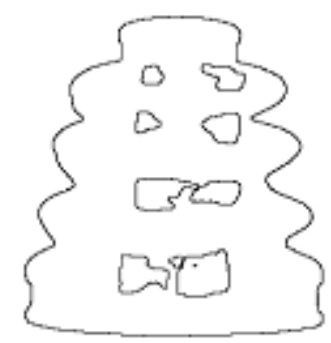

Figure 5. Result of Image Profile Extraction 


\title{
Effect of Machining Parameters
}

\section{on Hole Quality of Micro Drilling for Brass}

\author{
Azlan Abdul Rahman \\ Department of Engineering Design and Manufacture \\ Faculty of Engineering, University of Malaya \\ Kuala Lumpur, Malaysia \\ Tel: 60-3-7967-5383 E-mail: flowerhorn_best@yahoo.com \\ Azuddin Mamat \\ Department of Engineering Design and Manufacture \\ Faculty of Engineering, University of Malaya \\ Kuala Lumpur, Malaysia \\ Tel: 60-3-7967-5383 E-mail: azuddin@um.edu.my \\ Abdullah Wagiman (Corresponding author) \\ Department of Manufacturing and Industry \\ Faculty of Mechanical and Manufacturing Engineering \\ University of Tun Hussien Onn Malaysia, Batu Pahat, Johor, Malaysia \\ Tel: 60-7-453-7810 E-mail: abdulla@utho.edu.my
}

The research is financed by University of Malaya Research University (RU) Grant No. FR072/2007A

\begin{abstract}
This paper present the effect of drilling parameter such as spindle speed, feed rate and drilling tool size on material removal rate (MRR), surface roughness, dimensional accuracy and burr. In this work, a study on optimum drilling parameter for HSS drilling tool in micro-drilling processes in order to find the best drilling parameter for brass as a workpiece material. Micro drilling experiment with $0.5 \mathrm{~mm}$ to $1.0 \mathrm{~mm}$ drill sizes were performed by changing the spindle speed and feed at three different levels. The results were analyzed using microscope and surface roughness device. Comparatives analysis has been done between surface roughness, MRR and accuracy of drilled holes by experimentation. From the result, the surface roughness are mostly influenced by spindle speed and feed rate. As the spindle and feed rate increases, the surface roughness will decrease. The tool diameter gives less influence on the value of surface roughness. The value of MRR is decreased when the tool diameter, spindle speed and feedrate are decreases. As drilling tool diameter, feedrate and spindle speed increase the dimensional accuracy of drilled hole will decrease. The increment of spindle speed and feed rate value mostly will affect the tool wear and size of burr on the edge of drilled holes.
\end{abstract}

Keywords: Micro drilling, Surface roughness, Material removal rate, Dimensional accuracy

\section{Introduction}

Drilling is one of the most fundamental machining technologies and is moving toward high precision/high speed applications for productivity enhancement. The drill tools play a critical role is increasing the productivity of a cutting process. Although the price of a cutting tool itself is relatively low, the costs caused by tool failures are considerably higher. Therefore, from the viewpoint of cost and productivity, modeling and optimization of drilling processes are 
extremely important for the manufacturing industry (S.A. Jalali, 1991). The poor removal of chips in deep drilling of small diameter is often the cause of tool breakage and poor quality surface. There are a lot of studies being conducted in area of drilling in order to identify a machinability of drilling. These studies include in the area of modeling of drilling process, vibration drilling, twist drill shape, modeling of drilling tool, tool wear, surface roughness, burr formation (B.Y.Lee,1998, S.Arula,2006, A.S.Salama,1996, H. Hocheng, 2006, F.H. Jung, 2002, C. Sanjay,2005, M. Gerard,1999). Researchers also have interest in micro drilling of metal and not only for printed circuit board.

R. Mauri and S. Matti, (1995), study a tool wear and failure in the drilling of stainless steel. The main result of the tests with different drill materials found that expensive bright drills with or without TiN-coating had a lower productivity compared to cheaper black drills. This is due to the low feed rate values causing a strong decrease in the chip flow rate. The on-line measurement result show that all the quantities measured remain at an almost constant level during the entire tool life-time until the hole in which the drill totally fails. Y.C. Chen and Y.S. Liao (2003) study on wear mechanisms in drilling of Inconel 718 superalloy. This is done by conducting a drilling experiment with the use of the cutting fluid containing the nano-particle low friction surface modifier are conducted. It is found that the service life of the drill is lengthened significantly and indirectly reducing the machining.

One notable drilling technology, micro-hole drilling, is becoming increasingly more prominent in various precision industries, such as the production of automotive fuel injection nozzles, watch and camera parts. From several micro-hole-making methods, mechanical drilling is widely used because it is more independent of workpiece properties, subject to less thermal deformation, and minimizes finishing work. Thus micro-drilling can generate deeper holes with better straightness, better roundness and smoother surfaces. On the other hand, micro-drilling methods suffer from a number of difficulties. To get a better finishing for drilled holes, many factors need to be considered such as material, spindle speed, feed rate and tool diameter. Therefore, in the present commercial market, micro-drilling remains the operation of choice for the drilling of microholes.

It has been reported that even very small variations in the geometry of the drill point can have a very significant influence on the performance of the drill. Hence, the drill point geometry, which is uniquely defined by the shapes of the flute and flank surfaces, is a primary factor to be considered when attempting to improve the drill's machining performance. Due to its small physical size, conventional point geometries such as conical, spiral, cylindrical and multi-facet cannot be reproduced on micro-drills. Currently, micro-drills with planar point geometries are prevalent in industrial practice (C. Lin et al, 1992). However, this particular type of micro-drill has an extremely low heel clearance angle distribution along the intersection line of the primary and secondary flanks.

E. Kai and M. Katsumi, (2002), fabricate a three-dimensional and high aspect ratio of micro-shape. This is done by using micro-drilling on monocrystalline silicon using a small drilling tool. The smallest machinable hole achieved was of $6.7 \mu \mathrm{m}$ diameter. Furthermore, an aspect ratio is more than four was obtained in the drilling of a $22 \mu \mathrm{m}$ diameter and $90 \mu \mathrm{m}$ deep hole. S.C. Man, et al (1999), identifies the control for micro-drilling productivity enhancement. Therefore, a method for cutting force regulation was proposed to achieve continuous drilling. A proportional plus derivative (PD) and a sliding mode control algorithm are implemented and compared for controlling the spindle rotational frequency. Experimental results will show that sliding mode control reduces the nominal torque and cutting force and their variations better than PD control, resulting in a number of advantages, such as an increase in drill life, fast stabilization of the wandering motion, and precise positioning of the holes.

H. Nakagawa et al, (2007) has carried out surface roughness testing of a drilled hole wall. It was increases as drill temperature increases during drilling. Drill temperature tends to increase with the workload on the drill caused by the friction between the hole wall and the land or margin of the drill, regardless of drilling and material conditions. Therefore, a reduction in the workload caused by friction is effective for improving the quality of micro-drilled holes. $\mathrm{K}$. F. Ehmann and H.C. Chyan (1997) have developed a curved helical micro-drill point technology for micro-hole drilling. The drill point is the most important part of the drill which penetrates into the material of the workpiece during the machining process. The geometry of the drill tip is such that the normal rake and clearance angles and velocity of the cutting edge vary with the distance from the center of the drill. Even small variation in geometry or symmetry errors can have a very strong influence on the performance of the drill. The geometry of the point, uniquely defined by the shapes of the flute and flank surface, is the primary factor determining performance.

Z. Yang, (1998) be able to increase the micro-drilling reliability by using vibrating drilling. By comparing with ordinary drilling, the life-time of the micro-drill used under vibrating drilling conditions has different types of distributions. Vibrating drilling appears to increase reliability of the micro drill, embodying a life-time increase and scatter reduction. Wear reduction is an essential reason for increasing the reliability of micro-drill during vibrating drilling. G..L. Hak, (2004), had studied the tool life model for the micro-drill during wet micro-drilling of ceramic green body. The model predicted very well the axial force of micro-drill. From the modeling of chip flow for the worn-out micro-drill tip, the large wear on the side of micro-drill tip induced the rapid increase of the axial force during wet micro-drilling of ceramic green body, which could be used to determine the tool life of micro-drill. The model could also predict the 
number of micro-holes that could be drilled within the tool life of micro-drill.

The quality of drilling is too important in order to retain the industrial advantage for micro-drilling technologies over rival manufacturing processes. The aim of this work is to study an optimum drilling parameters for High Speed Steel (HSS) drilling tool in micro-drilling processes by analyzing their surface roughness, dimensional accuracy and burr formation. The cutting parameters that will be considered are spindle speed, feed rate and tool diameter for brass.

\section{Experimental Design}

The micro drilling experiment was conducted using DT110 Multi purpose Micro-Machine from MIKROTOOL Pte Ltd. There are three machining parameter that had been put into consideration of this experiment which is drilling tool size, spindle speed and feed rate. These parameters have large influences on the investigation result in the previous researches. HSS drilling tool is used in this project with starting diameter $0.5 \mathrm{~mm}$ to $1.0 \mathrm{~mm}$ with increment of $0.1 \mathrm{~mm}$. Example of drilling tool is shown in figure 1. 1000, 2000 and $3000 \mathrm{rpm}$ is chosen as rotation drilling speed and the feed rate are set as 1,5 and $10 \mathrm{~mm} / \mathrm{min}$. Brass was used as work material in this experiment. It is an alloy consists of copper and zinc. The material selected is chosen based on their characteristic such as brittle, ductile and hardness. The block size of brass is $40 \mathrm{~mm} \times 40 \mathrm{~mm} \times 10 \mathrm{~mm}$ for length, width and thickness respectively. The drill hole on brass workpiece is shown in figure 2 .

The performance of drilled holes are been measure in term of surface roughness, MRR and dimensional accuracy. In order to observes and measure the quality of surface finish on the machined surface, ICAMSCOPE light microscope and Perthometer Mahr PFK Model M4Pi with a styles type of flexible surface texture profiler was used. The surface roughness is a term used to describe the geometry quality of a mechanical surface. The quality of the surface roughness is importance in the evaluation of the machined surface. There are two method of measuring the surface roughness of material which is the arithmetic mean value and the root mean square value. Only the Arithmetical Mean Roughness, $\boldsymbol{R} \boldsymbol{a}$ parameter is selected to be measured the surface roughness. The $\boldsymbol{R} \boldsymbol{a}$ is an average or center line average of value. It is based on the schematic illustration of a rough surface. The arithmetic mean value is defined as [8]:

$\boldsymbol{R} \boldsymbol{a}=(\mathrm{a}+\mathrm{b}+\mathrm{c}+\mathrm{d}+\ldots \ldots+\mathrm{n}) / \mathrm{N}$

Where all coordinate, $\mathrm{a}, \mathrm{b}, \mathrm{c}, \ldots . ., \mathrm{n}$ are absolute value, and the $\mathrm{N}$ is the number of reading. The lowest value of $\boldsymbol{R} \boldsymbol{a}$ means that the surface is smoother. The MRR was calculated using model developed by B.Y. Lee et al, (1996). The MRR is:

$$
M R R=\frac{\pi D^{2} f N}{4}
$$

Which, MRR = Metal removal rate

$\mathrm{D}=$ Drill diameter $[\mathrm{mm}]$

$\mathrm{f}=$ Feed rate $[\mathrm{mm} / \mathrm{rev}]$

$\mathrm{N}=$ Rotational speed of the drill $[\mathrm{rpm}]$

$N=\frac{1000 U}{\pi D}$

Which, $\quad \mathrm{U}=$ Cutting speed $[\mathrm{m} / \mathrm{min}]$

Normal procedure of drilling process is using center drill to mark the location before drilling with selected tool diameter. In case of micro drilling or drilling with tool diameter less than $1 \mathrm{~mm}$, there is no such center drill available. Therefore the programming G-code is carefully design to overcome the location marking problem in micro drilling. The micro drilling process starts with rotating drilling tool with $0.5 \mathrm{~mm} / \mathrm{min}$ feedrate moves to the workpiece and drill slowly with $0.05 \mathrm{~mm}$ of repeated depth until it reached $1 \mathrm{~mm}$ of depth on brass. Then the experiment starts with selected drill diameter, feedrate and spindle speed.

\section{Result and Discussion}

Machining time, MRR, surface roughness and dimensional accuracy are obtained from the experiment using the calculation and measurement device as shown in Table 1. From the results, for $0.5 \mathrm{~mm}$ drilling tool diameter, the tool breaks when the drill tool rotates at $3000 \mathrm{rpm}$ and feed rate is $10 \mathrm{~mm} / \mathrm{min}$. Smaller drilling tool diameter rotates with higher rotation speed and faster feedrate will decrease their capability to withstand the drilling force. For a smaller drilling tool, smaller chip size was produce, therefore the chip is easily clogged inside the unfinished drilled hole and suddenly it will stick and break the tool. Also, from the Table 1, the time taken to finish the drill operations increases as feed rate is increases. In a logical sense, if the feed rate is increases, the time taken to finish the drill operation is faster.

The value of MRR is decreases when the tool diameter decreases as shown in table 1 . The reason for this phenomenon is when the tool diameter is large; the force acting towards on the material also increases. So that the large diameter can removes more material in one second. The large tool diameter has a large flank on the tool. So the material can be 
removed through this flank easily.

For $0.5 \mathrm{~mm}$ tool diameter, the tool will break if the feed rate reaches $10 \mathrm{~mm} / \mathrm{min}$. It is because of smaller tool diameter and higher feedrate, the force acting toward the cut material will increase. The cutting tool will easily bend and break. Another theory was, the chip clog inside tool spiral, after some times the rotating force will increase and cannot rotates anymore, so suddenly it will break. For a smaller tool size, smaller chip size was produce. The generated heat for small chip is more compare to larger chip size, therefore, the chip easily hot and stick to the cutting tool edge. Then tool become blunt and will increase their rotating force.

\subsection{Effect of Surface roughness on tool diameter, feedrate and spindle speed}

The size of drilled holes are small, therefore the workpiece has to cut into half using EDM wire cut machine to allow portable profiler travel on the inside drilled surface. The effect of tool diameter in drilling process will affect the surface roughness as shown in figure 3. Generally, as the tool diameter decrease, the $\boldsymbol{R} \boldsymbol{a}$ value also decreases. It is because, larger tool diameter will cut more material compare to the smaller drilling tool size, therefore, drilling with small chip size will increase the $\boldsymbol{R} \boldsymbol{a}$ value. The same behavior also found for different feed rate. As the spindle speed increase and feed rate increase, the different on $\boldsymbol{R} \boldsymbol{a}$ value will decrease. It can be conclude that to achieve a lower $\boldsymbol{R} \boldsymbol{a}$ value for smaller tool diameter, increase the spindle speed and decrease the feed rate. Figure 4 show that the surface of the drilled holes using brass material for drill 1.0 with $2000 \mathrm{rpm}$ and different feed rate. This image is taken under 100x using ICAMSCOPE. It is clearly seen that with the increment of feedrate, the surface are rougher. The effect of feed rate on surface roughness is shown in figure 5. Increasing the feedrate will increase the $\boldsymbol{R} \boldsymbol{a}$. For tool diameter $0.5 \mathrm{~mm}$ with 3000 RPM and $10 \mathrm{~mm} / \mathrm{min}$ feed rate, the tool will break during the drilling process. From the figure, it shows that increasing spindle speed and feed rate will give a very significant effect on surface roughness. It will reduce the value of surface roughness.

The accuracy of the holes drills is important in the drilling operation because in micro-drilling, a little bit of inaccurate holes drills will affect the inner surface roughness, dimensional accuracy and encourage a short of tool life. One of the factor that causing the inaccurate holes drills is vibration of the drilling tool. This is because of clamping on tool drills. Generally, to reduce vibration, the drill tool should be clamping with drilling length same as workpiece thickness. Longer drilling length will increase vibration; therefore it will reduce the dimensional accuracy. Dimensional accuracy for drilled holes is shown in figure 6 . There are 5 to $10 \%$ error records from these experiments. If the tool drill clamped out of procedure, it will effect to the holes drills on burr on surface finishing.

The observation of drilling tool after experiment is done to identify the wear occurs on it cutting edge. Example of wear is shown in figure 7. The breakage drilling tool with diameter $0.5 \mathrm{~mm}$ is shown if figure 8 . This drilling tool with diameter $0.5 \mathrm{~mm}$ will break while drilling with feedrate of $10 \mathrm{~mm} / \mathrm{min}$. It can be concluding that the smaller drilling tool diameter, the smaller feedrate require avoiding tool break.

\subsection{Burr Formation}

The burr formations are observed under different cutting condition, such as drill geometry, material properties, feed rate and cutting velocity. Burr can be observed at the entrance of drill and also form at the exit stage. Burrs are formed as the result of plastic deformation fracture. According to T. Miyake et al (1994), the burr can be classified into 3 type, burr without cap by fracture, burr with cap and burst burr without cap. Several effects on these materials are burr formation, inaccurate holes drills and the chip of the material removal still in the holes. Burr formation happened when incorrect tool clamped or maybe because of the material characteristic itself. Figure 9 shows a burr occur at the edge and its look like a bump around the edge. Thin phenomenon occurs on ductile material such as brass. The figure also show that a chip of the material removal still in the inside surface of drilled hole. Burr with cap occur at the exit drill is shown in figure 10. The similar phenomenon can also be found in macro size of drilled hole.

\section{Conclusion}

This study was done to find the effect of drilling parameter on surface roughness, MRR and dimensional accuracy of HSS micro drilling tool on brass. After data collection, analysis and discussion on the experiment, the optimum range of cutting parameter for micro drill with diameter 0.5 to $1.0 \mathrm{~mm}$ was 2000 to $3000 \mathrm{rpm}$ for spindle speed and for 5 to 10 $\mathrm{mm} / \mathrm{min}$ feedrate. Based on the main objective of the study and the result from the experiment, several conclusions have been made;

1) The value of surface roughness are mostly influenced by spindle speed and feed rate. If the value of these spindle and feed rate increases, the value of surface roughness will decrease. The tool diameter gives less influence on the value of surface roughness.

2) The value of MRR is decreases when the tool diameter, spindle speed and feedrate are decreases.

3) For the accuracy of the holes drills, as drill diameter, feedrate and spindle speed increase the dimensional accuracy of drilled hole will decrease. 
4) The increment of spindle speed and feed rate value mostly will affect the tool wear and size of burr on the edge of drilled holes.

\section{References}

A.S. Salama and A.H. E1Sawy, (1996). The dynamic geometry of a twist drill point, Journal of Materials Processing Technology, 56, pp. 45-53

B.Y. Lee, H.S. Liu and Y.S. Tarng, (1996). Modeling and Optimization of Drilling Process. Department of Mechanical Manufacture Engineering, National Huwei Institute of Technology, Huwei, 632, pp. 1-9.

B.Y. Lee, H.S. Liu and Y.S. Tarng, (1998). Modeling and optimization of drilling process, Journal of Materials Processing Technology, 74, pp. 149-157

C. Lin, S.M. Kang and K.F. Ehmann, (1992). Planar Micro-Drill Point Design and Grinding Methods, Transactions of the North American Manufacturing Research Institution of SME, pp. 173-179.

C. Sanjay, M.L. Neema and C.W. Chin, (2005). Modeling of tool wear in drilling by statistical analysis and artificial neural network, Journal of Materials Processing Technology, 170, pp. 494-500

E. Kai and M. Katsumi, (2002). Micro-drilling of monocrystalline silicon using a cutting tool, Journal of the International Societies for Precision Engineering and Nanotechnology, 26, pp. 263-268

F.H. Jung and D.L Psang, (2002). Mathematical model of multiflute drill point, International Journal of Machine Tools \& Manufacture, 42, pp. 1181-1193

G..L. Hak, (2004). Tool Life Model for Abrasive Wet Micro-Drilling of Ceramics Green Bodies, Department of Mechanical Engineering, Korea Advanced Institute of Science and Technology, 44(1), pp. 839-846.

H. Hocheng and C.C. Tsao, (2006). Effects of special drill bits on drilling-induced delamination of composite materials, International Journal of Machine Tools \& Manufacture, 46, pp. 1403-1416

H. Nakagawa, K. Ogawa, A. Kihara and T. Hirogaki, (2007). Improvement of micro-drilled hole quality for printed wiring boards, Journal of Materials Processing Technology, 191, pp. 293-296

K. F. Ehmann and H.C. Chyan, (1997). Development of Curved Helical Micro Drill Point Technology for Micro-Hole Drilling, PhD Thesis. Northwestern University, Department of Mechanical Engineering, Evanston, USA.

M. Gerard and C. Francis, (1999). Quantitative measurement of the hardness profile on carbo-nitriding steel by the hole drilling method, Measurement, 25, pp. 291-298

R. Mauri and S. Matti, (1995). Tool wear and failure in the drilling of stainless steel, Journal of Materials Processing Technology, 52, pp. 35 - 43

S. Arula, L. Vijayaraghavana, S.K. Malhotrab and R. Krishnamurthya, (2006). The effect of vibratory drilling on hole quality in polymeric composites, International Journal of Machine Tools \& Manufacture, 46, pp. 252-259

S.A. Jalali and W.J. Kolarik, (1991). Tool life and machinability models for drilling steels, International Journal of Machine Tools \& Manufacture, 31 (3), pp. 273-282

S.C. Man, W.C. Dong and K.F. Ehmann, (1999). Identification and control for micro-drilling productivity enhancement, International Journal of Machine Tools \& Manufacture, 39, pp. 1539-1561

T. Miyake, A. Yamamoto, K. Kitajima, Y. Yanaka and K. Takazawa, (1994). Syudy on mechanism of burr formation in drilling-deformation of material during burr formation JSPE-57-03, pp. 87-92

Y.C. Chen and Y.S. Liao (2003). Study on wear mechanisms in drilling of Inconel 718 superalloy, Journal of Materials Processing Technology, 140, pp. 269-273

Z. Yang, (1998). Study for Increasing Micro-Drilling Reliability by Vibrating Drilling, PhD Thesis. Reliability Engineering and System Safety, Jilin University of Technology, China. 
Table 1. Data Collection for Brass

\begin{tabular}{|c|c|c|c|c|c|c|}
\hline $\begin{array}{c}\text { Tool } \\
\text { Diameter } \\
\text { [mm] }\end{array}$ & $\begin{array}{c}\text { Spindle } \\
\text { Speed, S } \\
\text { [rpm] }\end{array}$ & $\begin{array}{c}\text { Feed Rate, } \\
\text { F [mm/min] }\end{array}$ & Time [s] & $\begin{array}{c}\text { Material } \\
\text { Removal } \\
\text { Rate, } \\
\text { (MRR) } \\
{[\mathrm{mm} / \mathrm{s}]}\end{array}$ & $\begin{array}{c}\text { Surface } \\
\text { Roughness, } \\
\operatorname{Ra}[\mu \mathrm{m}]\end{array}$ & $\begin{array}{c}\text { Hole } \\
\text { Diameter } \\
\text { (min) }\end{array}$ \\
\hline \multirow{9}{*}{1} & \multirow{3}{*}{1000} & 1 & 17.59 & 0.785 & 2.318 & 1.012 \\
\hline & & 5 & 11.41 & 3.927 & 2.329 & 1.031 \\
\hline & & 10 & 10.59 & 7.854 & 2.358 & 1.053 \\
\hline & & 1 & 18.01 & 1.571 & 2.315 & 1.113 \\
\hline & 2000 & 5 & 11.42 & 7.854 & 2.326 & 1.147 \\
\hline & & 10 & 10.58 & 15.708 & 2.341 & 1.173 \\
\hline & & 1 & 18.03 & 2.356 & 2.279 & 1.210 \\
\hline & 3000 & 5 & 11.41 & 11.781 & 2.307 & 1.211 \\
\hline & & 10 & 10.57 & 23.562 & 2.336 & 1.232 \\
\hline \multirow{9}{*}{0.9} & & 1 & 18.01 & 0.636 & 2.316 & 0.910 \\
\hline & 1000 & 5 & 11.4 & 3.181 & 2.327 & 0.914 \\
\hline & & 10 & 10.59 & 6.362 & 2.355 & 0.913 \\
\hline & & 1 & 18.02 & 1.272 & 2.313 & 0.917 \\
\hline & 2000 & 5 & 11.42 & 6.362 & 2.322 & 0.919 \\
\hline & & 10 & 10.58 & 12.723 & 2.338 & 0.921 \\
\hline & & 1 & 18.04 & 1.909 & 2.276 & 0.922 \\
\hline & 3000 & 5 & 11.41 & 9.543 & 2.304 & 0.923 \\
\hline & & 10 & 10.59 & 19.085 & 2.332 & 0.926 \\
\hline \multirow{9}{*}{0.8} & & 1 & 18.11 & 0.503 & 2.314 & 0.811 \\
\hline & 1000 & 5 & 11.52 & 2.513 & 2.325 & 0.813 \\
\hline & & 10 & 11.1 & 5.027 & 2.353 & 0.817 \\
\hline & & 1 & 18.13 & 1.005 & 2.311 & 0.822 \\
\hline & 2000 & 5 & 11.51 & 5.027 & 2.32 & 0.823 \\
\hline & & 10 & 11.1 & 10.053 & 2.336 & 0.831 \\
\hline & & 1 & 18.13 & 1.508 & 2.274 & 0.832 \\
\hline & 3000 & 5 & 11.53 & 7.54 & 2.302 & 0.833 \\
\hline & & 10 & 11.1 & 15.08 & 2.331 & 0.836 \\
\hline \multirow[b]{5}{*}{0.7} & & 1 & 18.32 & 0.385 & 2.311 & 0.717 \\
\hline & 1000 & 5 & 12.11 & 1.925 & 2.322 & 0.718 \\
\hline & & 10 & 11.3 & 3.848 & 2.35 & 0.722 \\
\hline & 2000 & 1 & 18.34 & 0.77 & 2.308 & 0.724 \\
\hline & & 5 & 12.09 & 3.848 & 2.317 & 0.725 \\
\hline
\end{tabular}




\begin{tabular}{|c|c|c|c|c|c|c|}
\hline & 2000 & 10 & 11.29 & 7.697 & 2.333 & 0.728 \\
\hline & & 1 & 18.35 & 1.155 & 2.271 & 0.729 \\
\hline & 3000 & 5 & 12.12 & 5.773 & 2.298 & 0.731 \\
\hline & & 10 & 11.28 & 11.545 & 2.327 & 0.733 \\
\hline \multirow{9}{*}{0.6} & & 1 & 19.12 & 0.283 & 2.308 & 0.609 \\
\hline & 1000 & 5 & 12.1 & 1.414 & 2.32 & 0.611 \\
\hline & & 10 & 11.27 & 2.827 & 2.346 & 0.613 \\
\hline & & 1 & 19.13 & 0.565 & 2.307 & 0.618 \\
\hline & 2000 & 5 & 12.11 & 2.827 & 2.315 & 0.622 \\
\hline & & 10 & 11.28 & 5.655 & 2.33 & 0.633 \\
\hline & & 1 & 19.13 & 0.848 & 2.267 & 0.635 \\
\hline & 3000 & 5 & 12.12 & 4.241 & 2.295 & 0.637 \\
\hline & & 10 & 11.28 & 8.482 & 2.324 & 0.638 \\
\hline \multirow{9}{*}{0.5} & & 1 & 19.15 & 0.196 & 2.305 & 0.511 \\
\hline & 1000 & 5 & 12.09 & 0.982 & 2.318 & 0.514 \\
\hline & & 10 & $\mathrm{~TB}$ & TB & TB & TB \\
\hline & & 1 & 19.13 & 0.393 & 2.304 & 0.517 \\
\hline & 2000 & 5 & 12.1 & 1.963 & 2.311 & 0.521 \\
\hline & & 10 & $\mathrm{~TB}$ & TB & $\mathrm{TB}$ & TB \\
\hline & & 1 & 19.09 & 0.589 & 2.262 & 0.532 \\
\hline & 3000 & 5 & 12.11 & 2.945 & 2.293 & 0.538 \\
\hline & & 10 & TB & TB & TB & TB \\
\hline
\end{tabular}

$\mathrm{TB}=$ Tool Break

Machining time, MRR, surface roughness and dimensional accuracy obtained from the experiment using the calculation and measurement device.

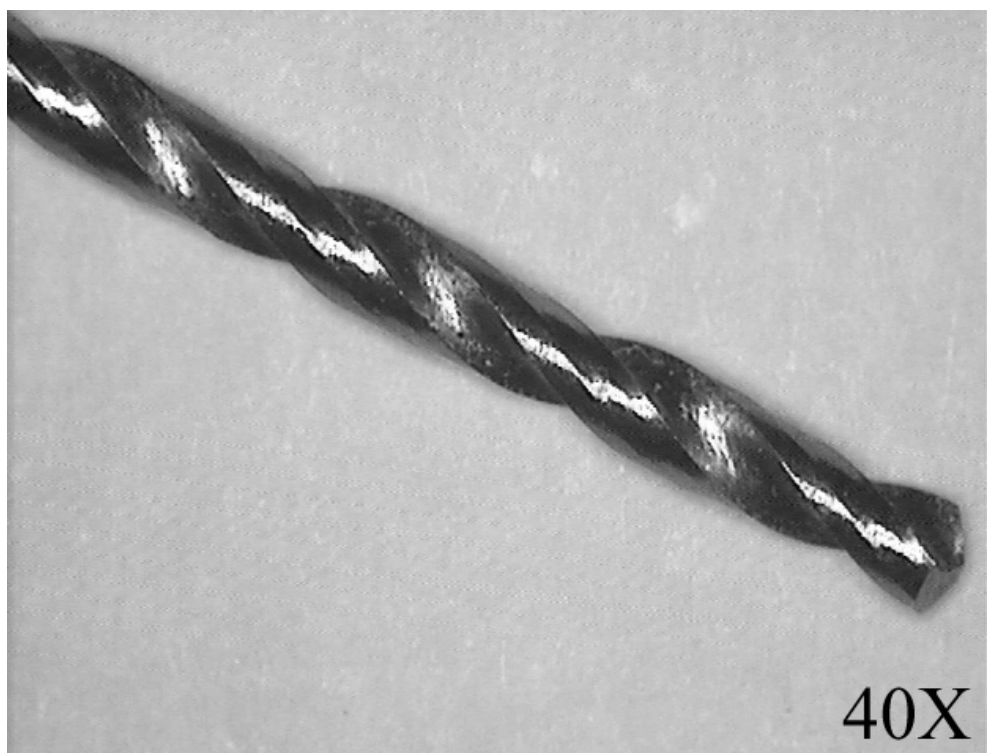

Figure 1. HSS drilling tool 1.0mm diameter under 40x by ICAMSCOPE 


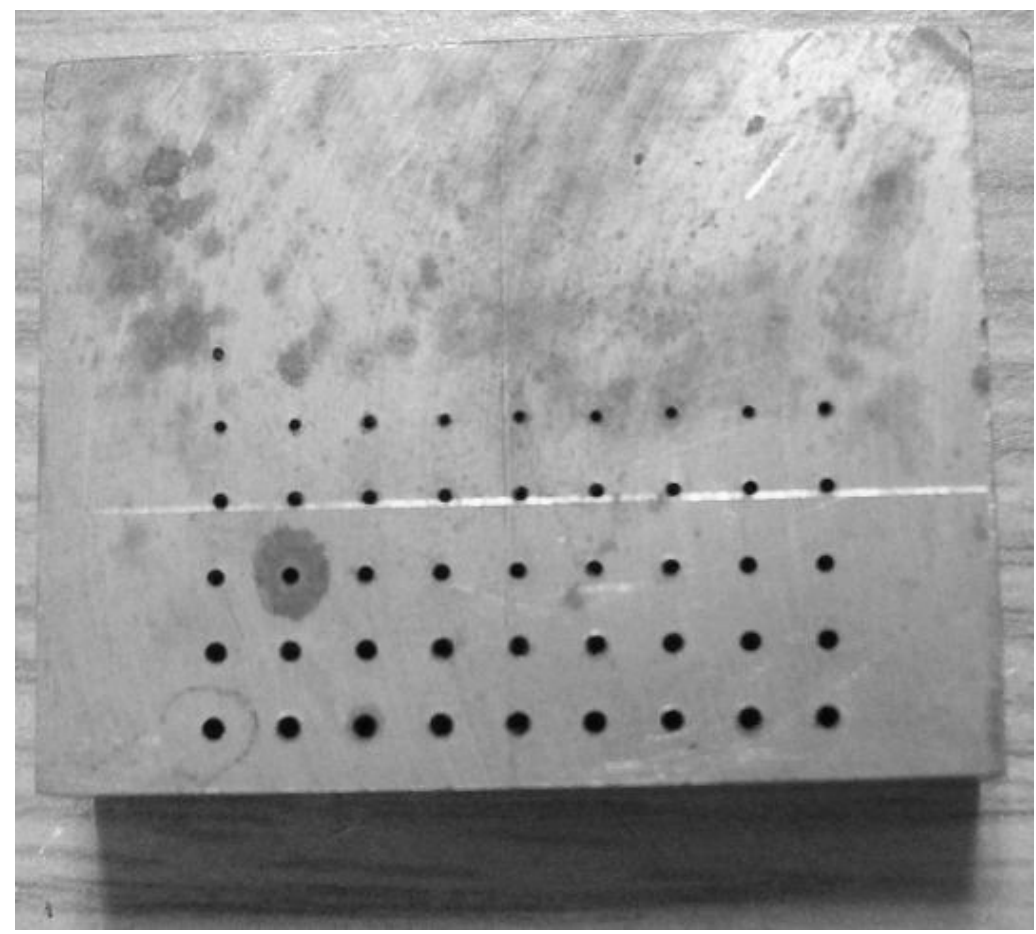

Figure 2. The drilled holes on brass

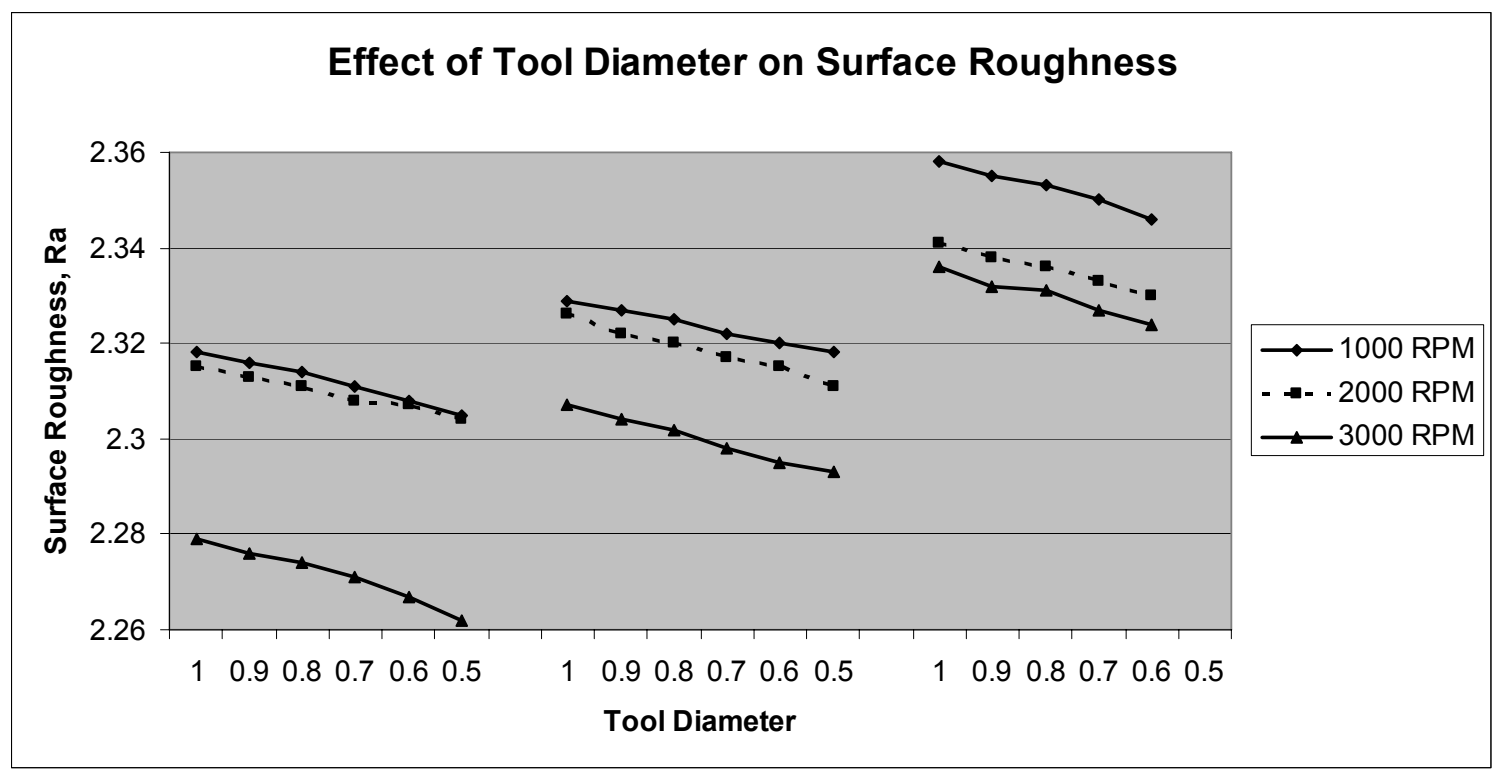

Figure 3. Effect of Tool Diameter on Surface Roughness

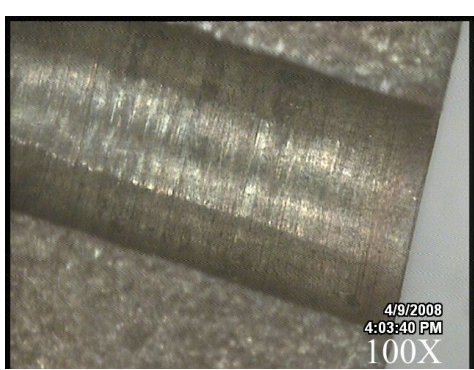

Feedrate $=1 \mathrm{~mm} / \mathrm{min}$

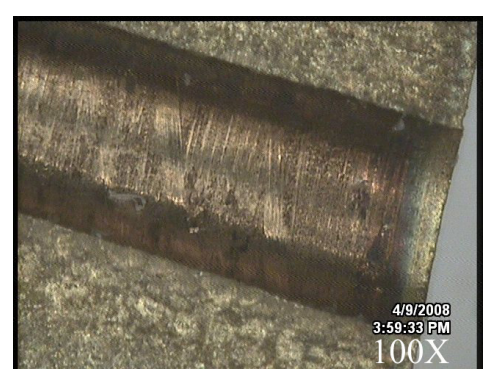

Feedrate $=5 \mathrm{~mm} / \mathrm{min}$

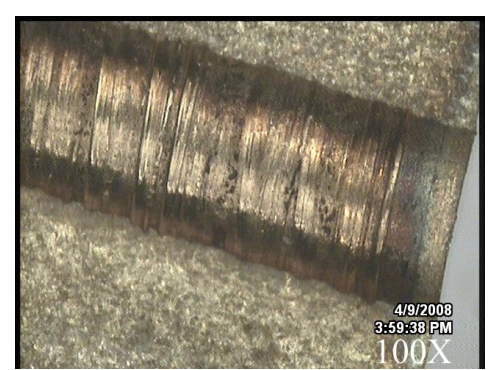

Feedrate $=10 \mathrm{~mm} / \mathrm{min}$

Figure 4. Surface roughness of brass for different feedrate 


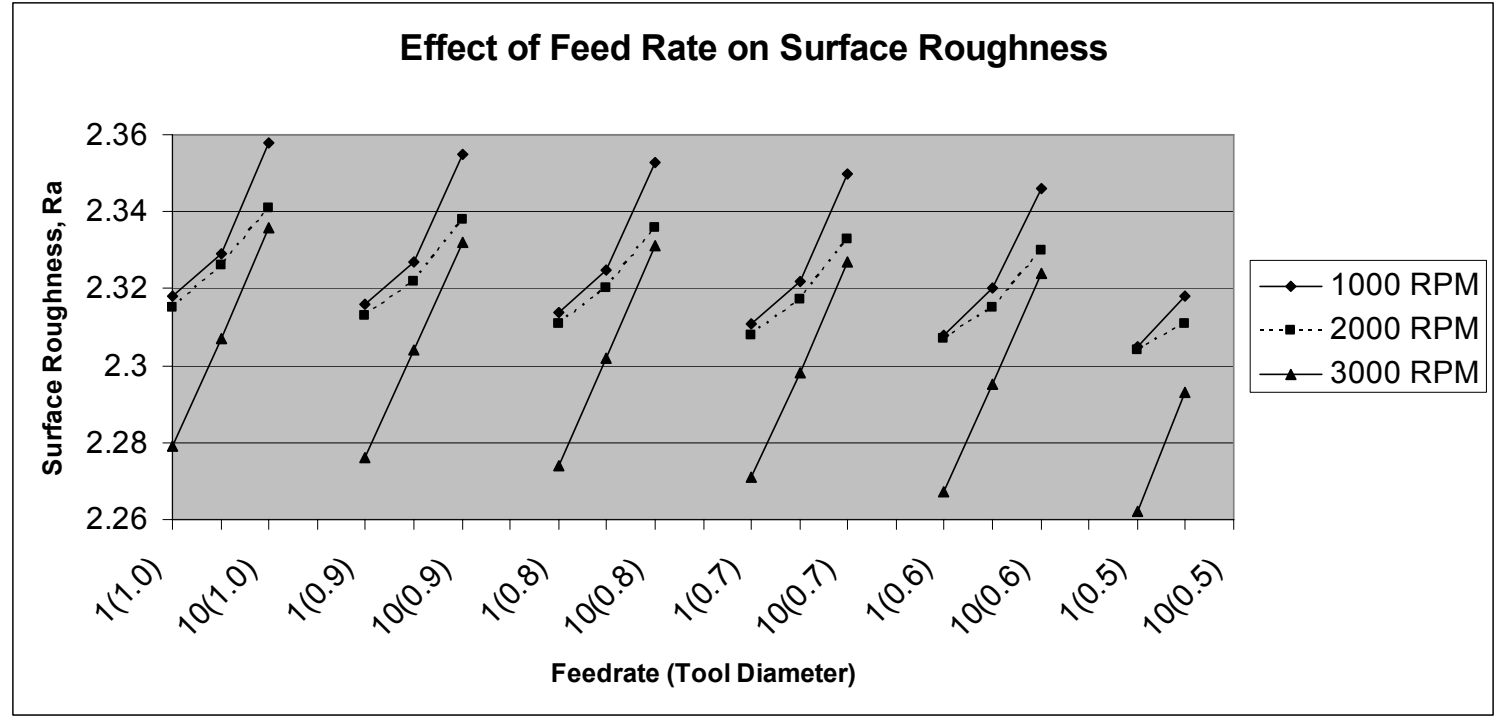

Figure 5. Effect of feed rate on surface roughness

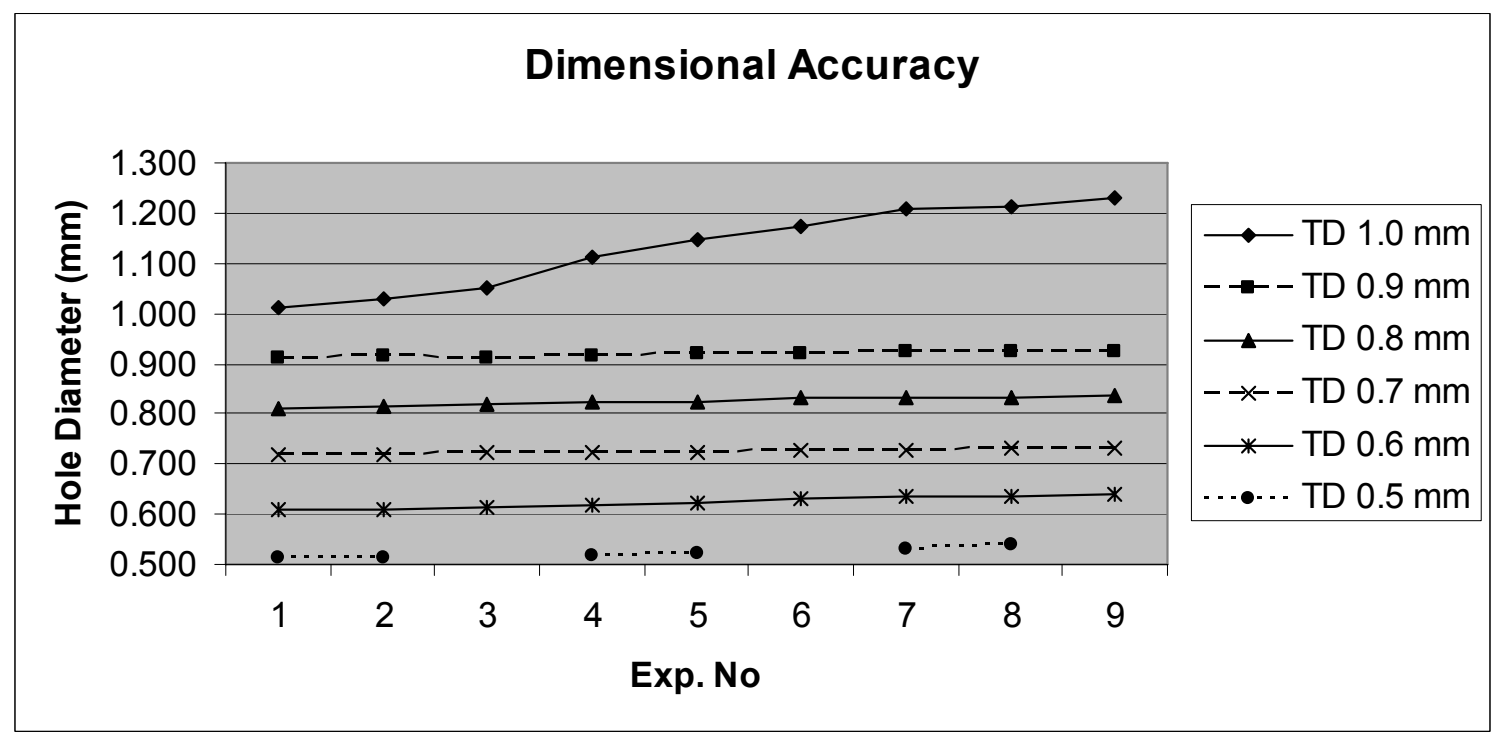

Figure 6. Dimensional accuracy for drilled holes

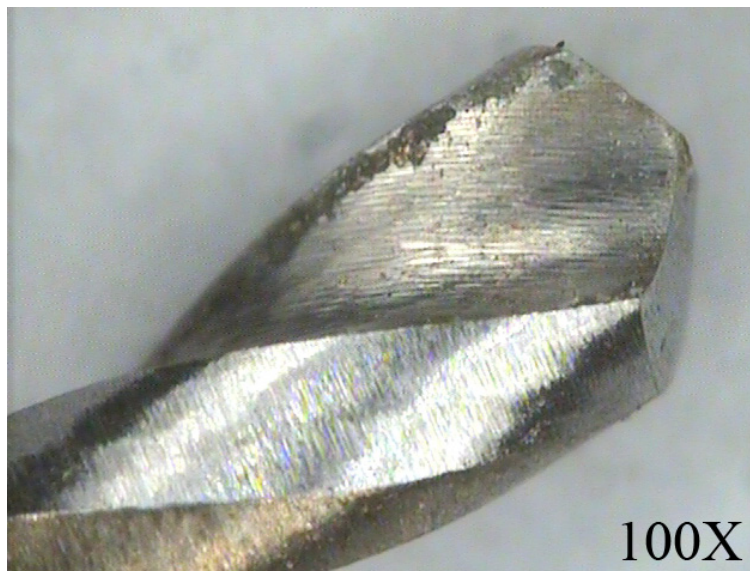

Figure 7. Tool wear occur at the edge of drilling tool 


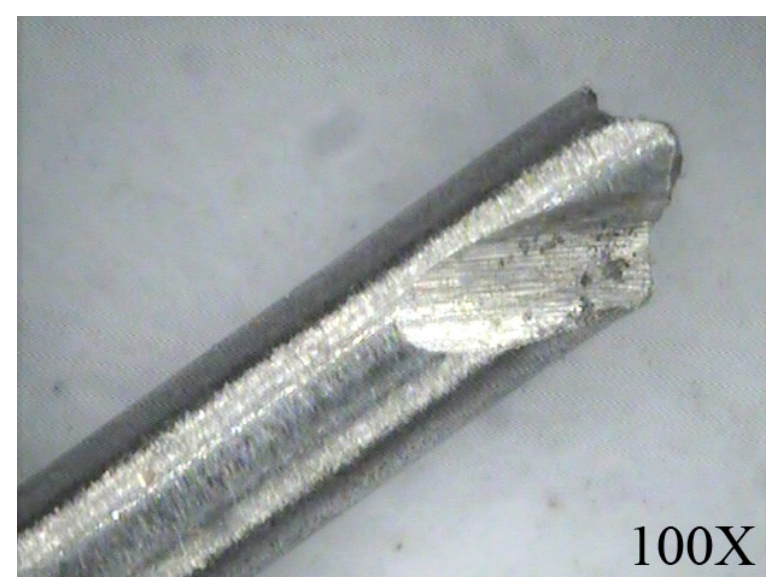

Figure 8. the breakages of drilling tool for $0.5 \mathrm{~mm}$ diameter

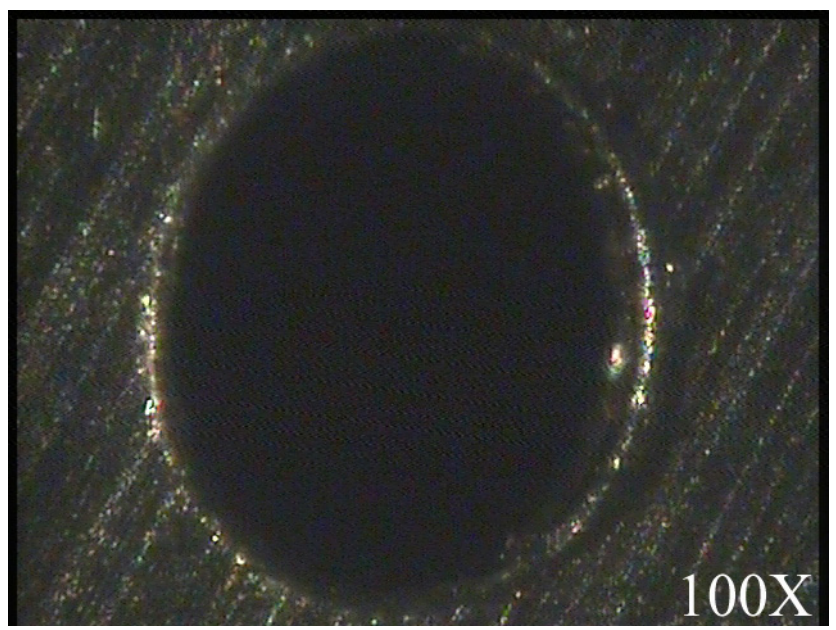

Figure 9. the on the edge and chip trapped inside the drilled hole

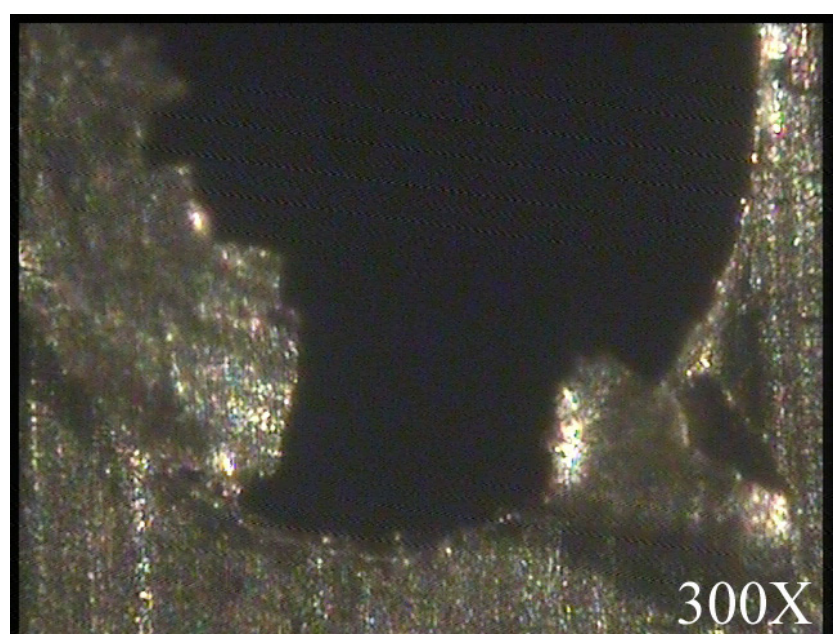

Figure 10. Burr with cap occur at the exit drill 
A journal archived in Library and Archives Canada

A journal indexed in CANADIANA (The National Bibliography)

A journal indexed in AMICUS

A journal indexed in Zentralblatt MATH

A journal included in DOAJ (Directory of Open-Access Journal)

A journal included in Google Scholar

A journal included in LOCKSS

A journal included in PKP Open Archives Harvester

A journal listed in Journalseek

A journal listed in Ulrich's

A peer-reviewed journal in applied science research

\section{Modern Applied Science}

Monthly

Publisher Canadian Center of Science and Education

Address 4915 Bathurst St. Unit \# 209-309, Toronto, ON. M2R 1X9

Telephone 1-416-208-4027

Fax 1-416-208-4028

E-mailmas@ccsenet.org

Website www.ccsenet.org

Printer William Printing Inc.

Price CAD. $\$ 20.00$ 